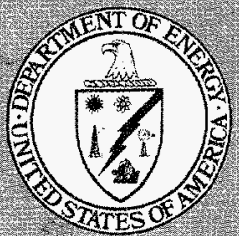

United States Department of Energy's

Reactor Core Protection Evaluation

Methodology for fires at RBMK and VVER Nuclear Power Plants

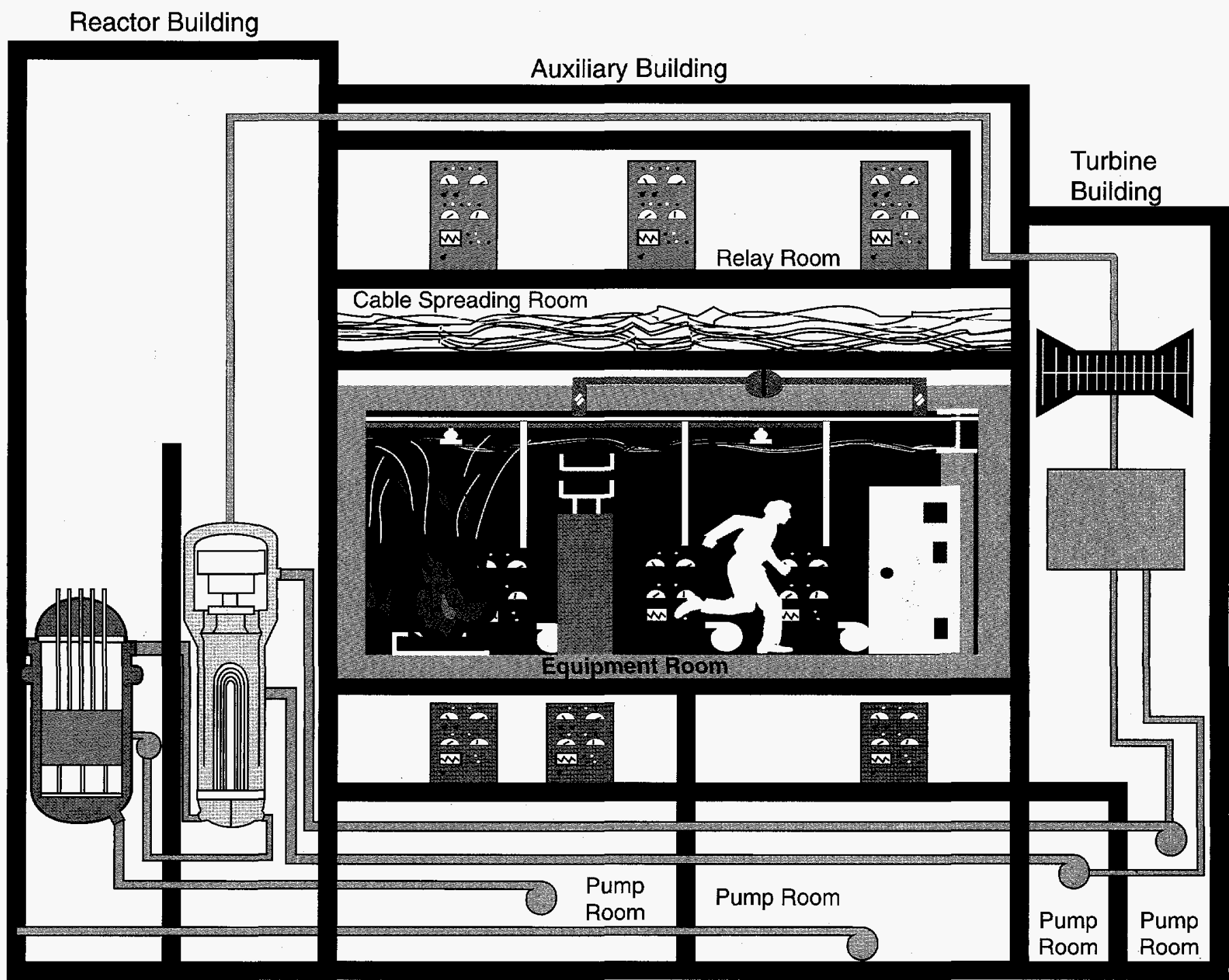

Propagation of Effect of Losing Element $X$

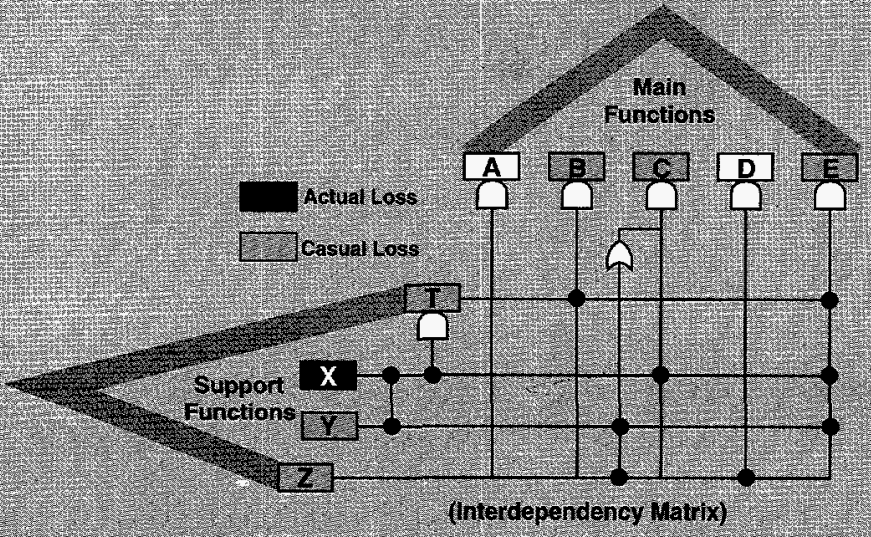

Plant Response - System and Component Performance Logic During Fire

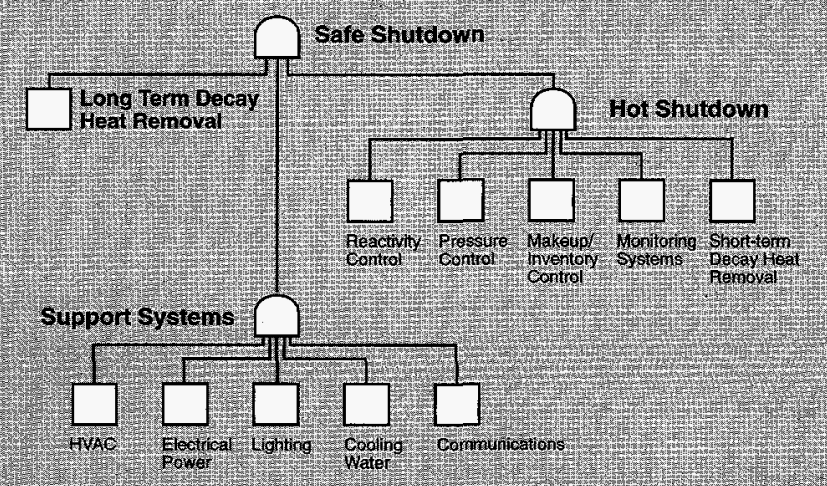




\section{CONDITIONS OF USE}

This report was prepared as an account of work sponsored by an agency of the United States Government. Neither the United States Government nor any agency thereof, nor any of their employees or subcontractors, makes any warranty, expressed or implied, or assumes any legal liability or responsibility for any third-party use, or the results of such use, of any information, apparatus, product, or process disclosed in this report, or represents that its use by such third party would not infringe privately owned rights. 
DOE/NE-0113(REV.1)

$$
\text { DOE/NE-O/13-ReV.1 }
$$

United States Department of Energy's Reactor Core Protection Evaluation Methodology for Fires at RBMK and VVER Nuclear Power Plants

Revision 1

\section{U.S. Department of Energy}

\section{June 1997}

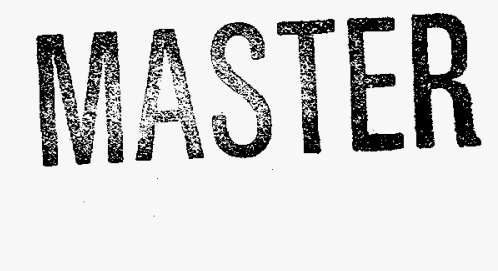



The original version of this document (Revision 0) was issued in both English and Russian in December 1996. Following its issuance, changes were recommended for the following pages that are consequently being issued as Revision 1 . All other pages will remain as they were originally published as Revision 0 . In addition to this listing of changed pages, vertical lines have been added throughout the document to indicate the sections of text that have been changed. Also, the footer on each page indicates from which revision the page has been taken.

\begin{tabular}{|c|c|c|}
\hline Rev. 0, 12/96 Pages & \begin{tabular}{|l|} 
Replace with \\
Rev. 1, 6/97 Pages \\
\end{tabular} & Nature of Change \\
\hline Cover and Title & Cover and Title & Changed "Rev. $0,12 / 96$ " to "Rev. $1,6 / 97$ " \\
\hline $\mathrm{P}-3,13 \& 14$ & $P-3,13 \& 14$ & $\begin{array}{l}\text { Spelling changes and additions to the } \\
\text { Acknowledgements section }\end{array}$ \\
\hline $2-2$ & $2-2$ & $\begin{array}{l}\text { Added "flash temperature" in parentheses to } \\
\text { the definition of combustible liquid. }\end{array}$ \\
\hline $2-5$ & $2-5$ & $\begin{array}{l}\text { Added "fire load density" in parentheses to } \\
\text { the definition of fire load. }\end{array}$ \\
\hline $2-6$ & $2-6$ & $\begin{array}{l}\text { Added "flash temperature" in parentheses to } \\
\text { the definition of flash point. }\end{array}$ \\
\hline $2-11$ & $2-11$ & Added " $\mathrm{MJ} / \mathrm{m}^{2 \text { " }}$ to list of abbreviations. \\
\hline 4.4-3 through $4.4-8$ & 4.4-3 through 4.4-8 & Reduced the size of the drawings. \\
\hline 4.4-9 through 4.4-10 & 4.4-9 through 4.4-10 & Added to the definition of "hot short". \\
\hline $4.8-8$ & $4.8-8$ & Changed units from feet and inches to meters \\
\hline 4.8-11 through $4.8-14$ & $4.8-11$ through $4.8-14$ & Changed units from $\mathrm{cm}$ to $\mathrm{mm}$. \\
\hline $4.11-5$ through $4.11-9$ & $4.11-5$ through $4.11-9$ & $\begin{array}{l}\text { Changed units to MJ } / \mathrm{kg} \text {. } \\
\text { Corrected table } 4.11-1 \text { values and added } \\
\text { information about "net" vs. "gross" heats of } \\
\text { combustion. } \\
\text { Updated sample problems using new values } \\
\text { and units. } \\
\text { Corrected Table } 4.11-2 \text { values and added } \\
\text { information about Table } 4.11-2 \text {. }\end{array}$ \\
\hline $5-2$ & $5-2$ & $\begin{array}{l}\text { Updated/added references } 5.17,5.18 \text { and } \\
5.19 \text {. }\end{array}$ \\
\hline $\mathrm{A}-24$ and $\mathrm{A}-25$ & $A-24$ and $A-25$ & $\begin{array}{l}\text { Changed (d) to (c) to preserve ordering and } \\
\text { deleted the word "and" from (1) and (2). }\end{array}$ \\
\hline
\end{tabular}





\section{DISCLAMIER}

Portions of this document may be illegible in electronic image products. Images are produced from the best available original docoment. 



\section{CONTENTS}

\section{PREFACE}

1.0 INTRODUCTION

1.1 Objectives

1.2 Methodology

2.0 GLOSSARY OF TERMS

2.1 Definitions

2.2 Acronyms and Abbreviations

3.0 ASSUMPTIONS AND LIMITING CONDITIONS

3.1 Assumptions

3.2 Limiting Conditions of Analysis

4.0 QUALITATIVE PROCESS

4.1 Collect Plant Data

4.2 Define Safe Shutdown for Plant

4.3 Identify Systems to Achieve Safe Shutdown

4.4 Identify Equipment/Components/Cables of Selected Safe Shutdown and Support Systems

4.5 Develop Color-Coded Drawings and Safety Sequence Logic Diagrams

4.6 Evaluate Design Data and Document Existing Fire Protection Features

4.7 Prepare Fire Compartment/Cell Drawings

4.8 Identify Locations of Major Equipment and Fire Hazards from Drawings

4.9 Perform Verification Walkdowns of Fire Compartments/Cells

4.10 Identify and Verify Locations of Power, Control, and Instrumentation Cables

4.11 Determine Effect of Fire on Ability to Achieve Safe Shutdown on a Fire Compartment/Cell Basis

4.12 List All Fire Vulnerabilities by Fire Compartment/Cell, System, and Subject

4.13 Analyze Possible Solutions to Post-Fire Safe shutdown Vulnerabilities and Identify Any Commonalities

4.14 Prioritize Needed Fire Safety Improvements

5.0 BIBLIOGRAPHY 



\section{Appendices}

A POSSIBLE APPROACHES FOR RESOLVING IDENTIFIED FIRE

VULNERABILITIES AND GUIDANCE FOR EVALUATING THE

EQUTVALENCY OF EXCEPTIONS TO ESTABLISHED CRITERIA

\section{A.1 Introduction}

Administrative Controls

Engineering Evaluations

Use of Alternate Equipment

Use of Operator Actions

Exceptions to Established Criteria

A.2 Illustrative Examples of Possible Solutions to Identified Problems (Fire Vulnerabilities)

Case 1-Large Penetration in Fire Cell Barrier

Case 2-Inadequate Separation Between Redundant Components

Case 3-Inadequate Separation Between Redundant Cables

Case 4 -Inadequate Electrical Independence/Isolation

Case 5-Potential for Inadvertent Spurious Valve Operations

Case 6-Potential for Loss of Heating, Ventilation, and Air Conditioning

A.3 Guidance for Evaluating Equivalency of Exceptions to Established Criteria

Demonstration Of Equivalency

Exception Development Process

A.4 Alternative Approaches to Completing the Methodology Steps When Plant Data is Not Available

Missing or Inadequate Information

Potential Alternate Solutions

B COMPUTER FIRE MODELS

C REACTOR CORE PROTECTION EVALUATION REPORT GUIDANCE

D BLANK FORMS 


\section{List of Figures}

1.2-1 Procedure Methodology $1-3$

4.2-1 Define Safe Shutdown $4.2-2$

4.3-1 Selection of Systems To Achieve Safe Shutdown $4.3-2$

4.4-1 Example System Before Analysis

4.4-2 Example System After Analysis $\quad$ 4.4-6

4.4-3 Short Circuit Example 4.4-11

4.4-4 Short to Ground Example 4.4-12

4.4-5 Open Circuit Example 4.4-13

4.4-6 Hot Shorts 4.4-14

4.4-7 Associated Circuits of Concern by Common Power Supply 4.4-18

4.4-8 Evaluation of Common Power Supply Associated Circuits 4.4-20

4.4-9 Selective Coordination and Cable Protection Time vs. Current Curves 4.4-22

4.4-10 Selective Coordination and Cable Protection Time vs. Current Curves 4.4-25

4.4-11 Typical 120 VAC or 125 VDC Electrical Distribution System 4.4-29

4.4-12 Associated Circuits of Concern by Common Enclosure-Electrical
Protection

4.4-13 Associated Circuits of Concern by Common Enclosure-Fire
Propagation

4.4-14 Associated Circuits of Concern by Common Enclosure- Open Current Transformer Secondary Windings

4.4-15 Associated Circuits of Concern by Spurious Operation 4.4-43

4.4-16 Spurious Equipment Review Methodology 4.4-46

4.4-17 Multiple High Impedance Fault Concern 4.4-49

4.4-18 SSD Path Determination 4.4-61

4.5-1 Development of Coded Drawings 4.5-2

4.5-2 Safety Sequence Logic Diagram Development 4.5-3

4.5-3 A Conceptual SSLD 4.5-4

4.5-4 Rules for Navigating Through SSLD 4.5-5

4.5-5 Example of SSLD $\quad 4.5-7$ 


\section{List of Figures (Continued)}

4.7-1 Sample Outdoor Structure Fire Compartment/Cell Drawing 4.7-3

4.7-2 Sample Building Fire Compartment/Cell Drawing 4.7-4

4.7-3 Selection of Buildings and Outdoor Structures To Be Evaluated 4.7-5

4.7-4 Assignment of Fire Compartment and Fire Cell Numbers to Outdoor

4.7-5 Assignment of Fire Compartment and Fire Cell Numbers to Buildings

4.11-1 Evaluation of Fire Compartment for Ability To Contain a Fire

4.11-2 Initial Evaluation of Fire Compartments for Shutdown Capability During/After Fire

4.11-3 Evaluation of Fire Cells as Fire Compartments for Shutdown Capability During/After Fire

4.13-1 Vulnerability Analysis

B-1 Two-Layer Zone Model

B-2

B-2A Target in Fire Plume

B-4

B-2B Target in Hot Gas Layer, Out of Plume

B-5

B-2C Target Lateral From Fire

B-6 


\section{List of Exhibits}

Page

4.2-1 Safe Shutdown Definition 4.2-5

4.2-2 Safe Shutdown Function Definition $\quad 4.2-6$

4.3-1 Safe Shutdown/Support System Safety Functions Worksheet $\quad 4.3-4$

4.4-1 Safe Shutdown Equipment Worksheet 4.4-63

4.4-2 Safe Shutdown Component Worksheet 4.4-64

4.4-3 Safe Shutdown Cable Worksheet 4.4-65

4.4-4 Input Data for Selective Coordination Study 4.4-66

4.4-5 Coordination Study Summary 4.4-67

4.4-6 Safe Shutdown Path Identification Worksheet 4.4-68

4.6-1 Fire Protection System Evaluation Checklist $\quad 4.6-7$

4.7-1 Site Buildings and Outdoor Structures $\quad 4.7-11$

4.8-1 Fire Compartment/Fire Cell Walkdown Checklist

4.11-1 Initial Screening of Fire Compartment $4.11-23$

4.11-2 Fire Containment Evaluation 4.11-24

4.11-3 Assessment of Explosion Potential 4.11-25

4.11-4 Results of Safe Shutdown Evaluation 4.11-26

4.13-1 Potential Design Changes Worksheet 4.13-5

4.13-2 Selection of Preferred Safe Shutdown Option 4.13-6

4.13-3 Safe Shutdown Solution Set 4.13-7

4.14-1 Calculation of Benefit-to-Cost Ratio 4.14-6

4.14-2 Prioritization of Improvements 4.14-7 


\section{PREFACE}

\section{PURPOSE}

This document provides operators of Soviet-designed RBMK (graphite moderated light water boiling water reactor) and VVER (pressurized light water reactor) nuclear power plants with a systematic Methodology to qualitatively evaluate plant response to fires and to identify remedies to protect the reactor core from fire-initiated damage.

\section{BACKGROUND}

Safety considerations are paramount to the design and operation of nuclear power plants because of the need to confine or control large quantities of radioactive substances. To accomplish this, fuel elements must not be seriously damaged due to insufficient cooling. Multiple, or at least redundant, independent safety systems should be incorporated into nuclear facility designs to guard against any known potential for this to happen. During normal operations, these safety systems should not be in use; they should be on standby and should respond automatically to any event or occurrence that threatens to damage the fuel elements in a nuclear reactor. Thus, safety at a nuclear facility depends profoundly on the diversity and continuous availability and reliability of these systems. They should not be rendered unavailable or inoperable by a common-cause failure.

Fire is a dominant risk at nuclear facilities because it is a common-cause failure initiator that could render redundant safety systems inoperable or cause their maloperation. This risk dominance can be quite specific to a particular facility but, in general, fire represents the most significant risk contributor at nuclear power reactors. Despite this dominance, the response of nuclear facility equipment to the environmental insults of fire has been poorly understood. There has been a general lack of understanding of fire environments, including fire suppression environments. Control systems and safety systems for nuclear power reactors generally have unavoidable systems interactions that are susceptible to fire-induced damage mechanisms through both direct and indirect damage scenarios and fault sequences. A single fire occurrence could cause multiple random failures, spurious operations in the form of maloperations or false signals, loss of control power for equipment, or total loss of component function due to redundant control equipment failures.

There has been much recent debate internationally by legislators, academia, fire protection engineers, regulators, and the general public over fire 
occurrences at Soviet-designed RBMK and VVER nuclear power plants located in the Commonwealth of Independent States (CIS) and Eastern Europe. These concerns have been initiated by fire incidents at Greifswald I in 1975; Belojarsk 2 in 1978; Armenia 1 in 1982; Chornobyl 4 in 1986; Ignalina 2 in 1988; Chornobyl 2 in 1991; Chornobyl in June 1992; Kursk in July 1992; Balakovo in October 1992; Kozloduy in September 1992; Chornobyl in January 1993, and Zaporizhzhya in May 1993.

Most RBMK and VVER nuclear power plants were not built with the intention of preventing common-cause failures by limiting the spread of fires to within small areas of the plant. While different generations of the same type of RBMK or VVER reactor at the same site may have different physical and operating characteristics, the sensitivity to common-cause failures such as fires seems to be a consistent characteristic of all generations and types of RBMK and VVER nuclear power plants. For the most part, fire confinement is within very large rooms containing both safety systems and service systems, including key instrumentation, power, and control electrical circuits. The potential risk of common-cause failures is also increased in the older plants by lack of fireresistant structures, lack of redundant safety system physical separation and electrical isolation, large combustible loads, and the presence of ignition sources.

To provide greater assurance that a safe, stable condition of the reactor core can be achieved and maintained in the event of fires at these plants, the U.S. Department of Energy (DOE) undertook a program to develop a reactor core protection evaluation Methodology for Soviet-designed RBMK and VVER nuclear power plants and to perform pilot studies in which the Methodology is implemented.

\section{DEVELOPMENT OF THE METHODOLOGY}

The Methodology was developed with direction from a U.S. Working Group under the leadership of DOE's Nuclear Safety Fire Protection Specialist, Mr. Charles B. Ramsey, and with program support from Mr. Richard Reister of DOE and Dr. Richard S. Denning of Pacific Northwest Laboratory. The Methodology was prepared by Bechtel Power Corporation and Burns and Roe Company under contract to DOE. DOE sponsored the development of the Methodology under its bilateral assistance program to upgrade Sovietdesigned nuclear reactors. This program is administered by the DOE Office of Nuclear Energy, Science and Technology's Soviet-Designed Reactor Safety Program. The Methodology uses a qualitative evaluation process that employs a different analytical approach than "Fire Hazard Analysis for VVER 
Nuclear Power Plants," IAEA-TECDOC-778, but that incorporates U.S. commercial reactor experience based on the combined use of checklists to aid in comprehensive documentation of plant features and appropriate levels of rigorous qualitative analysis.

To include the U.S. experience, the DOE established a Working Group comprising architect-engineers, DOE Laboratories, the U.S. Nuclear Regulatory Commission (NRC), and U.S. commercial utility experts to provide technical input into the Methodology development process. Participation by U.S. commercial nuclear industry experts was obtained on a voluntary basis through the American Nuclear Society. The NRC's participation was substantial, and it was helpful in assuring consistency with the NRC's bilateral assistance program to regulators of Soviet-designed nuclear power plants.

The Methodology was also reviewed and commented on by a Peer Review Group comprising Russian, Ukrainian, and U.S. fire protection and reactor safety experts to assess and confirm the suitability of the developed evaluation process.

The six logical elements of a nuclear power plant fire protection program are:

(1) Design and administrative controls for fire prevention to minimize fire hazards and maintain active and passive fire protection features

(2) Early fire detection and alarm signaling

(3) Prompt and effective automatic fire extinguishment

(4) Mitigation of fire effects

(5) Timely and effective manual fire extinguishment

(6) Performance of safe shutdown functions through configuration control, maintenance, quality assurance, and testing activities to prevent fireinduced reactor core damage

This layered protection is a "defense-in-depth" approach, which has proven to be effective at U.S. and Western nuclear power plants. Administrative controls designed to prevent fires are credited with the low fire incidence rate at U.S. nuclear power plants as compared with the general industry in the U.S. 
Recognizing that limited resources are available for fire safety upgrades, the DOE Soviet-Designed Reactor Safety Program emphasizes activities that most effectively ensure protection of the reactor core and avoidance of large releases of radioactive material as the result of a fire. Thus, the objective of the Methodology is to systematically analyze fire risks and to identify corrections needed to protect the reactor core in the event of fire. The Methodology developed accomplishes this by:

- Identifying the nuclear safety performance goals

- Identifying equipment needed to achieve the safety performance goals and development of successful logic diagrams to graphically illustrate how the safety performance goals will be met

- Specifying analysis of fire hazards and identification of the fire protection features needed to meet the safety performance goals

- Specifying evaluation of the response to fire damage of safety and nonsafety equipment and systems and identifying needed mitigative actions or upgrades

- Specifying the identification and systematic evaluation of the feasibility of nuclear power plant operator actions needed in Emergency Operating Procedures (EOPs) to meet the safety performance goals

\section{SCOPE AND APPLICABMITY}

This document contains the U.S. DOE's step-by-step Methodology to be used by trained analysts at Soviet-designed VVER and RBMK nuclear power plants to assess fire potential and obtain a current perception of fire risks and to identify needed upgrades to reduce fire risks at these facilities. The Methodology should be used as a guide for the analysts to take into account the peculiarities of VVER and RBMK nuclear power plants, considering the plant layout and the availability of basic plant data such as the age, type, and power of the reactor and the functional subdivisions of complex buildings (such as "controlled areas" and "uncontrolled areas") as they relate to the confinement of radioactivity.

For practical reasons, the Methodology has been subdivided into distinct stages because of the special problems encountered in fire protection and nuclear power plants. These problems are due to very diverse plant designs and plant layouts; systems interactions; various stages of plant life (construction, operating, decommissioning and dismantlement, etc); and the 
presence of different radioactive substances (solid, liquid or gaseous) with different activity levels and decay rates. The presence of radioactive substances is a primary reason for subdividing nuclear plants into controlled and uncontrolled areas. The presence of gaseous or airborne radioactive substances requires mechanical ventilation air pressure differentials to maintain the flow of air from the less towards the more contaminated areas. The design and arrangement of fire protection and smoke removal must accommodate this facility design feature.

The Methodology can be applied at any stage of design development or at operating VVER and RBMK nuclear power plants through the analysts' employment of the step-by-step qualitative approach delineated in the Methodology, depending on the peculiarities of the facility under evaluation. The peculiarities may include, but are not limited to, type of facility; siting; inventory of nuclear materials; reactor power level and operating pressure; production demands; and cost. If a large quantity of plant-specific data is available, different steps will be followed by analysts than if the data is sparse or unavailable. Ideally, it is desirable for the analysts to begin at the design stage of a nuclear power plant by first minimizing the potential for fires to occur and then eliminating structure, system, or component exposure to fires through plant layout and design details. However, at operating nuclear power plants whose design does not incorporate protection against initiators of common-cause failures such as fires as a precondition, alternative approaches must be taken that are aimed at protecting the core of a nuclear reactor. These alternative approaches are delineated in this Methodology as steps to be taken when decisions are made by the analysts that a given nuclear power plant peculiarity dictates following the steps.

Depending on the type of reactor and the space, compartments, and adjoining rooms where component operability or inoperability could adversely affect nuclear safety, fire protection practice would attempt to divide large spaces into smaller isolated compartments (cells) where possible to guard against component damage from smoke, heat, fire suppression activities, or corrosive species. Such a division needs to be balanced with the required interconnections of different compartments and with cost considerations. Known fire occurrences confirm the primary importance of this type of risk separation. When physical or electrical independence is established at Western nuclear power plants, it has been achieved through passive fire barrier protection, which acts to reduce risk through the sheer presence of the barrier (e.g., rated firewalls separating different compartments housing redundant safety equipment). 
The application of the evaluation Methodology is limited to RBMK and VVER nuclear power plants. Evaluation methodologies for other types of nuclear facilities should consider the employment of other materials (such as gas or liquid sodium as a reactor coolant) and different design approaches. The compartmentalization of such facilities will be tied to these considerations.

\section{LEVEL OF ANALYSIS RIGOR}

The rigor of the analysis and the amount of effort required to implement the Methodology will depend highly on the availability, completeness, and accuracy of the data supplied to the analysts by designers and operators of RBMK and VVER nuclear power plants. The Methodology uses qualitative methods to assess protection of the reactor core in the event of fire. It does not address protection of facilities from fires; nor, does it address quantitative dose values for workers, the public, or the environment as a result of radioactive or other toxic material releases caused by fires. Analysis of these aspects of safety should be part of a more comprehensive Safety Analysis Report (SAR). However, SARs could incorporate the results obtained from implementation of the Methodology into design basis fire assumptions and accident consequence analyses.

\section{ANALYTICAL LIMITATIONS}

The Methodology does not guarantee that all fire-induced accident scenarios will be identified by analysts implementing it or that all causes and effects of such scenarios will be fully considered by the analysts. However, because of the systematic approach to comprehensive documentation of the nuclear power plant status, design, operating characteristics, and fire potential required by the Methodology, it is expected that trained analysts will be able to identify both leading and discrete nuclear plant vulnerabilities to fire damage so that they can apply the analytical rigor necessary to consider possible accident sequences and their effects on a nuclear plant's ability to achieve and maintain safe shutdown during and after the fire scenarios postulated and considered by the analysts.

This necessarily requires that the analysts systematically consider and evaluate in a qualitative sense all possible direct and indirect effects of potential fires on both active and passive equipment, structures, or components in all areas of a nuclear power plant that could adversely impact nuclear safety. However, despite the thoroughness and intent of the Methodology or the alternative approaches inherent in it to address possible variations in type and generation 
of RBMK and VVER nuclear power plants; or despite the availability or unavailability of plant-specific data and drawings, various aspects of the Methodology are sensitive to analyst assumptions. Thus, analyst knowledge, skill, and performance are key attributes that will affect the success of the Methodology's implementation.

\section{COST-BENEFIT LOGIC AND COORDINATION WITH OTHER BILATERAL AND} INTERNATIONAL ASSISTANCE PROGRAMS

While major investments may be warranted within all of the six logical fire protection elements previously discussed, this Methodology focuses on protecting the nuclear reactor core from the effects of fire as a first step in reducing the risk to the public. Think of this as owning a $\$ 100000$ house in which you keep a million dollars in cash because you do not trust banks. Conscious that a fire could destroy the house and your million, you decide to put a fireproof safe in the house to store the million rather than spend the million on building a fireproof house.

Other assistance programs may address different aspects of fire safety at RBMK and VVER nuclear power plants. There are a large number of Western assistance programs for Soviet-designed nuclear power plants that include such multinational programs as The Nuclear Safety Account operated by the European Bank for Reconstruction and Development (EBRD); the Technical Assistance to the CIS (TACIS); and the Poland and Hungary Assistance (PHARE) of the Combined European Community (CEC). The U.S. DOE has coordinated informal technical review of the development of this Methodology with these assistance programs to exchange information and avoid duplication of work.

\section{METHODOLOGY IMPLEMENTATION}

The Methodology specifies an evaluation process to be used by analysts at RBMK and VVER nuclear power plants that should result in:

- The collection of all pertinent plant data

- Review of plant original design and as-built configuration

- Validation walkdowns of plant compartments/cells 
- Identification of all safe shutdown systems and verification of critical process performance parameters and performance goals by safety analysts competent for the nuclear power plant under review

- Validation of location, identification and documentation for major equipment and components for safe shutdown systems

- Identification and documentation of fire protection features such as fire compartments/cells and fire suppression and detection, as well as fire hazards such as combustibles, and ignition sources

- Identification and documentation of equipment failure modes and the sequence of events that represents the plant response during and following a fire

- Identification and documentation of the effects of fire on the ability to achieve and maintain safe shutdown

- Identification and documentation of the vulnerabilities of structural, mechanical, electrical, and fluid systems to fire damage, with particular emphasis on electrical distribution system responses

- Development of solutions to combat fire vulnerabilities in pre-fire plans, Emergency Operating Procedures (EOPS), and proposed plant upgrades for safety improvement

- Prioritization of safety improvements

\section{EQUIPMENT FUNCTIONAL TOLERANCE TO FIRE, DIRECT AND INDIRECT} EFFECT-ACTIVE AND PASSIVE

Analysts implementing the Methodology will determine the fire damage threshold (or the functional tolerance and damageability) of each type of equipment that could be exposed to fire, by reviewing vender information, fire damage reports, equipment qualification data, and material property reviews to establish equipment sensitivity to fire, combustion products, and fire suppression agents. Recorders, logic equipment, controllers, power supplies, meters, relays, and hand switches are prevalent in nuclear power plant safety systems and associated support systems. They are important for automatic or manual operation, and their functionality can effect the loss of a complete safety system or support system function. However, despite their importance, these components have a high sensitivity to fire-induced damage. 
The analysts will need to focus particularly on electrical cabling, especially where different size conductors are used and electrical isolation and/or sufficient physical separation of redundant cabling is not maintained. For these conditions, fire-induced thermal degradation of the cable insulation can cause a variety of failure modes that have to be considered as occurring simultaneously. Typically, failure mechanisms other than direct thermal damage may not have been considered in original nuclear power plant designs. In these cases, the only failure modes identified are most likely to have been an open circuit or a short to ground because these are commonly expected failures that normally lead to electrical circuits having short circuit overcurrent protection designed into the system. This is insufficient for fire scenarios because the fire environment will introduce numerous other failure modes. For example, it is possible that the presence of short circuit current in separate electrical cables caused by a fire may not be sufficient to trip individual breakers for the circuits. However, in all of the individual cables involved, the combined effects of the short circuit current may be sufficient to trip the main power supply breaker, causing a complete loss of power. Thus, it is important for analysts implementing this Methodology to consider not only the direct effect of a fire within each fire compartment, with respect to the impact on functionally redundant safety systems, but also the indirect impact of a fire, which may be outside of a particular compartment/cell.

This requires that the analysts systematically consider and evaluate in a qualitative sense all possible direct and indirect affects of potential fires on both active and passive equipment, structures, or components in all areas of a nuclear power plant that could adversely affect nuclear safety.

\section{SPECIFIC INDIRECT EFFECTS}

To guard against nuclear power reactor control and safety system potential failure mechanisms introduced by fires, this Methodology delineates steps to be followed by analysts that will lead to postulating event sequence scenarios for the prediction of fire effects on structure, systems, and components through thermal damage caused by direct flame impingement; indirect or secondary lower level thermal exposures; smoke and the interaction between smoke and moisture; corrosive compounds generated during a fire; and fire suppression activities. In making determinations about structure or equipment survivability during and after a fire, the analysts will need to be particularly cognizant of high humidity, water sprays, and flooding when water suppression systems are involved and to extremely low temperatures, high thermal gradients, high pressure differentials, and high static charge levels when gaseous flooding systems are involved. The analysts will evaluate for 
these concerns where there are existing manual and automatic fire suppression capabilities. However, this should be of particular concern when the remedy to existing vulnerabilities is determined to be the installation of fixed automatic suppression systems.

\section{SENSITTVE COMPONENTS}

The analysts should determine the generic types of components that are susceptible to fire suppression effects. The determination calls for identifying fire suppression equipment in various fire compartment/cells and assessing fire brigade response time and the potential impact of misdirected fire suppression efforts for the area of concern. Where it is determined that the primary means of fire suppression is manually operated water hoses, the fire suppression effects of water spray should be considered for components susceptible to water spray damage. The analysts should consider inaccessibility to a fire by firefighters or poor visibility due to smoke buildup as likely contributors to component damage from water spray fire suppression effects. Also, misapplied hose streams to susceptible equipment should be a consideration. Particular focus should be placed on the following types of equipment/components:
- Transformers
- Switchgear
- Pump motors
- Instrument racks
- Motor operated valves
- Low voltage power supplies
- Air compressors
- Batteries
- Relays
- Switches
- Recorders

\section{ANALYTICAL TECHNIOUES}

Various qualitative techniques can be used by analysts to analyze fire-induced failures that impair systems and to identify improvements to reduce accident potentials at RBMK and VVER nuclear power plants. What-If Analysis, Checklist Analysis, Process Safety Review, Hazard Operability Analysis, Failure Modes and Effects Analysis, Fault Tree Analysis, and Event Tree Analysis are methods that can be used to support implementation of this Methodology.

Although quantitative fire analysis methods can be used to resolve some problem areas as an alternative to making procedural or hardware changes, the Methodology only requires the application of qualitative analyses. The 
Methodology cautions users about the inherent large uncertainties and limitations associated with the use of quantitative fire risk analyses, including:

- Limitations in the ability to accurately model fire growth and progression sequences, including flashover and total fire involvement

- Large uncertainties in historical fire data and the applicability of such data to future nuclear plant fires

- No data on the survivability or specific failure modes of equipment during or following a fire

- No data on the effects of smoke and corrosive products generated by fire on the performance of sensitive safety equipment

- No data on the effects of fire suppression on the performance of sensitive safety equipment

- Other than cable insulation failure temperatures, no data on the fire damage threshold of electrically operated safety equipment that is sensitive to radical temperature changes that would be produced by fires

- Uncertain data on the fire progression of electrical cable tray fires

- A lack of data on the large volume of smoke generated in typical nuclear plant fires and the impairment of human performance in emergency plant response or timely fire suppression activities

\section{LEVEL OF EXPERTISE OF ANALYSTS}

To implement this Methodology, personnel with qualifications equivalent to the following should be organized and trained as a group for at least 72 hours on the Methodology process. The goal of this training should be to prepare individuals to systematically recognize, analyze, and recommend corrective actions for nuclear plant fire vulnerabilities that could result in reactor core damage. The individuals selected for this training should include at least the following types of personnel:

- Chief Engineer or designee who is thoroughly knowledgeable of the overall plant operations and management strategies 
- Reactor Design Engineer who is thoroughly knowledgeable of the design of the nuclear steam supply system and the reactor core protection systems and is capable of assessing failure modes and event sequences

- Plant Systems Design Engineer who is thoroughly knowledgeable of the design and interaction of safety systems and balance-of-plant systems and is capable of assessing failure modes and event sequences

- Plant Systems Engineer who is thoroughly knowledgeable of plant as-built configurations and critical process parameters for the safety systems and the interaction of balance-of-plant systems and is capable of evaluating fire damage effects on all plant systems, as well as assessing failure modes and event sequences

- Fire Protection Engineer who is thoroughly knowledgeable of fire science and of fire protection systems and their interaction with nuclear safety systems and is capable of evaluating fire damage effects on structures, systems and components important to safety

- Electrical Engineer who is thoroughly knowledgeable of the plant's electrical distribution system and is capable of evaluating fire-induced failure modes on critical power, control, and instrumentation circuits

- General Engineer who is capable of interacting with the team analysts and documenting the Methodology used to obtain results from the evaluation

\section{RELATIONSHIP TO A COMPREHENSIVE "DEFENSE-IN-DEPTH" FIRE PROTECTION PROGRAM}

Implementation of results originating from the Methodology at RBMK and VVER nuclear power plants should complement and augment a comprehensive "defense-in-depth" fire protection program. A program that focuses on reactor core protection in the event of a fire is expected to be effective in reducing public risk but is not and should not be considered to be a substitute for a comprehensive "defense-in-depth" fire protection program.

\section{IMPORTANCE OF MAINTAINING PLANT CONFIGURATION}

The Methodology is intended to be applied to the as-built configuration of RBMK and VVER nuclear power plants. If modifications to a plant are made after the Methodology has been implemented, the results can be invalidated. When the Methodology is applied, an integrated management system should 
be in place that is designed to maintain relationships between design requirements, physical configurations, facility activities, and processes and experiments and to maintain associated documentation throughout the life of the nuclear power plant. Whenever plant modifications are made, the affected portions of results obtained from implementing the Methodology should be reanalyzed to determine their impacts.

\section{MAINTENANCE AND RELIABILITY CONSIDERATIONS}

A maintenance program for fire protection and safe shutdown systems should be in place at RBMK and VVER nuclear power plants and contain the appropriate type and frequency of maintenance activities to ensure reliability and availability. Where appropriately suitable maintenance activities are in question, lacking, or nonexistent, solutions to counteract the maintenance vulnerabilities should be considered and recommended.

\section{QUALITY ASSURANCE}

Materials, components, and supplies of appropriate quality for their application should be provided and used throughout RBMK and VVER nuclear power plants. Where appropriate quality assurance measures are in question, lacking, or nonexistent, solutions to eliminate the quality vulnerabilities should be considered and recommended.

\section{ACKNOWLEDGEMENTS}

The following organizations provided Peer Review, technical advice, commentary, or other support to the development of this Methodology:

U.S. Nuclear Regulatory Commission, Washington, D.C. 20555

U.S. Department of State, Washington, D.C. 20520

Nuclear Energy Institute, USA

National Institute of Standards and Technology, Gaithersburg, Maryland 20899

University of California, Berkeley, California 94720

University of Maryland, College Park, Maryland 20742

Gasser Associates, USA

A.D. Rossin, Los Altos Hills, California 94024

Health and Safety Executive, Bootle, Merseyside L20 3LZ, England

International Atomic Energy Agency, Vienna, Austria

Teollisuuden Voima Oy, Olkiluoto, Finland

Imatran Voima Oy, Loviisa, Finland

IVO International, IVO, Finland

Sateilyturvakeskus (STUK), Helsinki, Finland

Institute for Energy Technology at Kjellar, Norway

Swedish International Project, Sweden 
ANSALDO, Italy

Gesellschaft fur Anlagen und Reaktorsicherheit (GRS) mbH, Germany

Commission of the European Community, Brussels, Belgium

European Bank for Reconstruction and Development, London, England

Goscomatom, NO9/11 Ukraine

Ukrainian Ministry of Internal Affairs, NO 9/11 Ukraine

Ministry of Interior, Moscow, Russia

Ministry of Internal Affairs, Moscow, Russia

Ministry for the Russian Federation for Atomic Energy, Moscow, Russia

The U.S. DOE also acknowledges the contributions to the completion of the U.S. Department of Energy's Reactor Core Protection Evaluation

Methodology for Fires at Soviet-Designed RBMK and VVER Nuclear Power Plants by the following U.S. commercial nuclear utilities and contractors, U.S. DOE contractors, and U.S. DOE Laboratories:

American Nuclear Society, La Grange, Illinois 60526

Arizona Public Service Corporation, Tonapah, Arizona 85354

Battelle Memorial Institute, Columbus, Ohio 43201

Bechtel Corporation, Gaithersburg, Maryland 20878

Brookhaven National Laboratory, Upton, New York 11973

Burns \& Roe Company, Oradell, New Jersey 07649

Computer Products, Inc., Arlington, Virginia

Duke Power Company, Charlotte, North Carolina 28201

Duke Engineering Services, Charlotte North Carolina 28202

Engineering Planning and Management Inc., Farmington, Massachusetts 01701

GPU Nuclear Corporation, Middletown, Pennsylvania 17057

IBEX Group, Bethesda, Maryland, 20814

Pacific Northwest Laboratories, Richland, Washington 99352

Raytheon Engineers \& Constructors, Augusta, Georgia 30909

Science Applications International Corporation, Reston, Virginia 22090

Tennessee Valley Authority, Chattanooga, Tennessee 37402

The following nuclear power plants were visited in support of this project:

Leningrad Nuclear Power Plant, Russia

Zaporizhzhya Nuclear Power Plant, Ukraine

Olkiluoto Nuclear Power Plant, Finland

Loviisa Nuclear Power Plant, Finland

Indian Point Nuclear Power Plant, USA

Fitzpatrick Nuclear Power Plant, USA

Oconee Nuclear Power Plant, USA

Catawba Nuclear Power Plant, USA 


\subsection{INTRODUCTION}

\section{$1.1 \quad$ OBJECTIVES}

The objective of this document is to develop recommendations for implementing fire-protection remedies that would enhance the capability to achieve and maintain cold shutdown for a fire at a NPP. The use of these remedies would enable an increase in the fire safety aspects of Soviet-designed RBMK and VVER nuclear power plants located in Central and Eastern Europe, based on the defense-in-depth approach to fire safety.

An overall fire protection program is typically based on the defense-in-depth concept for fire protection. The defense-in-depth principle, as used in the Methodology, is aimed at achieving an adequate balance in:

- Preventing fires from starting (remove or control combustibles and ignition sources)

- Detecting/suppressing fires quickly to limit damage

- Maintaining the reactor in a safe shutdown condition during and after a fire

While each of these echelons cannot be perfect or complete by itself, they are complimentary in nature and form an overall balance of protection against fire. Strengthening any one can compensate in some measure for weaknesses, known or unknown, in the others. Each contributes to minimizing both the probability and consequences of postulated fires.

\section{$1.2 \quad$ METHODOLOGY}

The Methodology presented herein provides guidelines to review and document plant fire vulnerabilities that might jeopardize protection of the reactor core in the event of fire. The objective of this methodology is to identify a means for achieving and maintaining nuclear reactors at Soviet-designed NPPs in a safe shutdown condition during and after a fire. The resulting evaluation document can provide input to an overall plant fire protection program but should not be considered to be a substitute for a complete and comprehensive fire protection program. 


\subsubsection{GENERAL}

This section describes the general methodology used to determine the safe shutdown capability of the nuclear power plant under review during and after fire. This methodology is similar to that generally utilized in the United States and other western countries. It has, however, been modified for use at Soviet-designed nuclear power plants. This approach is based on the following two general principles:

1. The focus of this Methodology is reactor core protection.

2. The implementation of the Methodology must be simple and direct.

Examples of the remedies to fire vulnerabilities that were found to be acceptable to authorities having jurisdiction over U. S. commercial nuclear power plants are provided in Appendix A. These example remedies to fire vulnerabilities are provided for consideration only. They may not be acceptable approaches to address nuclear power plant fire vulnerabilities to authorities having jurisdiction in the sovereign nations of Central and Eastern Europe.

Appendix A also provides examples of options for implementing the methodology analytical steps that were used in the U. S. and found to be technically acceptable and cost effective nuclear safety and fire protection practices.

The Methodology is intended to provide guidance that will assist the analyst at Soviet-designed NPPs located in Central and Eastern Europe to identify fire vulnerabilities associated with nuclear safety and potentially large radioactive releases to the public and the environment. The methodology incorporates aspects of discussions with and comments from designers, regulators, and operators of Soviet-designed NPPs in the sovereign states of Russia and Ukraine that addressed the enhancement of fire safety and reduction of nuclear safety risks at Sovietdesigned NPPs by allowing for adjustments that take into account the regulations and specific conditions that have to be considered in the respective Central and Eastern European countries.

\section{PROCEDURE METHODOLOGY}

The overall Methodology is based on the assumptions and limiting conditions given in Section 3.0. Each major step is briefly described below. A flowchart of the major steps is presented in Figure 1.2-1. The Methodology sections dealing with each major step are referenced in the description and shown on the flowchart. 


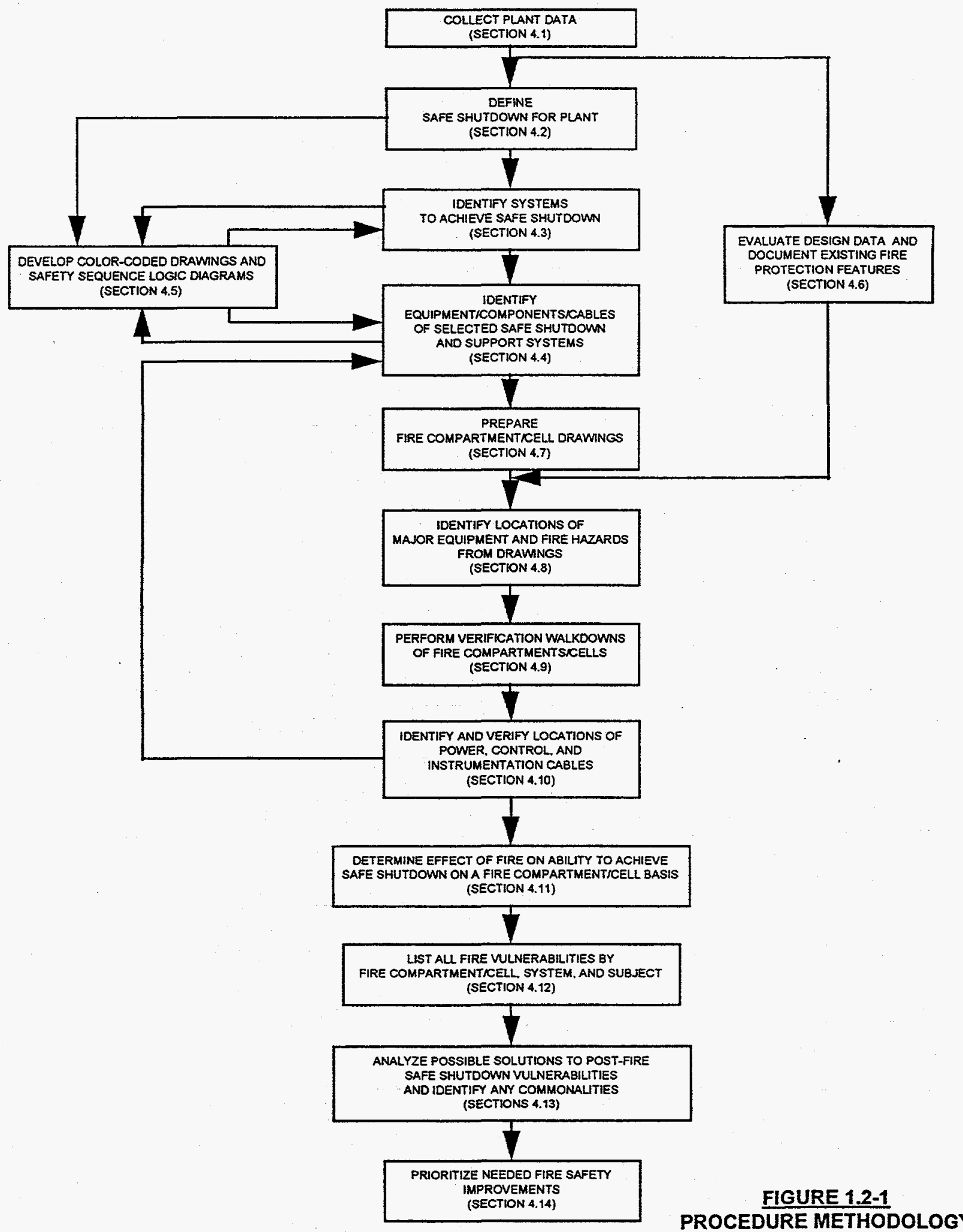




\subsubsection{Collect Plant Data (Section 4.1)}

The initial step is to identify, collect, and organize existing plant design documents and data that will be utilized in the various reviews and evaluations performed in Sections 4.2 through 4.11 . The data collected will consist of drawings, documents, procedures, equipment lists, system descriptions, and other similar items.

As required, additional data may be collected in other steps, such as walkdowns.

\subsubsection{Define Safe Shutdown for Plant (Section 4.2)}

This step develops a definition of safe shutdown by identifying the plant functions necessary to achieve and maintain reactor shutdown. The procedural methodology utilized is to describe the shutdown functions typically associated with reactors designed in the sovereign states of Russia and Ukraine. These shutdown function definitions can be verified for use for the Soviet-designed plant under evaluation.

This shutdown function definition is utilized in Sections 4.3 and 4.4 as the basis for identifying specific plant shutdown systems and equipment.

\subsubsection{Identify Systems to Achieve Safe Shutdown (Section 4.3)}

This step identifies any and all plant systems that may be used, either directly or as a support system, to achieve and maintain safe shutdown conditions based on the plant shutdown functions defined in Section 4.2.

The results of this step are used in Section 4.4 to identify specific pieces of equipment within these systems that, as a minimum, will be required to achieve and maintain safe shutdown.

\subsubsection{Identify Equipment/Components/Cables of Selected Safe Shutdown and} Support Systems (Section 4.4)

This step provides guidance for selecting the specific plant equipment required to achieve and maintain safe shutdown based on the systems identified in Section 4.3 and the Safety Sequence Logic Diagrams prepared in Section 4.5. Both power and control cables necessary for proper equipment functioning are identified.

This equipment is categorized into specific shutdown paths, with the primary shutdown path being the normal plant means to achieve shutdown. This section initially identifies three shutdown paths: a primary shutdown path, a secondary shutdown path, and one alternate shutdown path. Other alternate shutdown paths 
(those using equipment other than the normal shutdown equipment) are established for use as necessary as determined in Section 4.11.

This step also provides guidance on evaluating safe shutdown capability while considering the possible negative effects of fire damage to circuits that are not directly related to the successful operation of a safe shutdown component. The associated circuits of concern include any circuit whose fire-induced damage could prevent operation or cause maloperation of required shutdown systems. This step will use inputs derived in Section 4.10.

Guidance is provided on how to identify the associated circuits of concern and how to evaluate and resolve potential circuit problems.

\subsubsection{Develop Color-Coded Drawings and Safety Sequence Logic Diagrams} (Section 4.5)

Color-coded drawings will be prepared, based on Section 4.4, to serve as a tool for identifying the safe shutdown equipment and components. These drawings will be prepared by highlighting (color coding) each flow path on existing system piping or process and instrumentation diagram (P\&ID) drawings. They can potentially be used to achieve and maintain safe shutdown conditions. This will be done for each plant system identified on reactor shutdown sequence logic diagrams.

Safety sequence logic diagrams will be prepared at the same time as Sections 4.2 , 4.3 , and 4.4. These diagrams provide a visual presentation of safe shutdown logic interfaces between equipment and controls. Preparing these drawings helps in identifying systems and equipment necessary to achieve shutdown. The drawings are also used in training for fire mitigation.

1.2.2.6 Evaluate Design Data and Document Existing Fire Protection Features (Section 4.6)

The review of existing plant fire protection features provides a qualitative evaluation of the status of those features. The purpose of the qualitative evaluation is to provide a level of confidence that the features, as designed and as installed, will perform their intended function. This evaluation is not intended as a check of system design calculations, installation details, performance tests, etc., but as a value judgment of a system's capability to perform its intended function(s) associated with the safe shutdown of the reactor. The results of the value judgment may lead to the recommendation that additional system reviews, tests, and/or modifications be performed. 
This evaluation is performed both by reviewing existing drawings and documents and by collecting data/information from walkdowns, as required.

Information regarding existing fire barriers is used in Section 4.7 in defining the plant fire compartments and fire cells.

1.2.2.7 Prepare Fire Compartment/Cell Drawings (Section 4.7)

This step identifies the specific plant buildings and structures that will be evaluated and divides those buildings and structures into specific fire compartments and fire cells.

The results of this step are a set of fire compartment/fire cell drawings showing the compartment/cell numbers and the boundaries of those compartments/cells. The fire compartments and fire cells are used in Sections 4.8, 4.9, 4.10, and 4.11 to locate equipment and evaluate the effects of fires.

1.2.2.8 Identify Locations of Major Equipment and Fire Hazards from Drawings (Section 4.8)

This step uses existing plant arrangement and system drawings to locate reactor shutdown related equipment identified in Section 4.4 into the fire compartments and fire cells defined in Section 4.7 and to identify known fire hazards such as large concentrations of highly combustible materials. The equipment and any known fire hazards are entered into the appropriate section of the walkdown checklist, to be confirmed as part of the verification walkdowns performed in Section 4.9 .

\subsubsection{Perform Verification Walkdowns of Fire Compartments/Cells (Section 4.9)}

This step verifies information collected in Section 4.8 and collects new information for each fire compartment and fire cell that will be evaluated. The purposes of the walkdown are to determine or verify equipment locations, to verify and gather information on combustible loadings and fire hazards, to gather data on the physical condition of the compartment/cell, and to gather data on fire protection features and other support systems.

While it is intended that each fire compartment and fire cell be walked down only once to verify/gather information, subsequent walkdowns of specific compartments/cells may be required to support the evaluations performed in Section 4.11

1.2.2.10 Identify and Verify Locations of Power, Control, and Instrumentation Cables (Section 4.10) 
Power and control cables necessary to ensure that major system components function as required to achieve safe shutdown are identified in Section 4.4. In addition, associated circuits are identified to the extent necessary. This step of the procedure identifies the specific cable routings of those required safe shutdown cables.

These required cable routings may be obtained from drawings, computerized cable routing databases, or field tracing. Where drawings or computer databases are used, a representative sample of cables will be field verified (traced) to confirm the as-built accuracy of the drawings/database. This is described in Section 4.4.

This cable routing information is used in Sections 4.4 and 4.11 .

1.2.2.11 Determine Effect of Fire on Ability to Achieve Safe Shutdown on a Fire Compartment/Cell Basis (Section 4.11)

This step provides guidance on the evaluations required for each proposed fire compartment/fire cell. Three types of evaluations are considered: effects of a fire and potential for an explosion to occur, fire containment, and capability to achieve/maintain safe shutdown during and after a fire. Guidance is provided to determine if any or all of the evaluations are required.

Where a safe shutdown evaluation is required for a fire compartment/fire cell, the Methodology provides guidance to evaluate the effect of a fire in that compartment/cell. The objective of this review is to determine the effect of a fire in that compartment/cell on the plant's ability to achieve safe shutdown during and after a fire. The initial assumption is that all equipment and cables located in the compartment/cell are lost due to the fire. Using this initial assumption, the shutdown paths are evaluated to determine the plant's ability to achieve and maintain shutdown. Subsequent assumptions may entail the analysis of the effects of localized fires on safe shutdown equipment or components after dividing a compartment into cells and considering the location of the system or component with respect to fire origin and fire effects in which case credit may be taken for fire protection/prevention features. The acceptability of such assumptions would rest with the authority having jurisdiction.

Fire compartments and fire cells are also evaluated as required for the compartment's/cell's ability to contain the fire and for the possibility of fire spreading into the compartment/cell from adjacent compartments/cells. In addition, fire protection features such as automatic fire suppression systems, fire detection systems, and manual fire suppression equipment are reviewed to support conclusions about limiting or preventing the propagation of fire and combustion 
products so the consequential damage between adjacent fire compartments/ fire cells is not expected.

1.2.2.12 List All Fire Vulnerabilities by Fire Compartment/Cell, System, and Subject (Section 4.12)

This step uses the results of Section 4.11 and provides a list of fire vulnerabilities by compartment/cell, system, and subject.

The list by system provides specific system vulnerabilities that have been determined based on the compartment/cell vulnerabilities. An example of a system vulnerability is some specific fault discovered in the fire water supply system that prevents the system from performing as intended and required.

The list by subject provides specific subject vulnerabilities that have been identified as the result of the evaluations. An example of a subject vulnerability is a general lack of emergency lighting to support required operator manual actions to counter fire effects.

\subsubsection{Analyze Possible Solutions to Post-Fire Vulnerabilities and Identify any Commonalities (Section 4.13)}

Based on the results of Sections 4.11 and 4.12 , the Methodology provides guidance and examples for developing various typical solutions that, when implemented, would preserve or restore shutdown capability. These solutions are intended as examples of the various possible types of solutions that could be used to combat the vulnerabilities listed in Section 4.12. The intent is to minimize the need for physical plant modifications and to implement the least cost-intensive and least plant-invasive options possible.

The various solutions to individual compartment/cell, system, and subject vulnerabilities are reviewed for commonalities. The objective of this section is to determine a "best" set of improvements that provides a successful shutdown path for each plant fire compartment/fire cell.

\subsubsection{Prioritize Needed Fire Safety Improvements (Section 4.14)}

This step provides guidance to take the set of solutions developed in Section 4.13 and prioritize them using cost, ease of installation, and impact on achieving shutdown as qualitative factors. 


\subsubsection{TERMINOLOGY}

The terms used in this document generally conform to those used in the International Atomic Energy Agency (IAEA) Fire Hazards Analysis (FHA) procedure (Reference 5.1), and typically are in general usage for this topic. See Section 2.0.

This document uses the "fire compartment" and "fire cell" terminology used in the IAEA FHA procedure (Reference 5.1). These terms are essentially analogous to the "fire area" and "fire zone" terms used in United States (U.S.) codes, standards, and guidance documents.

This document also refers to various system names and terms that are commonly used in U.S. power plants, such as reactor coolant system (RCS). These system references are used only as examples. There may or may not be an analogous Soviet-designed system. In some cases, one or more Soviet-designed systems may serve the same purpose as the mentioned U.S. system. 


\subsection{GLOSSARY OF TERMS}

\section{DEFINITIONS}

The terms related to fire protection and fire hazards evaluations are presented below with their definitions as used in this document.

\begin{tabular}{|c|c|}
\hline accident conditions & $\begin{array}{l}\text { Deviations from normal operational states that cause or threaten } \\
\text { a release of radioactive materials into the plant and/or the } \\
\text { environment. }\end{array}$ \\
\hline $\begin{array}{l}\text { alternate shutdown } \\
\text { capability }\end{array}$ & $\begin{array}{l}\text { The ability to safely shut down the reactor and maintain } \\
\text { shutdown using equipment and processes outside the normal } \\
\text { reactor shutdown process (either the normal or redundant } \\
\text { shutdown capability). This alternative shutdown capability may } \\
\text { use equipment not normally used for shutdown or use equipment } \\
\text { after rerouting, relocating, or modifying mechanical or electrical } \\
\text { systems. }\end{array}$ \\
\hline associated circuits & $\begin{array}{l}\text { Circuits not directly related to the successful operation of a safe } \\
\text { shutdown component whose fire-induced failure could prevent } \\
\text { other circuits that directly support the operation of a safe } \\
\text { shutdown component from functioning as intended, thus causing } \\
\text { a failure of the safe shutdown equipment. }\end{array}$ \\
\hline automatic & $\begin{array}{l}\text { Self-acting, operating by its own mechanism when actuated by } \\
\text { some non-human influence such as a change in current, pressure, } \\
\text { temperature, or mechanical configuration. }\end{array}$ \\
\hline Authority having jurisdiction & $\begin{array}{l}\text { The decision making authority in sovereign nations who regulates } \\
\text { and determines the acceptability of matters concerning fire } \\
\text { protection and nuclear safety. }\end{array}$ \\
\hline auxiliary contact & $\begin{array}{l}\text { A contact on the safe shutdown equipment circuit whose state } \\
\text { could be affected by equipment from another circuit. }\end{array}$ \\
\hline bolted fault & See low impedance fault. \\
\hline cable coating & $\begin{array}{l}\text { A substance applied over the exterior surface of a cable to } \\
\text { decrease the fire propagating properties of the cable insulation. }\end{array}$ \\
\hline cable fire wrap & $\begin{array}{l}\text { A fire barrier enclosure added to a bare cable, conduit, or cable } \\
\text { tray to provide fire separation between the enclosed cable(s) and } \\
\text { the remainder of the fire compartment or fire cell. }\end{array}$ \\
\hline
\end{tabular}




\section{U.S. DEPARTMENT OF ENERGY'S REACTOR CORE \\ PROTECTION EVALUATION METHODOLOGY FOR FIRES AT \\ SOVIET-DESIGNED RBMK AND VVER NUCLEAR POWER PLANTS}

网

\begin{tabular}{|l|l|}
\hline cable scheme & $\begin{array}{l}\text { A unique cable identification given to a single or multiconductor } \\
\text { cable that is routed from point A to point B and terminated at } \\
\text { points A and B. }\end{array}$ \\
\hline color coding & $\begin{array}{l}\text { The process of marking drawings using either colors or symbols } \\
\text { to identify and distinguish specific post-fire safe shutdown flow } \\
\text { paths or systems. }\end{array}$ \\
\hline combustible liquid & $\begin{array}{l}\text { A liquid that that has a flash point (or flash temperature) at or } \\
\text { above } 38^{\circ} \text { C (100 }\end{array}$ \\
\hline combustible material
\end{tabular}




\begin{tabular}{|c|c|}
\hline $\begin{array}{l}\text { Emergency Operating } \\
\text { Procedure }\end{array}$ & $\begin{array}{l}\text { A procedure that directs actions necessary for the operators to } \\
\text { mitigate the consequences of transients and accidents that cause } \\
\text { plant parameters to exceed reactor protection system or } \\
\text { engineered safety feature actuation setpoints. }\end{array}$ \\
\hline exposure fire & $\begin{array}{l}\text { A fire in a given area that involves either in situ or transient } \\
\text { combustibles and is external to any structures, systems, or } \\
\text { components located in or adjacent to that same area. The effects } \\
\text { of such fire (e.g. smoke, heat, or ignition) can adversely affect } \\
\text { those structures, systems, or components important to reactor } \\
\text { safety. Thus, a fire involving one train of reactor safe shutdown } \\
\text { equipment may constitute an exposure fire for the redundant } \\
\text { reactor shutdown train located in the same area, and a fire } \\
\text { involving combustibles other than either redundant train may } \\
\text { constitute an exposure fire to both redundant trains located in the } \\
\text { same area. }\end{array}$ \\
\hline fire & $\begin{array}{l}\text { 1. A process of combustion characterized by the emission of } \\
\text { heat accompanied by smoke or flame or both. } \\
\text { 2. Rapid combustion spreading in an uncontrolled manner in } \\
\text { time and space. } \\
\text { 3. Ukrainian definition: Uncontrollable combustion outside } \\
\text { of a special location that is developing in time and in space. }\end{array}$ \\
\hline fire barrier & $\begin{array}{l}\text { Those components of construction (walls, floors, and their } \\
\text { supports), including beams, joists, columns, penetration seals or } \\
\text { closures, fire doors, and fire dampers that are used to prevent the } \\
\text { spread of fire. A fire barrier is characterized by a fire resistance } \\
\text { rating. }\end{array}$ \\
\hline fire brigade & $\begin{array}{l}\text { A specialized organization that is equipped for and trained in the } \\
\text { fighting of NPP fires. This organization is a separate entity from, } \\
\text { but located near, an NPP. }\end{array}$ \\
\hline fire cell & $\begin{array}{l}\text { A subdivision of a fire compartment, separated from other } \\
\text { portions of the fire compartment by either physical barriers } \\
\text { (walls, floors, ceilings) or distance. } \\
\text { A cell, if relied upon in a safe shutdown analysis, may provide fire } \\
\text { separation between components required for safe shutdown by } \\
\text { fire protection features (such as limitation of combustible } \\
\text { materials, spatial separation, fixed fire extinguishing systems, } \\
\text { fireproof coatings, or other features) so that consequential }\end{array}$ \\
\hline
\end{tabular}




\section{U.S. DEPARTMENT OF ENERGY'S REACTOR CORE \\ PROTECTION EVALUATION METHODOLOGY FOR FIRES AT \\ SOVIET-DESIGNED RBMK AND VVER NUCLEAR POWER PLANTS}

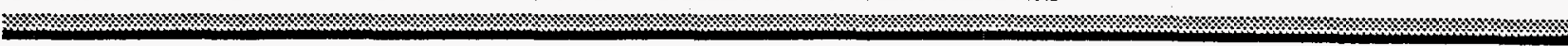

\begin{tabular}{|l|l|}
\hline & $\begin{array}{l}\text { damage to the other separated systems is not expected. In such } \\
\text { cases, the fire cell can be described as acting as a fire } \\
\text { compartment. }\end{array}$ \\
\hline fire compartment & $\begin{array}{l}\text { A building or part of a building comprising one or more rooms or } \\
\text { spaces constructed to prevent the spreading of fire to or from the } \\
\text { remainder of the building for a given period of time. A fire } \\
\text { compartment is completely surrounded by a fire barrier. (Note: } \\
\text { the exterior walls of a building are not always required to be } \\
\text { rated fire barriers for a fire compartment.) }\end{array}$ \\
\hline fire countermeasure & $\begin{array}{l}\text { Something that corrects or counteracts the effects of a fire, such } \\
\text { as a documented plan describing an overall course of action in } \\
\text { response to a reasonably anticipated fire event that may include } \\
\text { fire suppression, emergency repairs, and/or other manual actions. } \\
\text { Specific instructions in support of the overall course of action } \\
\text { may appear in individual plant procedures, such as Emergency } \\
\text { Operating Procedures, etc. }\end{array}$ \\
\hline fire damper & $\begin{array}{l}\text { A device that is designed, by automatic operation, to prevent the } \\
\text { passage of fire through a duct under given conditions. }\end{array}$ \\
\hline fire detector & $\begin{array}{l}\text { A device designed to automatically detect the presence of fire } \\
\text { and initiate an alarm system and other appropriate action. Some } \\
\text { typical fire detectors are classified as follows: } \\
\text { heat detector - A device that detects a predetermined (fixed) } \\
\text { temperature or rate of temperature rise. } \\
\text { fmoke detector - A device that detects the visible or invisible } \\
\text { products of combustion. } \\
\text { flame detector - A device that detects the infrared, ultraviolet, or } \\
\text { visible radiation produced by a fire. } \\
\text { line-type detector - A device in which detection is continuous } \\
\text { along a path, e.g., fixed-temperature, heat-sensitive cable and } \\
\text { rate-of-rise pneumatic tubing detectors. }\end{array}$ \\
\hline The door component of a fire door assembly. \\
\hline $\begin{array}{l}\text { Any combination of a fire door, frame, hardware, and other } \\
\text { accessories that together provide a specific level of fire resistive } \\
\text { protection to the opening. }\end{array}$ \\
\hline
\end{tabular}




\section{U.S. DEPARTMENT OF ENERGY'S REACTOR CORE \\ PROTECTION EVALUATION METHODOLOGY FOR FIRES AT \\ SOVIET-DESIGNED RBMK AND VVER NUCLEAR POWER PLANTS}

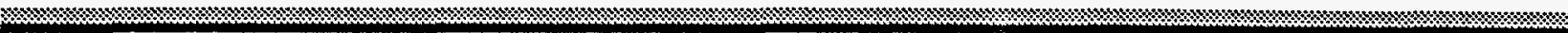

\begin{tabular}{|c|c|}
\hline fire hazards analysis & $\begin{array}{l}\text { An analysis used to evaluate the capability of a nuclear power } \\
\text { plant to perform safe shutdown functions and minimize } \\
\text { radioactive releases to the environment in the event of a fire. The } \\
\text { analysis includes the following important features: } \\
\text { 1. Identify potential permanent and transient fire hazards } \\
\text { 2. Determine the consequences of fire in any plant location on } \\
\text { the ability to safely shut down the reactor or on the ability } \\
\text { to minimize and control the release of radioactivity to the } \\
\text { environment } \\
\text { 3. Specify measures for preventing, detecting, suppressing, and } \\
\text { containing a fire, and alternative shutdown capability that } \\
\text { may be required for fire compartments containing } \\
\text { structures, systems, and components important to safety. }\end{array}$ \\
\hline $\begin{array}{l}\text { fire load (or fire load } \\
\text { density) }\end{array}$ & $\begin{array}{l}\text { The sum of the caloric energies that could be released by the } \\
\text { complete combustion of all the combustible materials in a space, } \\
\text { including the facings of the walls, partitions, floors, and ceiling. } \\
\text { Units are typically expressed in } \mathrm{MJ} / \mathrm{m}^{2} \text {. }\end{array}$ \\
\hline fireproofing & $\begin{array}{l}\text { The addition of coatings, wraps, or other types of surface } \\
\text { treatment to structural members to allow those members to resist } \\
\text { a fire without suffering serious structural damage. The fire- } \\
\text { resistive design is characterized by a time rating. }\end{array}$ \\
\hline fire protection feature & $\begin{array}{l}\text { Any component, system, or human resource installed or available } \\
\text { at a facility that is designed to mitigate the consequences of a } \\
\text { fire. }\end{array}$ \\
\hline fire protection program & $\begin{array}{l}\text { The integrated effort involving components, procedures, and } \\
\text { personnel utilized in carrying out all activities of fire protection. } \\
\text { It includes system and facility design, fire prevention, fire } \\
\text { detection, annunciation, confinement, suppression, administrative } \\
\text { controls, fire brigade organization, inspection and maintenance, } \\
\text { training, quality assurance, and testing. }\end{array}$ \\
\hline fire resistance & $\begin{array}{l}\text { The ability of an element of building construction, component, or } \\
\text { structure to fulfill, for a stated period of time, the required load } \\
\text { bearing function, integrity, and/or thermal insulation, and/or other } \\
\text { expected duty specified in a standard fire-resistance test. }\end{array}$ \\
\hline
\end{tabular}




\begin{tabular}{|c|c|}
\hline fire retardant & $\begin{array}{l}\text { The quality of a substance to suppress, reduce, or markedly delay } \\
\text { the combustion of certain materials. }\end{array}$ \\
\hline fire stop & $\begin{array}{l}\text { Physical barrier designed to restrict the spread of fire in cavities } \\
\text { within and between building construction elements. }\end{array}$ \\
\hline fire suppression & $\begin{array}{l}\text { Control and extinguishing of fires (fire fighting). Manual fire } \\
\text { suppression is the use of hoses, portable extinguishers, or } \\
\text { manually-actuated fire systems by plant personnel. Automatic } \\
\text { fire suppression is the use of automatically actuated fixed systems } \\
\text { such as water, Halon, or carbon dioxide systems. }\end{array}$ \\
\hline fire vulnerabilities & $\begin{array}{l}\text { Plant conditions and operational weaknesses that could lead to } \\
\text { unnecessary or increased susceptibility and damage/degradation. } \\
\text { of the reactor core in the event of a fire. }\end{array}$ \\
\hline flammable liquid & $\begin{array}{l}\text { A liquid that that has a flash point (or flash temperature) below } \\
38^{\circ} \mathrm{C}\left(100^{\circ} \mathrm{F}\right) \text { and a vapor pressure not exceeding } 275 \mathrm{kPa} \text { at } \\
38^{\circ} \mathrm{C}\left(40 \text { psia at } 100^{\circ} \mathrm{F}\right) \text {. }\end{array}$ \\
\hline $\begin{array}{l}\text { flash point (or flash } \\
\text { temperature) }\end{array}$ & $\begin{array}{l}\text { The lowest temperature of a combustible liquid or a flammable } \\
\text { liquid at which its vapor pressure is sufficient to form an } \\
\text { ignitable mixture with air near the surface of the liquid. }\end{array}$ \\
\hline heat of combustion & The caloric energy of a substance per unit weight. \\
\hline high impedance fault & $\begin{array}{l}\text { A circuit fault condition resulting in a current leakage to ground } \\
\text { where the fault current level is slightly below the component's } \\
\text { circuit breaker long-term setpoint. }\end{array}$ \\
\hline highlight (a drawing) & $\begin{array}{l}\text { To identify and center attention on or emphasize piping or } \\
\text { process lines by marking them in color. }\end{array}$ \\
\hline hot short & $\begin{array}{l}\text { An energized conductor within a cable comes in electrical contact } \\
\text { with an unenergized conductor(s) located within the same cable } \\
\text { or in another cable. }\end{array}$ \\
\hline hot work controls & $\begin{array}{l}\text { Administrative and procedural controls that reduce or eliminate } \\
\text { potential fire hazards associated with work requiring the use of } \\
\text { open flames or concentrated heat, such as welding and brazing. }\end{array}$ \\
\hline $\begin{array}{l}\text { housekeeping practices } \\
\text { (good) }\end{array}$ & $\begin{array}{l}\text { Administrative programs that reduce or eliminate potential fire } \\
\text { hazards through proper material handling and storage, waste } \\
\text { control, cleanliness and order, and the regulation of personal } \\
\text { practices, such as smoking. }\end{array}$ \\
\hline
\end{tabular}




\begin{tabular}{|c|c|}
\hline interrupting device & $\begin{array}{l}\text { A breaker, fuse, or similar device installed in an electrical circuit } \\
\text { to isolate the circuit (or a portion of the circuit) from the } \\
\text { remainder of the system in the event of an overload or fault } \\
\text { downstream of the interrupting device. }\end{array}$ \\
\hline isolation device & $\begin{array}{l}\text { A device in a circuit that prevents malfunctions in one section of } \\
\text { a circuit from causing unacceptable influences in other sections of } \\
\text { the circuit or other circuits. }\end{array}$ \\
\hline latching device & $\begin{array}{l}\text { A spring-loaded latch bolt or a gravity-operated steel bar used on } \\
\text { a door that after release by physical action returns to its operating } \\
\text { position and automatically engages the strike plate when it is } \\
\text { returned to the closed position. }\end{array}$ \\
\hline low impedance fault & $\begin{array}{l}\text { A circuit fault condition or failure where the circuit comes in } \\
\text { contact with ground, which results in a protective device } \\
\text { interrupting maximum available short-circuit current. }\end{array}$ \\
\hline non-combustible material & $\begin{array}{l}\text { A material that, in the form in which it is used and under the } \\
\text { conditions anticipated, will not ignite, support combustion, burn, } \\
\text { or release flammable vapor when subject to fire or heat. }\end{array}$ \\
\hline open circuit & $\begin{array}{l}\text { A failure condition that results when a circuit (either a cable or } \\
\text { individual conductor within a cable) loses electrical continuity. }\end{array}$ \\
\hline physical separation & $\begin{array}{l}\text { 1. Separation by geometry (distance, orientation, etc.), or } \\
\text { 2. Separation by appropriate barriers, or } \\
\text { 3. Separation by a combination thereof. }\end{array}$ \\
\hline protective device & See interrupting device. \\
\hline qualified (equipment) & $\begin{array}{l}\text { Tested and accepted for a specific purpose or application by a } \\
\text { recognized testing laboratory. Such laboratory shall be concerned } \\
\text { with product evaluations to determine compliance with } \\
\text { appropriate standards for the equipment being tested. } \\
\text { (Note: In the U.S., this type of equipment would be called } \\
\text { "approved" and be listed or labeled by the laboratory.) }\end{array}$ \\
\hline reactor core protection & $\begin{array}{l}\text { The integrated effort involving system and component design, } \\
\text { procedures, administrative programs, and personnel that provides } \\
\text { assurance that a safe, stable condition of the reactor core can be } \\
\text { achieved and maintained. }\end{array}$ \\
\hline redundant (equipment) & Equipment accomplishing the same essential function as other \\
\hline
\end{tabular}




\begin{tabular}{|l|l|}
\hline | & $\begin{array}{l}\text { equipment to the extent that either may perform the required } \\
\text { function. The provisions of redundancy enable the failure or } \\
\text { unavailability of equipment to be tolerated without loss of the } \\
\text { function to be performed. Redundancy may be of varying } \\
\text { degrees; for example, two, three, or four pumps might be } \\
\text { provided for a particular function when any one is capable of } \\
\text { accomplishing it. Redundancy may be achieved by using identical } \\
\text { or diverse components. }\end{array}$ \\
\hline $\begin{array}{l}\text { redundant shutdown } \\
\text { capability }\end{array}$ & $\begin{array}{l}\text { The ability to safely shut down the reactor and maintain } \\
\text { shutdown using a second, third, or other multiple option of } \\
\text { standard or normal means for accomplishing safe shutdown. }\end{array}$ \\
\hline safe shutdown analysis & $\begin{array}{l}\text { A process of determining equipment that is required to reach and } \\
\text { maintain a safe shutdown condition. }\end{array}$ \\
\hline safe shutdown condition & $\begin{array}{l}\text { The point in reactor shutdown where subcritical reactivity and } \\
\text { reactor coolant inventory, temperature, and pressure can be } \\
\text { maintained (over any period of time) at target values, depending } \\
\text { on the plant considered, and must be understood as defined in } \\
\text { plant procedures, e.g.: }\end{array}$ \\
\hline safety systems & $\begin{array}{l}\text { Subcritical reactivity conditions as in a cold shutdown. } \\
\text { - Reactor coolant level within target limits. } \\
\text { - Removal of decay heat. } \\
\text { Direct reading of process variables enough to control the } \\
\text { safe shutdown condition. } \\
\text { Availability of supporting functions (cooling, lubrication) } \\
\text { for safe shutdown systems performance. }\end{array}$ \\
\hline safe shutdown system & $\begin{array}{l}\text { Any structure, system, cable (power, instrumentation, and } \\
\text { control), and component identified as necessary to achieve and } \\
\text { maintain subcritical reactivity conditions in the reactor, reactor } \\
\text { coolant inventory, and safe shutdown conditions following a fire- } \\
\text { initiated event. Any plant system or human resource that } \\
\text { supports the above is also included. }\end{array}$ \\
\hline $\begin{array}{l}\text { Systems important to safety, provided to assure the safe } \\
\text { shutdown of the reactor or the residual heat removal from the } \\
\text { core, or to limit the consequences of anticipated operational } \\
\text { occurrences or accident conditions. }\end{array}$ \\
$\begin{array}{l}\text { Doors that, when opened and released, return to the closed } \\
\text { position. }\end{array}$ \\
\hline
\end{tabular}




\begin{tabular}{|c|c|}
\hline short circuit & $\begin{array}{l}\text { A failure condition that results when a circuit (either a cable or } \\
\text { individual conductor within a cable) comes into electrical contact } \\
\text { with another circuit. }\end{array}$ \\
\hline short to ground & $\begin{array}{l}\text { A failure condition that results when a circuit (either a cable or } \\
\text { individual conductor within a cable) comes into electrical contact } \\
\text { with a grounded conducting device such as a cable tray, conduit, } \\
\text { grounded equipment, etc. }\end{array}$ \\
\hline shutdown path & $\begin{array}{l}\text { A specific combination of systems and components capable of } \\
\text { achieving and maintaining a safe shutdown condition during and } \\
\text { following a postulated fire. }\end{array}$ \\
\hline single failure & $\begin{array}{l}\text { A random failure of a component within a system that prevents } \\
\text { the system from performing its intended safety function. All } \\
\text { components within a system have the potential to fail, but only } \\
\text { one component failure is assumed or considered for any one } \\
\text { event. Consequential failures resulting from that single, random } \\
\text { occurrence are also considered to be a part of the single failure. } \\
\text { Example: A system contains four components: components } A \text {, } \\
B, C \text {, and } D \text {. A single failure of this system means that either } A \text {, } \\
B, C \text {, or } D \text { will fail (no one component will fail exclusively, and } \\
\text { all four will not fail simultaneously). In addition, the failure of } \\
\text { either } A, B, C \text {, or } D \text { may affect other systems, and this must be } \\
\text { considered. }\end{array}$ \\
\hline site & $\begin{array}{l}\text { The area containing the plant, defined by a boundary and under } \\
\text { effective control of plant management. }\end{array}$ \\
\hline spurious operation & $\begin{array}{l}\text { The operation of equipment resulting from a fire-induced failure } \\
\text { that could impair the capability to achieve safe shutdown. }\end{array}$ \\
\hline $\begin{array}{l}\text { transient combustible } \\
\text { material }\end{array}$ & $\begin{array}{l}\text { Quantities of combustible material that are either temporary } \\
\text { (such as those required for maintenance or repairs), or that vary } \\
\text { over time. }\end{array}$ \\
\hline walkdown & $\begin{array}{l}\text { The process of visually verifying a physical plant condition such } \\
\text { as the location and condition of systems, structures, and } \\
\text { components. For this Methodology, the process is typically } \\
\text { performed on a cell-by-cell basis, with all elements within each } \\
\text { cell being reviewed as required. }\end{array}$ \\
\hline
\end{tabular}




\begin{tabular}{|l|l|}
\hline site & $\begin{array}{l}\text { The area containing the plant, defined by a boundary and under } \\
\text { effective control of plant management. }\end{array}$ \\
\hline spurious operation & $\begin{array}{l}\text { The operation of equipment resulting from a fire-induced failure } \\
\text { that could impair the capability to achieve safe shutdown. }\end{array}$ \\
\hline $\begin{array}{l}\text { transient combustible } \\
\text { material }\end{array}$ & $\begin{array}{l}\text { Quantities of combustible material that are either temporary } \\
\text { (such as those required for maintenance or repairs), or that vary } \\
\text { over time. }\end{array}$ \\
\hline walkdown & $\begin{array}{l}\text { The process of visually verifying a physical plant condition such } \\
\text { as the location and condition of systems, structures, and } \\
\text { components. For this Methodology, the process is typically } \\
\text { performed on a cell-by-cell basis, with all elements within each } \\
\text { cell being reviewed as required. }\end{array}$ \\
\hline
\end{tabular}


ACRONYMS AND ABBREVIATIONS

\begin{tabular}{|l|l|}
\hline ac/AC & Air Conditioning or Alternating Current \\
\hline ANI & American National Insurers \\
\hline ANS & American Nuclear Society \\
\hline ANSI & American National Standards Institute \\
\hline APCSB & Auxiliary and Power Conversion Systems Branch (NRC) \\
\hline ASTM & American Society for Testing of Materials \\
\hline BTP & Branch Technical Position 9.5.1 of the Standard Review Plan \\
\hline BTU & British Thermal Unit \\
\hline BWR & Boiling Water Reactor \\
\hline dc/DC & Direct Current \\
\hline DOE/U.S. DOE & United States Department of Energy \\
\hline EOP & Emergency Operating Procedure \\
\hline FHA & Fire Hazards Analysis \\
\hline FHE & Fire Hazards Evaluation \\
\hline GPM/gpm & Gallons Per Minute \\
\hline HVAC & Heating, Ventilating, and Air-Conditioning \\
\hline IAEA & International Atomic Energy Agency \\
\hline IEEE & Institute of Electrical and Electronic Engineers \\
\hline kPa & kilo-Pascal \\
\hline MCC & Motor Control Center \\
\hline MJ/m ${ }^{2}$ & Mega-Joules per meter squared \\
\hline NPP & Nuclear Power Plant \\
\hline NRC/U.S. NRC & United States Nuclear Regulatory Commission \\
\hline
\end{tabular}


U.S. DEPARTMENT OF ENERGY'S REACTOR CORE

PROTECTION EVALUATION METHODOLOGY FOR FIRES AT

SOVIET-DESIGNED RBMK AND VVER NUCLEAR POWER PLANTS

\%ం

\begin{tabular}{|l|l|}
\hline Pa & Pascal \\
\hline P\&ID & Process and Instrumentation Diagram \\
\hline psig & Pounds Per Square Inch Gauge \\
\hline PWR & Pressurized Water Reactor \\
\hline RCS & Reactor Coolant System \\
\hline SSA & Safe Shutdown Analysis \\
\hline SSD & Safe Shutdown \\
\hline SSE & Safe Shutdown Evaluation \\
\hline SSLD & Safety Sequence Logic Diagram \\
\hline U.S. & United States \\
\hline
\end{tabular}




\subsection{ASSUMPTIONS AND LMMITING CONDITIONS}

3.1

\section{ASSUMPTIONS}

The guidelines contained in this document are based on the assumptions listed and discussed below. These assumptions have been selected based on those normally made to perform this work and typically used in recognized codes, standards, and regulations. The validity of these assumptions should be reviewed on a case-bycase basis.

3.1.1 A single fire is assumed to occur at any plant location. The spreading of this original fire to adjacent plant fire compartments and fire cells need not be considered if it can be shown that the fire can be contained in the original fire compartment or fire cell by plant fire protection features.

3.1.2 For multiple reactor sites, simultaneous fires in more than one reactor plant are not postulated. However, a single fire at facilities shared between reactors may result in that fire affecting more than a single reactor.

3.1.3 For multiple reactor sites, the worst case system interdependence condition must be determined and evaluated for each unit on the site. This would include considering adjacent operating units, non-operating units, or shutdown and defueled units. The determination of worst case system interdependence is left to the NPP.

3.1.4 A single failure in the fire protection system may occur concurrently with a fire. This failure need only be considered to the extent that both primary and backup fire protection capability is impaired.

3.1.5 Onsite and offsite power are assumed to be available before, during, and after a fire, unless either or both are lost as a consequence of fire or lost due to a fire in the power/distribution equipment itself.

3.1.6 Design basis events (accidents) are not considered to occur concurrently with a fire, unless they are caused as a consequence of fire.

3.1.7 The effects of the most severe natural phenomena, such as tornado, flooding, earthquake, etc., are not concurrent with a fire. In addition, earthquake-induced fires are not considered. However, it is recommended that the effects of such phenomena be considered for plants located in vulnerable areas. 
3.1.8 Administrative controls are already in place, or will be incorporated as necessary by the NPP, to ensure that all plant equipment and components necessary to achieve shutdown before, during, and after a fire are available and functional, unless rendered inoperable as a result of fire.

3.1.9 The plant is operating in its normal operating mode at the time of the fire. The plant is operating at 100 percent power with a 3-month history at that level. All components are in the normal operating position at the onset of the fire. This assumption is meant to reflect a reactor operating at maximum fission rate with equilibrium operating conditions achieved (pellet clad contact and fuel temperature; samarium and xenon equilibrium, and startup transients will have subsided). Thus the assumption is that this would represent a worst-case scenario at 100 percent of the reactor design limit. (It should be noted that fire safety in plant modes other than full power operation, such as shutdown, should also be considered as part of a comprehensive fire protection program. However, the consideration of these modes is beyond the scope of this document.) This information will be used for implementation of this Methodology.

3.1.10 Circuit overcurrent protection is assumed to be provided and adequate for all plant cables. If such overcurrent protection is not provided or is not adequate, it is assumed that adequate circuit overcurrent protection will be provided prior to or in conjunction with any proposed plant modifications due to the implementation of this methodology.

\section{LIMITING CONDITIONS OF ANALYSIS}

The intent and objective of this Methodology is to enhance the ability of Sovietdesigned NPPs to achieve shutdown during and after a fire. Accordingly, its scope is limited to those aspects of the facility that directly contribute to enhancing shutdown capability during and after fire. The extent and content of reviews are bounded as described and discussed below.

3.2.1 The reviews performed in this Methodology are intended to be performed to the extent necessary to support operation of reactor safe shutdown equipment and systems and to support fire suppression activities in areas critical to plant shutdown. Detailed comparisons to the specific requirements of normally accepted codes and standards or local requirements are not performed as part of this Methodology. While such codes, standards, and local requirements provide useful information to determine the relative overall adequacy of systems, they have not been included, since shutdown of the existing as-built plant is the main focus of this evaluation. 
3.2.2 The Methodology requires a review and documentation of available fire detection and suppression capabilities, both manual and automatic, for each fire compartment and fire cell. The purpose and intent of the fire detection and fire suppression system review and documentation is to obtain and consolidate sufficient quantitative and qualitative information to permit an objective independent evaluation of system adequacy to support shutdown and shutdownrelated operations. Detailed system reviews and analyses of the designs of existing fire detection and suppression systems, including their inadvertent or spurious operation, have not been included in this Methodology.

3.2.3 The effects of actuation (whether inadvertent or intentional) of existing fire suppression systems, including the fire brigade, on safe shutdown should be evaluated separately from this analysis (i.e., the effect of sprinkler water overspray on a nearby safe shutdown pump). However, such an evaluation is required by this analysis if new fire suppression systems are installed as solutions to fire vulnerabilities or to create new fire cells.

3.2.4 The Methodology requires a review and documentation of the fire protection water supply system, including such items as water source (tanks, pond, etc.), pumps, controls, yard distribution piping, and other related items. The purpose of this review is limited to identifying the system capabilities and normal operating modes to achieve a reasonable level of assurance that fire suppression activities necessary to support and achieve shutdown can be reasonably achieved.

3.2.5 The Methodology reviews portable fire extinguishers only from the aspect that they constitute one means to provide manual fire suppression. The locations and types of extinguishers are considered only for the direct support of fire suppression to achieve shutdown or support shutdown-related activities.

3.2.6 The Methodology requires a review and documentation of available emergency lighting, ventilation, and communication capabilities and design features, both on a specific fire compartment/fire cell basis and on an overall design basis. These support systems are reviewed only to the extent necessary to demonstrate their overall adequacy to support shutdown and shutdown-related operations.

3.2.7 The Methodology permits the use of local manual intervention to achieve safe shutdown. The reliance on such manual actions must be added to and described in the plant EOPs. Where such manual intervention is used, both the required time frame and manning requirements must be discussed and defined, and the actions must be shown to be reasonably achievable (see Appendix A). 
3.2.8 The Methodology uses information obtained from existing plant drawings and visual observation of the as-built plant. The Methodology does not use any form of destructive examination or testing and does not require the disassembly of any equipment or enclosed cable trays or conduits. Such examination and testing and disassembly may be required at a future date to provide verification of the adequacy of specific plant materials and systems such as fire barriers, penetration seals, internal conduit seals, etc. 


\subsection{QUALITATIVE PROCESS}

The process presented here uses qualitative methods to assess reactor core protection in the event of a fire. Various aspects of the process are sensitive to analyst assumptions and the availability of plant data. However, when applied, this process should result in (a) collection and review of all pertinent plant data, including original plant design and as-built data; (b) identification and validation of plant functions necessary to achieve and maintain safe shutdown; (c) validation of location, identification, and documentation for major and safe shutdown system components; (d) identification and documentation of the effects of a fire on the ability to achieve and maintain safe shutdown; (e) identification and documentation of fire protection features such as fire compartments/cells, fire suppression, and fire detection systems; (f) identification of fire hazards such as combustibles and ignition sources; $(\mathrm{g})$ identification and documentation of the vulnerabilities of structural, mechanical, and electrical systems to fire damage; (h) verification walkdowns for the above; (i) development of solutions to fire vulnerabilities; and (j) prioritization of safety improvements. Refer to Figure 1.2-1 for a pictorial view of the process.

The process recognizes that all documentation and data necessary to complete the steps of the Methodology may not be available to the analyst. Accordingly, the Methodology requires that walkdowns be performed to obtain information missing in the documentation and to confirm the accuracy of the documentation found. In some cases, however, the information required to complete a step of the Methodology may not be available in the documentation and may not be obtainable by walkdown. In those cases, the analyst should refer to Appendix A. Part of this appendix addresses alternative approaches that can be pursued to complete the Methodology process when the required plant data is not available. 

A Safe Shutdown Analysis (SSA) relies on the availability of plant information. Although a lack of information does not necessarily preclude performing an SSA, as much plant-specific information must be assembled as possible to facilitate the analysis. This information can be assembled from various design sources, as well as from actual plant walkdowns where in situ information is gathered and/or verified. Sections $4.6,4.8$, and 4.9 provide guidance for gathering in situ information. This section deals primarily with gathering design information from documentation.

The key information described below should be assembled and placed in a central location such that it can be readily accessed by the analysis team. This information should be maintained in a controlled manner so that only the current revision of all referenced documentation is available for use. Care must be taken to document the source and revision status of each document utilized during the analysis process. This process helps to facilitate configuration control and minimize the scope of rework required in the event of plant changes.

System Descriptions: Detailed descriptions of the functions and capabilities of each plant system, especially those systems capable of accomplishing the safe shutdown functions.

Descriptions of all necessary support systems should also be compiled. Support systems are those systems that do not directly provide safety functions but are required to ensure that the systems that do provide safety functions will operate as required; for example: cooling water; electrical distribution; heating, ventilating, and air conditioning (HVAC).

Description of the Fire Protection Systems: A description of the fire protection approach that includes the types of suppression and detection used throughout the plant.

Plant Drawings: Several types of drawings are recommended, including:

- Architectural layout (general arrangement) drawings that depict the current, as-built, configuration of plant areas. These drawings should identify the location of major equipment.

- P\&IDs (flow diagrams) that show the major equipment and flow paths of the systems. 


\section{U.S. DEPARTMENT OF ENERGY'S REACTOR CORE}

PROTECTION EVALUATION METHODOLOGY FOR FIRES AT

SOVIET-DESIGNED RBMK AND VVER NUCLEAR POWER PLANTS

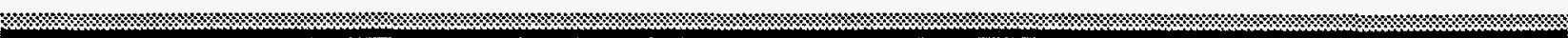

- Electrical drawings that show the motor control center (MCC) arrangement, cable and conduit routing, and connection of power and control circuits for each system.

- Diagrammatic representations of the operation of electrical equipment (electric logic diagrams).

- Electrical power distribution drawings (one-line diagrams).

- Fire barrier drawings that show walls (with construction material and thickness noted) and the locations of fire doors. If possible, the fire ratings of each of these barriers should be provided.

Procedures: A number of procedures should be available for use during the analysis:

- Normal plant operating procedures

- Normal plant shutdown procedures

- Emergency operating procedures 
To achieve the performance goal of reactor core protection, it is necessary to determine which systems and components are necessary to safely shut down the plant. Safe shutdown and the functions necessary to achieve safe shutdown must first be defined and clearly documented. Exhibit 4.2-1 should be used to define safe shutdown and discuss the bases of the definition. There may be a need to establish a time limit for reaching cold shutdown. If this is the case, the time limit should be established and the rationale for the time period documented on Exhibit 4.2-1.

\subsection{1}

\section{ESTABLISH THE SAFE SHUTDOWN FUNCTIONS}

The process of establishing the safe shutdown functions is shown on Figure 4.2-1. These functions are those minimum number of functions that must be accomplished and controlled to ensure that the reactor is brought to and maintained in a safe shutdown condition and that no design parameters are exceeded. These functions will probably closely parallel those discussed in Section 4.2.2 and should be agreed upon by the regulatory body, the design institutes, and the plant. Each function should be documented on Exhibit 4.2-2 and the reason for its selection discussed in detail in the space provided. This process is necessary to ensure that the information is clearly understood and applied during the analysis.

\subsection{2 - TYPICAL SAFE SHUTDOWN FUNCTIONS FOR PLANTS DESIGNED IN} THE SOVEREIGN STATES OF RUSSIA AND UKRAINE

The following presents the typical definition of safe shutdown used for plants in the sovereign states of Russia and the Ukraine:

A unit is shut down with: (1) the reactivity of the reactor kept to a margin below criticality; (2) the core decay heat removed at a controlled rate sufficient to prevent core or reactor coolant system thermal design limits from being exceeded; (3) radioactive material releases controlled to keep doses within prescribed limits; and (4) items necessary to maintain these conditions operating within their design limits

Safe shutdown is typically considered in two conditions: hot shutdown and cold shutdown. The following typical definitions apply to both the VVER and RBMK reactors: 


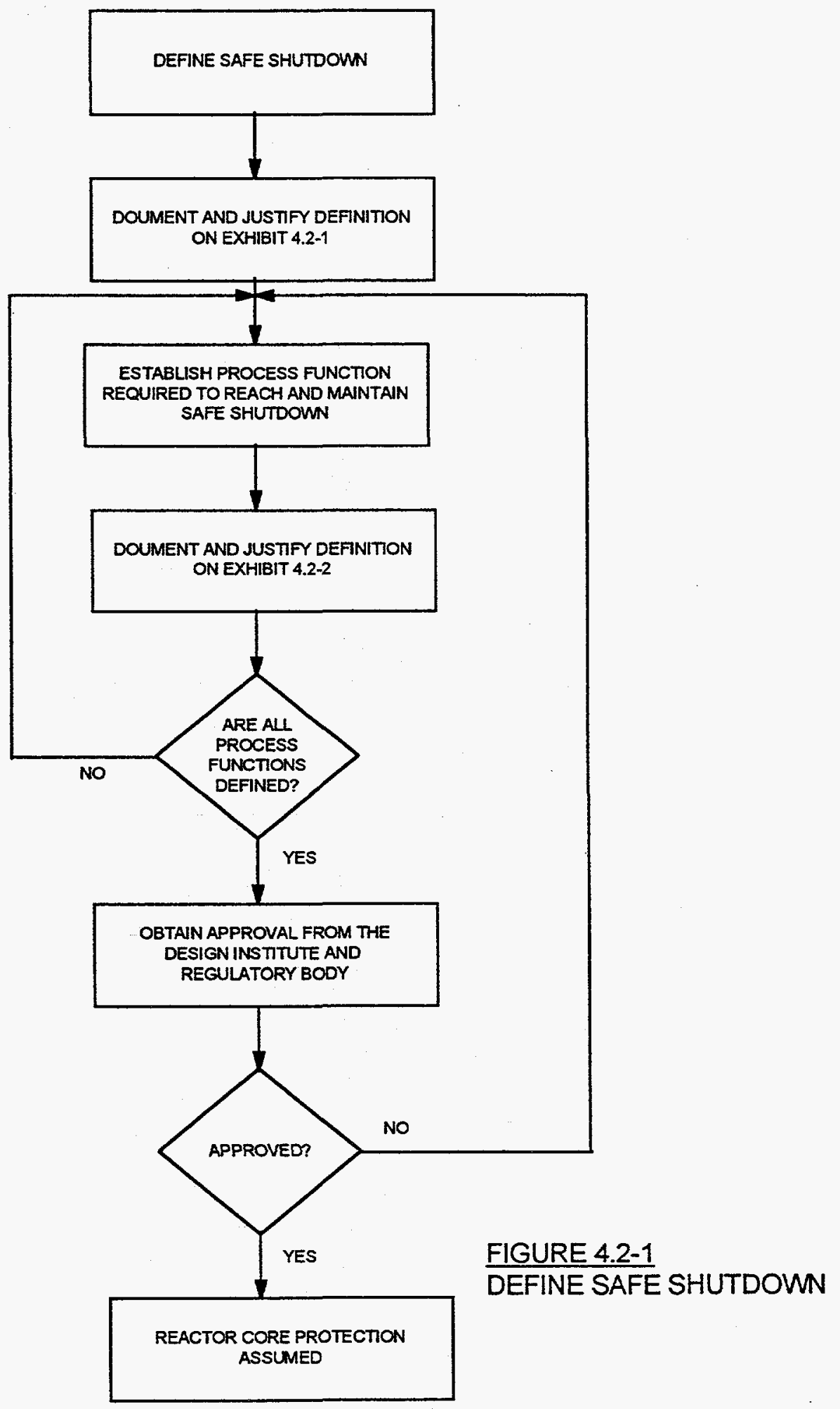


Hot shutdown: The condition in which the reactor power output of the core is reduced to the decay heat level. At this level, the emergency core cooling and/or the secondary heat-removal systems have sufficient capacity to remove the energy from the primary system.

Cold shutdown: The condition in which the reactor power output is below the level required to permit major maintenance.

Certain functions must be available to ensure that the VVER and RBMK plants are capable of safely shutting down. In general, these functions include:

- Reactivity Control - Reactivity control is necessary to decrease the reactor power output of the core to the decay heat level. At this level, the emergency core-cooling and/or the secondary heat-removal systems have sufficient capacity to remove the energy from the primary system and prevent core damage.

- Reactor Coolant Inventory Control - Reactor coolant inventory control is necessary to replace water that escapes from the reactor because of a break or leak in the primary system. Coolant plays a major role in short- and long-term reactor cooling, and it is important to ensure that the coolant inventory remains adequate following any type of LOCA, including transients leading to LOCA.

- Secondary Pressure Control - Secondary pressure control is necessary to control the pressure of the secondary loop by providing adequate means of establishing secondary coolant discharge paths. Thus, the normal secondary cooling system is reconfigured to permit several ways to establish discharge paths to an ultimate heat sink.

- Reactor Heat-Removal - Reactor heat removal is necessary to cool the primary loop of the reactor during LOCAs and transients. This function is necessary to prevent heat-up and subsequent uncovery and fuel-rod damage due to decay heat. Generally, the same systems used to achieve reactor coolant inventory control function may be used to attain this function. These systems draw borated water from various reservoir tanks and inject it into the reactor to remove decay heat. Two types of reactor-heat removal are usually available: short-term and long-term heat removal. 
- Secondary Heat Removal - The secondary heat removal function is performed to remove the heat deposited in the steam generators during all transient events and some LOCAL events. Performance of this function ensures that the ultimate heat sink is available for reactor decay heat removal.

- Secondary System Isolation (Integrity Control) - If the primary coolant were to come into contact with the secondary coolant or a break were to occur in the secondary loop, some isolation valves could be closed to isolate the two sides of the plant from each other or to isolate affected steam generators from non-affected ones. The ability to isolate both sides would mitigate the end results of such transients.

- Pressurizer Cooldown - Certain accident sequences in Soviet-designed reactors are subject to certain reactor hot-shutdown states that cannot be treated as a safe and stable state. Further reactor cooldown and depressurization are required to bring the reactor into safe cold shutdown. In some reactors, any time the reactor is being cooled down, the pressurizer will restrain primary depressurization. The primary reason for pressurizer cooldown is to avoid violating reactor vessel temperature-pressure limits (brittle fragility phenomenon).

- Primary Pressure Control - Primary pressure control is necessary during some very small loss of coolant accidents and leaks primarily to keep the vessel pressure within prescribed limits to prevent unnecessary reactor scram and ECCS actuation.

- Primary Isolation - For certain LOCA conditions it would be necessary to isolate the primary side. This would prevent primary-side coolant from leaking out.

- Supporting Functions - To provide safe shutdown functions, several critical support systems and equipment are necessary. The supporting functions include systems such as electrical power (AC and DC) and distribution systems, component cooling water, essential service water, and condenser cooling water systems. Additionally included are selected actuation and monitoring instrumentation for the ECCS, reactor protection, reactor control, I\&C to monitor and control the secondary plant, remote control, and sequence loading. The support functions are required only for those systems necessary to ensure that safe shutdown can be achieved and maintained. 
U.S. DEPARTMENT OF ENERGY'S REACTOR CORE

PROTECTION EVALUATION METHODOLOGY FOR FIRES AT

SOVIET-DESIGNED RBMK AND VVER NUCLEAR POWER PLANTS

\%

Exhibit 4.2-1

SAFE SHUTDOWN DEFINITION

DEFINITION OF SAFE SHUTDOWN:

DISCUSSION:

IS THERE A TIME LIMTT ASSOCIATED WITH ESTABLISHING SAFE SHUTDOWN? YES NO

DISCUSSION: 
U.S. DEPARTMENT OF ENERGY'S REACTOR CORE

PROTECTION EVALUATION METHODOLOGY FOR FIRES AT

SOVIET-DESIGNED RBMK AND VVER NUCLEAR POWER PLANTS

.

Exhibit 4.2-2

SAFE SHUTDOWN FUNCTION DEFINITION

SAFE SHUTDOWN FUNCTION:

DISCUSSION: 
4.3

4.3.1

4.3.2

4.3.2.1

\section{IDENTIFY SYSTEMS TO ACHIEVE SAFE SHUTDOWN}

The process detailed below and shown on Figure 4.3-1 identifies the maximum number of sets of systems capable of performing safe shutdown functions.

Assemble a list of all plant systems. Care must be taken to ensure that all plant systems are listed. The purpose of this list is to ensure that all systems are evaluated to identify all options to support safety functions. The systems should be identified by system identification number (if applicable) and the system name. Use the Safe Shutdown/Support System Safety Functions Worksheet (Exhibit 4.3-1) to record this information.

Using the list of systems generated in Section 4.3.1, review the design documentation, such as system descriptions, system drawings, and plant procedures described in Section 4.1, to identify which systems are capable of providing the safe shutdown functions. These systems will be defined as safe shutdown systems. It is important to note that systems supporting safe shutdown functions can include any systems that may be able to be lined up in either a normal or an abnormal manner to support the safe shutdown function.

If a system is determined to be a safe shutdown system, place a "Y" in the SSD/Support column and a check in the column or columns for the safe shutdown function supported on Exhibit 4.3-1 and proceed to Section 4.3.2-1.

As an example, in U.S. plants the service water and fire water systems may be lined up to inject water into the reactor through the residual heat removal system. This is not a normal lineup and would only be used in an extreme emergency. However, it is an option that should be considered. For this case, the SSD/Support column for both systems would be marked "Y" and the Reactor Coolant Inventory Control, Reactor Heat Removal, and Primary Pressure Control columns would be checked, since both systems can inject water into the reactor vessel they will maintain water level, provide water for decay heat removal, and they will help control pressure by cooling the fuel.

This step identifies those systems that are necessary to support the operation of the safe shutdown systems. Using system descriptions, operator knowledge, system drawings, and procedures, identify any systems that are necessary to support operation of each safe shutdown system designated on Exhibit 4.3-1. Place a "Y" in the SSD/Support column of Exhibit 4.3-1 for each system determined to be a support system and indicate the support function in the Support Function column on Exhibit 4.3-1. Note that several safe shutdown functions may be supported by one system. 


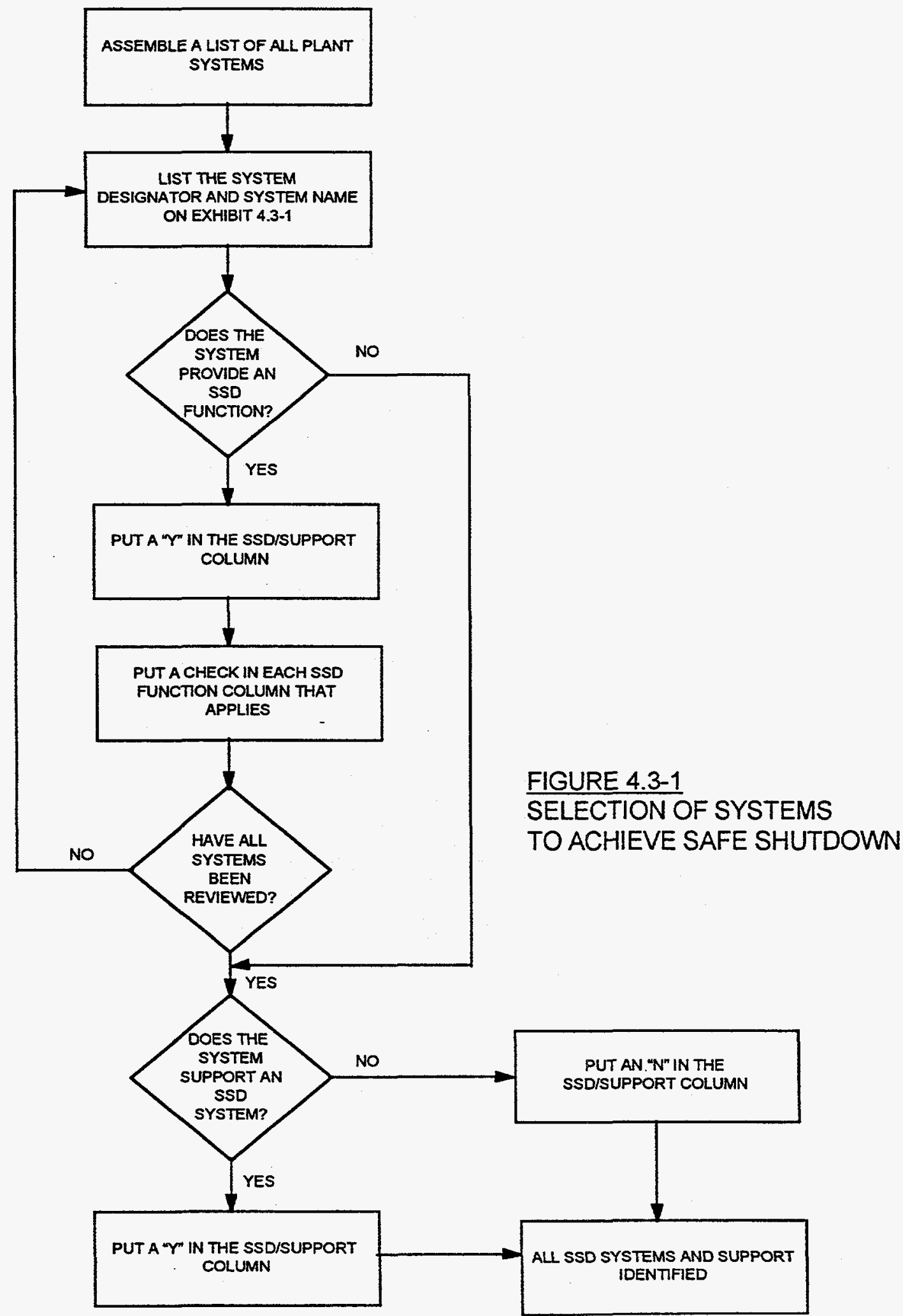




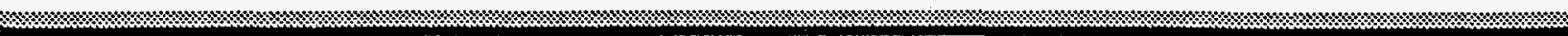

For example, a cooling water system used to cool equipment such as bearings, lubricating oil, heat exchangers, heating and ventilating systems (to maintain the environment within acceptable ranges), electrical power systems (to power required equipment), plant drainage (to prevent flooding of safe shutdown equipment in the event a suppression system is actuated), and plant air (for the operation of pneumatic equipment). These systems should have the SSD/Support column marked with a "Y," and the Support Function column should be filled out indicating what support function is being accomplished.

4.3.2.2 After all the systems listed on Exhibit 4.3-1 are reviewed, all safe shutdown and support systems will have been identified and a "Y" placed in the SSD/Support column on Exhibit 4.3-1. All other systems listed on the exhibit are not required for safe shutdown or support and should have an "N" placed in the SSD/Support column. These systems require no further evaluation. 


\section{Exhibit 4.3-1}

\section{SAFE SHUTDOWN/SUPPORT SYSTEM SAFETY FUNCTIONS WORKSHEET}

\begin{tabular}{|c|c|c|c|c|c|c|c|c|c|c|c|c|}
\hline \multirow[b]{2}{*}{$\begin{array}{c}\text { System } \\
\text { Designator }\end{array}$} & \multirow[b]{2}{*}{ System Name } & \multirow[b]{2}{*}{ 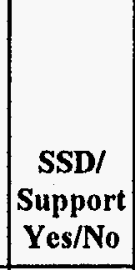 } & \multicolumn{9}{|c|}{ Safe Shutdown Function Provided } & \multirow[b]{2}{*}{$\begin{array}{l}\text { Supporting } \\
\text { Function }\end{array}$} \\
\hline & & & \begin{tabular}{|c|}
$\begin{array}{c}\text { Reactivit } \\
\text { Control }\end{array}$ \\
\end{tabular} & \begin{tabular}{|c|c} 
Reactor \\
Coolant \\
Inventry \\
Control \\
\end{tabular} & $\begin{array}{l}\text { Secondary } \\
\text { Pressure } \\
\text { Control }\end{array}$ & $\begin{array}{c}\text { Reactor } \\
\text { Heat- } \\
\text { Remova }\end{array}$ & $\begin{array}{c}\text { Secondary } \\
\text { Heat } \\
\text { Removal }\end{array}$ & $\begin{array}{l}\text { Secondary } \\
\text { SSsstem } \\
\text { Isolation } \\
\text { (nitergity } \\
\text { Control) }\end{array}$ & \begin{tabular}{|}
$\begin{array}{c}\text { Pressurzizer } \\
\text { Cooldown }\end{array}$ \\
Toldow \\
\end{tabular} & $\begin{array}{c}\text { Primary } \\
\text { Pressure } \\
\text { Control }\end{array}$ & \begin{tabular}{|} 
Primary \\
Isolation
\end{tabular} & \\
\hline & & & & & & & & & & & & \\
\hline & & & & & & & & & & & & \\
\hline & & & & & & & & & & & & \\
\hline & & & & & & & & & & & & \\
\hline & & & & & & & & & & & & \\
\hline & & & & & & & & & & & & \\
\hline & & & & & & & & & & & & \\
\hline & & & & & & & & & & & & \\
\hline & & & & & & & & & & & & \\
\hline & & & & & & & & & & & & \\
\hline & & & & & & & & & & & & \\
\hline & & & & & & & & & & & & \\
\hline & & & & & & & & & & & & \\
\hline
\end{tabular}



SHUTDOWN AND SUPPORT SYSTEMS

In Section 4.3 the safe shutdown and support systems are identified, and in Section 4.5 the drawings are marked up to show system success flow paths. This section uses the information developed in those sections to identify the safe shutdown equipment that must be evaluated in detail for fire effects. Safe shutdown equipment consists of the components, support components, piping, and circuits that are necessary to operate the safe shutdown and support systems. The safe shutdown system flow paths identified on the system piping drawings will be reviewed to identify the components in these systems that are necessary to ensure that the safe shutdown system will serve its safe shutdown function(s).

It should be noted that at any point within this process the option exists to use a dedicated shutdown system that may be installed in the plant. The dedicated shutdown system option is discussed in Appendix A of this Methodology. This option would be adopted either if the analysis of existing shutdown options cannot be accomplished due to the plant data or "as-built" configuration, or if the analysis of the cost of plant changes to meet this Methodology shows that a dedicated system is a cost-effective approach. Additionally, if a given step in this Methodology cannot be accomplished due to the absence of required information and the inability to derive such information, many alternative approaches are provided in Appendix A.

\subsubsection{GUTELINES}

4.4.1.1 Using the coded drawings and/or the safety sequence logic diagrams, develop a list of equipment that is necessary for the safe shutdown system to serve its safe shutdown function. Exhibit 4.4-1 is provided as an example of a form that can be used for this step. All system components must be reviewed to understand the impact of a fire and to determine whether they are necessary for the system to provide its safe shutdown or support function. Exhibit $4.4-2$ has been provided to document the reason a component is shown on the coded drawings but not included on the equipment list.

4.4.1.2 The following are guidelines regarding which components to include on Exhibit 4.4-1 for each system evaluated. Section 4.4 .3 provides an example system with an evaluation.

- Component position: All system components should be assumed to be in their normal operating position at the onset of the postulated fire. 
- Valves and dampers that constitute system boundaries should be included if a fire-induced fault could cause them to change position. Associated valve operators should also be included as part of the valve. These components are included to ensure that the process is not diverted from its safe shutdown function. (Valve V9 on Figure 4.4-1 falls into this category.)

- Valves and dampers in the flow path that are power operated should be included. Associated valve operators should also be included as part of the valve/damper. These components should be included whether or not they are required to change position during shutdown if a fire-induced fault could cause them to change position. These components ensure that the process flow path is maintained. (Valves V4 and V10 on Figure 4.4-1 fall into this category.)

- Safety relief valves that are power operated and provided for equipment protection have control circuits that must be evaluated to ensure that firerelated faults will not prevent the valve from operating as required.

- For tanks, all inlets and outlet lines should be evaluated for their functional requirements and isolation. For lines that are not required to be functional, a means of isolation should be included when necessary to prevent unnecessary drawdown of the tank. Tank inventory must be evaluated to ensure that it is always sufficient to support the system requirements. The tank on Figure 4.41 is an example of this category.

- Interlock circuitry between safe shutdown components and safe shutdown/non-safe shutdown components should be reviewed to determine if additional components require inclusion. This is to ensure that a failure of a non-safe shutdown component would not prevent the safe shutdown system from operating as required. (On Figure 4.4-1, the interlocks between the reactor level and the pump and the reactor pressure and valve V10 and the pump are examples of this category.)

- Power supplies for safe shutdown components that require power to achieve their safe shutdown function should be included back to their switchgear.

- Switchgear for safe shutdown equipment that requires power to achieve its safe shutdown function should be included. Equipment associated with the switchgear should be included back to its power source(s). 


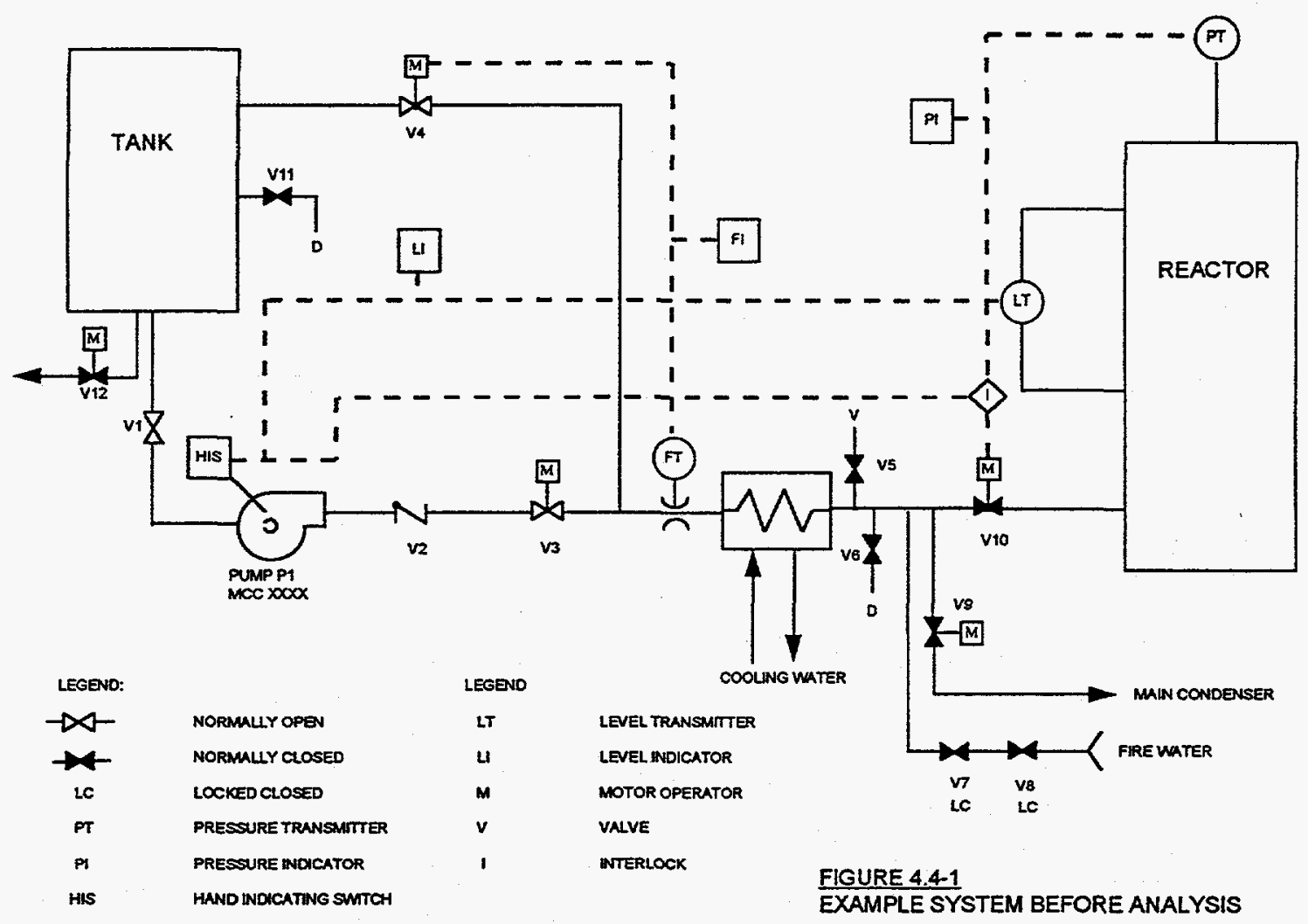

For equipment providing the process monitoring function, sufficient minimum instrumentation should be maintained available to perform and control the safe shutdown and support systems. (The reactor pressure and reactor level on Figure 4.4-1 are examples of this category.) The plant operators must make the final determination of the minimum process indications required to ensure the safe operation of a system.

The following lists provide examples of what is considered the minimum monitoring capability considered necessary to achieve and maintain safe shutdown for U.S. designed plants:

\section{Instrumentation Needed for PWRs}

a. Pressurizer pressure and level to ensure that the RCS is not filled solid or that a steam bubble has not formed in the reactor coolant loops.

b. Reactor coolant hot leg temperature or exit core thermocouple and cold leg temperature to ensure that there is process flow and that the reactor core is covered. 
c. Steam generator pressure and level (wide range) to ensure that the steam generators do not boil dry.

d. Source range flux monitor or boron concentration to ensure that the reactor is subcritical.

e. Instrumentation to monitor the proper operation of the shutdown and support systems.

f. Level indication for all tanks used to ensure that sufficient process fluid is available for system operation.

\section{Instrumentation Needed for BWRs}

a. Reactor water level and pressure to ensure that the reactor core is covered.

b. Suppression pool level and temperature to ensure that the reactor and containment heat sink is available.

c. Emergency or isolation condenser level to ensure that the reactor core heat sink is available for those plants that utilize an isolation condenser.

d. Instrumentation to monitor the proper operation of the shutdown and support systems.

e. Level indication for all tanks used to ensure that sufficient process fluid is available for system operation.

4.4.1.3 As indicated in Section 4.4.1.1, a number of components shown on the system drawings may not be shown on the equipment list. Figure 4.4-1 is an example of a system with all components shown, and Figure 4.4-2 is an example of the same system showing only those components of interest for this analysis (see Section 4.4.3). The following are guidelines regarding which components need not be included on the equipment list:

- Manual drain and vent valves (Valves V5, V6, and V11 on Figure 4.4-1 are examples of this category.)

- Passive manual and motor-operated valves with their power removed: Manual and motor-operated valves with their power removed will have no fire-related faults that could cause their misoperation; therefore, they would not be included. (Valves V1, V2, V3 [with the power removed], V7, and V8 on Figure 4.4-1 are examples of this category.) 
- Passive equipment: Equipment that is not power operated and has no firerelated failure that could cause it to misoperate would not be included. (The heat exchanger shown on Figure 4.4-1 is an example of equipment in this category.) Care must be taken to ensure that passive equipment is reviewed to ensure that a fire will not affect the passive equipment in such a way that it will prevent achieving and maintaining a safe shutdown condition. For example, if a cable is in a conduit that is routed through a fire cell and that cable is required to ensure that safe shutdown can be reached and maintained, the conduit and conduit supports must be evaluated to ensure that the fire will not cause the conduit, conduit supports, and the cable to be damaged to the extent that they cannot serve their safe shutdown function.

- Safety relief valves: Non-power-operated relief valves provided for equipment and piping protection should not be included. These valves have no fire-related failures that could cause them to malfunction.

- Instrument root valves: Instrument root valves should not be included since there are no fire-related faults that could cause their malfunction.

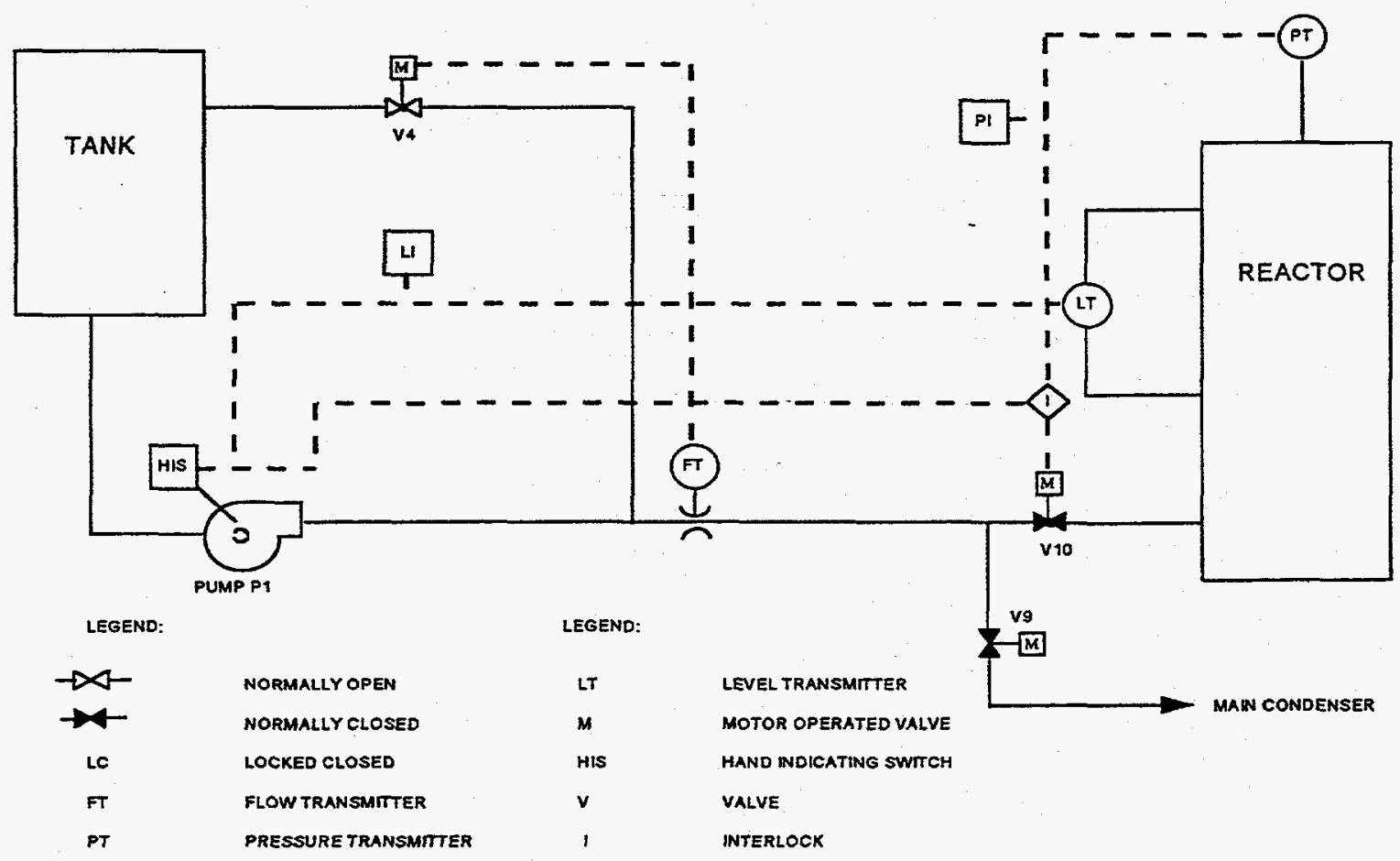

FIGURE 4.4-2

EXAMPLE SYSTEM AFTER ANALYSIS 
Loops or bypasses: Piping within a system where spurious actuation would not result in a loss of flow or inadequate flow to safe shutdown paths should not be included.

- Steam traps: Traps in the safe shutdown flow path that are designed to remove condensate and trap steam should not be included.

- Temporary equipment: Temporary equipment such as startup strainers and spool pieces should not be included.

- Cables not required: Cables to the following types of equipment need not be included in the equipment analyzed:

- Space heater circuits

- Annunciation circuits isolated from circuits that are required

- Circuits connected to dry relay contacts that are not required to perform a safe shutdown function and are isolated from the control circuit.

4.4.1.4 Systems that were identified as safe shutdown support systems must be analyzed using the same methodologies and to the same level of detail as is used for safe shutdown systems. Additionally, analyses may be used to reduce the dependence on support systems. For instance, an analysis may show that an HVAC system is not required for a period of time (for example, one hour) after a fire. In this case, a manual action meeting the criteria outlined in Appendix A could be relied upon to reduce the analyses required to ensure operability of the HVAC system.

\subsubsection{SELECTION PROCESS}

4.4.2.1 Using the methodology discussed in Section 4.4.1 with the safe shutdown system list developed in Section 4.3, record the following information on the Safe Shutdown Equipment Worksheet (Exhibit 4.4-1) for each component. Exhibit 4.4-1 is intended to be a working document. Some information required for the exhibit will be derived later in the analysis process. Information should be added to the exhibit as it becomes available. A separate set of sheets should be used for each system. The combination of all the Exhibits 4.4-1 completed for each safe shutdown and support system is termed the safe shutdown equipment list:

1. Path Number (PATH NO.) - see Section 4.4.4

2. System Mode or Line-up (SYS. MODE) - see Section 4.5.1

3. Equipment Identifier - the component identification number

4. Description of Component - e.g., makeup valve, charging pump, level instrumentation, cables) 
5. SSD Function - see Section 4.3.1

6. Drawing Reference (DWG. REF.) - P\&ID, elementary, equipment location

7. Normal Position (NORM. POS.) - open, closed, as is, energized, deenergized, on, off

8. SSD Position (SSD POS.) - open, closed, as is, energized, deenergized, on, off

9. Plant Location (PLANT LOCAT.) - building, elevation, fire compartment

10. Fire Compartment (FIRE COMPT.) - fire compartment designator for the location of the component

11. Power Supply (PWR. SUPPLY) - MCC designator, switchgear designator

12. Fire Cell - cell designator if applicable

\section{Notes}

4.4.2.2 For each component identified on the safe shutdown equipment list, obtain all the applicable elementary electrical drawings and one-line diagrams. Use these tools to determine the cables/circuits necessary to support operation of each of these components. Note that if these tools do not exist for a given component, either they must be developed or an alternate component serving the same function must be used.

4.4.2.3 Cables that are part of the circuits for a given component should be recorded on the Safe Shutdown Cable Worksheet (Exhibit 4.4-3). This subset of information is termed the cable list:

1. Component Identifier

2. Cable No.

3. Power Supply

4. Drawing Reference

5. Scheme (Circuit) Numbers of cables that provide power and control to the devices associated with that component

4.4.2.4 On a component-by-component basis, use the elementary electrical drawings to review the list developed in Section 4.4.2.3 and determine which circuits are required in order for the particular component to perform its safe shutdown 
function. Designate the cables which make up these circuits as safe shutdown cables. The purpose of this step is to identify the minimum number of cables that must be located and analyzed. These cables will be located using the process discussed in Section 4.10. It should be noted that cable selection and subsequent location determination is a process that may have to be repeated several times as additional/different equipment is selected during the analysis process. Several examples of circuits that should be analyzed and circuits that need not be analyzed have been provided in Section 4.4.3. Safe shutdown circuits may be classified as follows:

- Power Circuits: Cables that provide electrical power for operation of safe shutdown components.

- Control Power Circuits: Cables that provide electrical power for control to a safe shutdown component or required instrumentation loop.

- Control Circuit: Cables required for remote control capability of the component.

- Indication Circuits: Cables required to provide indication of condition or position of the component.

- Instrument Circuit: Cables required to transmit instrument signals from the instrument to the indicator, controller, or recorder.

- Permissive/Interlock Circuits: Cables required to provide the desirable permissive/interlock signal. These cables, when not affected by a postulated fire, should permit the operation of the component when either a required condition exists or a certain signal is received.

- Spurious Circuits: Cables required to be free of fire damage in order not to disable the operational capability of the component or spuriously reposition the component to an unwanted condition. This category of cables includes:

- Spurious Control Circuits: Cables that could reposition the component to an unwanted condition or cause loss of control capability.

- Spurious Indication Circuits: Cables that could cause loss of or inaccurate indication.

- Spurious Permissive/Interlock Circuits: Cables that could prevent receipt of a desirable permissive or interlock signal or provide a spurious permissive or interlock signal. 
- Associated Circuits: Circuits not directly related to the successful operation of a safe shutdown component, but whose fire-induced failure could prevent other circuits that directly support the operation of a safe shutdown component from functioning as intended, thus causing a failure of the safe shutdown equipment.

4.4.2.4.1 Each cable should be evaluated to determine the effect of its failure on the operation of the main safe shutdown component. Care must be taken to ensure that all possible failures are identified for each fire (with the impact and corrective action for each). The types of failures to be analyzed are discussed below. Each failure should be evaluated and the effect clearly documented on Exhibit 4.4-3. The types of failures to be considered are:

Short Circuit: An example of this type of failure is presented as Figure 4.4-3, which also includes a sample analysis.

Short to Ground: An example of this type of failure is presented as Figure 4.4-4, which also includes a sample analysis.

Open Circuit: An example of this type of failure is presented as Figure 4.4-5, which also includes a sample analysis.

Hot Short: An energized conductor within a cable comes in electrical contact with an unenergized conductor(s) located within the same cable or in another cable. An example of this type failure is presented as Figure 4.4-6, which also includes a sample analysis. NOTE: On U.S.-designed plants, each potential hot short is analyzed. Each spurious actuation resulting from a fire must be evaluated. However, only one spurious actuation is considered at a time. The following additional information is taken from reference 5.18:

"It is convenient to distinguish two types of hot shorts:

- intra-cable bot short for conductor-to-conductor shorts within a multi-conductor cable and,

- inter-cable hot short for a non-energized cable that comes into contact with a separate energized cable.

The short to ground and open circuit failure modes are the most likely for electric cables. The open circuit of failure leads to a loss of signal or loss of power supply. Deterioration of fibre optic cables that leads to a progressive loss of signaling has a similar effect. In the short to ground type of failure, deactivation of the electrical circuit occurs, either by tripping a circuit breaker, causing a fuse to open, or by melting open the wire or cable.

Failures of the above-mentioned types, particularly the open circuit and hot short, can simulate the action of a circuit breaker of a control circuit device leading to undesired effects, such as the reconfiguration of valves in an operating system, or opening of solenoid operated safety relief 
valves, for example on the pressuriser of a PWR Depending upon the plant and fire scenarios, these may be serious internal events (IEs) or additional contributors to system unavailability and should not be overlooked.

The most likely fault mode for a single conductor cable is a short to ground. A failure of this type can lead to deactivation of electrical circuits, either by tripping a circuit breaker, causing a fuse to open, or melting open the wire or cable. In control circuits, this fault would lead to a loss of the control function; in instrument circuits, the fault would cause either a loss of signal or a false signal at the high or low end of the range depending on the circuit. An open circuit fault will generally occur due to either a collapse of the cable support structure, failure of circuit protection devices to trip in the case of a sustained short to ground thus melting open the wire or cable or prolonged severe fire exposures. These two types of faults can be treated similarly in terms of their anticipated system impact.

For a multi-conductor cable, the most likely initial fault mode will be intra-cable hot shorts, that is conductor-to-conductor faults within the cable. Faults of this type can simulate the actions of a manual control circuit switch, circuit breaker or solenoid switch. This might lead to undesirable effects, such as the reconfiguration of valves in an operating system, opening of solenoid operated safety relief valves, for example on the pressurizer of a PWR, or to actuation of an inactive system. These faults can also lead to false readings on a sensor circuit. In the longer term, multi-conductor cables are expected to short to ground as fire damage progresses. The timing of this transition from intra-cable hot short to a short to ground remains a point of uncertainty. In severe fire exposures, a rapid transition is anticipated (within minutes or even seconds). In more moderate exposures or when fire suppression is quickly actuated, sustained intra-cable hot shorts are possible. The impact of both short-term and sustained intra-cable hot shorts in multiconductor cables should be considered in the analysis, especially in the context of control cables.

Inter-cable hot shorts, can occur in any system that includes energized power cables. A fault of this type can lead to actuation of non-energized circuits, or the application of destructive voltages to lower voltage systems."

4.4.2.4.2 The following criteria for analysis should be used to perform the safe shutdown circuit spurious analysis:

- Credit cannot be taken for proper function of any electrical circuit that has not been completely analyzed. For example, credit can be taken in the spurious analysis of the control circuit for automatic signals that position equipment to its safe shutdown position, but only if it can be demonstrated that the fire will not affect the proper operation of the circuits and equipment that generate the automatic signals. However, credit cannot be taken for automatic signals if the equipment or circuits that generate the automatic signals are exposed to the fire. That is, credit can never be taken for assuming that the fire will affect any electrical circuit in a such a way as to fail in its safe shutdown position. 
FIGURE 4.4-3

SHORT CIRCUIT EXAMPLE

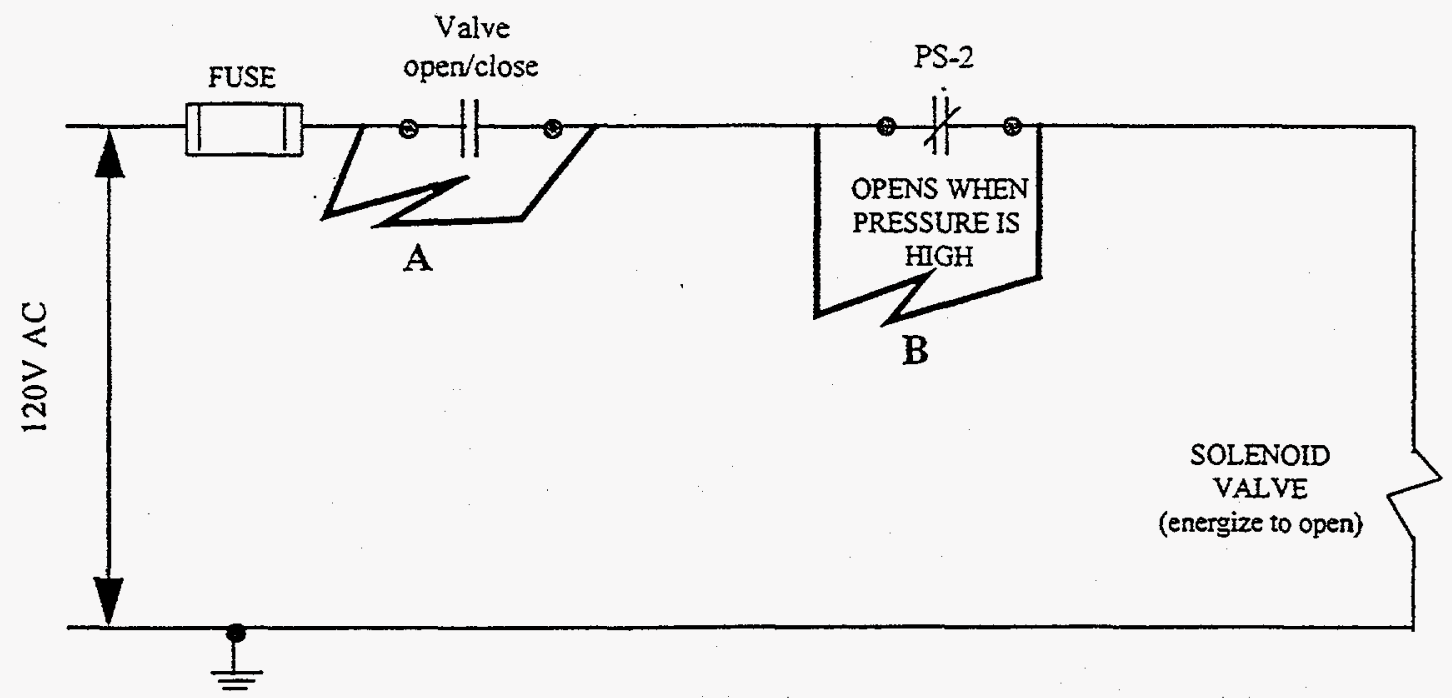

TYPICAL SCHEMATIC DIAGRAM

(INDICATING LIGHTS NOT SHOWN)

FAULT TYPE: SHORT CIRCUIT

CIRCUIT EXPLANATION:

This circuit is designed such that the solenoid valve cannot be opened when the system pressure is above a preset value. The valve will open if the switch is moved to OPEN and the pressure is below the preset value. The solenoid will fail CLOSED on loss of power.

ANALYSIS:

A short circuit at A would allow the valve to open for system pressures below the high pressure setpoint. The valve would close when system pressure exceeds the high pressure setpoint. This is acceptable since it does not defeat the interlock.

A short circuit at $B$ would defeat the high pressure interlock, causing the valve to open without regard to system pressure; this is not acceptable. 


\section{FIGURE 4.4-4}

SHORTS TO GROUND EXAMPLE

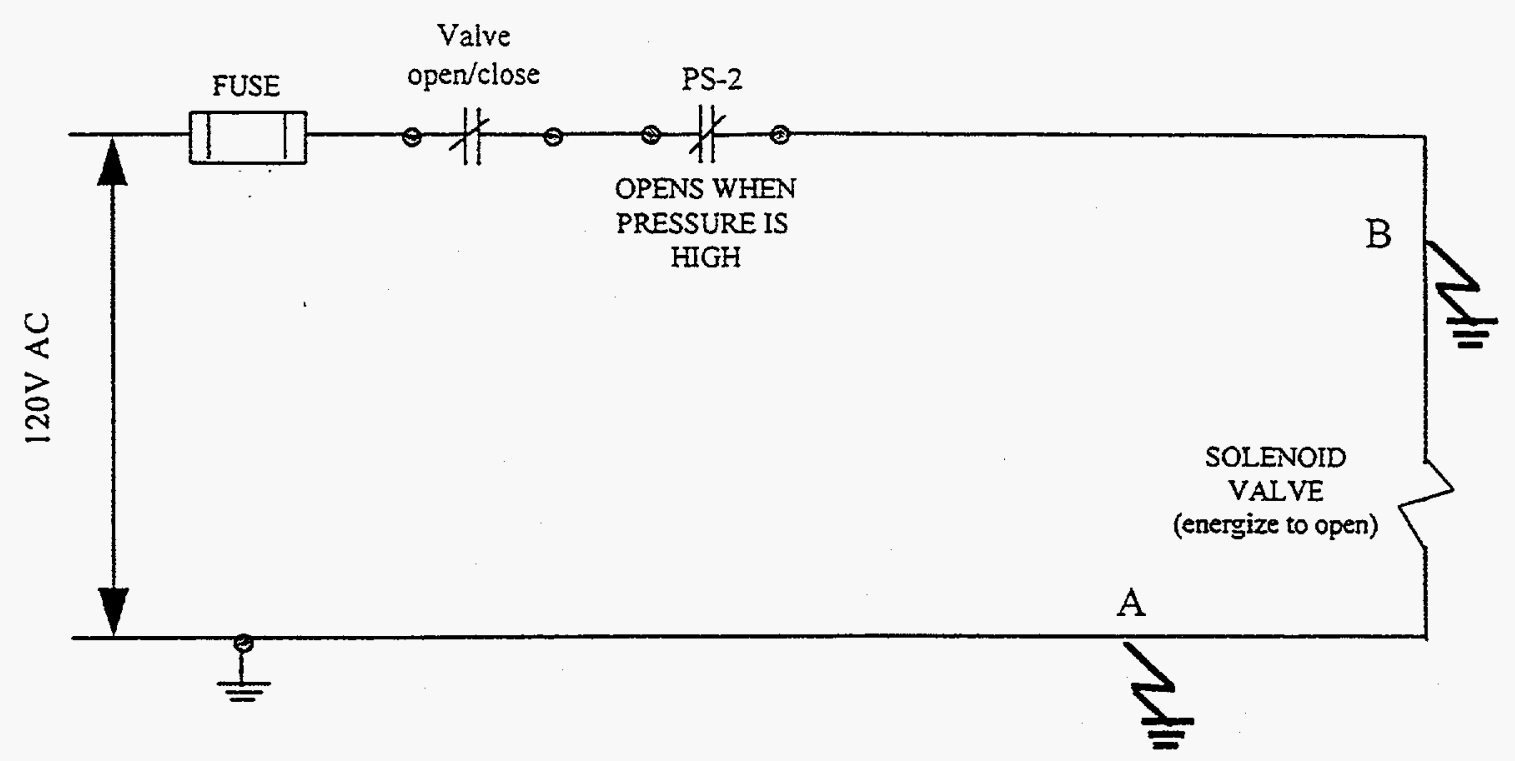

FAULT TYPE: SHORT TO GROUND

\section{CIRCUIT EXPLANATION:}

This circuit is designed such that the solenoid valve is normally energized and will close if the system pressure goes above a preset value. The valve will reopen if the pressure is below the preset value. The solenoid will fail CLOSED on loss of power.

ANALYSIS:

A short to ground at A would not affect system operation. This is acceptable.

If the switch is in the CLOSED position and there is a short to ground at $B$, there is no effect with the fault since the switch contact is open. If the switch is in the OPEN position and there is a short to ground at $B$, the fuse would blow, preventing the valve from operating. This would not be acceptable. 


\section{FIGURE 4.4-5}

OPEN CIRCUIT EXAMPLE

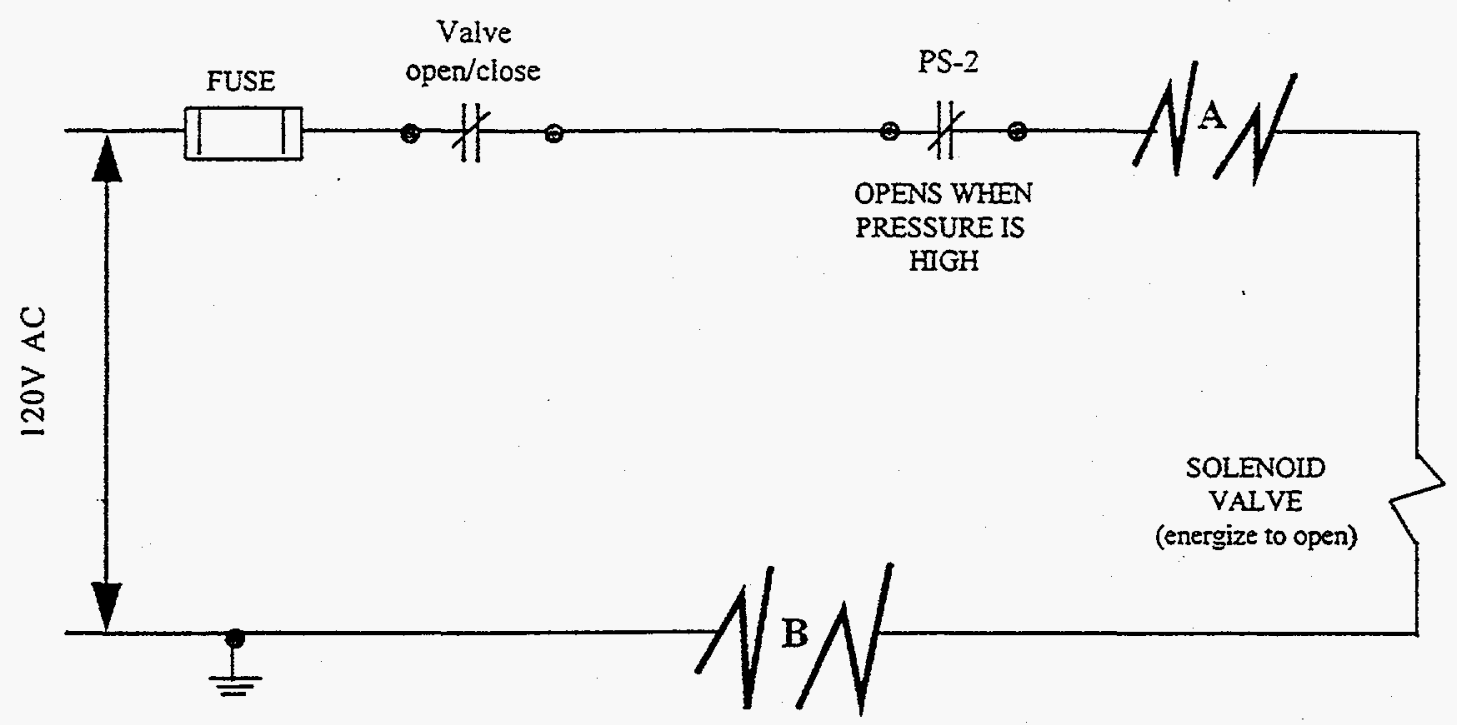

TYPICAL SCHEMATIC DIAGRAM

(INDICATING LIGHTS NOT SHOWN)

\section{FAULT TYPE: OPEN CIRCUIT}

\section{CIRCUIT EXPLANATION:}

This circuit is designed such that the solenoid valve is normally energized and will close if the system pressure goes above a preset value. The valve will reopen if the pressure is below the preset value. The solenoid will fail CLOSED on loss of power.

ANALYSIS:

An open circuit at any point in the circuit would result in the valve closing and remaining in the closed position. This is not acceptable in this example since the valve must open for the system to function.

If the circuit were designed such that the normal and shutdown position of the valve is CLOSED, then an open circuit would be acceptable. 
FIGURE 4.4-6

HOT SHORTS

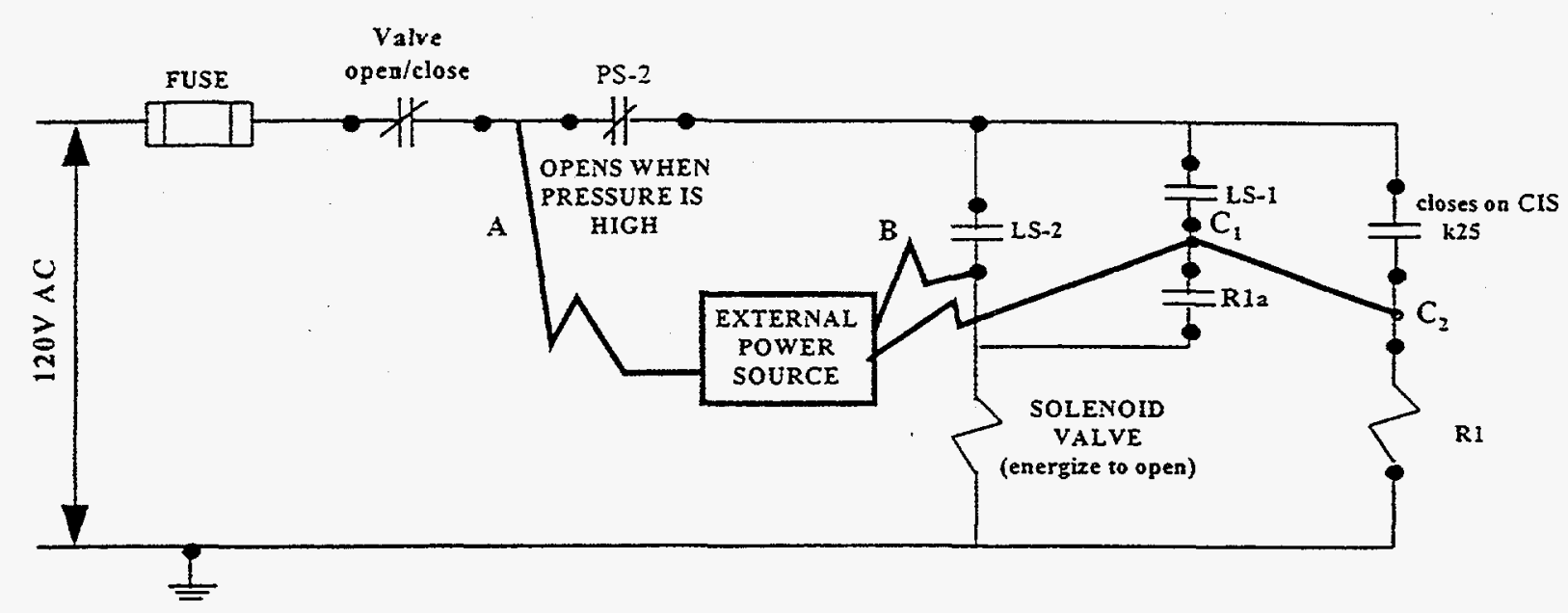

TYPICAL SCHEMATIC DIAGRAM

(INDICATING LIGHTS NOT SHOWN)

\section{FAULT TYPE: HOT SHORT}

\section{CIRCUIT EXPLANATION:}

This circuit is designed such that the solenoid valve is normally energized and will close if the system pressure goes above a preset value. The valve will reopen if the pressure is below the preset value. The solenoid will fail CLOSED on loss of power.

\section{ANALYSIS:}

A hot short at $A$ will permit the valve to open for system pressures below the high pressure setpoint. The valve would close when system pressure exceeds the high pressure setpoint. This is acceptable.

A hot short at $B$ will cause the valve to remain open and defeat the high pressure interlock. This is not acceptable.

A hot short at $C_{1}$ and $C_{2}$ is considered a single double-acting hot short and is not assumed in the spurious signal analysis. In this example, the fault would have to cause $\mathrm{Rl}$ relay to pick up and provide power to $R 1_{\mathrm{a}}$ contact to cause the solenoid valve to open when the pressure exceeds the preset value.

Note that in any case, a hot short that applies a voltage higher than $120 \mathrm{VAC}$ to the circuit could result in component damage. This potential must be considered. 
- Only a single hot short need be analyzed for circuits that are not part of a high/low system interface. Double hot shorts or two single hot shorts need not be considered. For example, in Figure 4.4-6, only a fault at $A$ or $B$ needs to be considered, not both. Additionally in Figure 4.4-6, the $C$ fault shown need not be considered, because two separate conductors are involved.

- Simultaneous fire induced spurious operations are not considered credible if it can be verified that the wiring for the components are not in a single cable or terminated in single electrical device. Each spurious operation must be analyzed but on a one-at-a- time bases. This does not apply to the spurious operation of components that fail in the unsafe position upon loss of electrical power and high/low pressure interface components. These cases may have to be analyzed simultaneously.

- Two double hot shorts are not considered credible events for any components, even if they are high/low pressure interface components.

- Where electrical permissive or interlock circuits are used to control safe shutdown equipment, all of the cables associated with the interlocking electrical circuit need to be analyzed. For example if a contact from a interlock relay controls the safe shutdown component, then the cables that could operate the interlock relay itself should also be included in the spurious operation analysis for the safe-shutdown component being evaluated.

4.4.2.4.3 Circuits/cables that do not directly affect the function of safe shutdown components must be considered to determine if failure could affect the operation of safe shutdown components. Methods for identifying and protecting each type of associated circuit are defined below and are discussed in the following sections. In all cases, if cost-effective measures for evaluating and protecting the safe shutdown capability from fire damage to non-essential associated circuits of concern are not possible, it is recommended that an alternative approach, such as a physically and electrically independent dedicated shutdown capability, be considered. Since the physical location of the cables being analyzed is of key importance, the analysis completed in this section is very dependent on information derived in Section 4.10. The extent to which this process will be completed will be related to the potential failure modes of the safe shutdown components and the extent to which the failure can be mitigated by other acceptable compensatory measures. Several examples of these compensatory measures are shown in Appendix A. 


\subsection{Associated Circuits of Concern}

The overall objective of the Safe Shutdown Analysis (SSA), is to demonstrate that a sufficient quantity of equipment will remain available to perform required shutdown functions as defined in Section 4.2 (e.g., reactivity control, reactor coolant makeup and pressure control, decay heat removal, etc.). Components and cables of required shutdown systems may share certain physical or electrical characteristics with non-essential systems (i.e., components and cables that are not required for safe shutdown). Because fire damage to circuits that are not directly related to the successful operation of safe shutdown equipment may negatively affect the operability of required systems the plant must consider, in performing the SSA, the effect of fire on both the primary, or "front-line," equipment (e.g., reactor coolant makeup pumps) and any non-essential equipment whose fire damage may affect the operability of required systems. Associated circuits of concern include any circuit (safety related or non-safety related) whose fireinduced damage could prevent operation or cause maloperation of required safe shutdown systems or components. These circuits may be found to be associated with circuits of required systems through any of the following configurations:

- Circuits that share a common power supply (e.g., switchgear, motor control center, fuse panel) with circuits of equipment required to achieve safe shutdown)

- Circuits that share a common enclosure (e.g., raceway, conduit, junction box) with cables of equipment required to achieve safe shutdown

- Circuits of equipment whose spurious operation or maloperation may adversely affect the successful accomplishment of safe shutdown functions

- A special category of common power supply circuits that require evaluation for multiple high-impedance faults

The sections that follow discuss each of these four configurations in turn.

\subsection{Circuits Associated bv Common Power Supply}

\subsection{1 Discussion}

Electrical power supplies (e.g., switchgear, motor-control centers, fuse and circuit breaker panels) required to power shutdown equipment in the event of fire are identified previously in this section. Once they are identified, the analyst must then assure that these required power supplies will remain available to perform their intended shutdown function. 
In most cases, only a few circuits of a required power supply are necessary to accomplish safe shutdown in the event of a fire. While it may not be necessary to provide power to the remaining circuits to accomplish safe shutdown, it must be assured that fire-initiated faults on cabling associated with these circuits will not affect the shutdown capability by causing a trip of a protective device (e.g., circuit breaker, fuse, or relay) upstream of the required supply. Therefore, the SSA must be extended to consider the effects of fire-induced faults on non-essential circuits of required power supplies. This analysis must ensure that: (1) non-required circuits that share a common power supply with circuits of required equipment are adequately protected or separated from the effects of fire, or (2) fire-induced faults on these circuits will not affect the capability of achieving safe shutdown conditions.

The common power supply associated circuit concern is graphically shown in Figure 4.4-7.

For the example shown, a fire is assumed to occur in the illustrated fire compartment that damages train $\mathrm{B}$ safe shutdown equipment. In this case, train $\mathrm{A}$ safe shutdown equipment, powered by safe shutdown bus $A$, is relied on to accomplish safe shutdown. Note, however, that a train $\mathrm{A}$ associated circuit cable (a cable not required for safe shutdown) is also routed through the fire area of concern. If a fire-initiated fault on this cable is not isolated by the individual branch load breaker at bus $\mathrm{A}$, the resulting fault current may propagate to cause the supply breaker of the required supply (bus A) to trip. This would result in a loss of electrical power to all equipment powered from safe shutdown bus $\mathrm{A}$.

Protection for circuits associated by a common power supply may be provided by the following means:

- Ensuring proper coordination (selective tripping) of all circuit protection devices (e.g., circuit breakers or fuses) associated with a required power source. In a properly coordinated circuit, fire-initiated faults are rapidly isolated by the protective device located nearest the fault, before the fault current propagates to cause a trip of any protective device upstream of a required power supply.

- Taking manual operator actions, governed by written procedure, to shed nonessential loads from potentially affected power supplies (i.e., tripping nonrequired plant loads). 
U.S. DEPARTMENT OF ENERGY'S REACTOR CORE

PROTECTION EVALUATION METHODOLOGY FOR FIRES AT

SOVIET-DESIGNED RBMK AND VVER NUCLEAR POWER PLANTS

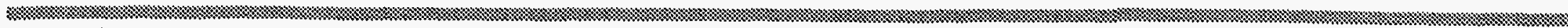

\section{FIGURE 4.4-7}

ASSOCIATED CIRCUITS OF CONCERN BY COMMON POWER SUPPLY

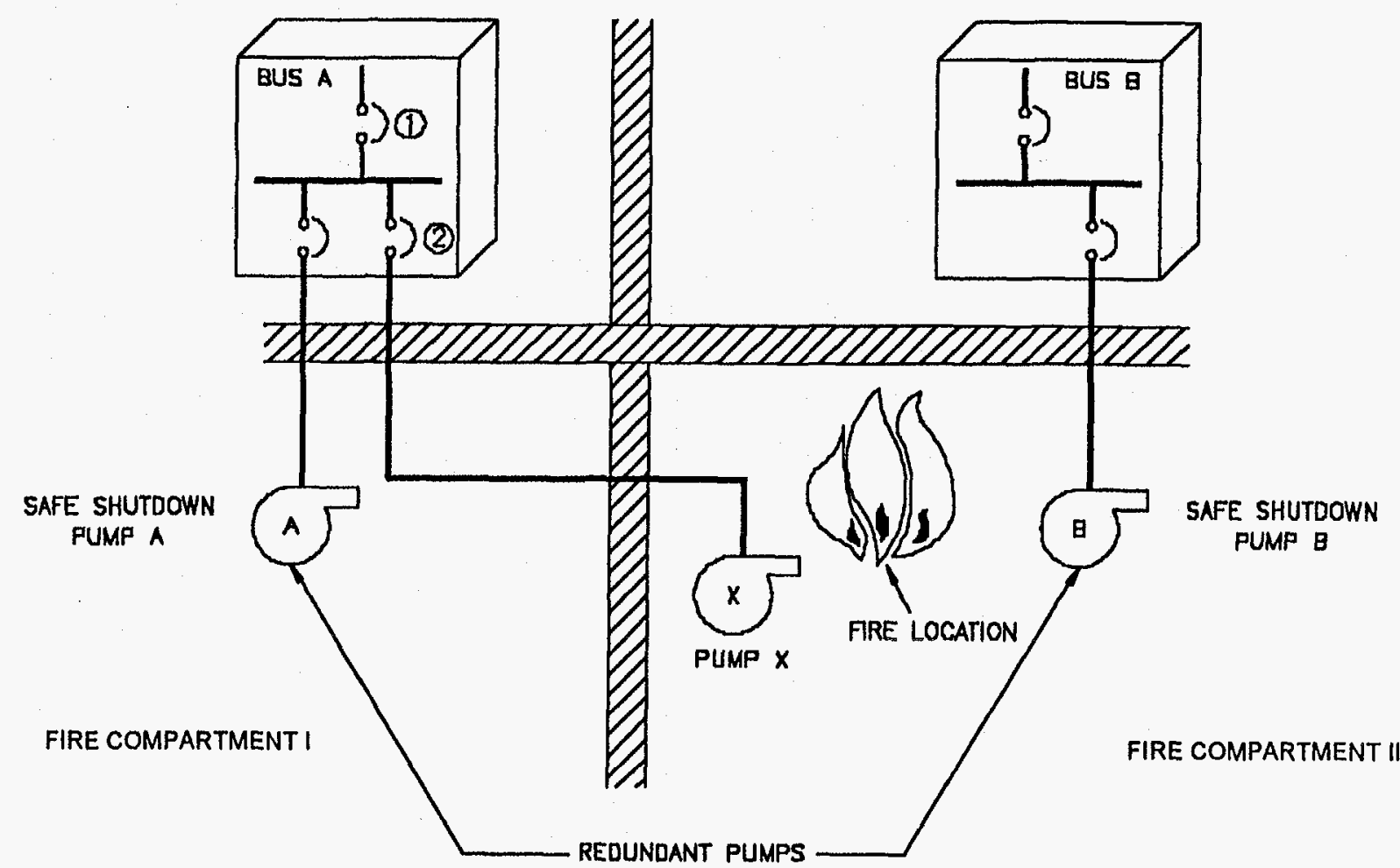


- Providing additional fire protection features (e.g., 1-hour rated fire barrier wrap) for non-required cables whose fire initiated failure could cause a loss of a required power supply).

- Rerouting cables whose fire-initiated failure could cause a loss of a required power supply.

\subsection{2 Evaluation Methodology}

The following paragraphs provide a systematic approach for identifying and evaluating common power supply associated circuits of concern. The methodology, which is shown in Figure 4.4-8, assumes that the SSA has been defined to the point where fire compartments/fire cells have been defined and the systems/equipment relied on to achieve safe shutdown conditions in the event of fire in each of these areas has been identified.

Typical steps for evaluating and resolving of common power supply circuits include:

\section{Select Compartment/Cell To Be Evaluated}

For each compartment/cell, identify the components available to support the achievement of required shutdown functions per Section 4.11 of this guidance document ( e.g., reactivity control, reactor coolant makeup, decay heat removal; reference: SSA)

\section{Identify Required Power Supplies}

For each shutdown path/system, identify the sources of electrical power (e.g., switchgear, motor control center, distribution panel, etc.) that are required to support its operation. (Reference: SSA Equipment List). Note: As shown in Figure 4.4-7, this portion of the analysis is directed at protecting the operability of required power supplies (as identified in the SSA) from the potential effect of fire damage to cables of non-essential loads. It is assumed that the SSA has already determined that the required power source and the power cables of required loads are adequately separated/protected from the effects of fire in the selected compartment/cell. 


\section{U.S. DEPARTMENT OF ENERGY'S REACTOR CORE PROTECTION EVALUATION METHODOLOGY FOR FIRES AT SOVIET-DESIGNED NUCLEAR POWER PLANTS}

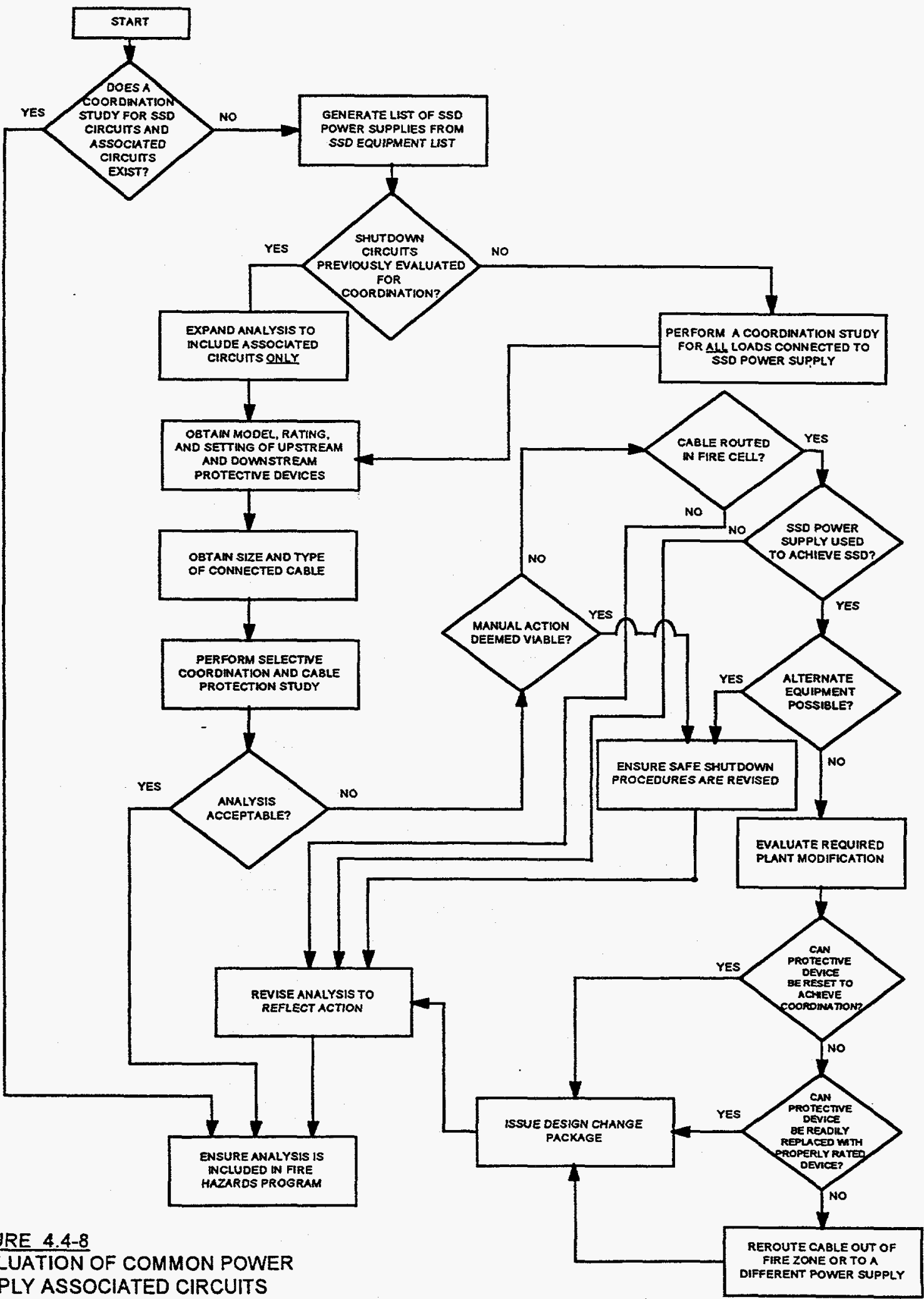

FIGURE 4.4-8

EVALUATION OF COMMON POWER SUPPLY ASSOCIATED CIRCUITS 


\section{Perform a Generic Evaluation of Coordination}

Demonstrate that all required power sources are provided with an acceptable level of circuit protective device coordination (selectivity). The evaluation should assure sufficient coordination (selective tripping) between the source or feed protection device (relay, breaker, or fuse) of the required supply and any protective device downstream of the supply such that fire-initiated faults to the associated connected cabling of a required supply will be isolated by the protective device nearest the fault without interrupting power to the required supply.

Figures 4.4-9 and 4.4-10 reflect typical time vs. current selective coordination and cable protection curves made to show the acceptability of the associated common power supply circuit. A detailed description of these coordination and protection curves is provided.

Input data needed to perform the coordination study includes the following information (see Exhibit 4.4-4):

\section{Input data:}

a. The list of safe shutdown power supplies. This list can be derived from the subset of information annotated in the safe shutdown equipment list as described in Section 4.4.2 and documented in the safe shutdown equipment and cable analysis worksheet as reflected in Exhibit 4.4-1.

b. The model, rating, and setting(s) of all of the upstream and downstream protective devices (breakers, fuses, relays) connected to each of the safe shutdown power supplies.

c. A list of all associated circuits for each safe shutdown power supply.

d. Documentation of the available short-circuit level at the safe shutdown buses. This information is typically taken from the electrical auxiliary system short-circuit study conducted for the plant.

The input data to the coordination study is typically derived from plant design drawings, vendor information, and design drawings. In U.S. plants, this documentation includes single-line drawings, metering and relay drawings (three-line drawings), cable and raceway schedules (automated or manual), vendor-submitted drawings, and literature and/or confirmed telephone calls with the vendors, and relay/breaker setting sheets. 


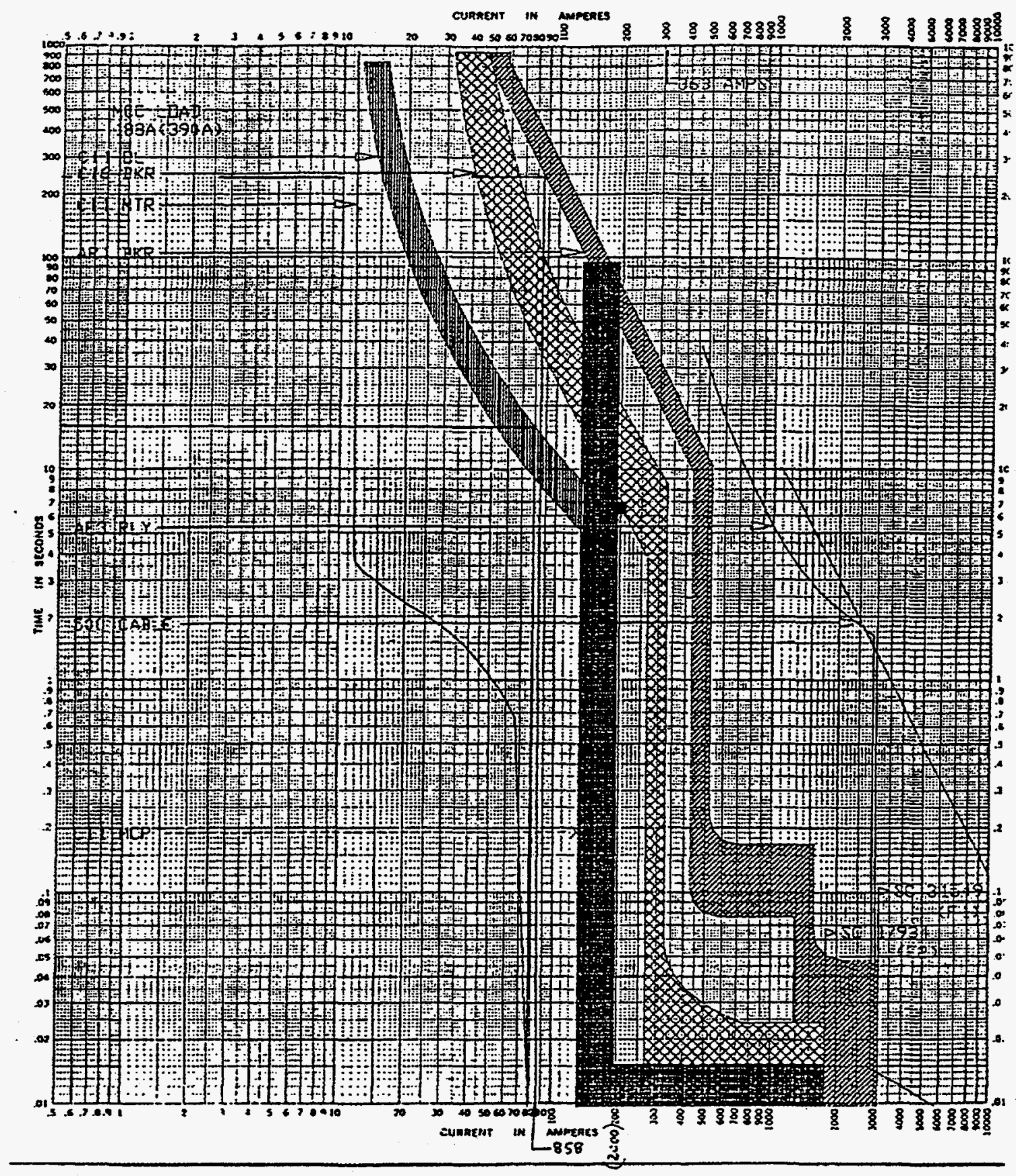

FIGURE 4.4-9 (Page 1 of 2)

SELECTIVE COORDINATION AND CABLE PROTECTION TIME VS CURRENT CURVES 


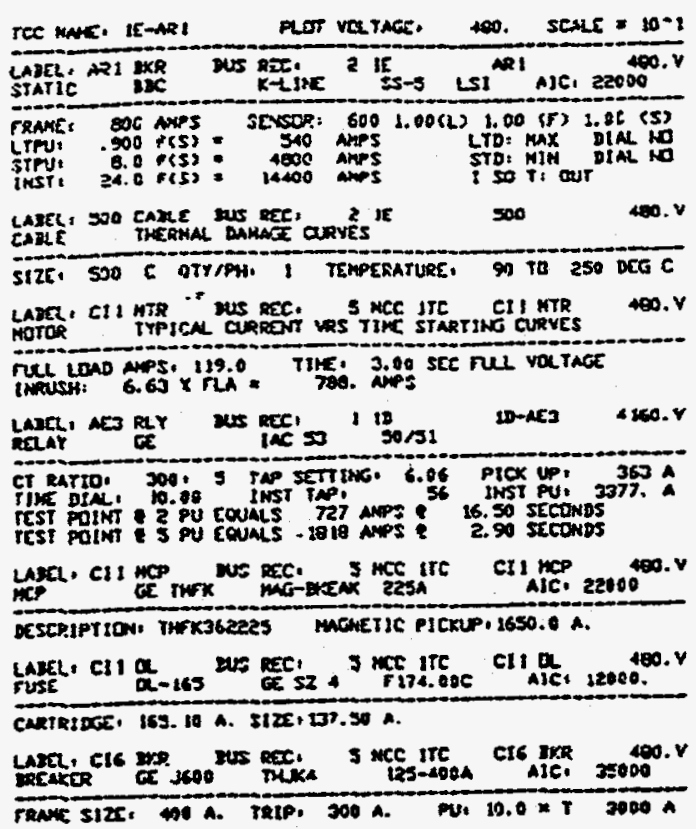

\section{Protective Devices Settings}

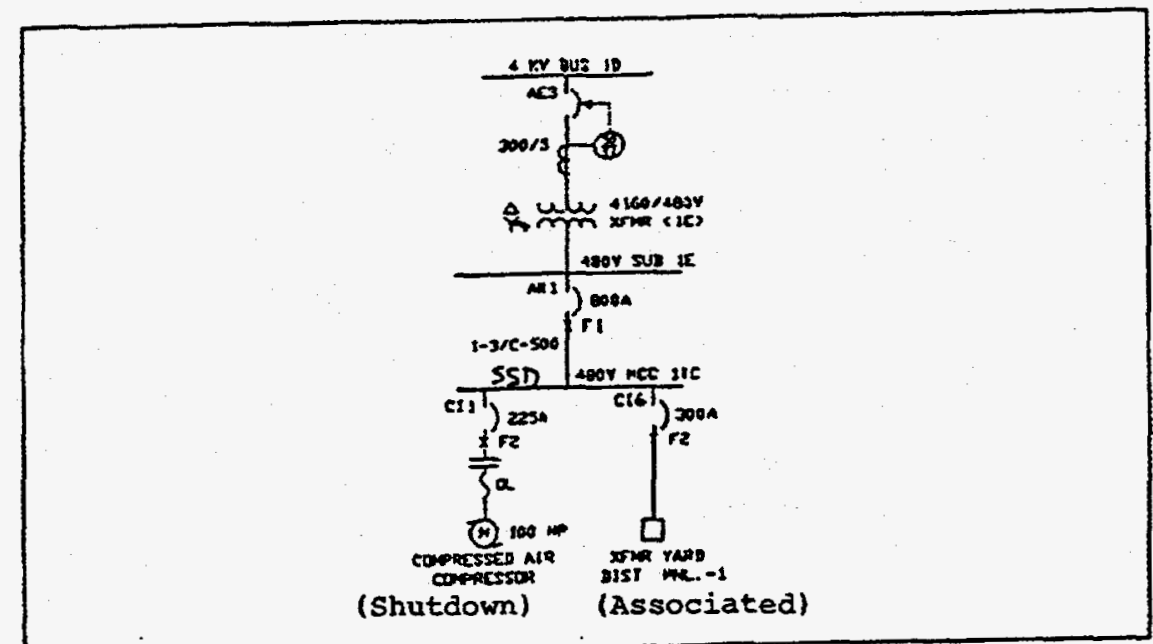

FIGURE 4.4-9 (Page 2 of 2 )

SELECTIVE COORDINATION AND CABLE PROTECTION (Input Data and Single Line Diagram) 


\section{Explanation of Figure 4.4-9}

\section{Legend:}

500 Cable: The 10-second short-circuit withstand current rating of the $500 \mathrm{MCM}$ cable that is routed between 480 Volt sub 1E and 480 Volt MCC 1TC.

AE3 Rly: The overcurrent relay that isolates $4 \mathrm{kV}$ bus 1D breaker AE3 based on the overcurrent settings. The vendor's trip characteristic curve based on the actual setting of AE3 Rly is plotted graphically on the time vs. current curve.

AR1 Bkr: The 800 Ampere feeder breaker from 480 Volt load center $1 \mathrm{E}$ to 480 Volt MCC 1TC. The vendor's trip characteristic curve based on the actual instantaneous and long-term overload settings for the AR1 breaker is plotted graphically on the timevs. current curve.

CI6 Bkr: The 300 Ampere load breaker from 480 Volt MCC 1TC. The vendor's trip characteristic curve based on the actual instantaneous and long-term overload settings for the $\mathrm{C} 16$ breaker is plotted graphically on the time vs. current curve.

F2: The available short-circuit current at the load terminals of breaker CI6.

Analysis: $\quad$ Typically, the time vs. current characteristic curve is used to graphically show selective coordination and cable protection. For this case example, the vendor's trip curves for the associated circuit breaker (CI6) and the incoming breaker to the safe shutdown power supply (AR1) are plotted and the available short-circuit current (F2) is also plotted. As can be seen by this example, selective coordination between the load breaker (CI6) and the upstream breaker (AR1) is achieved for all levels of short-circuit currents (maximum available short circuit current of 17,934 Amperes and below) and time, 0.01 second to 1000 seconds.

Please note that cable protection curve(s) can also be plotted to show if the protective device protects the cable at its various ratings, namely, ampacity, overload, short circuit, or autoignition. 


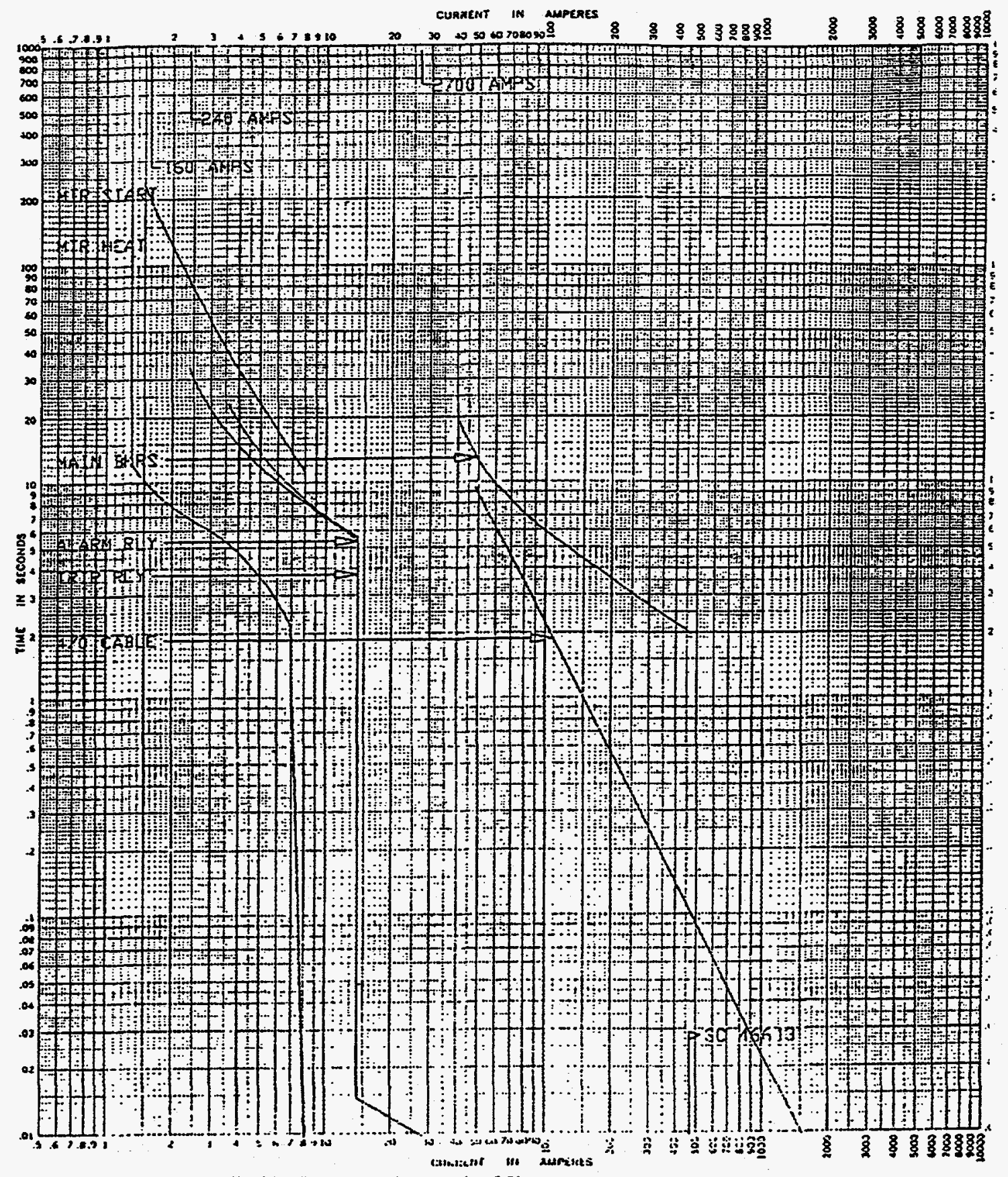

FIGURE 4.4-10 (Page 1 of 2)

SELECTIVE COORDINATION AND CABLE PROTECTION

TIME VS CURRENT CURVES 


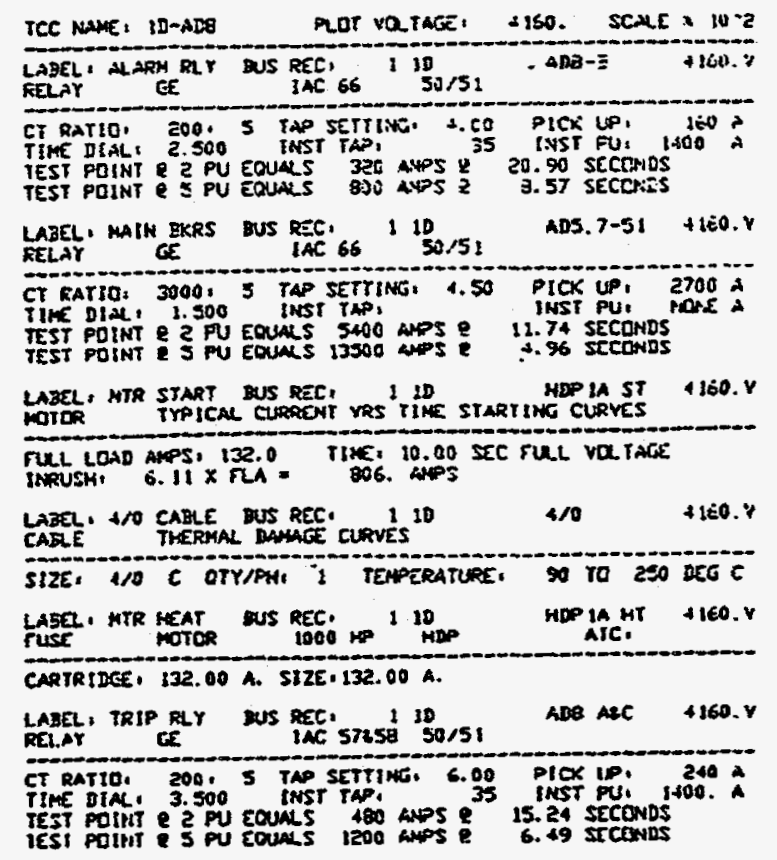

Protective Device Settings

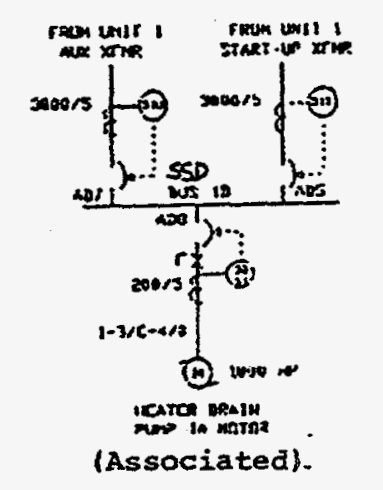

Figure 4.4-10 (Page 2 of 2)

SELECTIVE COORDINATION AND CABLE PROTECTION

(Input Data and Single Line Diagram) 
Plant walkdowns have also been conducted to develop information where the required information was not otherwise available. Section 4.9 establishes guidance for verification of the cable routing information for associated circuits.

The output of the selective coordination analysis is typically documented in a calculation that is controlled and becomes a part of the Fire Hazards Evaluation Program.

\section{Output Data:}

a. Bases and assumptions used in the analysis.

b. A list of references used to develop the input data.

c. Single-line diagrams of each safe shutdown bus evaluated.

d. A series of time versus current figures that show the selective coordination between the safe shutdown supply side protective device(s) and the safe shutdown load side protective device for the associated circuit. These curves should also show that each of the connected circuit's safe shutdown power supply is protected by its protective device, based on the maximum calculated available short-circuit for each of the identified safe shutdown power supplies.

Please note that every circuit that is connected to the safe shutdown power supplies need not be individually modeled. In U.S.-designed plants, there is typically redundancy and duplication of combinations of protective devices. Typically, fuse and breaker selection is based on general guidelines such as the National Electric Code. Therefore, to conserve costs, analysis should include as many typical combinations of protective devices as needed to cover all combinations of protective devices and cables that could be found at the plant safe shutdown power supplies.

e. A table comparable to Exhibit 4.4-5 should be developed that includes the following information:

- The list of associated circuits reviewed.

- Identification of the applicable time vs. current characteristic coordination curve that demonstrates proper selective coordination. 


\section{U.S. DEPARTMENT OF ENERGY'S REACTOR CORE \\ PROTECTION EVALUATION METHODOLOGY FOR FIRES AT \\ SOVIET-DESIGNED NUCLEAR POWER PLANTS}

- Identification of a recommended course of action to resolve any corrective actions (downstream device does not coordinate).

- The specific method actually used to correct the deficiency.

\subsection{3 Circuit Classification and Method of Analysis}

$\mathrm{AC}$ and $\mathrm{DC}$ power circuits: The coordination study should be performed to determine whether an overload or short-circuit on a nonsafe shutdown (associated) power circuit (or a safe shutdown circuit) could result in a loss of power to other safe shutdown circuits that share the same power supply as the faulted circuit.

Control and instrumentation circuits: The coordination study should evaluate the selective coordination of protective devices on circuits powered from ac and dc distribution panels. Figure 4.4-11 shows a typical U.S. configuration for $125 \mathrm{~V} \mathrm{dc}$ panels and $120 \mathrm{~V}$ ac panels. The study should consider the following conditions and evaluate the acceptability of each:

- Condition 1: A short in a non-safe shutdown circuit (i.e., load 3 or $4 \mathrm{C}$ ) that could cause the feeder breaker to trip, resulting in a loss of power to the entire distribution panel and safe shutdown loads powered from the panel.

- Condition 2: A short in one safe shutdown circuit (i.e., load 2, 4a, or $4 \mathrm{~b}$ ) that could cause the feeder breaker to trip, resulting in a loss of power to the entire distribution panel and safe shutdown loads powered from the panel.

- Condition 3: A short in a non-safe shutdown subcircuit (i.e., load 4c) that could cause the distribution panel branch breaker to trip, resulting in a loss of power to safe shutdown subloads (i.e., loads $4 a$ or $4 b$ ) on the same branch.

- Condition 4: A short in a safe shutdown subcircuit (i.e., load 4a) that could cause the distribution panel branch breaker to trip resulting in a loss of power to other safe shutdown subloads (i.e., load 4b) on the same branch.

\subsection{4 Alternative Approaches}

The following alternative approaches may be considered if the coordination of required sources of electrical power cannot be demonstrated or is in doubt: 


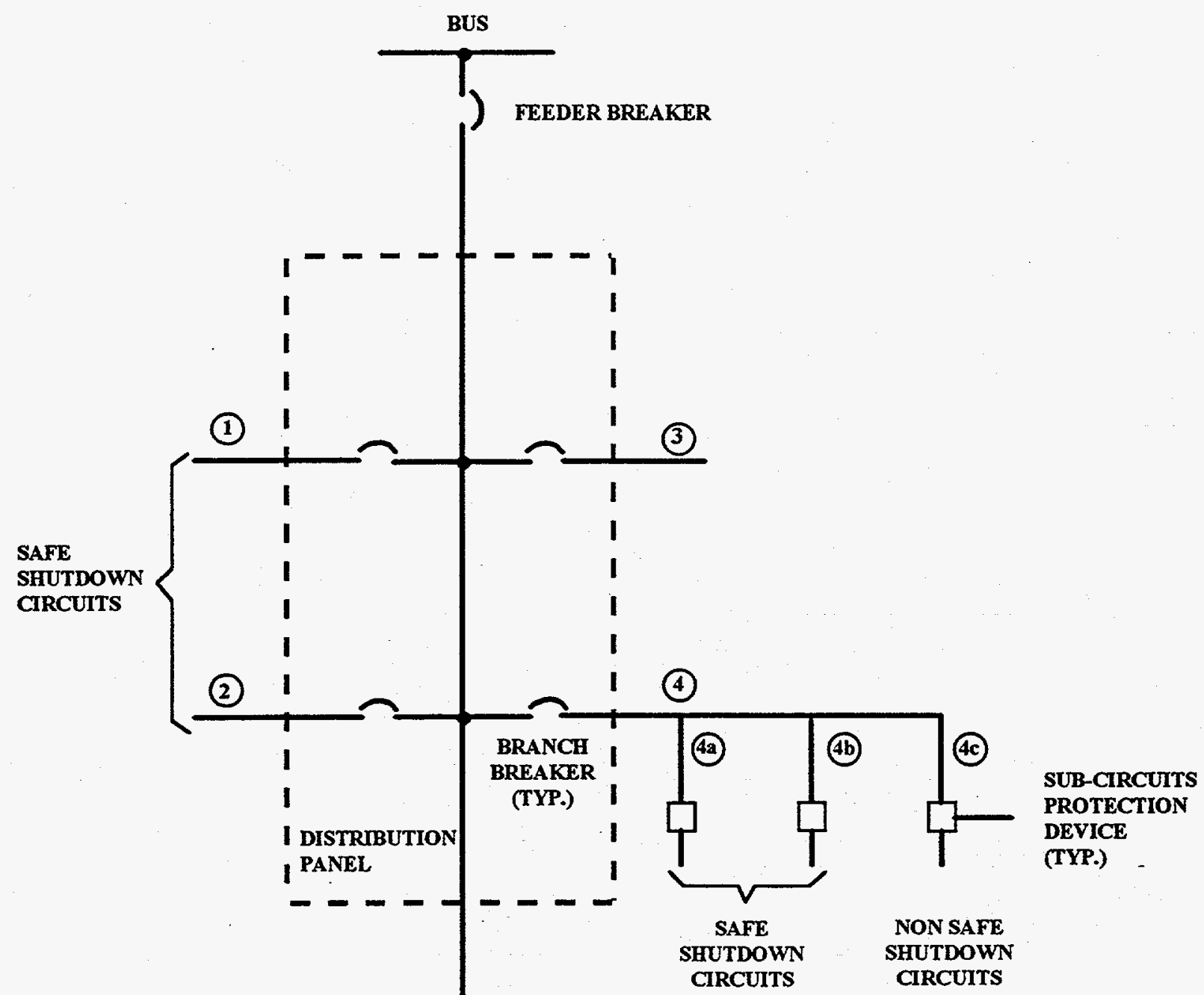

FIGURE 4.4-11

TYPICAL 120 VAC OR 125 VDC

ELECTRICAL DISTRIBUTION SYSTEM 
a. For the fire cell being evaluated, confirm that the specific uncoordinated safe shutdown power supply is actually relied on to achieve the shutdown path chosen, as alternate shutdown paths may have already been analyzed as acceptable for this fire cell. If it is not, record this fact in the coordination study and take no further action.

b. b. Determine if other equipment that is not powered from the safe shutdown power supply being evaluated (e.g., a new shutdown path evaluated as acceptable) can be used to achieve safe shutdown. If that is an option, identify this justification in the coordination study and ensure that the analysis being completed per Section 4.11 reflects this change for that particular fire cell and is revised to reflect the new shutdown path. Also ensure that a complete circuit analysis is performed for the new shutdown path.

c. Determine the time requirements for safe shutdown equipment being powered from the safe shutdown power supply being relied on to achieve the designated safe shutdown path. If it is determined that sufficient time exists to take manual action to isolate the deficient associated circuit(s) (e.g., tripping breakers or removing fuses and reclosing the incoming breaker or replace the incoming fuse), note that justification in the coordination study.

The Emergency Operating Procedures (EOPs) should (a) direct operators to shed all nonessential loads (equipment that is not required for safe shutdown) from potentially affected power supplies and (b) provide direction for restoring the operability of affected supplies (i.e., load shedding and reloading required loads). It is important to note that this approach does not provide the same high level of protection that is afforded by properly coordinated power sources or fire protection features. Additionally, this approach also requires operators to deenergize equipment that, while not identified in the SSA as required for safe shutdown, may be useful in mitigating the effects of fire. For cases where the alternatives described above are not achievable, the use of EOPs will greatly enhance the shutdown capability by identifying potential vulnerabilities to the operators and providing alternative courses of action. As a minimum, EOPs developed for this purpose should:

- Identify required power sources that are vulnerable to loss due to fire damage to connected cabling/loads

- Identify essential shutdown loads that must remain energized

- Identify non-essential loads that should be tripped (shed) to prevent the loss of a potentially affected supply 
- Provide direction for accomplishing load shedding activities

- Provide direction for restoring operability in the event a required power supply becomes unavailable as a result of fire damage to connected cabling

d. Determine whether the deficient associated circuit that is powered from the safe shutdown power supply is actually routed in the fire cell of concern. This may be accomplished through a review of "as-built" plant documents depicting the installed configuration of connected load cables. If this information is not available, is obsolete, or is of indeterminate quality, it will be necessary to verify the routing of connected cables through signal tracing techniques and/or field walkdowns. See the associated cable routing information discussed in Section 4.9 for more details. If the cable it is not routed in the fire cell of concern, record this fact in the coordination study. No further action is required since safe shutdown capability can be achieved and no plant modifications are required.

If it is confirmed that the cable is routed in the fire cell, determine the length of cable from the safe shutdown power supply to where the cable enters the fire cell being evaluated. Calculate the short-circuit current using the cable length information recorded above. Review time current curves and determine if the load side protective device coordinates with the supply side protective device at the point on the curve where the calculated short-circuit current intersects. (Example: assume the fault current seen by breaker CI6 on Figure 4.4-9, Sheet 2 of 2 , is 2000 Amperes. As can be seen by the graphical representation shown in Figure 4.4-9, Sheet 1 of 2, breaker CI6 would trip in approximately 7 seconds at this current level and, more importantly, prior to upstream breaker AR1. Thus the associated circuit achieves selective coordination with the supply side breaker for the 480 Volt MCC.) If coordination is achieved, document this fact in the analysis and take no further action.

e. If it is determined that none of the above analytical options or manual operations can be satisfied, one of the following plant modifications should be done as applicable:

- Replace or reset the protective device(s) as applicable with a new device(s) that provides selective coordination. (Usually the most economical and preferred modification, as protection and selective coordination are satisfied.) 
- Reroute the cable out of the fire cell being evaluated, provided it can be located in an area that will not cause the same coordination problem with the safe shutdown power supply when a new fire cell is evaluated.

- Reroute the cable to a different power supply that will not affect the safe shutdown analysis.

\subsection{Circuits Associated by Common Enclosure}

\subsection{1 Discussion}

Circuits that share enclosures, cable trays, ducts, and conduits with safe shutdown circuits must be analyzed to determine their potential effect on redundant safe shutdown components. This concern consists of three issues: (1) fire-initiated electrical faults on inadequately protected cables could cause an overcurrent condition, resulting in secondary ignition, (2) the effects of the fire may extend outside of the immediate area by means of fire propagation, and (3) current transformer secondary ignition may result from open circuits on the control power transformer secondary caused by the effects of a fire. Any of these cases could result in damage that could disable the redundant train of required shutdown equipment.

If a breaker coordination study (guidance provided in Section 4.4.2.4.3.2.3) has demonstrated that propagation of fire to an adjacent compartment is not possible, then this evaluation for that common enclosure may not be necessary. It must be shown that adequate electrical protection is provided for all cables, including nonessential cables such as lighting circuits, communications, etc.

Each type of common enclosure concern is addressed separately in the following subsections.

\subsection{1.1 Common Enclosure - Cable Ignition}

Cables of non-essential equipment may share a common enclosure (e.g., raceway, conduit, or panel) with cables of equipment required for safe shutdown. In the absence of adequate electrical protection (i.e., properly sized fuses and circuit breakers), heat generated by fire-induced faults on the non-essential cables may cause a secondary fire to occur within the common enclosure, thereby damaging required cables. 
A simple diagram that shows the "secondary ignition" common enclosure concern is provided in Figure 4.4-12. As shown in this diagram, the fire at instrument B causes a fault on a cable that is not properly electrically protected. The fault then results in the ignition of a secondary fire in the vicinity of the instrument $\mathrm{A}$ cables due to an overcurrent condition, resulting in cable jacket ignition. The result could be the loss of the two redundant trains

\subsection{1.2 Common Enclosure - Fire Propagation}

Fire that travels between redundant safe shutdown trains is possible where there are materials that can burn and allow the fire to travel from one location (safe shutdown train A compartment/cell) to another location (safe shutdown train B compartment/cell). Where the material is exposed cable, the cables are considered associated circuits of concern.

As shown in Figure 4.4-13, a postulated fire will render instrument B inoperable. The concern exists that the fire could travel through the connecting cable tray or conduit and cause the fire to travel to Instrument A.

In the U.S., cables are generally specified to demonstrate non-propagation (selfextinguishing) characteristics or flame-retardant properties. Approved and tested fire stops are used where the cable leaves the fire cell to keep the travel of the fire along the cable insulation system from spreading from one fire cell to the adjacent fire cell(s).

\subsection{1.3 Current Transformer Secondary Ignition}

Current power transformers are used throughout the electrical distribution system to monitor bus current and provide differential protection. The current power transformers are physically located on the electrical conductor (i.e., bus bar) and provide a signal through their secondary winding that is proportional to the current flowing through the conductor. Current transformers are designed to transform high primary current into low secondary current. Theoretically, the secondary voltage is as high as required to maintain a constant primary-to-secondary current ratio. In an attempt to maintain this ratio, an opening in the secondary circuit may cause excessively high voltages to be experienced in the current transformer secondary circuit. Depending on the design of the transformer and its connected cabling, the overvoltage condition may cause the transformer materials to ignite. 
U.S. DEPARTMENT OF ENERGY'S REACTOR CORE

PROTECTION EVALUATION METHODOLOGY FOR FIRES AT

SOVIET-DESIGNED NUCLEAR POWER PLANTS

FIGURE 4.4-12

ASSOCIATED CIRCUITS OF CONCERN BY COMMON ENCLOSURE

- ELECTRICAL PROTECTION -

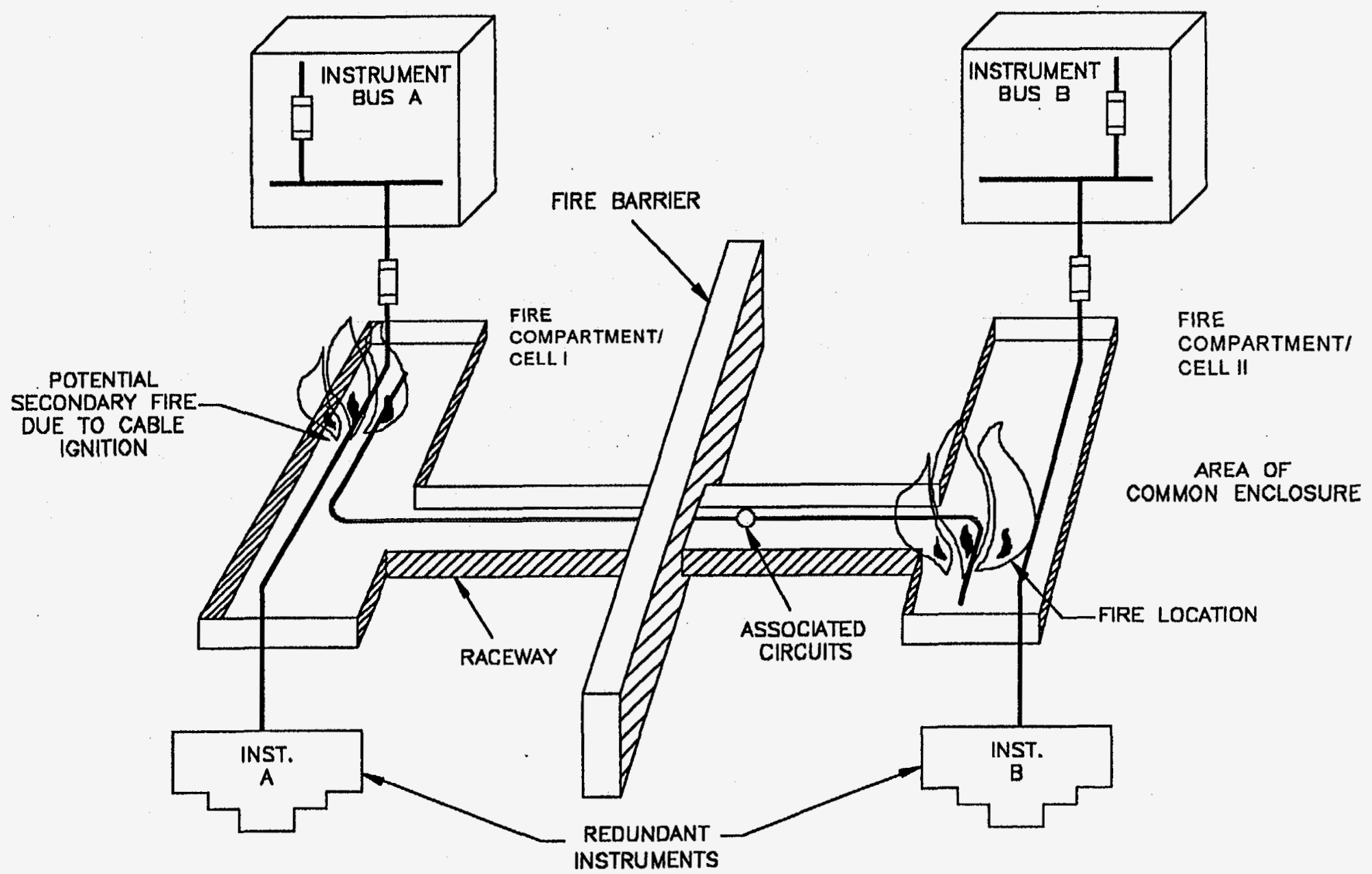


U.S. DEPARTMENT OF ENERGY'S REACTOR CORE

PROTECTION EVALUATION METHODOLOGY FOR FIRES AT

SOVIET-DESIGNED NUCLEAR POWER PLANTS

FIGURE 4.4-13

ASSOCIATED CIRCUITS OF CONCERN BY COMMON ENCLOSURE

- FIRE PROPAGATION -

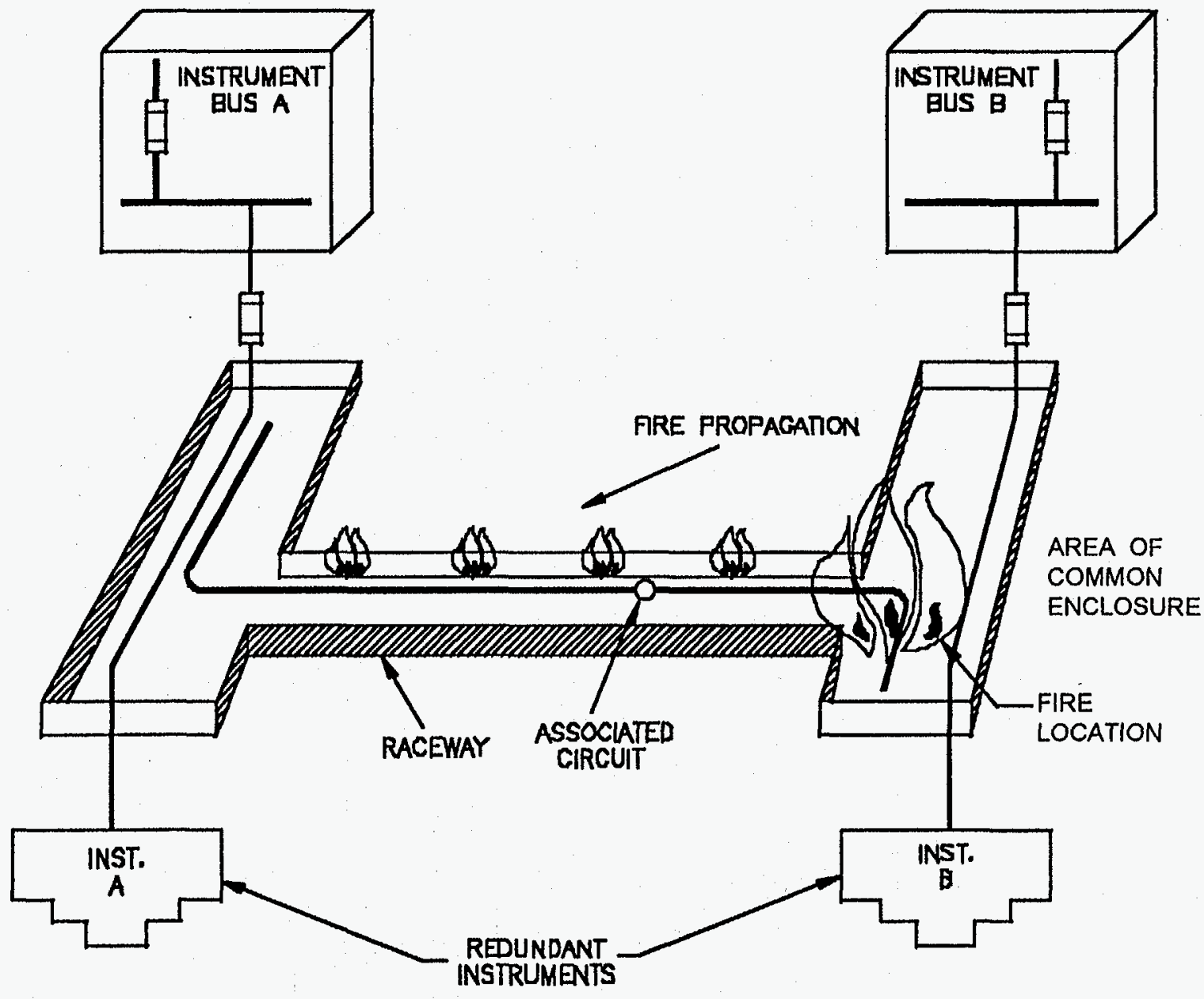


One type of current transformer circuit scheme is provided in Figure 4.4-14. In the example shown, a fire in the control room could cause a fire-initiated opening in the secondary circuit of the current transformers, causing an electrical fault at the current transformers in both safe shutdown buses A and B. This could result in a fire within each bus, thereby making both buses unavailable. This is not acceptable since redundant safe shutdown pumps would be unavailable to perform their intended function due to the fire at both safe shutdown buses.

The failures described above may be prevented by analysis or by providing suitable open circuit electrical protection for the associated circuit cable, such as current transformer shorting switches (solid-state/automatic and manual). These specific options are further discussed in detail in Section 4.10.5.2.

\subsection{2 Evaluation Methodology}

Concern with common enclosure associated circuits consists of three issues: (1) overheating of cables due to inadequately sized electrical protection, (2) the spreading of fire via materials that can burn (i.e., cable insulation), and (3) control power transformer secondary ignition due to open circuits on the current power transformer due to an exposure fire.

Verify the adequacy of electrical protection provided for cables that may share a common enclosure with cables of equipment required for safe shutdown. The objective of this review is to ensure that for all credible low-impedance and bolted faults, the cable temperature will not increase to its ignition point. This is accomplished by providing suitable electrical protection capable of limiting the temperature to a level below the cable's ignition point.

Please note that circuits typically used in annunciation schemes, computer schemes, communication schemes, and instrumentation control loops have insufficient energy to cause a secondary fire and can be removed from further analysis once this fact is confirmed.

Since it is very possible for a large number of nonessential cables whose routing is unknown to share a common enclosure (e.g., cable tray or junction box) with cables of equipment required for safe shutdown, verifying the adequacy of electrical protection for all cables could be extensive and potentially overwhelming. However, if it is known that electrical cable protection was included as part of the original plant design, the scope of the review can be greatly reduced to that of identifying any unknown or undocumented field modifications, such as fuse or cable replacements, that may have been performed subsequent to initial plant startup. 
FIGURE 4.4-14

ASSOCIATED CIRCUITS OF CONCERN BY COMMON ENCLOSURE

- OPEN CURRENT TRANSFORMER SECONDARY WINDINGS -

SWITCHGEAR ROOM A

SWITCHGEAR ROOM B

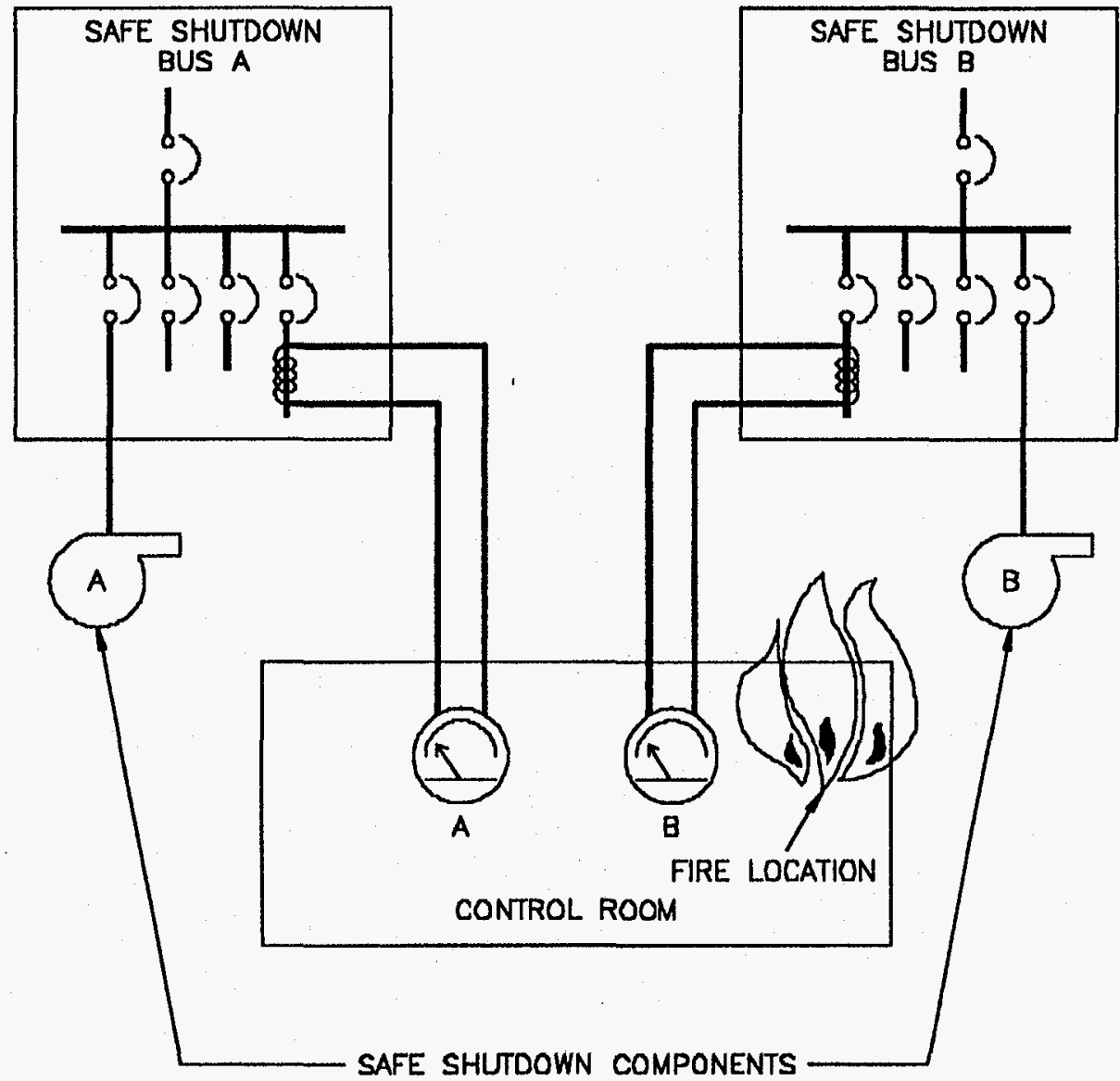


To obtain reasonable assurance that such changes have not compromised the original plant design, it is recommended that a plant-wide survey be performed. As a starting point, a minimum of 15 percent of power sources (motor control centers, distribution panels, etc.) associated with each level of voltage should be evaluated for the adequacy of electrical protection of connected cabling. This may be accomplished by a field walkdown of the selected power sources, noting the size and type of each connected load cable along with the size, type, and rating of the associated protective device (fuse, circuit breaker, etc.). From the data collected, the "as-installed" configuration may be compared to the original "asdesigned" configuration, and a determination of the adequacy of protection may be made.

By design, cables for U.S. plants typically have an ampacity rating of $90^{\circ} \mathrm{C}$, an overload rating of $150^{\circ} \mathrm{C}(100$-hour temperature rating for the life of the cable without sustaining insulation damage), a short-circuit withstand rating of $250^{\circ} \mathrm{C}$ (10-second temperature rating without sustaining insulation damage), and a combustion rating (insulation auto-ignition) of $350^{\circ} \mathrm{C}$ to $425^{\circ} \mathrm{C}$. All of the described cable ratings will change based on the actual insulation system used in constructing the cable.

Protecting the cable at its ampacity rating is ideal. The least conservative method is to protect the cable at its combustion or auto-ignition rating. The plant should decide (if not currently established) to what degree (i.e., ampacity, overload, short circuit, auto ignition, or some other rating) these categories of cables should be protected.

Although protecting the cable from auto-ignition will demonstrate that the cable insulation system will not ignite and thus eliminate this aspect of the common enclosure event, several factors need to be considered to ensure that the analysis is sufficiently conservative to keep the cable from igniting. Specifically, manufacturing tolerances of the protective devices must be determined, any drift or temperature correction factors that could affect the tripping of the protective device must be established, and the actual insulation type system used for the cable and its corresponding auto-ignition temperature (accounting for manufacturing tolerances in the insulation system) must be known. The resultant analysis should be conservatively adjusted to account for these variations.

Experience has shown that it is difficult, and sometimes impossible, to get and/or verify such information from the manufacturers of the protective devices and cables. If the plant is newer, the chances for getting this type of information are better than for an older plant. If the information is not obtainable, a more 
conservative value like short-circuit withstand ratings of the cable should be used as the acceptance criteria for the evaluations.

Based on the results of this initial review, the adequacy of the sample size (i.e., 15 percent evaluation of power sources) should be determined and the scope of the evaluation adjusted accordingly. Depending on the number of discrepancies identified in the sample of power supplies evaluated, review of additional power sources may be required.

A typical electrical protection methodology would include the following steps:

- Select the initial 15 percent circuit sample according to criteria established above.

- Create a table that includes:

- The circuits selected

- As-found protective device type, rating, and setting for each selected circuit

- As-found cable size and type

- Reference to figure/chart to ascertain acceptance or rejection

- Recommended solution for corrective action

- Actual method used for corrective action

- Perform plant walkdown to confirm as-built data needed for analysis.

- Determine whether the cable is protected, using the plant's agreed-upon acceptance criteria. Please note that coordination curves already developed for circuits classified as common power supply circuits (as discussed in Section 4.4.2.4.3.2) could easily be modified to include cable auto-ignition rating information. Industry charts/graphs and/or tables can be developed to also demonstrate acceptance.

- If failures are noted in the initial 15 percent sample population, consecutively increase the sample size by 15 percent until such time that it can be concluded that the cables are adequately protected.

- Finalize the analysis and make sure it is included in the Fire Hazards Evaluation Program. 


\subsection{3 Alternative Approaches}

In the event that the above review identifies instances of inadequate electrical protection, then alternative approaches for achieving an acceptable resolution should be considered. Any of the following corrective actions are deemed acceptable:

a. Use manual actions to trip the breaker or remove fuses as necessary to isolate the circuit connected to the non-safe shutdown related circuit.

b. Review the actual cable routing using techniques established in Section 4.9. If it is determined that for each fire zone, the cable is not routed in cable trays or conduits that are common to redundant safe shutdown equipment, than the circuit can be deemed acceptable.

c. Determine if alternate safe shutdown equipment can be used for each fire cell in which the cable is routed, thus eliminating the common enclosure issue for each applicable fire cell.

d. Reset the protective device if applicable or replace the protective device with a properly sized device.

e. Fire-wrap the circuit to protect it from damage. If this option is chosen, the owner should determine if its effect on the cable ampacity rating should be investigated further. Also, the weight of the fire wrap material must be considered on the conduit and cable tray supports for both normal and, if applicable, seismic conditions. If the wrap can be subjected to water spray from the fire sprinkler system, the additional weight from the wetted material must also be considered.

Considering that these cables are non-safe shutdown cables, the plant may elect to allow the cables to possibly operate above their ampacity rating thus reducing the useful cable life. Fire wrapping a circuit will reduce the allowable ampacity of the cable because the fire wrap reduces thermal conductivity between the cable and it environment. The cable ampacity would be reduced in accordance with the fire wrap manufacturer's requirements for ampacity reduction.

The effectiveness of fire-wrap is very dependent on its proper installation. The installation process must be closely supervised to ensure that all the manufacturer's recommendations are followed. Maintenance practices must ensure that the fire-wrap installations are maintained over the operating life of the plant. 
f. Reroute the affected cable so that it no longer shares a common enclosure.

Ensure that the electrical analysis for the common enclosure issues is updated to reflect the method(s) used to correct any deficiencies.

\subsection{Fire Propagation}

As depicted in Figures 4.4-13 and 4.4-14, there is a potential for non-essential cables that share a common enclosure with cables required for safe shutdown to cause a fire to spread beyond its initial location. To address this portion of the common enclosure associated circuit concern, the owner must:

- Ensure that suitable flame-spread mitigating features (e.g., fire stops, cable coatings) are installed in safe shutdown cable trays or conduits capable of preventing fire from propagating and damaging redundant divisions of shutdown cables

- Ensure that electrical cable penetrations are appropriately sealed or otherwise configured in a manner that mitigates the potential for fire propagation.

- For current power transformers (CPTs), either:

a. Show that the CPTs are capable of withstanding an open secondary winding. That is, the manufacturer designs the CPT to withstand an open circuit on the secondary side

\section{OR}

b. Show that actual testing by the CPT manufacturer demonstrates that the primary fuses isolate the CPT before any major damage can occur that would cause a fire in the switchgear. Various U.S. manufacturers conducted such testing and showed that, at worst, the open circuit voltage on the secondary side would eventually cause winding-towinding faults internal to the secondary of the CPT and would eventually result in sufficient levels of current to blow the fuses in the primary of the CPT. Thus, the circuit was electrically isolated before any additional damage could be done that could lead to a fire at the CPT.

\section{OR}

c. Install shorting-type switches at the CPT that can be automatically or manually thrown as part of the response to a safe shutdown due to a fire. Zener diode networks have also been used at U.S. plants to ensure shorting across the CPT secondary. 


\subsection{Circuits Associated by Spurious Signals}

\subsection{1 Discussion}

Fire-induced cable damage (e.g., hot shorts, open circuits, shorts to ground) may cause connected equipment to operate in an undesirable manner. For example, a fire-induced short circuit on control wiring of a normally open motor-operated valve could cause the valve to spuriously close, thereby blocking a required flow path that was previously assumed to be open (Figure 4.4-15). Conversely, the spurious opening of a normally closed valve could divert flow from a required flow path. Additional examples include false instrument indications, the spurious starting or stopping of electrically powered equipment such as pumps and motors, and the initiation of false control and interlock signals.

Achievement of safe shutdown depends on actively controlling of some components and preventing the maloperation of others. The circuits of both categories of components have the potential for being associated circuits of concern by spurious operation.

Circuits that could cause undesirable spurious equipment operations must be identified and evaluated for their effect on safe shutdown capability. Wherever necessary, appropriate methods of control must then be implemented. The specific method of control must be consistent with the potential severity of the spurious actuation. For example, the spurious opening of valves that form a high/low pressure interface boundary may place the plant in a potentially unrecoverable condition. Therefore, the spurious actuation of these valves must be prevented. Spurious actuations of these valves may be prevented by implementing plant modifications to install additional fire barrier material (fire wrap) on potentially affected cabling or by adopting plant operating procedures that require at least one of the redundant valves to be locked closed, with its associated power circuit breaker disconnected from the electrical bus, during normal plant operation. 


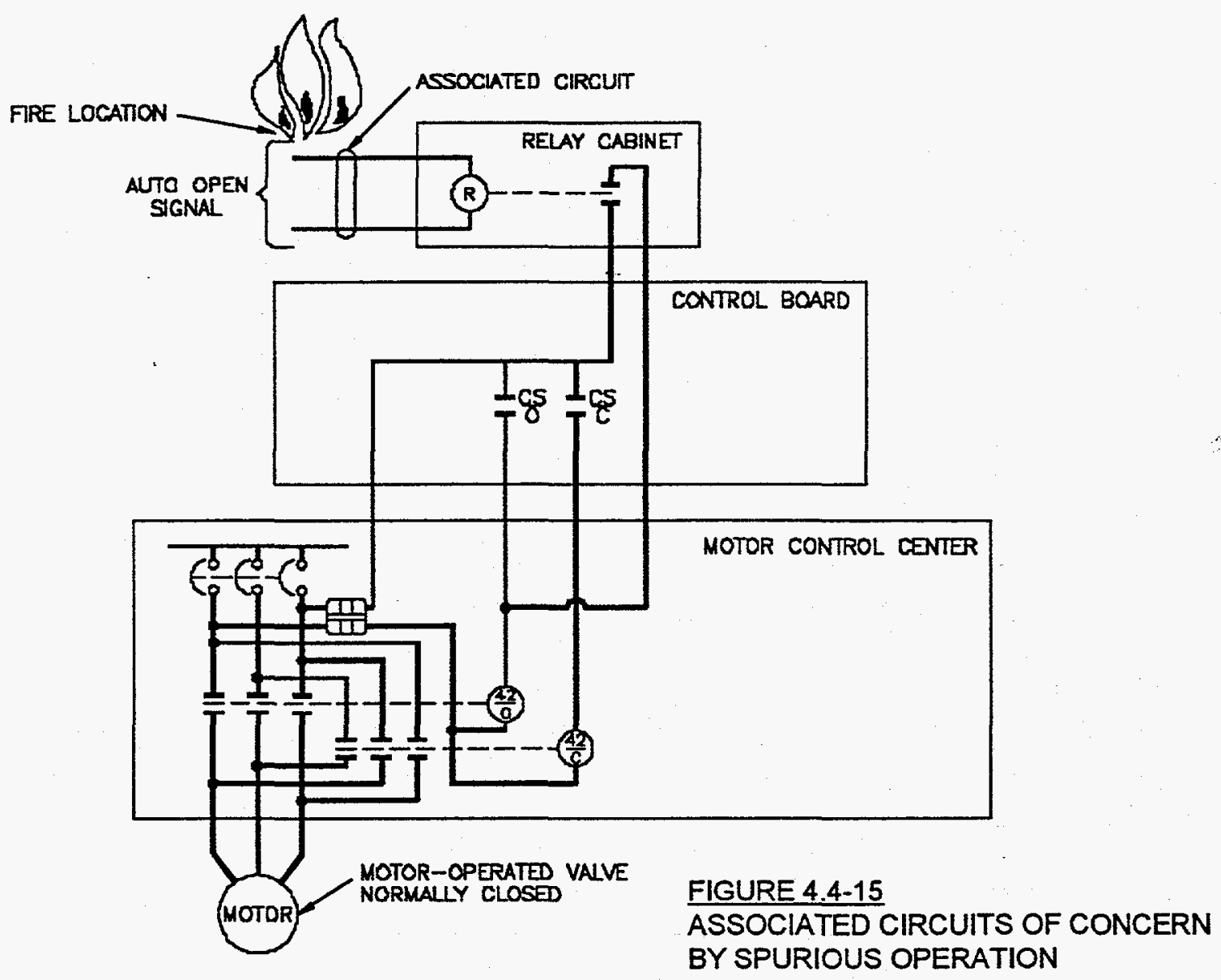


Other potential spurious equipment operations may not require this level of protection, provided it can be demonstrated that the spurious actuation would not have an immediate adverse effect on the safe shutdown capability of the plant. A specific example of this case is a spurious actuation that causes the loss of ventilation in an area containing safe shutdown equipment. If it can be demonstrated that the required equipment will remain operable (i.e., capable of performing its intended function) for a sufficient length of time without ventilation, expensive plant modifications necessary to preclude the spurious operation may not be necessary. In this case, additional procedural guidance that directs operators to perform actions necessary to recover ventilation may be sufficient to ensure the operability of required equipment. In certain cases, analyses have demonstrated that simply opening the doors of the affected area will provide an adequate level of ventilation.

Spurious actuations of equipment may significantly affect the post-fire safe shutdown capability of the plant. Once this problem is identified, appropriate methods of control can be planned. However, it is imperative that the safe shutdown analysis include a thorough evaluation of all plant systems so that potential spurious equipment operations of concern can be properly identified for each compartment/cell. The following assumptions are typically applied during this analysis:

1. The plant is operating with a 100 percent power history (approximately 3 continuous months at 100 percent power) at the time of the fire.

2. All components are in their normal operating condition when the fire-induced spurious signal occurs.

3. Unless cables are protected by acceptable methods, fire-induced damage will occur.

4. The fire-induced cable damage may cause either one or a combination of the possible cable failure modes discussed in Section 4.4.2.4.1.

5. All possible functional failure modes must be considered for components subject to spurious operation. For example:

- Valves may spuriously open or close.

- Valves may fail to reposition on automatic actuation signal or by normal remote operation.

- Circuit breakers may close or trip open.

- Pumps and motors may start or stop. 
- Process instrumentation and control signals may initiate unacceptable automatic operations.

- Process instrumentation may provide erratic or incorrect indications

\subsection{2 Evaluation Methodology}

Cables that are not part of safe shutdown circuits may be damaged by the effects of postulated fires. The cable damage may consequently prevent the correct operation of safe shutdown components or result in the maloperation of equipment that would directly prevent the proper performance of the safe shutdown systems.

A methodology for identifying and evaluating spurious operating equipment is described in the following paragraphs and depicted graphically in Figure 4.4-16. This methodology is based on a systems approach for identifying and resolving spurious operating equipment concerns within each compartment/cell.

1. Select a compartment/cell.

2. Identify the systems relied on to accomplish required shutdown functions.

3. Identify potential spurious components of concern. From a review of system design documents (e.g., flow diagrams, electrical schematics, etc.), identify components whose inadvertent operation could prevent the system from performing its intended shutdown function. This list should include components of non-essential systems whose spurious operation could affect the shutdown capability.

4. For each required system, prepare a list of potential spurious operating equipment of concern.

If a method of protection or mitigation is available, identify this method in the analysis, implement hardware or procedural change as necessary, and go to the next compartment/cell. If not, proceed to step 5 . 


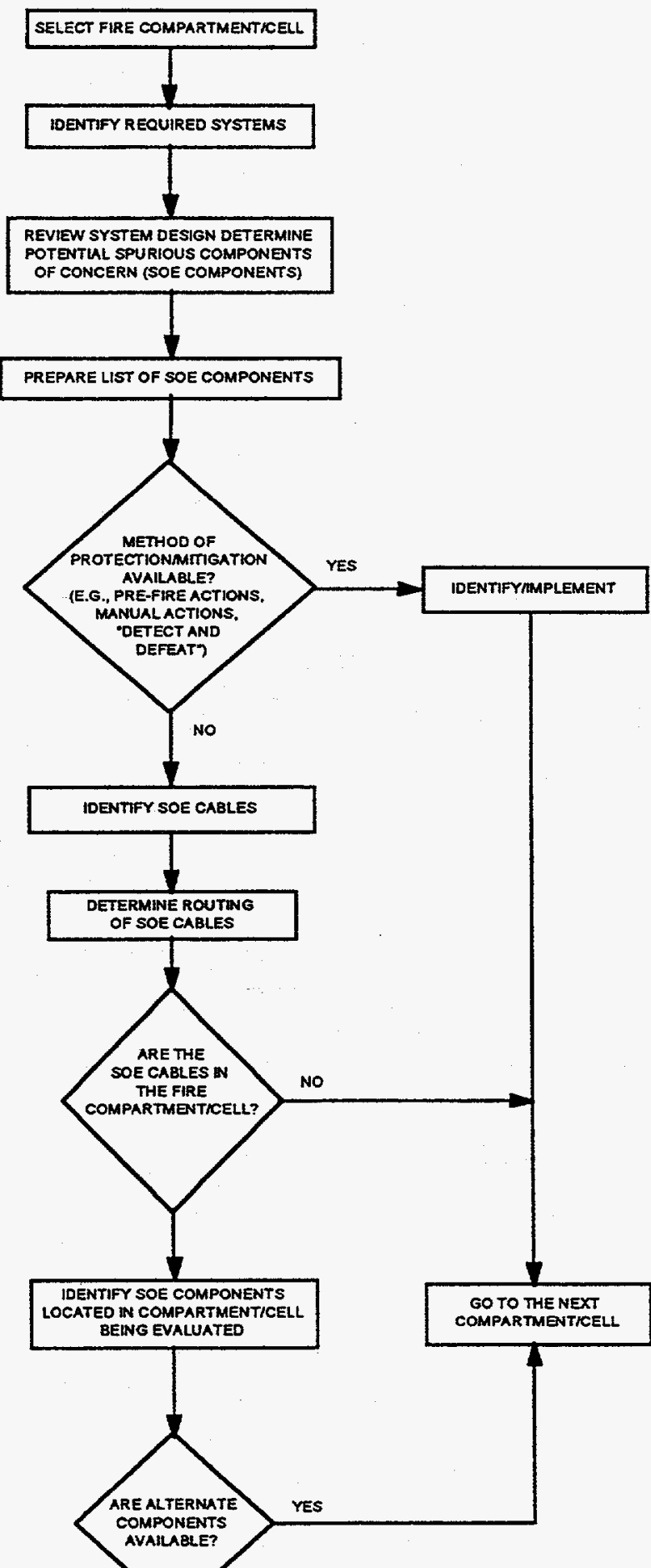

FIGURE 4.4-16

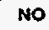


5. Identify cables associated with spurious operating equipment listed in step 4 . This may be done by cross-referencing equipment identifiers (i.e., unique equipment numbers) to wiring diagrams and schematics or by physical plant verification of connected cables.

6. Determine the routing, by compartment/cell, of all spurious operating equipment cables identified in step 5 .

7. Identify spurious operating equipment cables located within the selected compartment/cell.

8. If no spurious operating equipment cables are located in the compartment/cell being evaluated, go to the next compartment/cell.

9. If spurious operating equipment cables are located in the compartment/cell being evaluated, then:

- Identify the spurious operating equipment component(s).

- Determine if a redundant component is available to provide the system function.

- Evaluate the effect of spurious operation on safe shutdown capability. Determine if the spurious actuation(s) can cause the plant to enter an unrecoverable condition such as an uncontrollable loss of reactor coolant inventory. For example, spurious operating equipment components that constitute the isolation boundary between high and low pressure systems (high/low pressure interface boundary) require special consideration as described above. The objective is to provide a level of protection for potential spurious operating equipment appropriate to the consequences of its occurrence.

- Perform a detailed circuit review that demonstrates that fire damage (hot short, open circuit, or short to ground) to the affected spurious operating equipment cable will not cause the equipment to spuriously operate. Record analysis on Exhibit 4.4-1. Refer to Figures 4.4-3 through 4.4-6 for examples.

- Provide additional fire protection features (separation, fire protective wrap, routing in conduit) to prevent fire damage to spurious operating equipment cables. 
- Assume the spurious actuation(s) will occur and:

- Provide a means to "detect and defeat" the spurious actuation. For example, the spurious opening of a discharge valve of a required water storage tank may be detected by level instrumentation and then defeated by manual operator actions to close the affected valve.

- Develop pre-fire actions, such as racking out circuit breakers, to prevent fire-induced spurious operation.

- Develop post-fire actions to defeat the maloperation of equipment before an unrecoverable plant condition is reached. (For example, open breakers or isolation switches to mitigate the spurious operation of air-operated valves, open breakers and manually position motor-operated valves, etc.) Note: The post-fire action must be part of approved emergency operating procedures.

\subsection{Multiple High-Impedance Faults}

\subsection{1 Discussion}

Section 4.4.2.4.3.3.2 presents a method of evaluating the potential effect of bolted (line-to-ground and line-to-line) cable faults on the availability of required power sources. To demonstrate that a required power source will not be affected by fire damage to its connected cabling, nuclear power plants operating in the U.S. must also consider another type of common-mode cable fault condition called multiple high-impedance fault (MHIF). Specifically, this evaluation involves determining the effect of high-impedance (arcing) faults on all cables of a required power supply that may be exposed to fire damage. Figure 4.4-17 provides a graphical representation of this concern.

When a faulted cable is in firm contact with a grounded metallic surface, a bolted low impedance fault will develop, and maximum available fault current will flow through the circuit. This high fault current will be interrupted and cleared by the circuit protective device closest to the fault. However, if the fault contact is not firm or is erratic, an arc will be struck at the contact point between the live conductor(s) and ground. The fault current in this case is low and may not be of sufficient magnitude to trip the protective device. A coordination problem will exist if, instead of multiple simultaneous low level fault currents tripping the downstream breakers closest to each fault, the cumulative effect trips the upstream breaker, causing a loss of power to the entire electrical bus. 
U.S. DEPARTMENT OF ENERGY'S REACTOR CORE

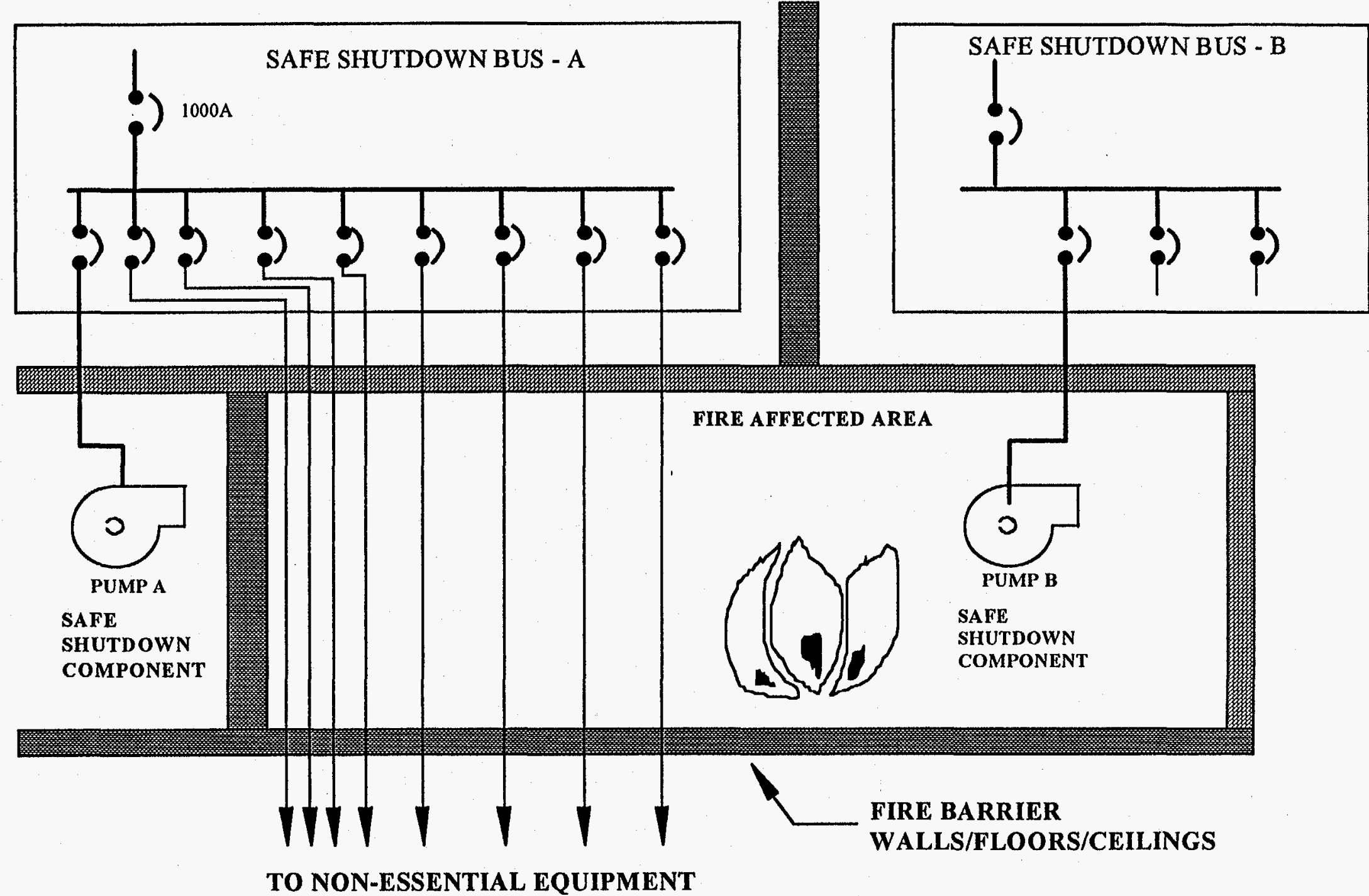

FIGURE 4.4-17

MULTIPLE HIGH IMPEDANCE FAULT CONCERN 
For the example shown in Figure 4.4-7, if a fire occurs in the designated compartment, the Safe Shutdown Analysis (SSA) recognizes that the train B safe shutdown component may not be available due to fire damage, and, therefore, places reliance on the redundant train A components, located in separate fire compartments, to achieve safe shutdown conditions. However, as shown in Figure 4.4-17, a number of non-essential cables that are associated with (connected to) the required train $A$ power source are routed through the fire-affected compartment. Although coordination of the individual load breakers to the train A bus supply breaker may have been demonstrated for bolted faults (i.e., lowimpedance short circuits on the individual load cables will not affect the continuity of service of the required supply), there is a possibility that if a sufficient number of non-essential cables simultaneously fail in a high-impedance (arcing fault) condition, the feed breaker to the required supply may trip on overcurrent prior to a trip of the individual load protective devices. For the example shown in Figure 4.4-17, assume that the individual load breakers have a long-time trip setting of 200 Amperes. Since the feed breaker to the supply is rated at 1000 Amperes, it is possible that if more than five load cables were to simultaneously fail in a highimpedance fault condition (assumed value of 199 Amperes/cable), the upstream breaker to the required supply could trip before the individual protective devices.

\subsection{2 Overview}

Typically in the U. S., the focus of multiple high impedance fault analyses is on high voltage ( $480 \mathrm{~V}$ and above) power supply systems; particularly power supplies for time-critical systems performing a safety function. In the U. S., an event involving multiple high impedance faults is considered to be a low probability event because of the quality of the design of power supply systems (i.e., complete bonding and grounding, use of copper conductors and IEEE qualified cable insulation, circuit breaker designs and coordination schemes, and validating set points). However, the event is analyzed because of the potentially significant consequences of faulted circuits to cause a coordination problem during a fire. For this to happen, there must be simultaneous high impedance faults on multiple cables connected to a safe shutdown power supply. The faulted cables must have specific current magnitudes of fault current and remain at that magnitude for an extended duration (i.e., just below the long-time trip setting of the protective device for 1000 seconds) so that even though the individual magnitudes of current are insufficient to trip the load breakers of each of the faulted circuits connected to the safe shutdown power supply, the collective current is sufficient to cause the supply-side breaker to trip. The potential for this event to occur and the extent to which it is analyzed at Soviet-designed nuclear power plants needs to be determined on a plant-specific basis, considering electrical distribution system and power supply designs and their reaction to dynamic exposure fire conditions. A 
high impedance fault may or may not quickly degrade to a low impedance fault condition, or cable insulation may or may not continue to degrade or be consumed by fire and the resultant bare electrical conductors come in contact with grounded plant structures (cable tray, conduit, structural supports, etc.). Hence the necessity of establishing the existence of adjacent exposed conductors in the same cable tray or conduit or adjacent exposed conductors of other cables, to determine the extent and duration of possible faults. It is possible that low voltage power supply systems (i.e., $208 \mathrm{~V}$ ac and $115 \mathrm{~V} \mathrm{dc}$ ) can be excluded from the analysis if it can be shown that insufficient maximum peak-to-line voltage can be generated to cause an arc restrike on a faulted circuit. Typically, the principal methods for resolving multiple high impedance fault issues are (1) manual operator actions; (2) implementation of protective features based on multiple high impedance fault analysis; and (3) inclusion of the potential for multiple high impedance faults in coordination schemes and studies.

\subsection{3 Emergency Operating Procedures}

Since the multiple high-impedance fault event is considered a low probability event, it could be analyzed and the effects of fire-induced faults could be documented in the Plant Operating Procedures. A note could be added to the Procedures indicating that in the event of a fire, if a safe shutdown power supply required to achieve safe shutdown for a specific fire cell tripped unexpectedly, an operator must go to the specific safe shutdown power supply, trip all non-safe shutdown circuits (associated circuits) established for that given fire cell, and reset the incoming breaker or replace the fuse as necessary. This action would ensure that associated circuits that may be subjected to high-impedance faults are isolated so that power to the safe shutdown power supply can be restored. The action of tripping all non-safe shutdown circuits should be used as an operator action of last resort and should be governed by strict adherence to emergency operating procedures.

\subsection{4 Evaluation Methodology}

Alternatively, each safe shutdown power supply could be analyzed for a multiple high-impedance fault. Two different analytical approaches can be used to identify and resolve multiple high-impedance fault issues. They are classified as a generic approach or a fire-compartment approach and are discussed below. For the purpose of performing this analysis, the following assumptions are applicable:

- The high-impedance fault (HIF) current of each cable that may be exposed to fire damage is of a value just below the trip point setting of the individual protective device for the load. 
- All unprotected load cables of the power supply being evaluated that are located within the zone of influence of the fire (e.g., located in the same fire cell) are assumed to simultaneously fault to the HIF condition.

\subsection{4.1 Generic Approach}

1. Identify required power safe shutdown equipment supplies.

2. Assume that all non-essential cables connected to the required supply will be affected by multiple high-impedance faults, then either:

a. Demonstrate that adequate margin exists between the feed breaker and load breaker trip points so that the feed breaker to the supply will not trip even if all potentially affected cables (associated circuits) fail simultaneously. (For example: Assume that each connected associated circuit develops a high-impedance fault due to a fire, and the fault current is just below the long-term setting of its respective protective device. If each load breaker that protects the 8 associated circuits is rated at 70 Amperes and the safe shutdown circuit component A breaker is rated at 100 Amperes, as shown on Figure 4.4-17, then perform the following steps: 1) Add all of the load amperages at the bus ( 8 breakers $x 70$ Amperes plus 100 Amperes $=660$ Amperes); 2) Determine if 660 Amperes continuous current will trip the upstream breaker. In this example the upstream breaker is rated 1000 Amperes and would not trip. Thus the safe shutdown power supply would be available to perform its intended function).

OR

b. Develop post-fire emergency operating procedures that direct operators to strip non-essential loads from potentially affected power sources.

\subsection{4.2 Fire-Compartment Approach}

1. Select compartment/cell.

2. Identify available shutdown paths.

3. Select an available shutdown path.

4. Identify required power supplies.

5. Select a required power supply for detailed evaluation. 
6. Identify all non-essential load cables connected to the supply.

7. Identify the routing of the non-essential load cables by compartment/cell.

8. Determine the specific number of non-essential load cables that may be affected by a single fire in the selected compartment/cell.

9. Evaluate the effects of multiple high-impedance faults on the actual number of cables that could be affected as a result of fire in the selected compartment/cell.

10. If multiple high-impedance faults could cause a loss of the required supply, then:

a. Assume that the selected shutdown path will be affected by multiple highimpedance faults and select another available path(s) for evaluation (go to step 2).

OR

b. Modify the trip-settings of the upstream feed breaker to the supply. OR

c. Identify the maximum number of multiple high-impedance faults that may be experienced by the supply without causing an interruption of service and either:

1. Identify the minimum number of loads that must be shed and develop emergency operating procedures

OR

2. Reroute the minimum number of cables out of the compartment/cell.

OR

3. Provide fire protection (fire-barrier wrap) for critical circuits.

\subsubsection{EXAMPLE OF THE SELECTION PROCESS}

4.4.3.1 The following example outlines the evaluation process described in Section 4.4.2 and is to be applied to complete Exhibit 4.4-1. Figure 4.4-1 is provided as an example system to demonstrate the selection process that should be used to 
identify components, support components, piping, and circuits to be included in the analysis. The example system's function is to maintain reactor level, at low pressure, by taking suction from the tank and injecting water into the reactor through valve $\mathrm{V} 10$.

4.4.3.2 Refer to Figure 4.4-1. Pump P1 takes suction from the tank and discharges through a heat exchanger to the reactor. The heat exchanger is cooled by cooling water. There is a fire water connection to the system that is isolated by two locked closed gate valves (V7 and V8), and there is a connection to allow system drainage to the main condenser through a normally closed motor-operated gate valve (V9). There are also tank drain and system vent and drain connections, each isolated by normally closed valves (V11, V5, and V6). A normally closed motor-operated gate valve is provided to drain the tank to the main condenser (V12).

Several interlocks are associated with the system, as follows:

Valve V10 is interlocked with reactor pressure such that it will not open if the reactor pressure is above a selected value. V10 will also not open unless pump $\mathbf{P} 1$ is running.

Pump P1 is interlocked with reactor level. The pump will start on low level and stop on high level.

Valve V4 is the pump minimum flow valve. It is normally open. When pump P1 starts, V4 will remain open until a preestablished flow rate is measured through the flow transmitter (FT). This prevents the pump from operating below its minimum flow rate.

Several control room indications are provided, as follows:

Pump running indication (HIS)

System flow (FI)

Reactor pressure indication (PI)

Reactor water level indication (LI)

Valve position for the motor-operated valves (lights on the hand switch)

4.4.3.3 All system components must be reviewed to understand the impact of a fire and to determine whether they are necessary in order for the system to provide its safe shutdown or support function. Exhibit 4.4-2 can be used to document this evaluation. The following is an example based on the system shown as Figure 4.4- 
1. The explanation provided for each component is typical of the type of explanation that can be documented on Exhibit 4.4-2.

Tank: The tank is a safe shutdown component since it is the source of water for the system. The area around the tank must be evaluated to ensure that fire damage would not cause the tank to fail. System operating characteristics (time required and flows) must be considered in determining the requirements for the tank. Tank failure modes to be considered are basically those involving the maintenance of tank integrity.

Valve V1: Valve V1 would not be included since it is a normally open manual valve, and equipment is assumed to be in its normal operating position at the onset of a fire. Therefore, the failure of this valve would not prevent the tank from providing water to the system. Manual valves are assumed to fail in the "as is" position.

Pump P1: Pump P1 would be included since it is the pump that injects the water into the reactor. In addition, the power and control cables that are required to ensure that the pump will start and stop as required must be included. Cables required to power pump running indication are not required because there are other ways to determine that the pump is running. If the indication circuit is not included, however, a through review of the circuit must be completed to demonstrate that its failure would not prevent the pump from operating. The pump failure modes to be considered in the event of a fire are "RUN" or "Not RUN."

Valve V2: Valve V2 would not be included since it is a check valve and no firerelated failures would prevent it from operating. Failure modes for a check valve as the result of a fire are not considered.

Valve V3: Valve V3 is a motor-operated valve that is normally open and is not required to change position for the system to operate. This valve would be included on the list because a fire-induced fault could cause the valve to close, preventing the system from injecting water into the reactor. The power and control circuits for this valve would be reviewed, and the control circuits that could cause the valve to close would be included and, if necessary, fully protected. In this case, there would be no need to include the power cables since the valve is normally open and the required position is open. The operating requirements for the system would be reviewed, and removing power from the valve during operations should be considered. If power is removed by procedure during power operation, there would be no need to include the power or control circuits on the list. Another option would be to consider an operator action to remove power and manually open the valve if a fire-induced fault could cause the valve to close. 
Operator actions must be evaluated to ensure that they can reasonably be accomplished within the time available. In this example, it is assumed that power would be removed by procedure. Failure modes to be considered for a power operated valve are:

- Loss of motive power: The valve fails "as is."

- Loss of control power: The valve fails "as is."

- Control power fault: A circuit analysis considering the faults presented in Section 4.4.2.4.1 must be completed to determine the effect on the valve. It could go open, go closed, and/or modulate, depending on the type of fault experienced.

- Instrumentation signal fault: A circuit analysis considering the faults presented in Section 4.4.2.4.1 must be completed to determine the effect on the valve. It could go open, go closed, and/or modulate, depending on the type of fault experienced.

Flow transmitter (FT): The flow transmitter and its associated circuits would be included since it is required to control the position of the pump minimum flow valve (V4) and provide a signal to the flow indicator for required operator information. Failure modes to be considered include the transmission of the correct signal, no signal, or an erroneous signal, depending-on the type of electrical fault experienced. Again, a circuit analysis considering the faults presented in Section 4.4.2.4.1 must be completed.

Flow Indicator (FI): The flow indicator and related circuits provide system flow indication to the operators. They would not be included unless their failure could prevent minimum flow valve V4 from operating properly or if it is essential to provide the operator with system flow indication. The plant operators would determine if they must have this indication. In this case, the system is required to maintain reactor level, and reactor level indication is also provided. Since the ultimate goal of the system is to maintain reactor level, the level indication is the most appropriate system diagnostic information to maintain. System flow would be a redundant indication and as such would not be included. The failure modes that need to be considered are loss of or erroneous indication to the operator. In some cases, flow indicators also provide some automatic control functions. In these cases, failure modes presented for flow transmitters must also be considered.

Valve V4: Valve V4 is the pump minimum flow valve. This valve could be either open or closed depending on the flow from the pump. It would be included since its operation is required to prevent pump damage due to low flow. The pump 
starts on reactor low level, but valve V10 will not open until the reactor pressure is at a preset low pressure; therefore, the pump could be running with V10 closed, which could damage the pump. Valve V4 would open and permit sufficient flow to protect the pump. This valve could also have a fire-induced fault, causing it to prematurely fail closed, resulting in pump damage, or causing it to fail open and reduce the flow to the reactor. In order to accept this failure, an analysis would have to demonstrate that this reduction in flow to the reactor would be acceptable. If time is sufficient, it may be possible, during a fire, to station an operator at the valve to manually operate it. For the purpose of this example, it is assumed that the automatic controls are required. The failure modes provided above for power operated valves must be considered.

Heat Exchanger: This component would not be included because it is a passive component and no fire-related failures could cause it to malfunction. Note that any instrumentation on the heat exchanger that the plant operators determine they need would be included, along with the circuits that power the instruments. The cooling water system would be included as a support system. Since the heat exchanger is a passive device, no failure modes need to be considered.

Vent and Drain valves: V5, V6, and V11 are normally closed manual vent and drain valves. These valves would not be included since no fire-related failures could cause them to open. The failure modes presented above for manual valves should be considered for vents and drains.

Valves V7 and V8: These are normally closed, locked closed fire water cross tie valves. They would not be included on the list because no fire-related failures could cause the valves to open. This flow path needs to be considered as an alternate flow path to the reactor if the pump is lost. Manual actions would be required to open the valves to support water injection to the reactor from the fire water system. Note that V7 and V8 are locked closed; therefore, any manual actions would require that the keys for the valves would be available to the operator. The failure modes presented above for manual valves should be considered for these manual valves.

Valve V9: Valve V9 is a valve that can be used to divert flow to the main condenser. During a fire this valve must remain closed to prevent diverting injection flow from the reactor. Similar to valve V3, only the control circuits must be examined for inclusion, since valve V9 is normally in the desired position (in this case, closed) and must remain in that position. In this case, the opening circuits must be analyzed to ensure that no fire-related failure could cause V9 to open. If this flow path is infrequently used, removing power from this valve may be an option. If power is removed during power operation, the power and control circuits would not require analysis, since no fire-related failure could cause the 
valve to open, and valve V9 could be excluded from the list. If operator action time is available and the system operating parameters permit, procedures could be developed to remove power from V9 and manually close it during a fire if it spuriously opened. For purposes of this example, it has been assumed that power has not been removed. The failure modes provided above for power-operated valves must be considered.

Valve V10: V10 is the reactor injection valve and would be included on the list. The power and control circuits for V10 would also be included on the list. This valve is interlocked so that it will not open unless the pump is running and the reactor pressure is below a set value. All circuits required for these controls must be included. Note, if the piping of the injection system could be damaged by valve V10 opening with the reactor at high pressure, then provisions must be made to ensure that no single fire-related failure could cause the valve to go open. In the case of this example system, positive controls to prevent spurious actuation or an additional motor-operated valve with independent controls would have to be added. In U.S.-designed plants this is termed a high/low pressure boundary, and a second motor-operated valve with independent controls would be required. The design would have to ensure that a single fire with multiple failures postulated would not cause both valves to open. The failure modes provided above for power-operated valves must be considered.

Valve V12: Valve V12 is a motor-operated drain valve to the main condenser. It is a normally closed valve that must remain closed to prevent inventory loss to the main condenser. The power circuits do not need to be included since the valve is normally closed and will fail in that position upon loss of power. The control circuits would require review to ensure that no fire-induced fault would cause the valve to go open. As an option, motive and control power could be removed from the valve or, if time permits, operator actions could be established to remove power from the valve and manually close it if a fire-induced fault caused the valve to open. If manual actions are used, sufficient indication must be available to the operator to reasonably permit the operator action before the tank is drained to an unacceptably low level. For the purpose of this example, it is assumed that power is removed. The failure modes provided above for power-operated valves must be considered.

Level Transmitter (LT): The level transmitter measures the reactor level and provides a signal to start and stop pump P1. It also provides a signal to the level indicator for operator indication. The circuits for this instrument would be included on the list. Failure modes to be considered include the transmission of the correct signal, no signal, or an erroneous signal, depending on the type of electrical 
fault experienced. Again, a circuit analysis considering the faults presented in Section 4.4.2.4.1 must be completed.

Level Indicator (LD): The level indicator provides the operator with level indication in the reactor and should be included. The failure modes that need to be considered are loss of or erroneous indication to the operator. In some cases, level indicators also provide some automatic control functions. In these cases, failure modes presented for flow transmitters must also be considered,

Pressure Transmitter (PT): The pressure transmitter measures the reactor pressure and sends a signal to the control circuits for valve V10, permitting it to open when the pressure is below a preset value. The circuits for this instrument would be included on the list. Failure modes to be considered include the transmission of the correct signal, no signal, or an erroneous signal, depending on the type of electrical fault experienced. Again, a circuit analysis considering the faults presented in Section 4.4.2.4.1 must be completed.

Pressure Indicator (PI): The pressure indicator provides operator indication of the reactor pressure and should be included unless the plant operator determines it is not required. It should be noted that the plant operators must make the final determination of the minimum process indications required to safely operate a system. The failure modes that need to be considered are loss of or erroneous indication to the operator. In some cases, pressure indicators also provide some automatic control functions. In these cases, failure modes presented for pressure transmitters must also be considered,

Figure 4.4-2 is provided as an example of the system with only those components that must be included in the program. For this example, it is assumed that power is removed from V3 and V12 but not from V9.

The cooling water system for the heat exchanger and the fire water systems would be analyzed as separate systems.

\subsubsection{SHUTDOWN PATH IDENTIFICATION}

To ensure that a safe shutdown path is available in the event of a fire, each fire compartment and fire cell must be evaluated to determine which other equipment in the plant is capable of bringing the plant to, and maintaining it in, a safe shutdown condition, assuming the loss of all equipment in the cell being evaluated. This step is important since it will identify several safe shutdown paths that may be used for this purpose. A shutdown path is a set of systems lined up in such a way as to provide all the safe shutdown functions identified in Section 4.2 for all operating conditions that may be experienced while reaching and maintaining safe 
shutdown. Defining specific shutdown paths is necessary for the completion of Section 4.11 of this methodology, which provides a shutdown evaluation for each fire compartment/fire cell.

The process detailed below and shown on Figure 4.4-18 suggests that three shutdown paths be identified for each fire compartment/cell. There may be a need to identify several additional shutdown paths as the result of the analyses completed in Section 4.11. A system or support system could be used as part of several different shutdown paths. The process detailed above can be used to identify any additional path needed.

4.4.4.1 The analyst, using the safe shutdown equipment functions identified on Exhibit 4.3-1, selects as many sets of equipment as possible to provide the safe shutdown functions. In order for a set of equipment to be considered a viable shutdown path, it must satisfy all safe shutdown functions identified in Section 4.3. This evaluation must consider all process operating conditions expected to reach and maintain a safe shutdown condition. Exhibit 4.4-6 has been used to identify the systems available and the safe shutdown functions they perform.

4.4.4.2 Select the first path. This selection should be that set of equipment that would normally be used to achieve and maintain safe shutdown. It must be verified that the safe shutdown functions are supported for all operating conditions and temperatures expected during the shutdown process and to maintain a safe shutdown condition. This set of systems should be designated as Path A, and the appropriate columns should be completed on Exhibit 4.4-6.

4.4.4.3 Select support systems for the Path A safe shutdown equipment. Exhibit 4.3-1 should be used as an aid during this selection process. This set of systems should be listed in the space provided on Exhibit 4.4-6. 


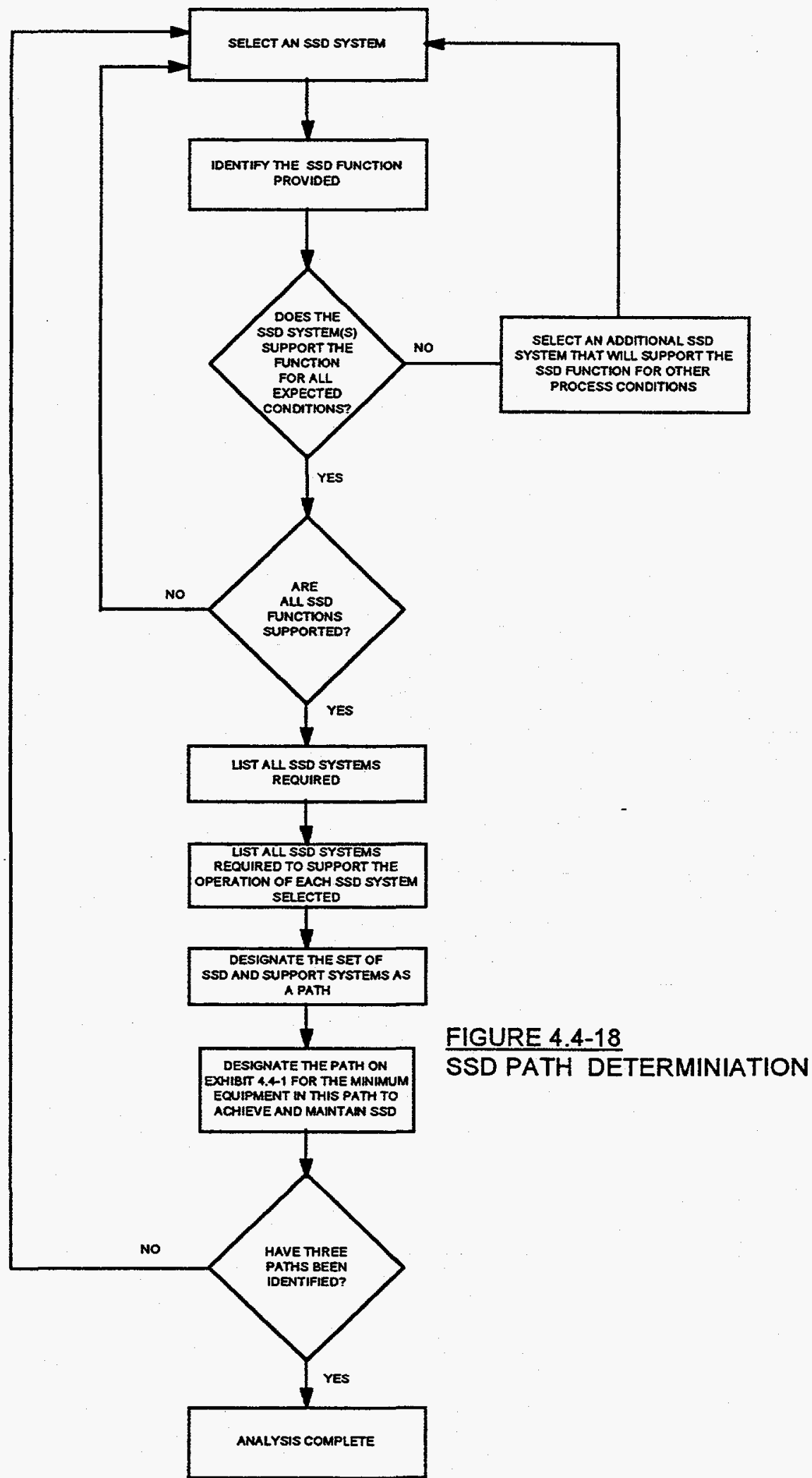




\section{U.S. DEPARTMENT OF ENERGY'S REACTOR CORE \\ PROTECTION EVALUATION METHODOLOGY FOR FIRES AT \\ SOVIET-DESIGNED RBMK AND VVER NUCLEAR POWER PLANTS}

4.4.4.4 Select the second path. This selection should be that set of equipment that would be the alternate to the set of equipment normally used to achieve and maintain safe shutdown. It must be verified that the safe shutdown functions are supported for all operating pressures and temperatures expected during the processes of shutting down and of maintaining a safe shutdown condition. This set of equipment should be designated as Path $\mathrm{B}$, and the appropriate columns should be completed on a new copy of Exhibit 4.4-6.

4.4.4.5 Select support systems for the Path B safe shutdown equipment and complete the appropriate columns on Exhibit 4.4-6.

4.4.4.6 Using the process discussed above, select one additional path of safe shutdown and support equipment and designate it as Path $\mathrm{C}$. The designation of three paths should be sufficient to achieve and maintain safe shutdown, but it should be noted that additional, alternate equipment may need to be selected during the fire-cell-byfire-cell evaluation that will be completed in Section 4.11. Additional paths may be selected if necessary to resolve identified fire vulnerabilities. Complete the appropriate columns on a new Exhibit 4.4-6.

4.4.4.7 Using Exhibit 4.4-1 indicate in the PATH NO. (path number) column what safe shutdown path each piece of equipment is associated with. This information will be used in Section 4.11 to determine which shutdown path will be used in a given fire cell.

4.4.4.8 If no path can be identified for a given fire compartment/cell, then alternatives discussed in Appendix A should be evaluated or the use of a dedicated shutdown system should be considered. 


\section{EXHIBIT 4.4-1}

SYSTEM:

SAFE SHUTDOWN EQUIPMENT WORKSHEET

SYSTEM DESIGNATOR:

IS THIS SYSTEM A SUPPORT SYSTEM? YES NO IF YES, WHICH SYSTEM(S) DOES IT SUPPORT?

MODE OF OPERATION: 1

2.

3.

4.

\begin{tabular}{|c|c|c|c|c|c|c|c|c|c|c|c|c|}
\hline $\begin{array}{c}\text { PATH } \\
\text { No. }\end{array}$ & $\begin{array}{l}\text { SYS. } \\
\text { MODE }\end{array}$ & \begin{tabular}{|l|} 
EQUIPMENT \\
DENTIFIER
\end{tabular} & $\begin{array}{l}\text { COMP. } \\
\text { DESC. }\end{array}$ & SSD FUNCTION & $\begin{array}{l}\text { DWG. } \\
\text { REF. }\end{array}$ & $\begin{array}{c}\text { NORM. } \\
\text { POS. }\end{array}$ & $\begin{array}{l}\text { SSD } \\
\text { POS. }\end{array}$ & $\begin{array}{l}\text { PLANT } \\
\text { LOCAT. }\end{array}$ & $\begin{array}{c}\text { FIRE } \\
\text { COMPT. }\end{array}$ & $\begin{array}{c}\text { PWR } \\
\text { SUPPLY } \\
\end{array}$ & $\begin{array}{l}\text { FIRE } \\
\text { CELL } \\
\end{array}$ & NOTES \\
\hline & & & & & & & & & & & & \\
\hline & & & & & & & & & & & & \\
\hline & & & & & & & & & & & & \\
\hline & & & & & & & & & & & & \\
\hline & & & & & & & & & & & & \\
\hline & & & & & & & & & & & & \\
\hline & & & & & & & & & & & & \\
\hline & & & & & & & & & & & & \\
\hline
\end{tabular}


U.S. DEPARTMENT OF ENERGY'S REACTOR CORE

PROTECTION EVALUATION METHODOLOGY FOR FIRES AT

SOVIET-DESIGNED RBMK AND VVER NUCLEAR POWER PLANTS

EXHIBIT 4.4-2

SAFE SHUTDOWN COMPONENT WORKSHEET

COMPONENT:

NORMAL POSTTION:

REQUIRED POSITION FOR A FIRE:

INCLUDED ON SAFE SHUTDOWN EQUTPMENT LIST (EXHIBIT 4.4-1) YES NO

BASIS FOR ABOVE: 


\section{EXEIBIT 4.4-3}

\section{SAFE SHUTDOWN CABLE WORKSHEET}

COMPONENT:

SSD POSITION:

CABLE NO:

POWER SUPPLY:

SCHEME NUMBER:

REF. DWG.

CABLE FUNCTION:

ISOLATION DEVICE: YES

CABLE LOCATION KNOWN: Y YES

NO

NO

(If NO, Refer to Section 4.8)

TYPE OF POTENTIAL FAILURE:

SHORT CIRCUIT

OPEN CIRCUIT

SHORT TO GROUND

HOT SHORT
YES

YES

YES

YES
NO NO

NO

NO

ANALYSIS:

EFFECT OF FAIIURE(S):

PROTECTION REQUIRED:

YES

NO

COMPENSATORY ACTION POSSIBLE: YES

NO

SUGGESTED RESOLUTION: 
U.S. DEPARTMENT OF ENERGY'S REACTOR CORE

PROTECTION EVALUATION METHODOLOGY FOR FIRES AT

SOVIET-DESIGNED RBMK AND VVER NUCLEAR POWER PLANTS

Exhibit 4.4-4

INPUT DATA FOR SELECTIVE COORDINATION STUDY

SAFE SHUTDOWN POWER SUPPLY DESIGNATION:

AVAILABLE SHORT-CIRCUTT CURRENT:

\begin{tabular}{|l|l|l|l|}
\hline $\begin{array}{c}\text { Associated } \\
\text { Circuit } \\
\text { Number }\end{array}$ & $\begin{array}{c}\text { Protective Device } \\
\text { Manufacturer/Model } \\
\text { Number }\end{array}$ & Rating/Setting & Remarks \\
\hline & & & \\
\hline & & & \\
\hline & & & \\
\hline & & & \\
\hline & & & \\
\hline & & & \\
\hline & & & \\
\hline & & & \\
\hline & & & \\
\hline
\end{tabular}


Exhibit 4.4-5

COORDINATION STUDY SUMMARY

\begin{tabular}{|l|l|l|l|l|}
\hline $\begin{array}{c}\text { Associated Circuit } \\
\text { Number }\end{array}$ & $\begin{array}{c}\text { Applicable } \\
\text { Figure Number }\end{array}$ & $\begin{array}{c}\text { Coordinate } \\
\text { Yes/No }\end{array}$ & $\begin{array}{c}\text { Recommended } \\
\text { Action }\end{array}$ & Final Action \\
\hline & & & & \\
\hline & & & & \\
\hline & & & & \\
\hline & & & & \\
\hline & & & & \\
\hline & & & & \\
\hline & & & & \\
\hline & & & & \\
\hline & & & & \\
\hline & & & & \\
\hline
\end{tabular}


U.S. DEPARTMENT OF ENERGY'S REACTOR CORE

PROTECTION EVALUATION METHODOLOGY FOR FIRES AT

SOVIET-DESIGNED RBMK AND VVER NUCLEAR POWER PLANTS

.

EXHIBIT 4.4-6

SAFE SHUTDOWN PATH IDENTIFICATION WORKSHEET

SHUTDOWN PATH:

\begin{tabular}{|l|l|}
\hline SAFE SHUTDOWN SYSTEM & SAFE SHUTDOWN FUNCTION \\
\hline & \\
\hline & \\
\hline & \\
\hline & \\
\hline & \\
\hline
\end{tabular}

DISCUSSION:

\begin{tabular}{|l|l|}
\hline SUPPORT SYSTEMS & FUNCTION \\
\hline & \\
\hline & \\
\hline & \\
\hline & \\
\hline & \\
\hline
\end{tabular}

\section{DISCUSSION:}



LOGIC DIAGRAMS

\section{CODED DRAWINGS}

4.5.1.1 Use design documentation such as system descriptions, system drawings, and procedures for each safe shutdown system to determine which system modes (lineups) will accomplish each of the safe shutdown functions that are checked in the SAFE SHUTDOWN FUNCTION PROVIDED column of Exhibit 4.3-1. A system may provide more than one safe shutdown function, in which case more than one system line-up must be considered. In addition, each system could have more than one line-up that could support a given safety function. Each of these lineups should be considered. Figure 4.5-1 shows the process by which this step is completed.

4.5.1.2 On the system piping or P\&ID drawings for each system identified as a safe shutdown system, use a unique identifier to mark each shutdown path that can potentially be available to support safe shutdown. These drawings will be used in Section 4.4 to identify safe shutdown components.

\section{SAFETY SEQUENCE LOGIC DIAGRAM PREPARATION}

This process (see Figure 4.5-2) will be completed at the same time as the processes outlined throughout Section 4.0 of this Methodology. The purpose of a safety sequence logic diagram (SSLD) is to illustrate the logic associated with using various success paths to achieve safe shutdown.

SSLDs provide a visual presentation of the shutdown logic interfaces between equipment and controls. The goal is to have a graphical tool that allows the plant operators to quickly see what equipment and variables are necessary to safely shut down the plant.

The SSLD shows the interrelationships among systems and functions; Figure 4.5-3 provides a conceptual SSLD. For each of the main functions shown on the top of the SSLD, the available success paths are shown. On the left side of the diagram, the set of supporting functions needed to ensure a success path are displayed. The logical AND and OR gate model defines the relationships, while the solid nodes (i.e., dots) at the intersection of lines indicate which system/functions are required to achieve the desired outcome. By proceeding through the logic gates and tracing the lines connecting the systems and functions on the SSLD, paths for achieving successful outcomes are determined. Figure $4.5-4$ provides the rules for navigating the SSLD. 


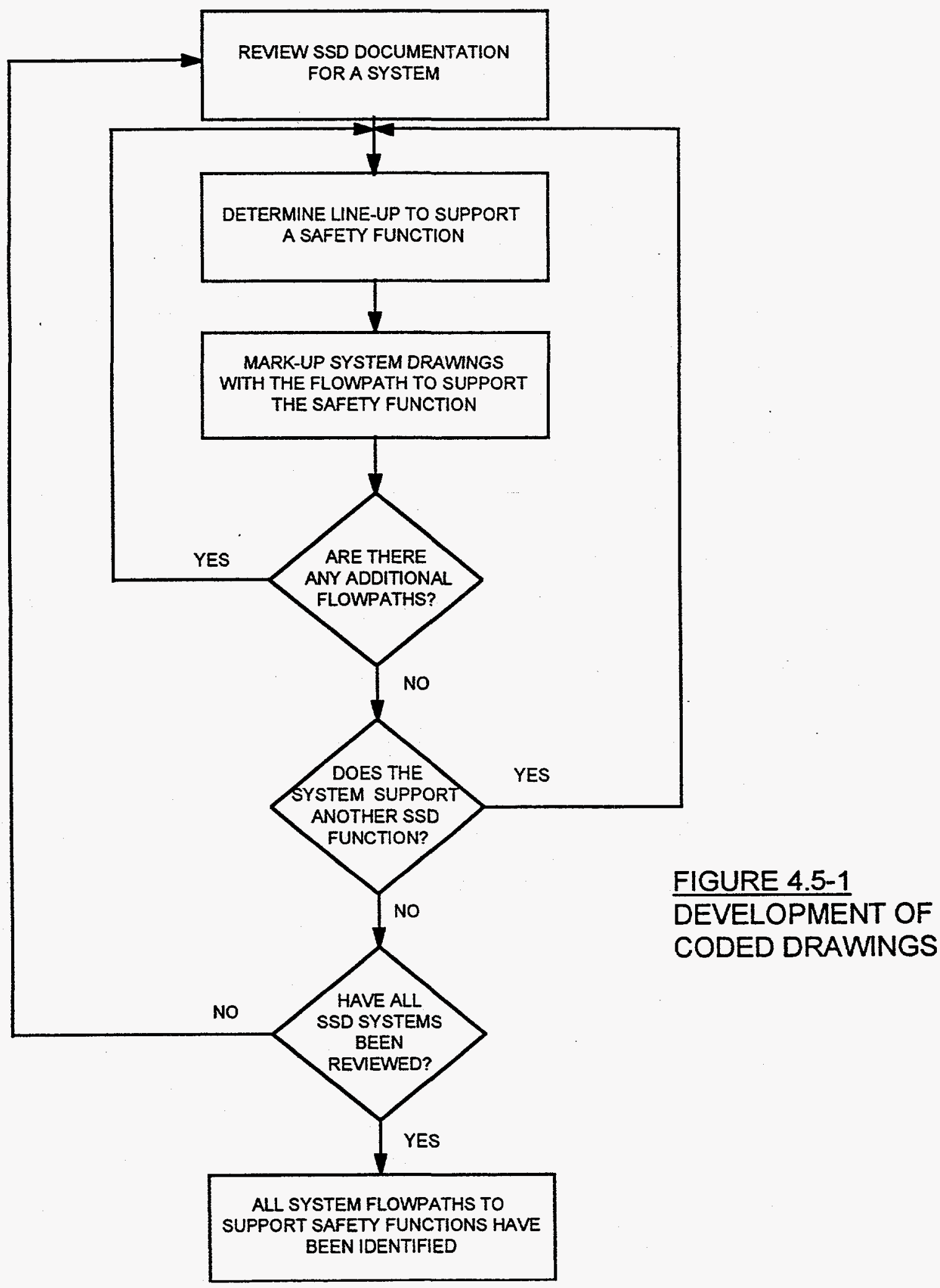




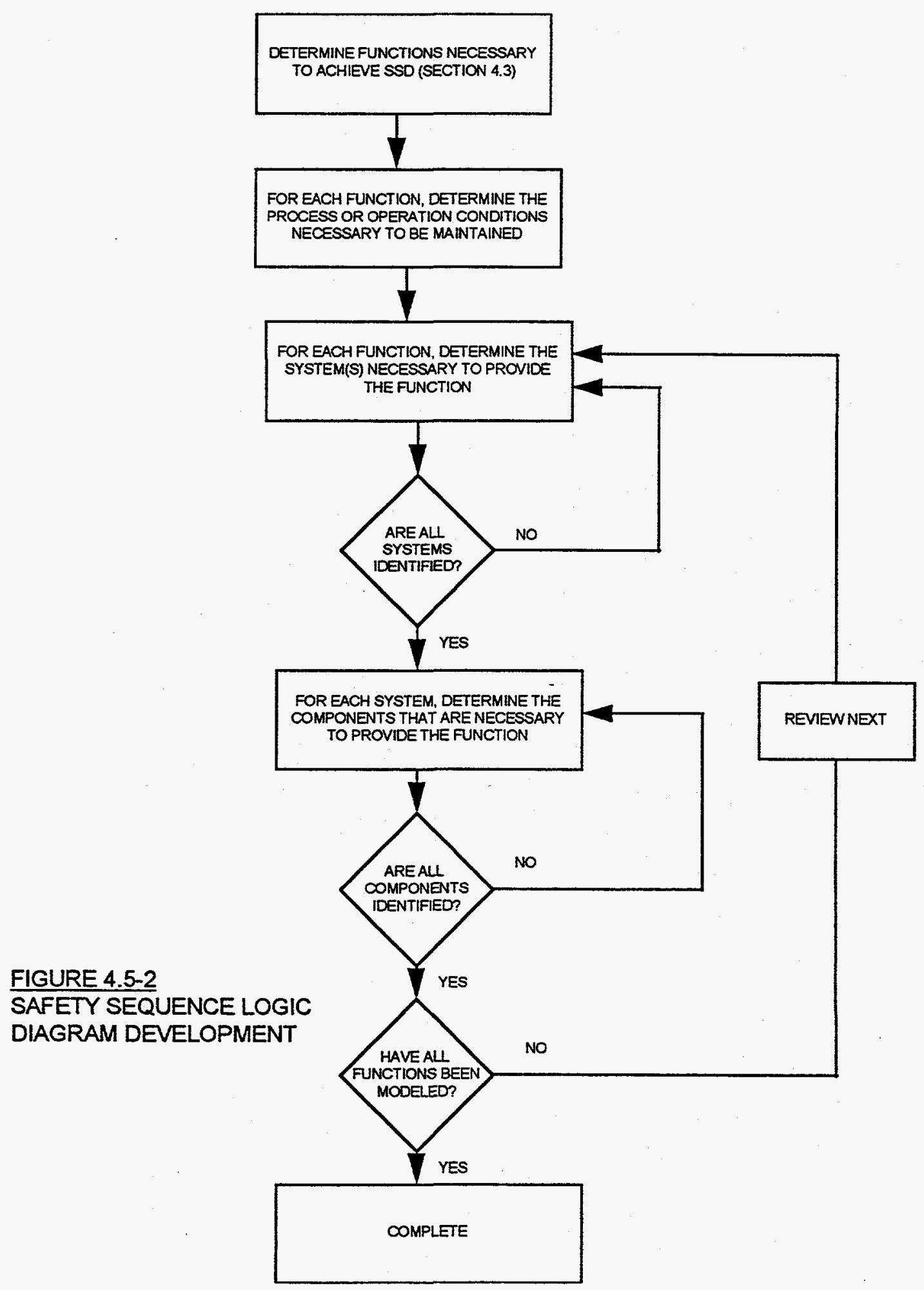




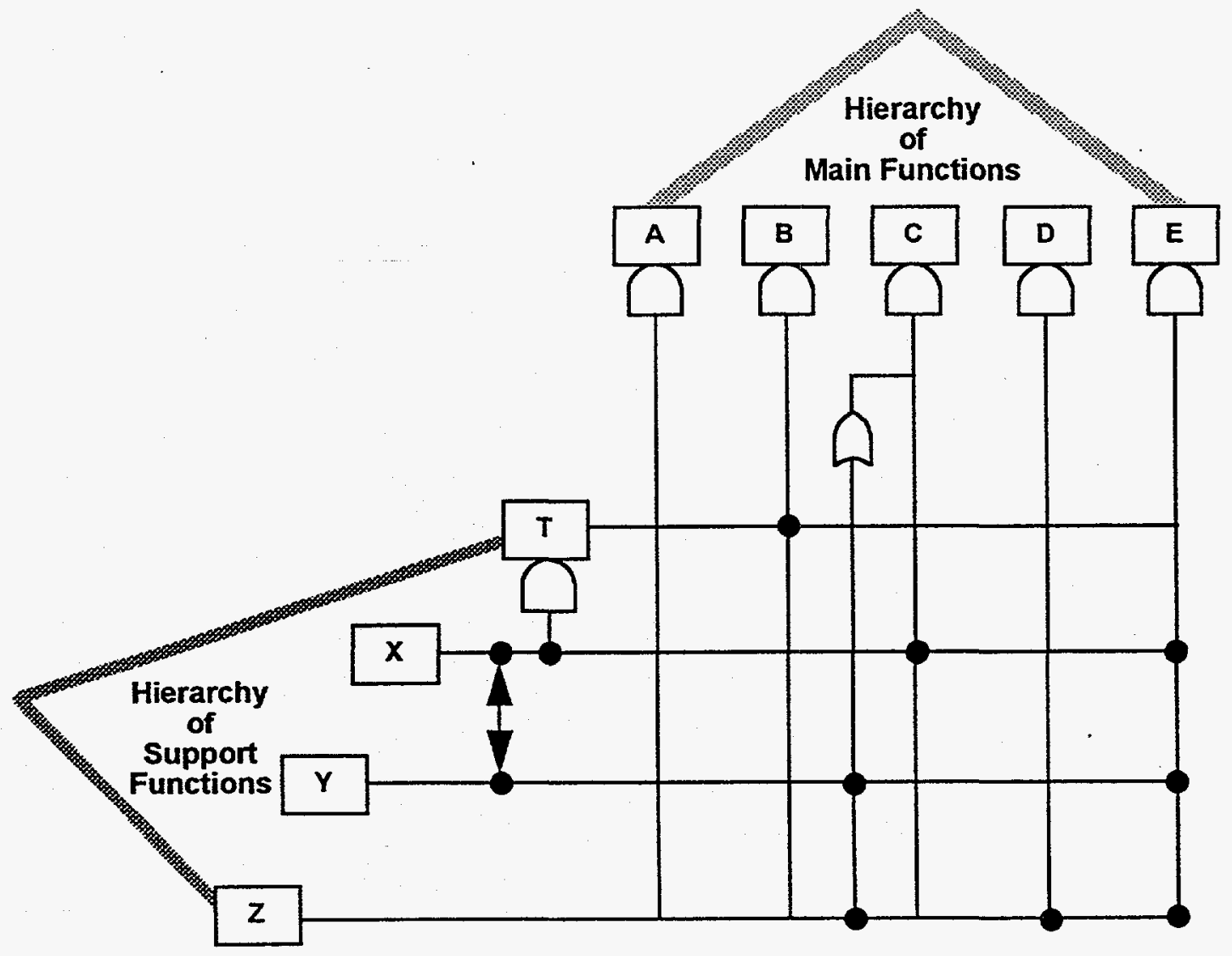

Figure 4.5-3

A CONCEPTUAL SSLD 


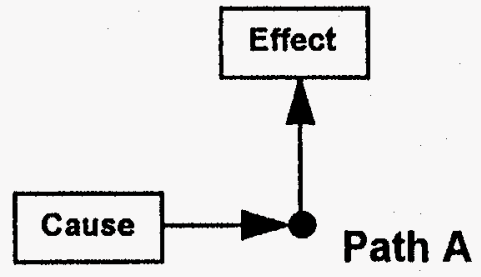

To determine the effect of a node failure, follow the failure from left to right and from bottom to top.

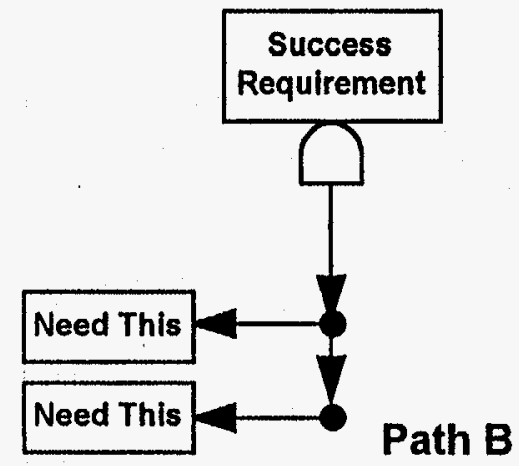

To determine success requirements of a node, follow the node down from the top and the point(s) of dependency and follow from right to left.

$$
\begin{aligned}
& \text { And }-\square \\
& \text { Or- } \square
\end{aligned}
$$

Logical gates are used to model the system/ component relationships.

Figure 4.5-4

RULES FOR NAVIGATING THROUGH SSLD 
Stepping through Figure 4.5-3, the interrelationships of the systems/functions can be determined:

- Item A functions regardless of the status of Items T, X, Y, or Z.

- Failure of Item $\mathrm{X}$ results in failure of Item $\mathrm{Y}$, and vice versa.

- Item $\mathrm{T}$ is functional if Items $\mathrm{X}$ and $\mathrm{Y}$ are functional.

- Item B's success requires Item $\mathrm{T}$ to function, which requires Item $\mathrm{X}$ to function, which also requires Item $\mathrm{Y}$ to correctly function.

- Item $\mathrm{C}$ is achieved if either Items $\mathrm{X}$ and $\mathrm{Y}$ are functional or if Items $\mathrm{X}, \mathrm{Y}$, and $\mathrm{Z}$ are functional.

- Item $\mathrm{D}$ can be achieved if Item $\mathrm{Z}$ is functional.

- Item E's success requires Item $X$, Item $Y$, and Item $Z$.

The SSLD can be used in two different manners:

1. By working from the left of the diagram to the right, the ultimate effect of a failure can be determined. For example, if Item $\mathrm{X}$ was lost, Items $\mathrm{T}$ and $\mathrm{Y}$ would fail. Subsequently, Items B, C, and E would also fail.

2. By working from the top down, an alternate way in which a function can be achieved or a system/subsystem would successfully work can be found. For example, Item $\mathrm{C}$ can be achieved if either Items $\mathrm{X}$ and $\mathrm{Y}$ are functional or if Items $\mathrm{X}, \mathrm{Y}$, and $\mathrm{Z}$ are functional.

Figure 4.5-5 shows a more complex SSLD of a U.S. plant.

4.5.2.1 Development of an SSLD is based on the process for developing a "success tree." This involves the definition of the top event or objective for the tree. In the case of an SSLD the top event (objective) is safe shutdown.

4.5.2.2 With the objective established, those events that lead directly to this objective need to be defined and logically modeled. Use the safe shutdown functions defined in Section 4.3 to model how safe shutdown is achieved. Position these functions across the top of the diagram.

For example, in Figure 4.5-5, the functions of Reactor Control, Secondary Cooling, Inventory Control, and Decay Heat Removal are required to prevent core damage. 
U.S. DEPARTMENT OF ENERGY'S REACTOR CORE

PROTECTION EVALUATION METHODOLOGY FOR FIRES AT

SOVIET-DESIGNED RBMK AND VVER NUCLEAR POWER PLANTS

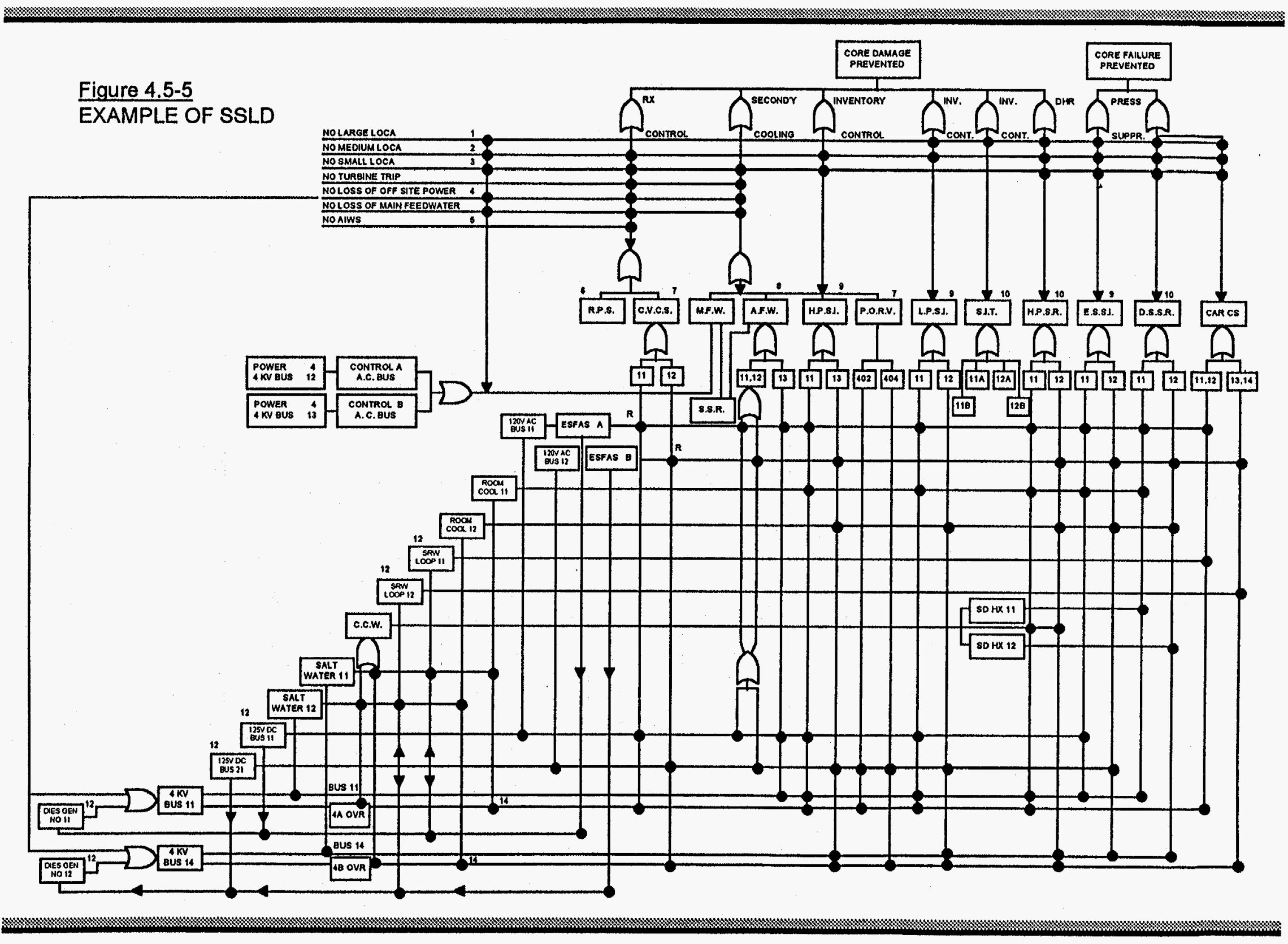


4.5.2.3 Once the functions leading to safe shutdown are logically modeled, the next step is to branch down and model how each safe shutdown function is accomplished.

Figure 4.5-5 shows that secondary cooling is necessary in the event of the following events: a small LOCA, a turbine trip, a loss of offsite power, or a loss of main feedwater. Given one of these events, at least one of the following systems/components must be operable: main feedwater (MFW), auxiliary feedwater (AFW), high pressure safety injection, or the pressurizer relief valve (PORV).

4.5.2.3.1 The uppermost goal is the safe shutdown function.

4.5.2.3.2 Logical AND and OR gates should be used as necessary to depict which systems are required to achieve success. Include necessary support systems as appropriate.

4.5.2.3.3 These steps must be repeated for every safe shutdown function.

4.5.2.4 Each safe shutdown system will then need to be logically modeled. Figure 4.4-1 is used as a typical example to demonstrate the process. Figure $4.5-4$ provides the SSLD for this system.

According to Figure 4.5-5, in order for the PORVs to be operable, both valve 402 and valve 404 must be operable. Note: When no AND/OR gate is shown, it is assumed that it is an AND gate.

4.5.2.4.1 The top objective is operation of the system.

4.5.2.4.2 Logical AND and OR gates should be used as necessary to depict the paths or equipment required to achieve success.

4.5.2.4.3 System diagrams should be used to model the components in the flow path that are necessary to support system operation. At this point, all the necessary subsystems/components necessary for successful operation of the safe shutdown systems must be determined. These subsystems/components should be positioned down the left-hand side of the diagram. A matrix of vertical and horizontal lines must be drawn from each system and subsystem/component, respectively .

Step down the lines. When two lines intersect, determine if the subsystem/component listed on the left is necesssary for the system/function at the top to be operable. If it is, place a solid node at that intersection.

Using Figure 4.5-5 as an example, in order for auxiliary feedwater Train 13 to be operable, Train A of the engineered safeguards features actuation system 
(ESFAS), Bus 11 of the $125 \mathrm{~V}$ dc system, and Bus 11 of the $4 \mathrm{kV}$ system must all be operable.

4.5.2.4.4 These steps must be repeated for every system identified as a safe shutdown system. 



\section{EVALUATE DESIGN DATA AND DOCUMENT EXISTING FIRE PROTECTION FEATURES}

This section of the Methodology documents and evaluates the existing plant fire protection features that have been provided to mitigate the consequences of fire throughout the plant. This evaluation is one of functionality, and is done to provide reasonable assurance that fire protection systems will start and operate as required. Areas that will be addressed include:

- Fire Water Supply System

- Fire Suppression Systems

- Fire Detection Systems

- Fire Separation and Fireproofing

- Fire Brigade

Documents that should be obtained for use in completing this section include:

- Fire Protection System Description

- Fire Protection System P\&IDs

- Fire Protection System Routing Drawings

- Plant Fire Response Procedures

The information obtained from this section should be gathered in one place for ease of use while performing the evaluation. It is suggested that sketches or other pertinent information be added as required to the above list of documents. All information collected should be utilized in completing the evaluation described in Section 4.6.6.

\subsection{1 $\quad$ FIRE WATER SUPPLY SYSTEM}

The fire water supply system includes the source of fire water, fire pumps, fire water distribution piping, and yard fire hydrants. All pertinent information developed in this section should be recorded on the flow diagram or sketch.

4.6.1.1 Using the available fire protection system documents, identify the source or sources of water (water tank, lake, river, holding pond, etc.) to be used as fire water. Indicate the capacity of each water source. Determine if any source can be considered as a dedicated fire water source (i.e., no other system is capable of 
using the water source). Determine if any instrumentation is available to determine if an adequate supply of fire water is available for use. Determine the design water flow required to adequately fight a postulated fire at the plant. This design water flow should account for the largest required concurrent water flow from the largest automatic suppression system, manual hoses, and any other water flow required at the same time.

4.6.1.2 Identify each fire pump that has been provided for the plant. For each fire pump, determine its location, function (pressure maintenance, full fire flow, etc.), flow capacity, pressure rating, power source (normal electrical power, diesel generator electrical power, diesel driven, etc.), mode of operation (automatic or manual for both pump starting and stopping), controlling parameter, and sequence of operation. Identify on the drawings any valves (shutoff, check, flow control, etc.), strainers, flow orifices, or other items that have been provided in the inlet and/or outlet piping for each fire pump.

4.6.1.3 Determine the size and location of the plant fire water piping, including the piping from the fire water source or sources to each fire pump, from each fire pump to the plant fire loop, the plant fire loop, and the piping from the fire loop to each building. If this information is not provided by a drawing, develop a sketch so that all the pertinent data is available in one place. Identify any screens, strainers, and/or isolation valves that are located in the fire water distribution piping.

4.6.1.4 Determine if any fire water piping can be damaged due to adverse effects such as freezing, mechanical damage, ground movement, etc.

4.6.1.5 Identify the locations and capacities of the yard fire hydrants. Indicate if each location has an aboveground fire hydrant or is provided with an underground hydrant for use with an aboveground adaptor. Identify the locations and sizes of any fire hose stations that have been provided for use with the fire hydrants.

4.6.1.6 Identify the locations of standpipes and hose stations. If dry standpipes are installed, indicate how water is admitted to the system and where controls are located. Also indicate the type and quantity of hose at each hose station and the type of nozzle provided. Determine if nozzles are appropriate for the fire hazard protected. If hose is not provided, identify the nearest hose storage location.

4.6.1.7 Determine the frequency of testing and inspection of the various aspects of the fire protection system to provide assurance that the system will operate as intended. Review the records of the testing and inspection program and provide an assessment of the reliability of the fire protection system. 


\subsection{2}

\section{FIRE SUPPRESSION SYSTEMS}

The fire suppression systems include all plant features contained in buildings and/or outdoor structures that have been provided to fight fires throughout the plant.

4.6.2.1 Identify the types of suppression systems used at the plant. Typical examples are:

- Wet Pipe Sprinkler System

- Dry Pipe Sprinkler System

- Deluge System

- Pre-action System

- Gas Flooding System

- Foam Spray System

- Fire Standpipe System with Hose Stations

- Water Cannon System

- Portable Fire Extinguishers

4.6.2.2 Determine the mode of operation for each type (manual or automatic). For manual operation, identify how the system is placed into operation. This may be remote manual, which requires an operator to push a button to open a remote valve or may require a manual opening at the valve location. For automatic operation, identify the controlling device (heat detector, smoke detector, etc.).

4.6.2.3 Identify the sequence of operation for each type of suppression system. Determine if the plant operators receive indication that a fire suppression system has been activated. Identify where this indication is received.

\subsubsection{FIRE DETECTION SYSTEMS}

The fire detection systems include all plant features that have been provided for the detection and alarm of fires throughout the plant.

4.6.3.1 Identify the types of fire detection systems that are used at the plant. Typical examples are:

- Fixed Temperature Heat Detectors 
- Linear Thermal Detectors

- Ionization Smoke Detectors

- Photoelectric Smoke Detectors

- Pneumatic Detectors

- Water Flow Detectors

- Manual Pull Stations

4.6.3.2 Determine the function of each fire detection system. This may be local alarm, remote alarm, and/or actuation of an automatic system. For remote alarms, indicate where the alarm is sounded.

4.6.3.3 Determine the location of each local and remote fire detection panel. Indicate the primary and secondary power supplies and their source.

4.6.3.4 Determine the control circuitry for each panel. Determine if all circuits are supervised to indicate faulted conditions. Determine where the faulted conditions are indicated to alert the operators.

\subsubsection{FIRE SEPARATION AND FIREPROOFING}

Fire separation consists of fire-rated barriers (floors, ceilings, and walls), fire-rated penetration seals, cable fire wraps, fire dampers, and fire doors.

Fireproofing consists of coatings, wraps, enclosures, or other surface treatments added to structural members to allow those members to resist a fire without suffering serious structural damage.

4.6.4.1 Determine the design criteria and the qualification testing criteria that allowed walls, floors, and ceilings to be considered as fire barriers. This is typically expressed in hours of fire resistance. Indicate if any evaluations and/or fire tests were performed to verify that the construction of the fire barriers will maintain their integrity for the time frame specified.

4.6.4.2 Identify the types of seal systems used for penetrations through fire-rated barriers. Indicate if any evaluations and/or fire tests were performed to verify that each type of penetration seal will maintain its integrity for the time frame specified.

4.6.4.3 Identify the types of fire dampers used for duct penetrations through fire-rated barriers. Indicate if any evaluations and/or fire tests were performed to verify that each type of fire damper will maintain its integrity for the time frame specified. 
4.6.4.4 Identify the types of fire doors used for openings through fire-rated barriers. Indicate if any evaluations and/or fire tests were performed to verify that each type of door will maintain its integrity for the time frame specified.

4.6.4.5 Identify any other types of closures used for openings through fire-rated barriers. Indicate for each type if any evaluations and/or fire tests were performed to verify that each type of closure will maintain its integrity for the time frame specified.

4.6.4.6 Identify the types of fireproofing systems used for structural members. Indicate if any evaluations and/or fire tests were performed to verify that each fireproofing system will allow structural members to retain their structural integrity for the time frame specified.

\subsubsection{FIRE BRIGADE}

The fire brigade, through its agreement with an NPP, is a vital part of the overall plant fire fighting strategy. A complete description of the personnel, equipment, method of operation, response times, and training is collected using the guidance in this section.

4.6.5.1 Identify the number of fire brigade members on duty during a typical shift and the total number of fire brigade members. Provide a summary of the type and frequency of training that each fire brigade member receives. Describe the special "nuclear" training provided to fire brigade members to permit them to function in the nuclear plant environment during a fire. Determine if the brigade's equipment is properly suited for fighting nuclear plant fires. Determine the frequency of fire drills for each shift.

4.6.5.2 Provide a summary of the type and location of the fire fighting equipment available for use by the fire brigade. Determine how often the equipment is inspected, how it is maintained, and spare parts retained in inventory.

4.6.5.3 Provide a summary of the type of personal protective equipment that is provided to each fire brigade member (such as air packs, etc.). Determine how often the gear is inspected, how it is maintained, and spare parts retained in inventory.

4.6.5.4 Provide a summary of how the fire brigade is notified and responds to a fire and what the response times are to various areas of the plant. If written procedures are provided for fighting fires in specific areas of the plant, obtain a copy of all procedures for use during the evaluation of fire compartments/fire cells.

\subsubsection{EVALUATION}

The following evaluation checklist for the fire protection features will ensure that multiple paths are available to control and manually extinguish fires at the plant. 
(Note: a path is a combination of piping and equipment capable of providing water to extinguish a fire.)

Fire protection system components should be examined to determine that their function can be maintained assuming the failure of any component along a single path. The information collected in Sections 4.6.1 through 4.6.5 will be used to complete Exhibit 4.6-1, the Fire Protection System Evaluation Checklist.

Exhibit 4.6-1 should be completely filled out. Each item will lead to one of the following conclusions:

\section{- S - Satisfactory}

The particular fire protection feature is provided in accordance with normally: accepted design codes and standards and/or local requirements and appears functional. No enhancements are required. Record specific details that form the basis for such a determination. In the Comments column, record the specific details that form the basis for this determination.

\section{- $\mathrm{N}$ - Needs Further Evaluation}

Either the particular fire protection feature does not meet the normally accepted design requirements, or further details must be provided before a definite judgment can be made. In the former case, a specific recommendation or plan must be made on how to resolve the issue, and that plan considered as part of the evaluations done in Section 4.11. In the latter case, further details can be gathered from plant walkdowns. These should be in addition to the walkdown information requested in Section 4.9.

\section{- U - Unsatisfactory}

The particular fire protection feature is not provided in accordance with normally accepted design requirements and does not appear functional. This could be the case due to inadequate material, systems, or equipment; inadequate fire resistance of specific components; inappropriate design approach; etc. In the Comments column, record the specific details that form the basis for this determination. 
Exhibit 4.6-1

FIRE PROTECTION SYSTEM EVALUATION CHECKLIST

\begin{tabular}{|c|c|c|c|c|c|}
\hline \multirow[t]{2}{*}{ No. } & \multirow[t]{2}{*}{ Item } & \multicolumn{3}{|c|}{ Adequacy } & \multirow{2}{*}{$\begin{array}{c}\text { Comments \& Objective } \\
\text { Evidence Reviewed }\end{array}$} \\
\hline & & $\mathbf{S}$ & $\mathbf{N}$ & $\mathbf{U}$ & \\
\hline \multicolumn{6}{|c|}{ Fire Water Supply System } \\
\hline 1. & $\begin{array}{l}\text { The capacity of the fire water source is } \\
\text { adequate to meet the design water flow } \\
\text { requirements as described in Section 4.6.1.1. }\end{array}$ & & & & \\
\hline 2. & $\begin{array}{l}\text { Redundant components are available in the fire } \\
\text { water path so that a failure of one component } \\
\text { will not prevent fire water from being } \\
\text { delivered to each building or outdoor structure. }\end{array}$ & & & & \\
\hline 3. & $\begin{array}{l}\text { A testing and inspection program indicates } \\
\text { that the fire water supply system is reliable and } \\
\text { can be expected to operate when called on. }\end{array}$ & & & & \\
\hline 4. & $\begin{array}{l}\text { There is more than one supply pipe from the } \\
\text { water source to the fire pumps. }\end{array}$ & & & & \\
\hline 5. & $\begin{array}{l}\text { There is more than one fire pump for each fire } \\
\text { pump function (pressure maintenance, full } \\
\text { flow, etc.). }\end{array}$ & & & & \\
\hline 6. & There is more than one set of fire pumps. & & & & \\
\hline 7. & $\begin{array}{l}\text { Each fire pump or set of fire pumps is located } \\
\text { in a separate fire compartment. }\end{array}$ & & & & \\
\hline 8. & $\begin{array}{l}\text { The capacity of each set of fire pumps is } \\
\text { adequate to supply the minimum amount of } \\
\text { fire water required. }\end{array}$ & & & & \\
\hline 9. & $\begin{array}{l}\text { The fire pumps are connected to different } \\
\text { power sources so that upon loss of one power } \\
\text { source, the fire pumps can continue to perform } \\
\text { their intended function. }\end{array}$ & & & & \\
\hline 10. & $\begin{array}{l}\text { Fire pumps are tested periodically to determine } \\
\text { their continued ability to provide the required } \\
\text { design water flow and pressure. }\end{array}$ & & & & \\
\hline
\end{tabular}


Exhibit 4.6-1 (Continued)

FIRE PROTECTION SYSTEM EVALUATION CHECKLIST

\begin{tabular}{|c|c|c|c|c|c|}
\hline \multirow[t]{2}{*}{ No. } & \multirow[t]{2}{*}{ Item } & \multicolumn{3}{|c|}{ Adequacy } & \multirow{2}{*}{$\begin{array}{c}\text { Comments \& Objective } \\
\text { Evidence Reviewed }\end{array}$} \\
\hline & & $\mathbf{S}$ & $\mathbf{N}$ & $\mathbf{U}$ & \\
\hline 11. & $\begin{array}{l}\text { Fire pump test results are recorded and } \\
\text { compared to previous tests in order to } \\
\text { determine any problems and/or unacceptable } \\
\text { trends. }\end{array}$ & & & & \\
\hline 12. & $\begin{array}{l}\text { Each set of fire pumps has a separate discharge } \\
\text { pipe and connection to the plant fire loop. }\end{array}$ & & & & \\
\hline 13. & $\begin{array}{l}\text { There is more than one connection from the } \\
\text { fire loop to each building. }\end{array}$ & & & & \\
\hline 14. & $\begin{array}{l}\text { Isolation valves are located in the fire loop so } \\
\text { that sections of the fire loop may be isolated for } \\
\text { maintenance and repair without preventing the } \\
\text { flow of fire water to any required building or } \\
\text { outdoor structure. }\end{array}$ & & & & \\
\hline 15. & $\begin{array}{l}\text { Isolation valves are properly located in the fire } \\
\text { loop so that closing one isolation valve will not } \\
\text { prevent fire water from being delivered to any } \\
\text { required building or outdoor structure. }\end{array}$ & & & & \\
\hline 16. & $\begin{array}{l}\text { Locations of yard hydrants allow for adequate } \\
\text { coverage of all buildings and outdoor } \\
\text { structures. }\end{array}$ & & & & \\
\hline 17. & $\begin{array}{l}\text { Yard main piping and hydrants are routinely } \\
\text { flushed out to remove sediment and debris. }\end{array}$ & & & & \\
\hline 18. & $\begin{array}{l}\text { Fire water piping is protected from damage by } \\
\text { such adverse effects as freezing, mechanical } \\
\text { damage, ground movement, etc. }\end{array}$ & & & & \\
\hline
\end{tabular}




\section{Exhibit 4.6-1 (Continued)}

\section{FLRE PROTECTION SYSTEM EVALUATION CHECKLIST}

\begin{tabular}{|c|c|c|c|c|c|}
\hline \multirow[t]{2}{*}{ No. } & \multirow[t]{2}{*}{ Item } & \multicolumn{3}{|c|}{ Adequacy } & \multirow{2}{*}{$\begin{array}{c}\text { Comments \& Objective } \\
\text { Evidence Reviewed }\end{array}$} \\
\hline & & $\mathbf{S}$ & $\mathbf{N}$ & $\mathbf{U}$ & \\
\hline \multicolumn{6}{|c|}{ Fire Detection Systems } \\
\hline 19. & $\begin{array}{l}\text { Plant operators receive indication, either in the } \\
\text { control room or at a central staffed location, } \\
\text { that a fire detection system (as listed in Section } \\
\text { 4.6.3.1) has been activated. }\end{array}$ & & & & \\
\hline 20. & $\begin{array}{l}\text { Plant operators receive indication of where the } \\
\text { activated fire detection system is located. }\end{array}$ & & & & \\
\hline 21. & $\begin{array}{l}\text { Each fire detection panel receives power from } \\
\text { two different sources. }\end{array}$ & & & & \\
\hline 22. & $\begin{array}{l}\text { All fire detection circuits are electronically } \\
\text { supervised to identify any faulted conditions. }\end{array}$ & & & & \\
\hline \multicolumn{6}{|c|}{ Fire Suppression Systems } \\
\hline 23. & $\begin{array}{l}\text { Plant operators receive indication, either in the } \\
\text { control room or at a central staffed location, } \\
\text { that a fire suppression system (as listed in } \\
\text { Section } 4.6 .2 .1 \text { ) has been activated. }\end{array}$ & & & & \\
\hline 24. & $\begin{array}{l}\text { Plant operators receive indication of where the } \\
\text { activated fire suppression system is located. }\end{array}$ & & & & \\
\hline 25. & $\begin{array}{l}\text { Plant operators have written procedures } \\
\text { available to indicate what manual actions are } \\
\text { required to place manual fire suppression } \\
\text { systems into operation. }\end{array}$ & & & & \\
\hline
\end{tabular}


Exhibit 4.6-1 (Continued)

FIRE PROTECTION SYSTEM EVALUATION CHECKLIST

\begin{tabular}{|c|c|c|c|c|c|}
\hline \multirow[t]{2}{*}{ No. } & \multirow[t]{2}{*}{ Item } & \multicolumn{3}{|c|}{ Adequacy } & \multirow{2}{*}{$\begin{array}{c}\text { Comments \& Objective } \\
\text { Evidence Reviewed }\end{array}$} \\
\hline & & $\mathbf{S}$ & $\mathbf{N}$ & $\mathbf{U}$ & \\
\hline \multicolumn{6}{|c|}{ Fire Separation and Fireproofing } \\
\hline 26. & $\begin{array}{l}\text { Evaluations and/or fire tests were performed to } \\
\text { verify that each type of fire barrier will } \\
\text { maintain its integrity for the time frame } \\
\text { specified. }\end{array}$ & & & & \\
\hline 27. & $\begin{array}{l}\text { Evaluations and/or fire tests were performed to } \\
\text { verify that each type of penetration seal will } \\
\text { maintain its integrity for the time frame } \\
\text { specified. }\end{array}$ & & & & \\
\hline 28. & $\begin{array}{l}\text { The fire ratings of penetration seal systems are } \\
\text { compatible with the fire ratings of their } \\
\text { associated fire barriers. }\end{array}$ & & & & \\
\hline 29. & $\begin{array}{l}\text { Evaluations and/or fire tests were performed to } \\
\text { verify that each type of fire door will maintain } \\
\text { its integrity for the time specified. }\end{array}$ & & & & \\
\hline 30. & $\begin{array}{l}\text { The fire ratings of fire doors are compatible } \\
\text { with the fire ratings of their associated fire } \\
\text { barriers. }\end{array}$ & & & & \\
\hline 31. & $\begin{array}{l}\text { Evaluations and/or fire tests were performed to } \\
\text { verify that each type of fire damper will } \\
\text { maintain its integrity for the time specified. }\end{array}$ & & & & \\
\hline 32. & $\begin{array}{l}\text { The fire ratings of fire dampers are compatible } \\
\text { with the fire ratings of their associated fire } \\
\text { barriers. }\end{array}$ & & & & \\
\hline 33. & $\begin{array}{l}\text { Evaluations and/or fire tests were performed to } \\
\text { verify that other types of closures will maintain } \\
\text { their integrity for the time specified. }\end{array}$ & & & & \\
\hline 34. & $\begin{array}{l}\text { The fire ratings of other types of closures are } \\
\text { compatible with the fire ratings of their } \\
\text { associated fire barriers. }\end{array}$ & & & & \\
\hline
\end{tabular}


Exhibit 4.6-1 (Continued)

FIRE PROTECTION SYSTEM EVALUATION CHECKLIST

\begin{tabular}{|c|c|c|c|c|c|}
\hline \multirow[t]{2}{*}{ No. } & \multirow[t]{2}{*}{ Item } & \multicolumn{3}{|c|}{ Adequacy } & \multirow{2}{*}{$\begin{array}{c}\text { Comments \& Objective } \\
\text { Evidence Reviewed }\end{array}$} \\
\hline & & $\mathbf{S}$ & $\mathbf{N}$ & $\mathbf{U}$ & \\
\hline 35. & $\begin{array}{l}\text { Evaluations and/or fire tests were performed to } \\
\text { verify that each type of fireproofing will } \\
\text { maintain the structural integrity of structural } \\
\text { members for the time frame specified. }\end{array}$ & & & & \\
\hline 36. & $\begin{array}{l}\text { The fire ratings of fireproofing systems are } \\
\text { compatible with the anticipated duration and } \\
\text { intensity of fires. }\end{array}$ & & & & \\
\hline \multicolumn{6}{|c|}{ Fire Brigade } \\
\hline 37. & $\begin{array}{l}\text { Adequate fire fighting equipment is available } \\
\text { for use in fighting a fire. }\end{array}$ & & & & \\
\hline 38. & $\begin{array}{l}\text { Records are available to indicate that the fire } \\
\text { fighting equipment has been inspected and is } \\
\text { in proper operating condition for use in } \\
\text { fighting a fire. }\end{array}$ & & & & \\
\hline 39. & $\begin{array}{l}\text { Adequate personal protective equipment is } \\
\text { available for use in fighting a fire. }\end{array}$ & & & & \\
\hline 40. & $\begin{array}{l}\text { Records are available to indicate that the } \\
\text { personal protective equipment has been } \\
\text { inspected and is in proper condition for use in } \\
\text { fighting a fire. }\end{array}$ & & & & \\
\hline 41. & $\begin{array}{l}\text { A particular supervisor of the fire brigade is } \\
\text { identified for each shift }\end{array}$ & & & & \\
\hline 42. & $\begin{array}{l}\text { Specific members of the fire brigade are } \\
\text { identified for each shift. }\end{array}$ & & & & \\
\hline 43. & $\begin{array}{l}\text { Records are available that show that each } \\
\text { member of the fire brigade is properly trained } \\
\text { to fight NPP fires. }\end{array}$ & & & & \\
\hline 44. & $\begin{array}{l}\text { Records are available that indicate what the } \\
\text { fire brigade response times are to various areas } \\
\text { of the plant. }\end{array}$ & & & & \\
\hline
\end{tabular}




\section{Exhibit 4.6-1 (Continued)}

\section{FIRE PROTECTION SYSTEM EVALUATION CHECKLIST}

\begin{tabular}{|c|c|c|c|c|c|}
\hline \multirow[t]{2}{*}{ No. } & \multirow[t]{2}{*}{ Item } & \multicolumn{3}{|c|}{ Adequacy } & \multirow{2}{*}{$\begin{array}{c}\text { Comments \& Objective } \\
\text { Evidence Reviewed }\end{array}$} \\
\hline & & $\mathbf{S}$ & $\mathbf{N}$ & $\mathbf{U}$ & \\
\hline 45. & $\begin{array}{l}\text { The fire brigade is provided with a means to } \\
\text { communicate with the control room to } \\
\text { coordinate fire fighting activities with plant } \\
\text { operators. }\end{array}$ & & & & \\
\hline 46. & $\begin{array}{l}\text { The communication system is available and } \\
\text { operable in all portions of the plant. }\end{array}$ & & & & \\
\hline 47. & $\begin{array}{l}\text { All communication devices are regularly tested } \\
\text { and maintained, and spare devices and spare } \\
\text { parts are available. }\end{array}$ & & & & \\
\hline 48. & $\begin{array}{l}\text { The authorities and responsibilities of all } \\
\text { groups of personnel (control room operators, } \\
\text { fire brigade, plant workers, etc.) are clearly } \\
\text { defined before and during a fire. }\end{array}$ & & & & \\
\hline 49. & $\begin{array}{l}\text { Training sessions are implemented to practice } \\
\text { plant and fire brigade response and } \\
\text { coordination. }\end{array}$ & & & & \\
\hline 50. & $\begin{array}{l}\text { Written fire brigade procedures are available } \\
\text { for fighting fires in specific areas of the plant. }\end{array}$ & & & & \\
\hline
\end{tabular}




\section{PREPARE FIRE COMPARTMENT/CELL DRAWINGS}

Fire separation between shutdown systems and equipment reduces the possibility that fire-related damage could occur to redundant/alternate shutdown equipment. Such fire separation divides the plant into distinct fire compartments, which are plant areas completely surrounded by fire barriers or separated from other buildings and structures by distance. Each fire compartment can contain rooms or distinctly separate areas of usage. The rooms and areas may be separated by walls or distance from the other rooms, but these walls may not be fire-rated boundaries. These rooms and areas are considered fire cells of the fire compartment. The use of fire compartments and fire cells permits systematic, definable analysis of the plant.

This section of the Methodology provides guidance to divide the plant into fire compartments and cells and to create fire compartment and fire cell drawings. All plant buildings and major outdoor structures are initially considered; however, only those buildings and outdoor structures that contain or are adjacent to shutdown systems and equipment are assigned fire compartment/fire cell numbers. In addition, the fire compartment/cell designations may need to be re-evaluated or changed based on the results of Section 4.11 .

The process of assigning fire compartment and fire cell numbers involves three basic steps:

1. Buildings and outdoor areas that contain or are adjacent to shutdown equipment are selected from an overall list of all buildings and structures.

2. The bounds of outdoor structures are determined and divided into fire compartments and fire cells with unique identification numbers.

3. The buildings are divided into fire compartments and fire cells with unique identification numbers.

Fire compartment and fire cell identification numbers should be comprehensive. As a minimum, they should identify the building or outdoor structure and whether the area under evaluation is a fire compartment or a fire cell. The following numbering scheme is suggested:

XXX - YYY - ZZZ

where $\mathrm{XXX}=\mathrm{a}$ two- or three-letter or digit identifier for the building or outdoor structure 


\section{U.S. DEPARTMENT OF ENERGY'S REACTOR CORE \\ PROTECTION EVALUATION METHODOLOGY FOR FIRES AT \\ SOVIET-DESIGNED RBMK AND VVER NUCLEAR POWER PLANTS}

\$mж)

$$
\begin{aligned}
\text { YYY = a three-letter identifier for fire compartment or fire cell, such as } & \text { COM for compartment and CEL for cell } \\
\mathrm{ZZZ} \mathrm{=} & \text { a three-digit sequential number to uniquely identify the } \\
& \text { compartment or cell }
\end{aligned}
$$

Fire compartment and fire cell drawings can best be made from plant arrangement drawings. The arrangement drawings already show building walls/barriers and outdoor structure boundaries. These barriers and boundaries can be highlighted or color coded and compartment/cell numbers added.

Sample fire compartment and fire cell drawings are provided in Figures 4.7-1 and 4.7-2. Figure 4.7-1 shows the limits of fire compartments for an outdoor pump structure (PY-COM-001) and an outdoor transformer yard (TY-COM-002). Figure 4.7-2 shows one floor of a building that is a single fire compartment (RB-COM-001). This fire compartment is separated into several fire cells (RB-CEL-001 through 009). Both the numbering system and "line" legends shown on the samples are plant specific and are not intended as direct guidance.

During the course of the evaluation performed in Section 4.11, the fire compartment and fire cell drawings may require modification to add, delete, or modify compartments/cells. When the entire methodology has been completed, the fire compartment and fire cell drawings should clearly reflect the final status of all fire compartments/cells and indicate those fire compartments and fire cell boundaries that are being relied upon for fire separation to support safe shutdown. The adequacy of boundary fire separation is evaluated in Section 4.11.

\subsubsection{SELECTION OF SITE BUILDINGS AND OUTDOOR STRUCTURES}

This subsection provides guidance to select buildings and outdoor structures that require fire compartment and fire cell numbers and to identify those buildings and structures that need no further evaluation. This process is shown on Figure 4.7-3.

4.7.1.1 Identify all site buildings and outdoor structures by listing them on the Site Buildings and Outdoor Structures form (Exhibit 4.7-1).

Guidance: Examples of outdoor structures include a pump intake structure, fuel oil tank, transformer yard, and storage area. 


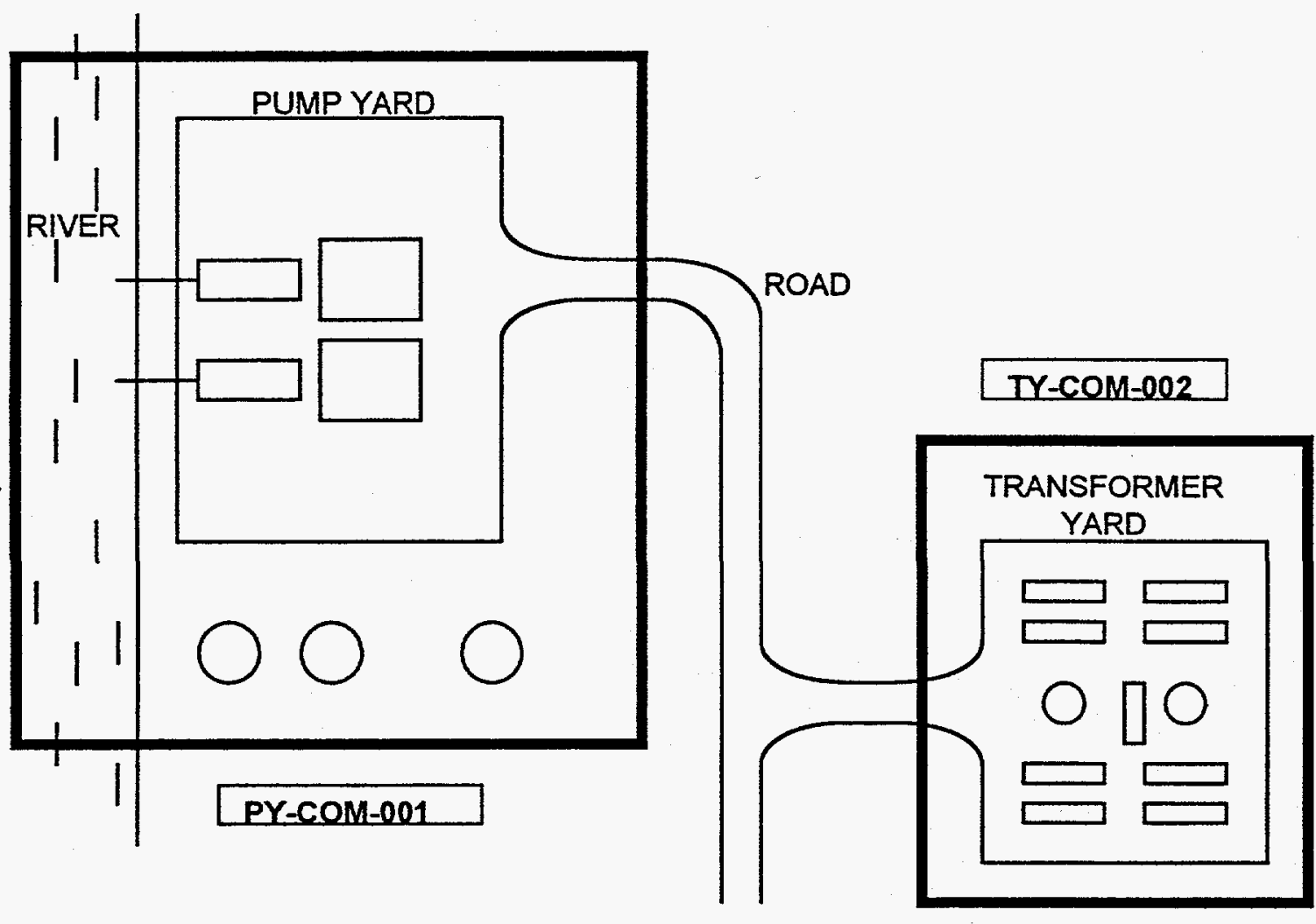

Not to Scale

FIRE COMPARTMENT BOUNDARY

FIRE CELL BOUNDARY

COMPARTMENT/CELL NUMBER

FIGURE $4.7-1$

SAMPLE OUTDOOR STRUCTURE

FIRE COMPARTMENT/CELL DRAWING 
U.S. DEPARTMENT OF ENERGY'S REACTOR CORE

PROTECTION EVALUATION METHODOLOGY FOR FIRES AT

SOVIET-DESIGNED RBMK AND VVER NUCLEAR POWER PLANTS

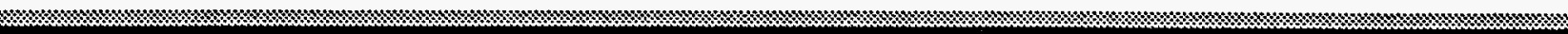

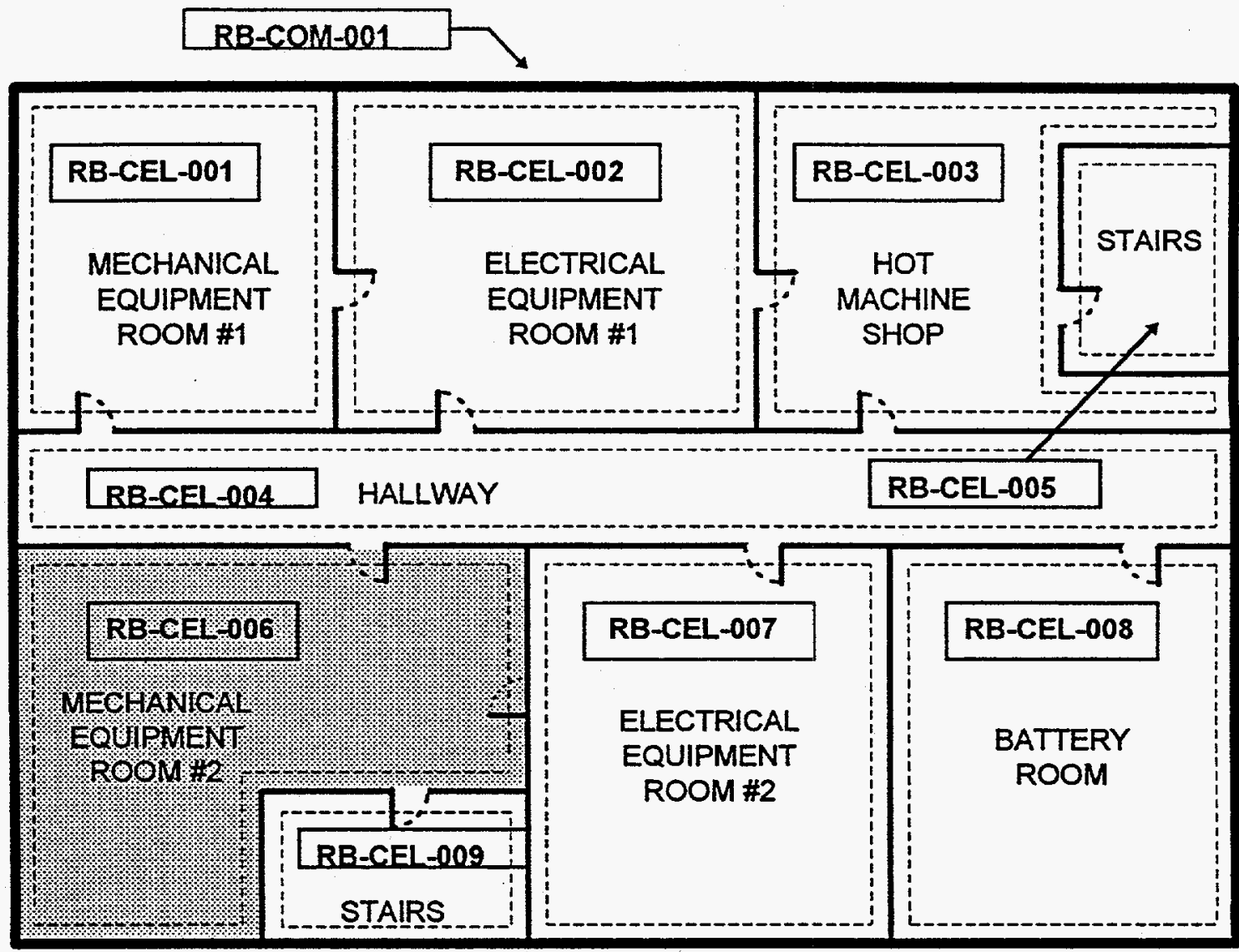

Not to Scale

FIRE COMPARTMENT BOUNDARY

FIRE CELL BOUNDARY

COMPARTMENT/CELL NUMBER

FIGURE 4.7-2

SAMPLE BUILDING FIRE COMPARTMENTI

CELL DRAWING 


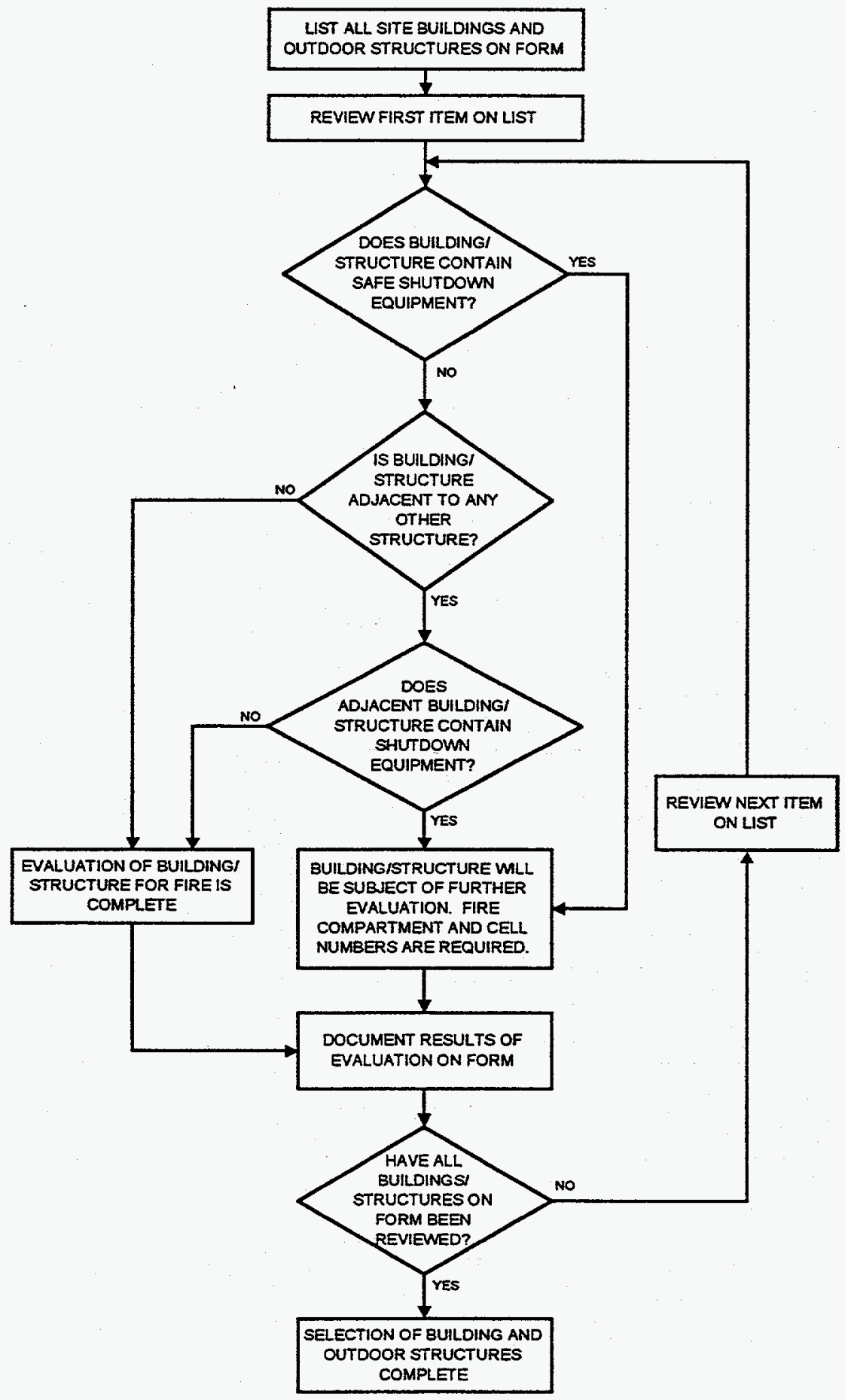

FIGURE 4.7-3

SELECTION OF BUILDINGS AND OUTDOOR

STRUCTURES TO BE EVALUATED 
4.7.1.2 For each building and outdoor structure listed, determine if it contains shutdown equipment and note this in the space provided on the form.

NOTE: If unsure whether a building or structure contains shutdown equipment, assume it does and note it as such on the form. Section 4.4 identifies shutdown equipment, and Sections 4.9 and 4.10 verify the actual equipment locations. The completed Exhibit 4.7-1 should be verified as being correct and complete after the walkdowns have been completed.

4.7.1.3 If a building or structure does not contain shutdown equipment, determine if it is adjacent to another building or structure that contains safe shutdown equipment. A distance of approximately 15 meters (50 feet) or less between structures could be considered adjacent. (See guidance in Section 4.7.2.1) Note this in the space provided on the form. If unsure, use guidance in the note for Section 4.7.1.2.

4.7.1.4 A "yes" response to either of the questions on the form identifies those structures requiring further evaluation (requiring compartment/cell numbers). A "no" response to both questions eliminates the structure from further evaluation, and compartment/cell numbers are not required. In the third column, check the "yes" response if the building or structure has a "yes" answer in either column.

Example: An administration building is an example of a building not requiring further evaluation if it is separated from other plant buildings/structures by fire barriers or distance. Such a structure includes offices and personnel only, with no plant equipment or systems required for shutdown.

\section{ASSIGNMENT OF FIRE COMPARTMENT AND FIRE CELL NUMBERS TO OUTDOOR STRUCTURES}

This subsection provides guidance in assigning fire compartment and cell numbers to outdoor areas of the plant identified in Section 4.7.1 as requiring further evaluation. This process is shown on Figure 4.7-4. 


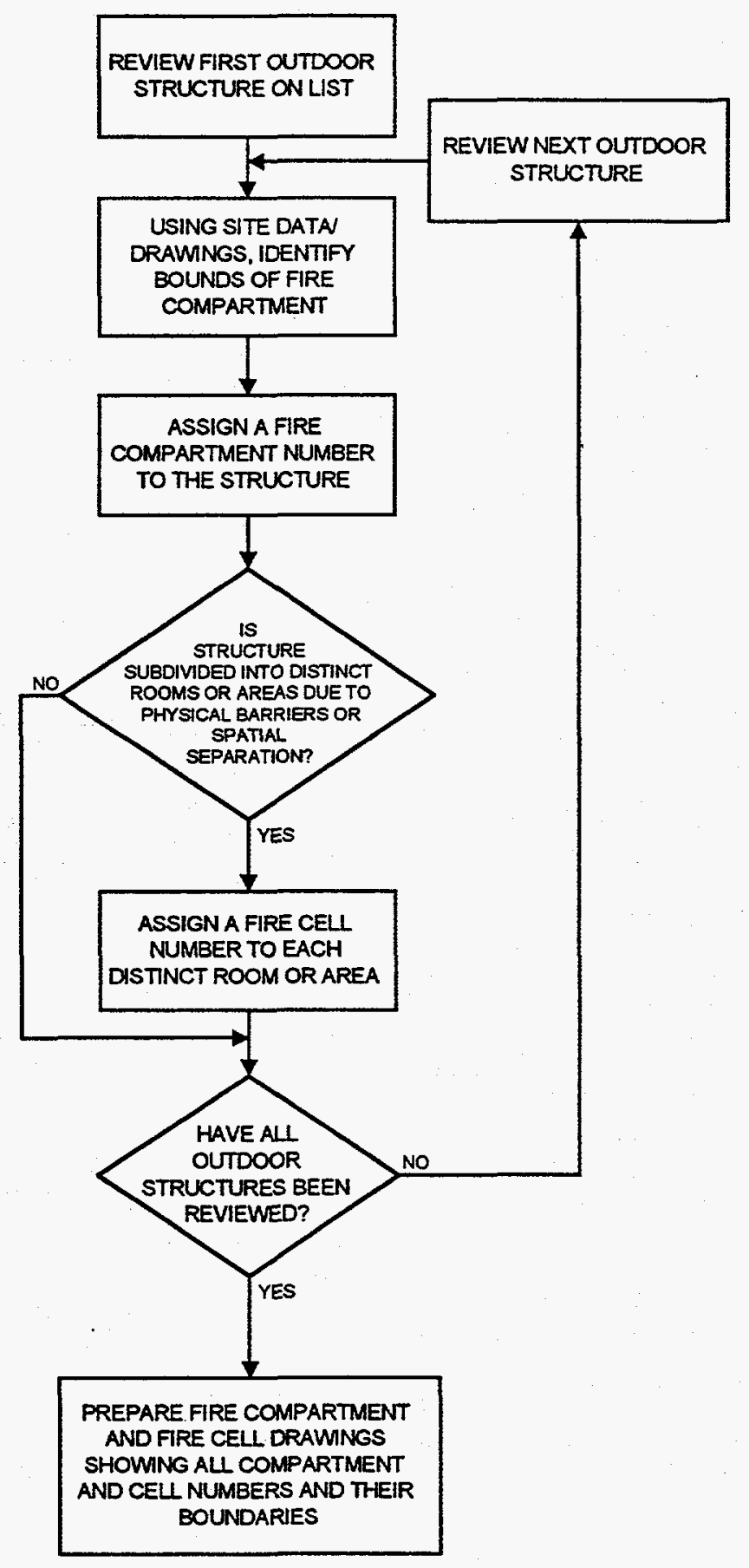

FIGURE 4.7-4

ASSIGNMENT OF FIRE COMPARTMENT AND

FIRE CELL NUMBERS TO OUTDOOR STRUCTURES 
4.7.2.1 Using site documents and drawings, identify fire compartment bounds for the outdoor structures identified in Section 4.7.1 as requiring further evaluation.

Guidance: Fire compartment bounds for outdoor structures should be chosen such that a fire would not reasonably be expected to spread beyond them. In the U.S., a typical minimum distance between compartments is approximately 15 meters ( 50 feet). If sufficient distance between structures is not available, then both structures would be part of the same fire compartment.

4.7.2.2 Assign a fire compartment number to the outdoor structure.

4.7.2.3 Based on site documents and drawings, determine if the outdoor structure is subdivided into distinct rooms or areas due to non-fire-rated physical barriers or spatial separations. If so, assign a fire cell number to each distinct room or area.

4.7.2.4 When the above steps have been completed for each outdoor structure identified in Section 4.7.1, prepare fire compartment and fire cell drawings. These drawings should show all compartment and cell numbers as well as their boundaries. A sample drawing is given in Figure 4.7-1.

ASSIGNMENT OF FIRE COMPARTMENT AND FIRE CELL NUMBERS TO BUILDINGS

This subsection provides guidance to assign fire compartment and cell numbers to plant buildings. This process is shown on Figure 4.7-5.

4.7.3.1 Using site documents and plant arrangement drawings, identify fire barriers for the buildings identified in Section 4.7.1 as requiring further evaluation.

Guidance: Building exterior walls can be included even though they are not required to be fire barriers (the need for the exterior to be a fire barrier will be established later).

4.7.3.2 Identify those areas within a building that are completely bounded by either fire barriers or the building exterior.

4.7.3.3 Assign fire compartment numbers to each area identified.

4.7.3.4 Based on existing plant documents and drawings, determine if the fire compartments can be subdivided into distinct rooms or areas due to non-rated physical barriers or spatial separations. If so, identify each distinct area and assign a fire cell number to each distinct room or area. 


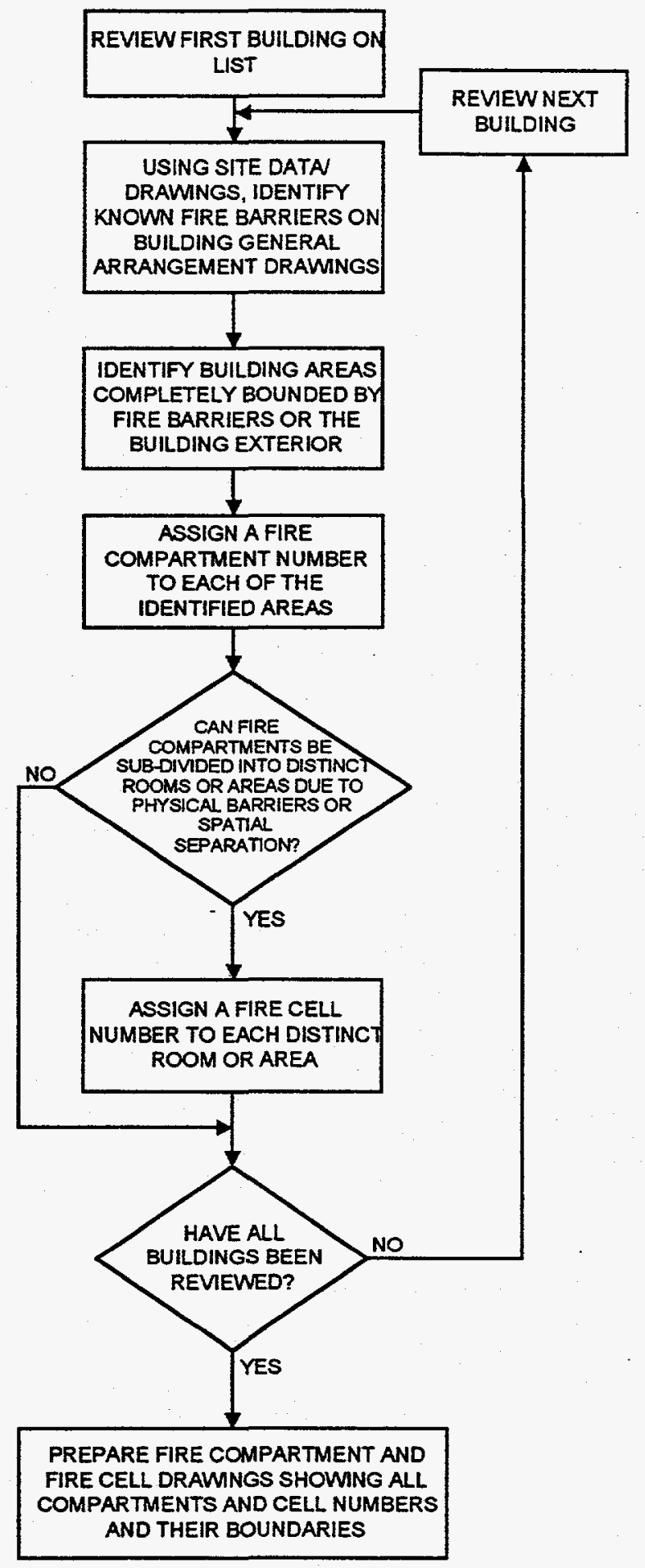

FIGURE 4.7-5

ASSIGNMENT OF FIRE COMPARTMENT AND

FIRE CELL NUMBERS TO BUILDINGS 
Guidance: In some cases, such as a pump house, the entire building may be one fire compartment. An auxiliary building that has six distinct rooms would be divided into six fire cells.

4.7.3.5 When the above steps have been completed for all buildings identified in Section 4.7.1, prepare formal fire compartment and fire cell drawings. These drawings should show all compartment and cell numbers as well as their boundaries/barriers. Use the guidance provided in Section 4.7.2.4. A sample drawing is given in Figure 4.7-2. 
Exhibit 4.7-1

\section{SITE BUILDINGS AND OUTDOOR STRUCTURES}

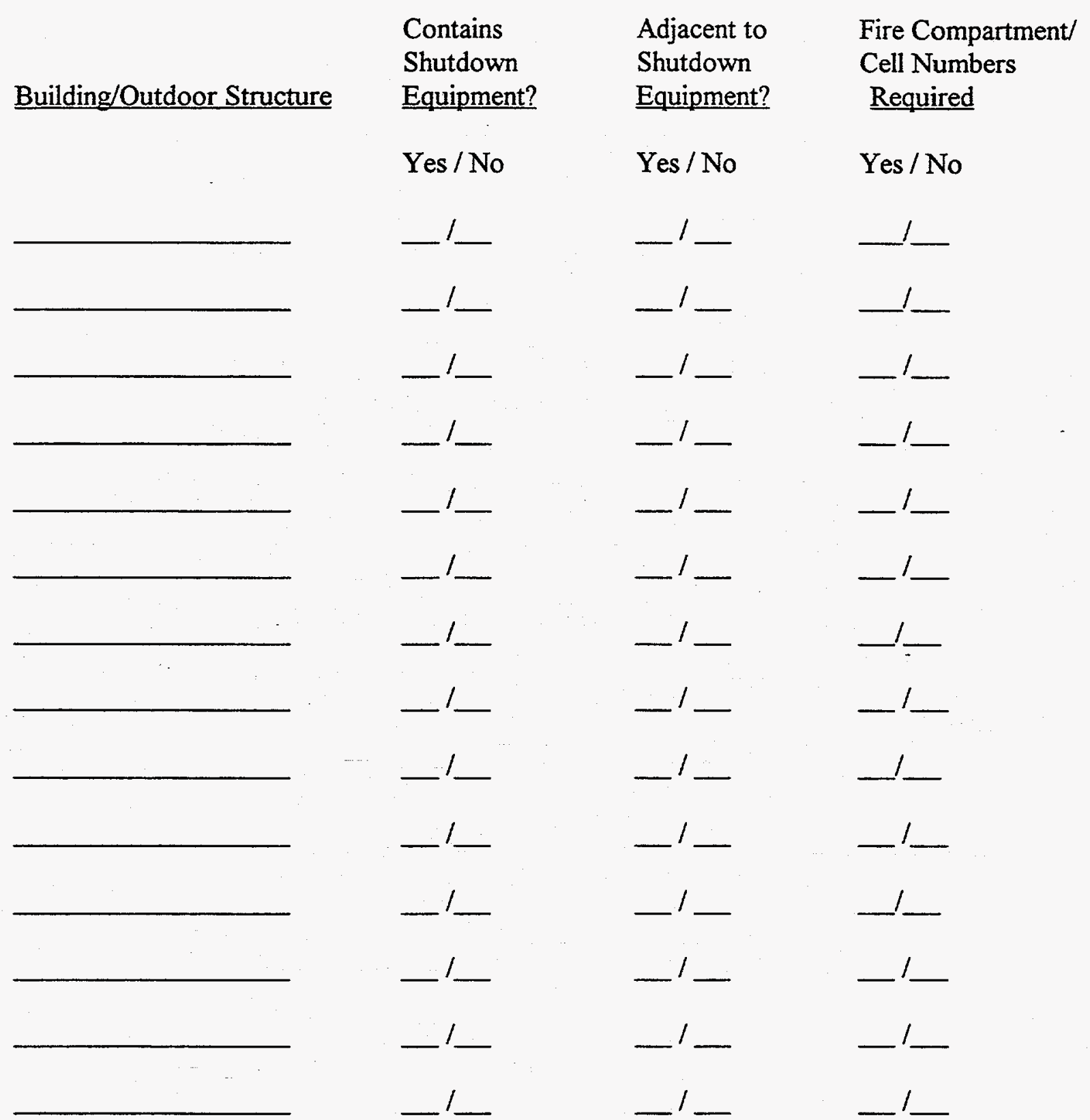

A "yes" response in either of the first two columns identifies the building/outdoor structure as requiring further evaluation. A "no" response in both columns eliminates the structure from further evaluation. 



\section{IDENTIFY LOCATIONS OF MAJOR EOUIPMENT AND FIRE} HAZARDS FROM DRAWINGS

This section of the Methodology provides guidance for filling out certain sections of the individual Fire Compartment/Fire Cell Walkdown Checklists prior to the actual walkdown. Section 4.9 addresses the procedure for the actual plant walkdowns. It is recommended that this section be done on a building-by- building basis. A sample form for the Fire Compartment/Cell Walkdown Checklist is provided in Exhibit 4.8-1. This information should be completed based on plant documentation so that it can be field verified by the walkdown.

This section will utilize the Fire Compartment and Fire Cell Drawings developed in Section 4.7. These drawings will be "marked-up" (annotated) with additional information in this section and in Section 4.9.1 to prepare for the plant walkdown: These marked-up drawings will be utilized for the walkdowns and should be retained in conjunction with the walkdown checklists.

As an example, portions of the Fire Compartment/Cell Walkdown Checklist have been filled in. The data is based on "Mechanical Equipment Room \#2," which is shown in Figure 4.7-2. This room is assumed to contain some safe shutdown equipment. The sample checklist contains both pre-walkdown and post walkdown information.

\subsubsection{FIRE COMPARTMENT AND FIRE CELL DATA}

4.8.1.1 Prepare an individual Fire Compartment/Fire Cell Walkdown Checklist for each fire compartment or fire cell identified in Section 4.7 and shown on the Fire Compartment/Fire Cell Drawings.

4.8.1.2 Using the Fire Compartment/Fire Cell Drawings, enter the following information into Part 1 of the individual Fire Compartment/Fire Cell Walkdown Checklists:

- Fire Compartment: Enter title and number

- Fire Cell: Enter title and number

- Reference Drawing: Enter the number of the Fire Compartment/Fire Cell Drawing or the plant area under consideration

- Building: Enter the building or outdoor structure name

- Elevation: Enter the elevation of the fire compartment/fire cell. 


\subsubsection{CONSTRUCTION BOUNDARIES}

4.8.2.1 Number each wall of the fire compartment or fire cell consecutively (i.e., 1, 2, 3, 4, etc.) on the Fire Compartment/Fire Cell Drawing. The walls should be numbered for each individual cell and compartment.

4.8.2.2 In Part 2 of the Fire Compartment/Fire Cell Walkdown Checklists, enter each wall number and indicate whether the wall is a fire barrier (by entering either "yes" or "no"). If known, enter the fire resistance rating (in minutes), construction material, and approximate thickness of the boundary. Also enter the adjacent fire compartment/fire cell number for each wall. Do the same for the ceiling and floor of the fire compartment/fire cell under consideration.

\subsubsection{MAJOR EQUIPMENT AND COMPONENTS OF SELECTED SHUTDOWN SYSTEMS}

4.8.3.1 Use the Safe Shutdown Equipment Worksheets (Exhibit 4.4-1) that were generated in Section 4.4 to identify safe shutdown equipment. Each of the following steps should be completed for each fire compartment and fire cell.

4.8.3.2 In Part 3A of the Checklists, enter the identification number and name/description of each piece of shutdown equipment located in the fire compartment/fire cell.

4.8.3.3 Review the list of shutdown equipment from Section 4.4. Generate another list of all components that have not been located. If known, indicate the possible location of equipment on the list. This list will be used to verify the equipment and component locations during the plant walkdowns.

4.8.3.4 Obtain a copy of the General Arrangement Drawings or Equipment Location Drawings of the plant area under consideration for use during the plant walkdown. In Part 3B of the Checklists, enter the identification number and name/description of each piece of major (large), non-shutdown equipment located in the fire compartment/fire cell.

\subsubsection{DOORS}

4.8.4.1 For each compartment/cell, number each door (i.e., 1, 2, 3, 4, etc.) on the Fire Compartment/Fire Cell Drawings.

4.8.4.2 For each door, enter the door number, its associated wall number, and the reference drawing the door appears on in Part 4 of the appropriate Fire Compartment/Fire Cell Walkdown Checklists. Indicate whether the door is supposed to be a fire door (by entering either "yes" or "no"). 
Guidance: A door's reference drawing could be any drawing where the door appears, such as a general arrangement or a door schedule.

4.8.4.3 If known, enter the fire rating, in minutes, for each door.

Guidance: Fire door resistance rating information, if any, was determined in Section 4.6. This information may also be available on the door's reference drawings or from the manufacturer's data. In some cases, the door's rating is given on a tag affixed to the door or its jamb. The plant walkdown will verify this. It should not be assumed that a fire door has the same fire resistance rating as its associated wall.

4.8.4.4 Enter the number of the adjacent fire compartment/fire cell (compartment/cell that the door leads to).

\subsection{5}

\section{PENETRATIONS}

4.8.5.1 Obtain a copy of the plant drawings that show the wall, ceiling, and floor penetrations for each fire compartment/fire cell.

Note: If these drawings are not available, sketch each fire barrier wall, ceiling, and floor in a scale large enough to indicate penetration locations, penetration numbers, and other pertinent information for use during the plant walkdown. Add these sketches to the applicable compartment/ cell Checklists.

4.8.5.2 In Section 5A of the Fire Compartment/Fire Cell Walkdown Checklists, enter the wall numbers, adjacent fire compartment/fire cell numbers, and whether the walls are fire barriers (from Part 2); penetration seal fire resistance rating (if known); penetration numbers of all penetrations; penetration type (if known); approximate wall opening size and shape (if known); and type of seal material (if known).

Assign penetration numbers to all penetrations if they are not numbered on the drawings.

4.8.5.3 In Section 5B of the Fire Compartment/Fire Cell Walkdown Checklists, for the ceiling, enter the adjacent fire compartment/fire cell number, whether the ceiling is a fire barrier (from Part 2), penetration seal fire resistance rating (if known), penetration numbers of all penetrations, penetration type (if known), approximate opening size and shape (if known), and type of seal material (if known). 
4.8.5.4 In Section 5C of the Fire Compartment/Fire Cell Walkdown Checklists, for the floor, enter the adjacent fire compartment/fire cell number, whether the floor is a fire barrier (from Part 2), penetration seal fire resistance rating (if known), penetration numbers of all penetrations, penetration type (if known), approximate opening size and shape (if known), type of seal material (if known), and the height of curbs around the penetration (if any).

Guidance: Penetration seal fire resistance rating information, if any, was determined in Section 4.6. It should not be assumed that a penetration seal has the same fire resistance rating as its associated wall.

\subsubsection{STRUCTURAL}

4.8.6.1 Part 6 of the Fire Compartment/Fire Cell Walkdown Checklists will be used during the actual plant walkdown to identify and record those structural beams and/or columns located in the fire compartment/fire cell. No information is required to be entered before the walkdown.

\subsubsection{COMBUSTIBLE MATERIAL}

4.8.7.1 Part 7 of the Fire Compartment/Fire Cell Walkdown Checklists will be used during the actual plant walkdown to identify and record all combustible materials located in the fire compartment/fire cell. Transient combustible materials, such as those items brought into the compartment/cell to perform maintenance or repairs, may be listed prior to the walkdown based on previous experience and maintenance procedures. Fixed quantities of combustibles may also be entered based on drawings/documents. For example, known quantities of lubricating oil, grease, or fuel oil contained in tanks, reservoirs, and other equipment could be added to the list prior to the walkdown.

\subsubsection{FIRE SUPPRESSION SYSTEMS}

4.8.8.1 Using the fire protection system P\&IDs and the fire protection system piping drawings, identify all known types of fixed fire suppression systems (sprinkler, deluge, gas flooding, etc.) located in the fire compartments/fire cells in Part 8 of the Checklists.

4.8.8.2 If the information was obtained from a drawing showing the physical locations of the systems and components, make a copy of the drawing and attach it to the Checklists so it can be verified during the plant walkdown. 
4.8.8.3 If drawings are not available, sketch the area in a scale large enough to indicate suppression system locations, detection system locations, fire hose station locations, portable fire extinguisher and water cannon locations, and other pertinent information for use during the plant walkdown. These sketches will also be utilized in Parts 9 and 10 of the Checklists.

\subsubsection{FIRE DETECTION SYSTEMS}

4.8.9.1 Using the fire protection system P\&IDs and the plant fire system drawings, identify all known types of fixed fire detection systems (heat, smoke, etc.) located in the fire compartments/fire cells in Part 9 of the Checklists. Also indicate where the systems alarm: locally, in the control room, at other remote location(s), or at all locations.

4.8.9.2 If the information was obtained from a drawing showing the physical locations of the systems and components, make a copy of the drawing and attach it to the Checklists so it can be verified during the plant walkdown.

\subsubsection{FIRE HOSE STATIONS AND WATER CANNONS}

4.8.10.1 Identify all known fire hose stations and water cannons in or adjacent to the fire compartments/fire cell in Part 10 of the Checklists using the fire protection system P\&IDs and the fire protection system piping drawings.

Note: Fire hose stations should be considered as adjacent to the fire compartment/fire cell being reviewed if the hose is long enough to be used to fight a fire in the compartment/cell. This will be verified during the plant walkdown.

\subsubsection{FIRE EXTINGUISHERS}

4.8.11.1 Identify the type of all known portable fire extinguishers located in or adjacent to the fire compartments/fire cell in Part 11 of the Checklists using available plant drawings. For portable fire extinguishers, the adjacent compartment/cell is taken as the compartments/cells used to gain access to the compartment/cell being reviewed.

\subsubsection{DRAINAGE}

Part 12 of the Fire Compartment/Fire Cell Walkdown Checklists will be used during the plant walkdown to identify and record the drainage systems located in the fire compartment/fire cell. No information is required to be entered prior to the walkdown. 


\subsubsection{VENTILATION}

4.8.13.1 Using the ventilation system P\&IDs, identify the ventilation system(s) that supplies and/or exhausts air from the fire compartment/fire cell in Part 13 of the Checklists.

4.8.13.2 Determine if there is an automatic shutdown of the supply and/or exhaust system upon receipt of a fire and/or smoke detection signal.

4.8.13.3 Determine if there is a fixed smoke removal system connected to the fire compartment/fire cell.

4.8.13.4 Determine if fire dampers are provided in both the supply and exhaust ducts that pass through fire barriers.

4.8.13.5 Determine if transfer air openings have been provided. If these openings pass through fire barriers, determine if fire dampers have been provided in the openings.

\subsubsection{EMERGENCY LIGHTING}

4.8.14.1 Section 14 of the Fire Compartment/Cell Walkdown Checklists will be used during the actual plant walkdown to identify and record emergency lighting fixtures located in the access route to, the egress route from, and in any fire compartment/cell in which indications are to be read or manual actions are to be taken in support of fighting a fire or performing post-fire safe shutdown. No information is required to be entered prior to the walkdown.

The suitability of emergency lighting, including brightness and directional aim, cannot be determined until manual shutdown actions have been defined. This will be determined in Sections 4.12 and 4.13.

\section{EMERGENCY COMMUNICATIONS}

Section 15 of the appropriate Fire Compartment/Fire Cell Walkdown Checklists will be used during the plant walkdown to identify and record the type of emergency communications system provided in the fire compartment/fire cell. No information is required to be entered before the walkdown.

\subsubsection{COMPLETION}

4.8.16.1 Review the Fire Compartment/Fire Cell Drawings and confirm that a Checklist has been prepared for each fire compartment and each fire cell. 
4.8.16.2 Check that all drawings and/or sketches have been prepared for use during the plant walkdowns and attach them to the appropriate Fire Compartment/Cell Walkdown Checklist. Separate the Checklist packages according to building or outdoor structure. 
Exhibit 4.8-1

\section{FIRE COMPARTMENT/FIRE CELL WALKDOWN CHECKLIST}

\section{FIRE COMPARTMENT AND FIRE CELL DATA}

Fire Compartment: RB-COM-001

Fire Cell: $\quad$ RB-CEL-006

Reference Drawing: FAD-RB-001

Building: __ Reactor Building

Elevation: $++3 \mathrm{~m}$

\section{CONSTRUCTION BOUNDARIES}

\begin{tabular}{|c|c|c|c|c|c|c|c|}
\hline \multirow[t]{2}{*}{ Boundary } & $\begin{array}{c}\text { Fire } \\
\text { Barrier }\end{array}$ & \multirow[t]{2}{*}{$\begin{array}{c}\text { Fire } \\
\text { Barrier } \\
\text { Rating } \\
\text { (Minutes) }\end{array}$} & \multirow[t]{2}{*}{$\begin{array}{c}\text { Material of } \\
\text { Construction }\end{array}$} & \multirow[t]{2}{*}{$\begin{array}{c}\text { Thickness } \\
\text { (mm, } \\
\text { approx.) }\end{array}$} & \multirow[t]{2}{*}{ Covering } & \multirow[t]{2}{*}{$\begin{array}{l}\text { Adjacent } \\
\text { Fire } \\
\text { Comp/Cell }\end{array}$} & \multirow[t]{2}{*}{$\begin{array}{l}\text { Verified } \\
\text { (as built) }\end{array}$} \\
\hline & Yes/No & & & & & & \\
\hline Wall 1 & Yes & 90 & concrete & 300 & paint & none & RN. \\
\hline Wall 2 & No & - & concrete & 150 & paint & RB-CEL-004 & RN. \\
\hline Wall 3 & No & - & concrete & 150 & paint & RB-CEL-007 & RN. \\
\hline Wall 4 & No & - & concrete & 150 & paint & RB-CEL-009 & RN. \\
\hline Wall 5 & No & -- & concrete & 150 & paint & RB-CEL-009 & RN. \\
\hline Wall 6 & Yes & 90 & concrete & 300 & paint & none & RN. \\
\hline \multicolumn{8}{|l|}{ Wall 7} \\
\hline \multicolumn{8}{|l|}{ Wall 8} \\
\hline Ceiling & No & - & concrete & 200 & paint & RB-CEL-010 & RN: \\
\hline Floor & No & - & concrete & 200 & paint & none & RN. \\
\hline
\end{tabular}

COMMENTS: None. 


\section{U.S. DEPARTMENT OF ENERGY'S REACTOR CORE}

PROTECTION EVALUATION METHODOLOGY FOR FIRES AT

SOVIET-DESIGNED RBMK AND VVER NUCLEAR POWER PLANTS

«\%:

\section{FIRE COMPARTMENT/FTRE CELL WALKDOWN CHECKLIST (Continued)}

3. MAJOR EQUTPMENT AND COMPONENTS Compartment No. RB-COM-001

Cell No. RB-CEL-006

3A. Safe Shutdown Related

\begin{tabular}{|l|l|l|}
\hline Item & \multicolumn{1}{|c|}{ Equipment Number } & \multicolumn{1}{|c|}{ Equipment Name/Description } \\
\hline 1. & P-ES-001 & Emergency Pump \#1 \\
\hline 2. & P-ES-002 & Emergency Pump \#2 \\
\hline 3. & T-ES-001 & Emergency Storage Tank \\
\hline 4. & MV-ES-001 & Motor Operated Valve \#1 \\
\hline 5. & MV-ES-002 & Motor Operated Valve \#2 \\
\hline 6. & & \\
\hline 7. & & \\
\hline 8. & & \\
\hline 9. & & \\
\hline 10. & & \\
\hline 11. & & \\
\hline 12. & & \\
\hline 13. & & \\
\hline 14. & & \\
\hline 15. & & \\
\hline 16. & & \\
\hline 17. & & \\
\hline 18. & & \\
\hline 19. & & \\
\hline 20. & & \\
\hline
\end{tabular}

COMMENTS: None. 
U.S. DEPARTMENT OF ENERGY'S REACTOR CORE

PROTECTION EVALUATION METHODOLOGY FOR FIRES AT

SOVIET-DESIGNED RBMK AND VVER NUCLEAR POWER PLANTS

w1

FIRE COMPARTMENT/FIRE CELL WALKDOWN CHECKLIST (Continued)

3. MAJOR EQUTPMENT AND COMPONENTS

Compartment No. RB-COM-001

Cell No. RB-CEL-006

3B. Non-Shutdown Related (large or significant equipment and components)

\begin{tabular}{|l|l|l|}
\hline Item & \multicolumn{1}{|c|}{ Equipment Number } & \multicolumn{1}{|c|}{ Equipment Name/Description } \\
\hline 1. & P-OS-010 & Transfer Pump \#10 \\
\hline 2. & T-OS-003 & Holding Tank \#3 \\
\hline 3. & & \\
\hline 4. & & \\
\hline 5. & & \\
\hline 6. & & \\
\hline 7. & & \\
\hline 8. & & \\
\hline 9. & & \\
\hline 10. & & \\
\hline 11. & & \\
\hline 12. & & \\
\hline 13. & & \\
\hline 14. & & \\
\hline 15. & & \\
\hline 16. & & \\
\hline 17. & & \\
\hline 18. & & \\
\hline 19. & & \\
\hline 20. & & \\
\hline
\end{tabular}

COMMENTS: None. 
FIRE COMPARTMENT/FIRE CELL WALKDOWN CHECKLIST (Continued)

\section{DOORS}

Compartment No. RB-COM-001

Cell No._RB-CEL-006

\begin{tabular}{|c|c|c|c|c|c|c|c|c|}
\hline $\begin{array}{c}\text { Door } \\
\text { Number } \\
\text { /Wall } \\
\text { Number }\end{array}$ & $\begin{array}{c}\text { Reference } \\
\text { Drawing }\end{array}$ & \begin{tabular}{|c|}
$\begin{array}{c}\text { Fire } \\
\text { Door }\end{array}$ \\
Yes/No
\end{tabular} & $\begin{array}{c}\text { Rating } \\
\text { (Minutes) }\end{array}$ & Material/ Type & \begin{tabular}{|c|}
$\begin{array}{c}\text { Door } \\
\text { Closer }\end{array}$ \\
Yes/No
\end{tabular} & $\begin{array}{c}\text { Condition/Fit } \\
\text { /Operation } \\
\text { (A/M/U) }\end{array}$ & $\begin{array}{c}\text { Position } \\
(\mathrm{O} / \mathrm{BO} / \mathrm{C} / \mathrm{LC})\end{array}$ & $\begin{array}{c}\text { Adjacent Fire } \\
\text { Comp/Cell }\end{array}$ \\
\hline $1 / 2$ & A-001 & No & - & $\begin{array}{l}\text { single wood door, } 1 \mathrm{~m} \\
\text { wide, } 20 \mathrm{~mm} \text { thick }\end{array}$ & No & $M / M / U$ & 0 & RB-CEL-004 \\
\hline $3 / 4$ & A-001 & No & - & same & Yes & $A / A / A$ & $\mathrm{BO}$ & RB-CEL-009 \\
\hline \multicolumn{9}{|l|}{$4 /$} \\
\hline \multicolumn{9}{|l|}{51} \\
\hline \multicolumn{9}{|l|}{61} \\
\hline \multicolumn{9}{|l|}{$10 /$} \\
\hline COMMEN & None. & & & LEGEND: & $\begin{array}{l}\text { cceptable } \\
\text { larginal } \\
\text { nacceptable }\end{array}$ & $\begin{array}{l}\text { O - Open } \\
\text { BO - Blocked } \\
\text { C - Closed }\end{array}$ & pen & cked Closed \\
\hline
\end{tabular}




\section{FIRE COMPARTMENT/FIRE CELL WALKDOWN CHECKLIST (Continued)}

\section{PENETRATIONS}

Compartment No. RB-COM-001

Cell No. RB-CEL-006

\section{A. Wall Penetrations}

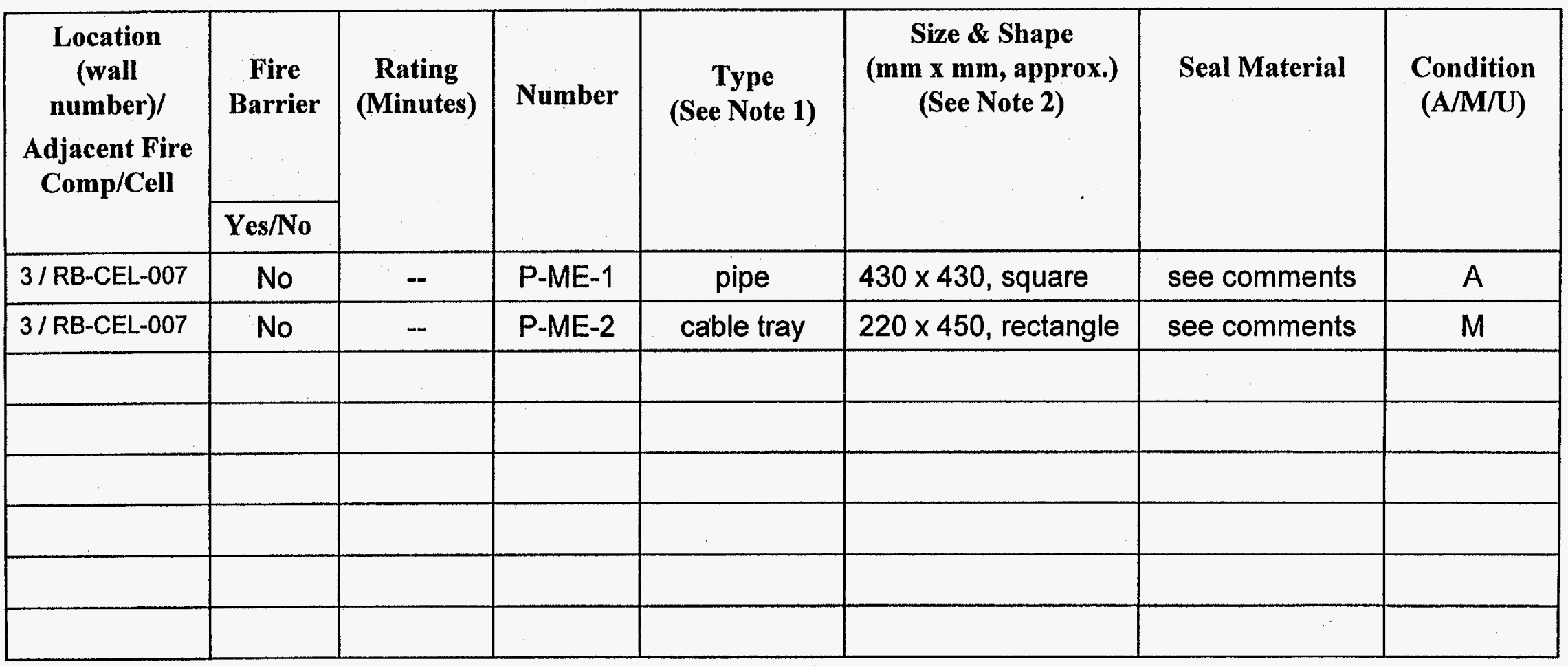

Note 1: Enter type, such as: Cable, Cable Tray, Conduit, Pipe, Duct, etc. Note 2: Indicate shape as rectangular, circular, etc.

COMMENTS: Seal material is an unknown foam.
LEGEND:

$$
\begin{aligned}
& \text { A - Acceptable } \\
& \text { M - Marginal } \\
& \text { U - Unacceptable }
\end{aligned}
$$




\section{FIRE COMPARTMENT/FIRE CELL WALKDOWN CHECKLIST (Continued)}

5. PENETRATIONS (continued)

Compartment No. RB-COM-001 Cell No. RB-CEL-006

5B. Ceiling Penetrations

\begin{tabular}{|c|c|c|c|c|c|c|c|}
\hline $\begin{array}{c}\text { Location/ } \\
\text { Adjacent } \\
\text { Fire Comp/ } \\
\text { Cell }\end{array}$ & $\begin{array}{c}\text { Fire } \\
\text { Barrier } \\
\text { Yes/No }\end{array}$ & $\begin{array}{c}\text { Rating } \\
\text { (Minutes) }\end{array}$ & Number & $\begin{array}{c}\text { Type } \\
\text { (See Note 1) }\end{array}$ & $\begin{array}{l}\text { Size \& Shape } \\
\text { (mm x mm, } \\
\text { approx.) } \\
\text { (See Note 2) }\end{array}$ & Seal Material & $\begin{array}{c}\text { Condition } \\
\text { (A/M/U) }\end{array}$ \\
\hline $\begin{array}{l}\text { Ceiling / } \\
\text { RB-CEL-010 }\end{array}$ & No & - & P-ME-3 & pipe & $380 \times 380$, square & see comments & $\mathrm{U}$ \\
\hline & & & & & & & \\
\hline & & & & & & & \\
\hline & & & & & & & \\
\hline
\end{tabular}

Note 1: Enter type, such as: Cable, Cable Tray, Conduit, Pipe, Duct, etc. Note 2: Indicate shape as rectangular, circular, etc.

COMMENTS: Seal material is an unknown foam.
LEGEND:

A - Acceptable

M - Marginal

U - Unacceptable 
FIRE COMPARTMENT/FIRE CELL WALKDOWN CHECKLIST (Continued)

\section{PENETRATIONS (continued)}

\section{C. Floor Penetrations}

\begin{tabular}{|c|c|c|c|c|c|c|c|c|c|}
\hline \multirow[t]{2}{*}{$\begin{array}{c}\text { Location/ } \\
\text { Adjacent } \\
\text { Fire Comp/ } \\
\text { Cell }\end{array}$} & \multirow{2}{*}{$\begin{array}{c}\begin{array}{c}\text { Fire } \\
\text { Barrier }\end{array} \\
\text { Yes/No }\end{array}$} & \multirow[t]{2}{*}{$\begin{array}{c}\text { Rating } \\
\text { (Minutes) }\end{array}$} & \multirow[t]{2}{*}{ Number } & \multirow[t]{2}{*}{$\begin{array}{c}\text { Type } \\
\text { (See Note 1) }\end{array}$} & \multirow[t]{2}{*}{$\begin{array}{c}\text { Size \& } \\
\text { Shape } \\
\text { (mm x mm, } \\
\text { approx.) }\end{array}$} & \multirow[t]{2}{*}{$\begin{array}{c}\text { Seal } \\
\text { Material }\end{array}$} & \multirow[t]{2}{*}{$\begin{array}{l}\text { Condition } \\
(\mathrm{A} / \mathrm{M} / \mathrm{U})\end{array}$} & \multicolumn{2}{|c|}{ Floor Curbs } \\
\hline & & & & & & & & Yes/No & $\begin{array}{l}\text { Height } \\
\text { (mm) }\end{array}$ \\
\hline $\begin{array}{l}\text { Floor / } \\
\text { RB-CEL-BAS }\end{array}$ & No & - & P-ME-4 & pipe & $\begin{array}{l}380 \times 380, \\
\text { square }\end{array}$ & $\begin{array}{c}\text { see } \\
\text { comments }\end{array}$ & $u$ & Yes & 100 \\
\hline & & & & & & & & & \\
\hline & & & & & & & & & \\
\hline & & & & & & & & & \\
\hline & & & & & & & & & \\
\hline & & & & & & & & & \\
\hline
\end{tabular}

Note 1: Enter type, such as: Cable, Cable Tray, Conduit, Pipe, Duct, etc.

Note 2: Indicate shape as rectangular, circular, etc.

COMMENTS: Seal material is an unknown foam.
Compartment No. RB-COM-001

Cell No. RB-CEL-006
LEGEND:

A - Acceptable

M - Marginal

$\mathrm{U}$ - Unacceptable 
U.S. DEPARTMENT OF ENERGY'S REACTOR CORE

PROTECTION EVALUATION METHODOLOGY FOR FIRES AT

SOVIET-DESIGNED RBMK AND VVER NUCLEAR POWER PLANTS

FIRE COMPARTMENT/FIRE CELL WALKDOWN CHECKLIST (Continued)

6. STRUCTURAL

Compartment No. RB-COM-001

Cell No. RB-CEL-006

\begin{tabular}{|c|c|c|c|c|c|}
\hline \multirow[t]{2}{*}{ Item } & \multirow[t]{2}{*}{ Material } & Fireproofing & Rating & Condition & \multirow[t]{2}{*}{ Comments } \\
\hline & & Yes/No & (Minutes) & $(\mathrm{A} / \mathrm{M} / \mathrm{U})$ & \\
\hline \multicolumn{6}{|c|}{ Beams } \\
\hline 1. $\mathrm{B}-1$ & steel & No & - & - & $\begin{array}{l}\text { Beams were } \\
\text { arbitrarily }\end{array}$ \\
\hline 2. $\mathrm{B}-2$ & steel & No & - & - & $\begin{array}{l}\text { numbered in the } \\
\text { field. }\end{array}$ \\
\hline 3. $B-3$ & steel & No & - & - & Need formal beam \\
\hline 4. $B-4$ & steel & No & - & - & numbers. \\
\hline \multicolumn{6}{|l|}{5.} \\
\hline \multicolumn{6}{|l|}{6.} \\
\hline \multicolumn{6}{|l|}{7.} \\
\hline \multicolumn{6}{|c|}{ Columns } \\
\hline 1. C-A & steel & Yes & 60 & A & Columns were \\
\hline 2. C-B & steel & Yes & 60 & A & $\begin{array}{l}\text { arbitrarily numbered } \\
\text { in }\end{array}$ \\
\hline 3. $C-C$ & steel & Yes & 60 & M & $\begin{array}{l}\text { the field. Need } \\
\text { formal }\end{array}$ \\
\hline 4. $C-D$ & steel & Yes & 60 & $\mathrm{U}$ & column numbers. \\
\hline \multicolumn{6}{|l|}{5.} \\
\hline \multicolumn{6}{|l|}{6.} \\
\hline 7. & & & & & \\
\hline
\end{tabular}

LEGEND: A - Acceptable

M - Marginal

U - Unacceptable 
FIRE COMPARTMENT/FIRE CELL WALKDOWN CHECKLIST (Continued)

7. COMBUSTIBLE MATERIAL

Compartment No. RB-COM-001

Cell No. RB-CEL-006

\begin{tabular}{|l|c|c|}
\hline \multicolumn{1}{|c|}{ Type } & Fixed Quantity & Transient Quantity \\
\hline Cable insulation & $110 \mathrm{~kg}$ & \\
\hline Lube Oil & 2001 & \\
\hline Wood & & $10 \mathrm{~kg}$ \\
\hline Plastic & & \\
\hline Plastic Floor Covering & & \\
\hline Paper & & \\
\hline Grease & & \\
\hline $\begin{array}{l}\text { Gases, in bottles/tanks } \\
\text { (list) }\end{array}$ & & \\
\hline & & \\
\hline & & \\
\hline & & \\
\hline Other (list) & & \\
\hline kerosene & & \\
\hline rags & & \\
\hline & & \\
\hline
\end{tabular}

COMMENTS: Kerosene is stored in rated containers. Rags are stored in an open drum. Wood and plastic are maintenance items temporarily stored in this compartment. 
FIRE COMPARTMENT/FIRE CELL WALKDOWN CHECKLIST (Continued)

8. FLRE SUPPRESSION SYSTEMS

Compartment No. RB-COM-001

Cell No. RB-CEL-006

\begin{tabular}{|c|c|c|c|c|c|}
\hline \multicolumn{2}{|c|}{$\begin{array}{c}\text { Primary Means of } \\
\text { Fire Suppression }\end{array}$} & \multirow[t]{2}{*}{$\begin{array}{c}\text { Type of } \\
\text { Fixtures } \\
\text { (See Note 1) }\end{array}$} & \multirow[t]{2}{*}{$\begin{array}{l}\text { Number of } \\
\text { Fixtures }\end{array}$} & \multirow[t]{2}{*}{$\begin{array}{c}\text { Location } \\
\text { (Reference Drawing or } \\
\text { Sketch Number) }\end{array}$} & \multirow[t]{2}{*}{$\begin{array}{l}\text { Condition } \\
(\mathrm{A} / \mathrm{M} / \mathrm{U})\end{array}$} \\
\hline Type & Yes/No & & & & \\
\hline Sprinkler & Yes & Fusible Link & 11 & sketch A & $M$ \\
\hline Deluge & No & & & & \\
\hline Halon & No & & & & \\
\hline $\mathrm{CO}_{2}$ & No & & & & \\
\hline & & & & & \\
\hline
\end{tabular}

Note 1: Enter type, such as closed head (fusible link) sprinkler, open head sprinkler, nozzle, etc.

COMMENTS: Sprinkler head in northwest corner of room is leaking onto pump P-ES-002.

\section{FIRE DETECTION SYSTEMS}

\begin{tabular}{|c|c|c|c|c|c|}
\hline \multicolumn{2}{|c|}{ Fire Detection } & \multirow[t]{2}{*}{$\begin{array}{l}\text { Number of } \\
\text { Detectors }\end{array}$} & \multirow[t]{2}{*}{$\begin{array}{c}\text { Location } \\
\text { - (Reference } \\
\text { Drawing or Sketch } \\
\text { Number) }\end{array}$} & \multirow[t]{2}{*}{$\begin{array}{l}\text { Condition } \\
(\mathrm{A} / \mathrm{M} / \mathrm{U})\end{array}$} & \multirow[t]{2}{*}{$\begin{array}{c}\text { Alarm } \\
\text { Location } \\
\text { (See Note 2) }\end{array}$} \\
\hline Type & Yes/No & & & & \\
\hline Smoke & Yes. & 2 & sketch A & A & $\begin{array}{c}\text { Remote Panel } \\
\text { B } \\
\end{array}$ \\
\hline Heat & No & & & & \\
\hline Linear Thermal & No & & & & \\
\hline Pneumatic & No & & & & \\
\hline $\begin{array}{l}\text { Manual Pull } \\
\text { Station }\end{array}$ & Yes & 1 & sketch A & $\mathrm{U}$ & $\begin{array}{l}\text { Remote Panel } \\
\text { B \& Control } \\
\text { Rm. }\end{array}$ \\
\hline
\end{tabular}

Note 2: Enter location of fire annunciator, such as Local or Remote Panel, Control Room, etc.

COMMENTS: Manual Pull Station is painted LEGEND: A - Acceptable over. May not operate properly. 
FIRE COMPARTMENT/FIRE CELL WALKDOWN CHECKLIST (Continued) 10. FIRE HOSE STATIONS AND WATER CANNONS

Compartment No. RB-COM-001 Cell No. RB-CEL-006

10A. Fire Hose Stations

\begin{tabular}{|c|c|c|c|c|c|c|c|}
\hline \multirow[t]{2}{*}{ Area } & Hose Station & \multirow[t]{2}{*}{$\begin{array}{l}\text { Number } \\
\text { of } \\
\text { Stations }\end{array}$} & \multirow[t]{2}{*}{$\begin{array}{c}\text { Location } \\
\text { (Reference } \\
\text { Drawing Number) }\end{array}$} & Accessible & $\begin{array}{c}\text { Shutoff } \\
\text { Valve } \\
\text { Operable } \\
\end{array}$ & \multirow[t]{2}{*}{$\begin{array}{c}\text { Hose } \\
\text { Condition } \\
\text { (AVU) }\end{array}$} & \multirow[t]{2}{*}{$\begin{array}{l}\text { Nozzle } \\
\text { Condition } \\
\text { (A) }\end{array}$} \\
\hline & Yes/No & & & Yes/No & Yes/No & & \\
\hline Inside & Yes & 1 & $A-001$ & Yes & Yes & A & A \\
\hline
\end{tabular}

COMMENTS: None.

10B. Water Cannons

\begin{tabular}{|l|c|c|c|c|c|}
\hline \multirow{2}{*}{ Area } & Water Cannon & \multirow{2}{*}{ Number } & $\begin{array}{c}\text { Location (Reference } \\
\text { Drawing Number) }\end{array}$ & Accessible & $\begin{array}{c}\text { Condition } \\
\text { (A/U) }\end{array}$ \\
\cline { 2 - 3 } & Yes/No & & & Yes/No & \\
\hline Inside & No & & & & \\
\hline Adjacent & No & & & & \\
\hline
\end{tabular}

COMMENTS: None.

\section{PORTABLE FIRE EXTINGUISHERS}

\begin{tabular}{|c|c|c|c|c|c|c|c|}
\hline \multirow{2}{*}{ Area } & $\begin{array}{l}\text { Portable Fire } \\
\text { Extinguishers }\end{array}$ & \multirow[t]{2}{*}{ Number } & \multirow[t]{2}{*}{ Type } & \multirow[t]{2}{*}{$\begin{array}{c}\text { Location } \\
\text { (Reference } \\
\text { Drawing } \\
\text { Number) }\end{array}$} & Accessible & \multirow[t]{2}{*}{$\begin{array}{c}\text { Condition } \\
\text { (A/U) }\end{array}$} & $\begin{array}{c}\text { Type Correct } \\
\text { for } \\
\text { Application }\end{array}$ \\
\hline & Yes/No & & & & Yes/No & & Yes/No \\
\hline Inside & Yes & 1 & $\begin{array}{l}\text { see } \\
\text { below }\end{array}$ & sketch B & Yes & A & Yes \\
\hline Adjacent & Yes & 1 & $\begin{array}{l}\text { see } \\
\text { below }\end{array}$ & & Yes & $\mathrm{U}$ & Yes \\
\hline
\end{tabular}

COMMENTS: Both extinguishers are suitable for ordinary LEGEND: combustibles, flammable liquids, and A - Acceptable electrical fires. However, extinguisher in U - Unacceptable cell RB-CEL-004 does not read "full". 


\section{FIRE COMPARTMENT/FIRE CELL WALKDOWN CHECKLIST (Continued)}

12. DRAINAGE

Compartment No. RB-COM-001 Cell No. RB-CEL-006

\begin{tabular}{|c|c|c|c|c|c|c|}
\hline Floor Drains & $\begin{array}{c}\text { Do Floor Drains Appear } \\
\text { To Be in Working } \\
\text { Condition }\end{array}$ & $\begin{array}{c}\text { Drain } \\
\text { Pits/Sumps }\end{array}$ & $\begin{array}{c}\text { Drain Located } \\
\text { in Pit/Sump }\end{array}$ & $\begin{array}{c}\text { Equipment } \\
\text { Curbs }\end{array}$ & $\begin{array}{c}\text { Curb Height } \\
\text { (cm) }\end{array}$ & $\begin{array}{c}\text { Dikes Around } \\
\text { Tanks }\end{array}$ \\
\hline Yes/No & Yes/No & Yes/No & Yes/No & Yes /No & Yes/No \\
\hline Yes & Yes & Yes & No & No & - & No \\
\hline
\end{tabular}

COMMENTS: Drain pits are located at pumps P-ES-001 and P-ES-002 to contain lube oil spills. Tanks T-ES-001 and T-OS-003 do not contain combustible fluids, so dikes should not be required.

13. VENTILATION

\begin{tabular}{|c|c|c|c|c|c|c|}
\hline Supply Air & $\begin{array}{c}\text { Supply Air } \\
\text { Automatic } \\
\text { Shutdown }\end{array}$ & Exhaust Air & $\begin{array}{c}\text { Exhaust Air } \\
\text { Automatic } \\
\text { Shutdown }\end{array}$ & $\begin{array}{c}\text { Fixed Smoke } \\
\text { Removal } \\
\text { System }\end{array}$ & $\begin{array}{c}\text { Fire Dampers in } \\
\text { Ducts at Fire } \\
\text { Barriers }\end{array}$ & Transfer Air \\
\hline Yes/No & Yes/No & Yes/No & Yes/No & Yes/No & Yes/No & Yes/No \\
\hline Yes & No & No & No & No & No & Yes \\
\hline
\end{tabular}

COMMENTS: Opening in Wall 3 allows transfer air between this cell and RB-CEL-007. Opening in Wall 2 allows transfer air between this cell and RB-CEL-004. 
U.S. DEPARTMENT OF ENERGY'S REACTOR CORE

PROTECTION EVALUATION METHODOLOGY FOR FIRES AT

SOVIET-DESIGNED RBMK AND VVER NUCLEAR POWER PLANTS

.

FIRE COMPARTMENT/FIRE CELL WALKDOWN CHECKLIST (Continued)

14. EMERGENCY LIGHTING

Compartment No. RB-COM-001

Cell No. RB-CEL-006

\begin{tabular}{|l|c|c|c|c|l|}
\hline \multirow{4}{*}{ Area } & \multicolumn{3}{|c|}{$\begin{array}{c}\text { Number of Each } \\
\text { Type of Fixture }\end{array}$} & $\begin{array}{c}\text { Do } \\
\text { Lights } \\
\text { Work }\end{array}$ & \multicolumn{1}{|c|}{ Apparent lighting function(s) } \\
\cline { 2 - 6 } & $\begin{array}{c}\text { Battery } \\
\text { Pack }\end{array}$ & $\begin{array}{c}\text { Hard } \\
\text { Wired }\end{array}$ & $\begin{array}{c}\text { Other } \\
\text { (Type) }\end{array}$ & Yes/No & \\
\hline $\begin{array}{l}\text { Compart./ } \\
\text { Cell }\end{array}$ & 3 & & & No & $\begin{array}{l}\text { 2 of the 3 fixtures provide general } \\
\text { area lighting. Other unit is aimed at } \\
\text { Start/Stop switch of pump P-ES-001. } \\
\text { See comments. }\end{array}$ \\
\hline $\begin{array}{l}\text { Access } \\
\text { Route }\end{array}$ & & 6 & & Yes & Provide general area lighting. \\
\hline $\begin{array}{l}\text { Egress } \\
\text { Route }\end{array}$ & & & & & $\begin{array}{l}\text { Access/Egress routes are the same, } \\
\text { RB-CEL-004. }\end{array}$ \\
\hline
\end{tabular}

COMMENTS: The lighting fixture aimed at the Start/Stop switch of P-ES-001 does not function.

\section{EMERGENCY COMMUNICATIONS}

\begin{tabular}{|c|c|c|c|c|c|}
\hline \multirow{2}{*}{ Area } & $\begin{array}{c}\text { Telephones/ } \\
\text { Two-way PA } \\
\text { System }\end{array}$ & Operational & $\begin{array}{c}\text { Portable } \\
\text { Radio }\end{array}$ & Operational & $\begin{array}{c}\text { Communication } \\
\text { Available with } \\
\text { Control Room } \\
\text { and Fire } \\
\text { Command } \\
\text { Center? }\end{array}$ \\
\cline { 2 - 7 } & Yes/No & Yes/No & Yes/No & Yes/No & Yes/No \\
\hline Compart./Cell & Yes & Yes & No & - & No \\
\hline Access Route & Yes & Yes & No & - & No \\
\hline Egress Route & & & & & \\
\hline
\end{tabular}

COMMENTS: Telephone in cell only communicates with the Control Room. 


\section{PERFORM VERIFICATION WALKDOWNS OF FIRE} COMPARTMENTS/CELLS

This section of the Methodology provides guidance for performing fire hazard analysis walkdowns for each fire compartment/fire cell. Using the individual Fire Compartment/Fire Cell Walkdown Checklists that were generated in Section 4.8, previously entered data is verified and new information added based on visual examinations of each compartment and cell. Upon completion, all pertinent information will have been entered onto or attached to the Checklist so that each fire compartment and fire cell can be qualitatively evaluated.

The following general suggestions are given for walkdowns:

- Walkdown parties should consist of at least two people for safety reasons. One can perform the visual examinations and the other can record them on the Checklists. The two can then check each other's work.

- For efficiency, walkdowns should be performed in the compartments/cells of one building at a time. Multiple walkdown parties can work in a single building, referring to each other's drawings and documents if necessary.

- As a minimum, the following items should always accompany a walkdown party: drawings, hard hats, flashlights, mirrors, and a tape measure. These should be obtained before the walkdown begins.

- Missing information should be entered and erroneous information corrected on the Checklists. If drawings are found to be incorrect, note this in the Comment section of the Checklist so that they may be corrected later.

- The control room should be notified of the locations being walked down and of the intent of the walkdown.

- Permission should be obtained if any doors must be opened, equipment hatches opened, valves/switches operated, etc.

- The plant radiation control personnel should be notified of the intent to enter any radiation controlled area.

Each data sheet that is filled out should be initialed and dated by the preparer. If more than one person enters data onto a sheet, then the person entering the data should initial and date next to the specific information that he entered. 
Some reviews of equipment and materials utilize three categories: Acceptable, Marginal, and Unacceptable. The "marginal" category is intended to be utilized only when the condition is close to being acceptable but certain features leave some doubt that the item will function as intended. All "marginal" items will require a confirmation walkdown during the compartment/cell evaluations performed in Section 4.11 to finalize their classification to either "Acceptable" or "Unacceptable".

The personnel assigned to perform the walkdowns should be qualified to assess the physical conditions of the items being reviewed and to perform the evaluations required by the checklist.

In addition, if further details are needed to complete the functional evaluation in Section 4.6, these details should be gathered during the walkdowns. Exhibit 4.6-1 should then be completed before continuing with Section 4.11 .

\subsubsection{FIRE COMPARTMENT AND FIRE CELL DATA}

This section uses the Fire Compartment/Fire Cell Walkdown Checklists and their attached drawings/sketches that were prepared in Section 4.8. Part 1 of the Checklist identifies the fire compartment/cell and its location. This part should be completely filled out.

4.9.1.1 Verify that all requested information has been provided in Part 1 of the Checklist.

4.9.1.2 Perform a walkdown for each fire compartment/fire cell.

\subsubsection{CONSTRUCTION BOUNDARIES}

Part 2 of the Fire Compartment/Fire Cell Walkdown Checklist identifies the construction boundaries (walls, floor, and ceiling) of the fire compartment/fire cell.

4.9.2.1 Review the marked-up Fire Compartment/Fire Cell Drawings for the wall numbers and fire barriers pertaining to the fire compartment/fire cell. Verify that the fire barrier layout is indicated correctly on the drawings.

4.9.2.2 Examine each wall one at a time. Verify or determine the wall's construction material and its approximate thickness.

4.9.2.3 Identify the type of covering on each wall, if any.

Guidance: Examples of wall covering are paint, plastic sheets, and wood paneling. 
4.9.2.4 As the examination of each wall is completed, place an initial in the Verified (asbuilt) column of the Checklist to indicate that all information for that wall is complete and visually confirmed.

4.9.2.5 Repeat the above steps for the ceiling and floor of the fire compartment/fire cell.

\section{MAJOR EQUTPMENT AND COMPONENTS OF SELECTED SHUTDOWN SYSTEMS}

Part 3 of the Fire Compartment/Fire Cell Walkdown Checklist identifies safe shutdown equipment located in the fire compartment/fire cell. Large or significant pieces of non-safe shutdown related equipment are also identified.

4.9.3.1 Verify that all equipment identified in Part 3A of the Checklist is located in the fire compartment/fire cell.

4.9.3.2 A list of shutdown equipment that could not be located on any drawing was generated in Section 4.8.3. Determine if any of the equipment on that list is in the fire compartment/fire cell. If so, enter the equipment in Part 3A of the Checklist and mark its location on the Fire Compartment/Fire Cell Drawings.

4.9.3.3 Add to Part 3B of the Checklist all large or significant pieces of non-safe shutdown equipment found in the compartment/cell.

Guidance: Equipment to be listed would include any equipment that could initiate a fire or contribute to the continuance of a fire, such as electrical power cabinets, equipment with large motors, equipment with lubricating oil reservoirs, etc.

\subsubsection{DOORS}

Part 4 of the Fire Compartment/Fire Cell Walkdown Checklist identifies the doors associated with each fire compartment/fire cell, determines their condition, and assesses their capability to maintain the fire rating of their associated fire barriers.

4.9.4.1 Review the Fire Compartment/Fire Cell Drawings for door numbers. Verify that fire doors are indicated correctly on the Checklist. Correct the Checklist as required.

4.9.4.2 Verify the fire rating of each door by locating its resistance rating tag, if it exists (the tag may be affixed to the door itself or its jamb).

4.9.4.3 Record the material of construction and the type of doors. 
Guidance: An example entry would be "single steel door, 1 meter wide, $4 \mathrm{~cm}$ thick."

4.9.4.4 Indicate if the door is provided with an automatic closing device that will automatically close and latch the door when it is released from the open position.

4.9.4.5 Indicate the physical condition of each door, using the legend in Part 4 of the Checklist.

Guidance: The physical condition of the door may be evaluated using the following descriptions.

- A - Acceptable

Door appears to be well constructed. All edges are sound with no space between materials. Frames are well anchored to walls. If doors have a fire resistance rating and are labeled as fire doors, indicate this information in the comments section. If it appears that the door would offer some resistance to fire, indicate this information in the comments section.

- $\quad$ M - Marginal

Door appears to be moderately constructed. Minor separation between materials. Door frame is of marginal quality.

- U - Unacceptable

Doors are poorly constructed. Separation between materials is readily apparent. Door appears damaged or in very poor condition.

4.9.4.6 In the same column in Part 4, indicate the fit between the door and the door frame, using the legend on the Checklist.

Guidance: The fit of the doors may be evaluated using the following descriptions:

- A - Acceptable

Door is tight fitting to frame. Door does not bind in frame. No visible gaps between door and frame. No direct line of sight through gap.

- $\quad$ M - Marginal

Door fits moderately in frame. Minor gaps between door and frame. 
- U - Unacceptable

Door fits poorly in frame. Visible gaps between door and frame. Effort required to open and/or close door. Direct line of sight through gaps.

4.9.4.7 In the same column in Part 4, indicate the overall operation of the door, using the legend on the Checklist.

Guidance: Examine how the door opens and closes. The operation of the doors may be evaluated using the following descriptions:

- A - Acceptable

Door opens and closes smoothly without sticking. Latching mechanism operates smoothly. Door closers, if applicable, return doors to the closed and latched position.

- M - Marginal

Door opens and closes with minor sticking. Minor binding of latching mechanism. Door closers, if applicable, return door to the closed position, but latch does not engage.

- U - Unacceptable

Effort required to open and close door. Door binds in frame. Latching mechanism difficult to operate. Door closers, if applicable, do not return door to the closed position.

4.9.4.8 Indicate the as-found position of each door, using the legend on the Checklist.

\subsubsection{PENETRATIONS}

Part 5 of the Fire Compartment/Fire Cell Walkdown Checklist identifies the penetrations through each fire barrier, determines their conditions, and qualitatively assesses their capabilities to maintain the fire rating of each barrier.

4.9.5.1 Using the wall, ceiling, and floor penetration drawings gathered in Section 4.8.5, verify the entries previously made in Parts 5A, 5B, and 5C of the Checklist.

4.9.5.2 Examine each penetration of the compartment/cell. Indicate the condition of each penetration's seal material, using the legends in Parts 5A, 5B, and 5C. 


\section{U.S. DEPARTMENT OF ENERGY'S REACTOR CORE PROTECTION EVALUATION METHODOLOGY FOR FIRES AT

Guidance: The condition of penetration seals may be evaluated using the following descriptions.

- A - Acceptable

Penetration seal appears to be undisturbed and undamaged. Surface may have minor cosmetic defects but does not have any deep gouges or cracks. Seal material appears to adhere or butt up tightly against the sides of the penetration opening and all penetrating items. Seal material appears to be sound, with no sign of flaking, dusting, or peeling. No through holes. No visible passage of light.

- $\quad$ - Marginal

Penetration appears to have some minor physical damage but is generally undisturbed. Defects may be more than cosmetic, with some deep gouges (less than $5 \mathrm{~mm}$ ) or tightly fitting cracks. Some minor separation appears at the penetration/seal interface or at the penetrating items. Seal material appears generally sound, with little or no sign of flaking, dusting, or peeling. No through holes. No visible passage of light.

- U - Unacceptable

Penetration seal appears to have been disturbed or is damaged. Surface is not smooth and has noticeable defects such as gouges or cracks. Seal material may be separated from penetrations at edges or at penetrating items. Signs of significant flaking, dusting or peeling. Seal has through holes or passes light.

Note: Any holes that go completely through a penetration or any penetration that passes light through the penetration should result in an unacceptable condition without regard to any other seal characteristics.

\subsubsection{STRUCTURAL}

Part 6 of the Fire Compartment/Fire Cell Walkdown Checklist identifies structural beams and columns within the fire compartment/fire cell.

4.9.6.1 Record all visible beams and columns in the fire compartment/fire cell on the Checklist. Formal column or beam numbers, if assigned by the plant, should be used. If no beams or columns are located in the fire compartment/fire cell, note this in the Comments column of the Checklist.

4.9.6.2 Indicate the material of each beam or column. 
4.9.6.3 Indicate if each beam or column has a fireproof coating and the rating of that coating. Coating resistance rating information, if any, was determined in Section 4.6.4.

4.9.6.4 Examine each beam or column with fireproof coating. Indicate the condition of the coating using the legend in Part 6 of the Checklist.

Guidance: The conditions of fireproof coatings are normally assessed based on comparisons with manufacturer's photographs of properly and improperly applied coatings. If such photographs are not available, coating condition may be evaluated using the following descriptions.

- A - Acceptable

The coating material appears uniform and undamaged throughout. The surfaces do not have deep gouges or cracks that reveal the beam or column beneath. The coating appears to be sound, with no sign of flaking, dusting, or peeling.

- M - Marginal

The coating material appears to have some minor physical damage but is generally uniform and undisturbed. Some gouges or tightly fitting cracks are present. The gouges are not more than $5 \mathrm{~mm}$ wide and do not reveal the beam or column beneath. The coating appears generally sound, with little or no sign of flaking, dusting, or peeling.

- U - Unacceptable

The coating material appears to have been disturbed or is damaged. Coating coverage is not uniform. Deep cracks or gouges are present that reveal the beam or column beneath. Surface is not smooth and has noticeable defects such as gouges or cracks. The coating material may be separated from the beam or column. Signs of significant flaking, dusting or peeling are present.

\subsubsection{COMBUSTIBLE MATERIAL}

Part 7 of the Fire Compartment/Fire Cell Walkdown Checklist estimates the extent of combustible materials located or stored within the fire compartment/fire cell.

4.9.7.1 Estimate the quantities of fixed combustible materials such as cable insulation, oil, gas, wood, plastic, and paper within the fire compartment/fire cell and enter them on the Checklist. 
Guidance: Quantities of combustible solids should be listed only if they are normally exposed to the compartment. Examples of combustible solids not exposed include cables within conduits, cables in enclosed cable trays with solid bottoms, sides, and covers, and rags located in covered metal containers. However, combustible liquids and/or gases should be included, even if they are contained in a rated container. The list should note that the container is rated for such usage.

Quantities for cable insulation should be expressed in kilograms, quantities for oil should be expressed in liters, quantities for gases should be expressed in cubic meters, and quantities for wood, plastic, and paper should be expressed in kilograms. Other items should be expressed in their appropriate units.

Use as many Checklist pages as required. It is often helpful to separately list the estimated combustible materials associated with specific pieces of equipment. For example: feedwater pump (1 liter oil, 1 kilogram of plastic). This provides a means to check if the overall quantities appear reasonable.

For cable trays, it may be easier to determine a "standard" estimate of kilograms of cable insulation per meter of cable tray, based on the maximum allowable tray fill. This should result in conservative estimates.

4.9.7.2 Repeat the above step for transient quantities of material.

Guidance: "Transient" refers to temporary quantities of materials.such as those materials required for maintenance or repairs, or those that vary over time. Normally, there are no transient quantities of cable insulation. Note that the presence or absence of transient materials may not be a true indication of the normal plant condition.

\subsubsection{FIRE SUPPRESSION SYSTEMS}

Part 8 of the Fire Compartment/Fire Cell Walkdown Checklist identifies the various types of fire suppression systems that are available to extinguish a fire in a compartment/cell.

4.9.8.1 Using the information gathered in Section 4.8.8, verify the entries previously made in Part 8 of the Checklist. In addition, verify the locations of suppression fixtures on the drawings or sketches gathered or prepared in Section 4.8.8.

4.9.8.2 Assess the physical condition of each system, using the legend on the Checklist. 
Guidance: The physical condition of the fire suppression systems may be evaluated using the following descriptions:

- A - Acceptable

All piping and fixtures (valves, strainers, switches, vents, spray heads, drains, etc.) are intact. No visible signs of leakage. Valves appear to be regularly inspected for proper operation. Fixtures are not obstructed and are in proximity to visible/known combustibles. Spray heads are not painted. System can be expected to operate on demand when required.

- M - Marginal

All piping and fixtures intact. Visible signs of minor leakage. One or two fixtures partly obstructed or adequate proximity to visible/known combustibles is in question. Fixtures not painted. (Valves that may or may not operate as required should be so noted in the Comments section.)

- U - Unacceptable

Piping and/or fixtures not connected. Visible signs of excessive leakage. Fixtures are obstructed or are not in proximity to visible/known combustibles. Some or all fixtures are painted. Valves do not operate properly. Systems cannot be expected to operate on demand as required.

\subsection{9}

\section{FIRE DETECTION SYSTEMS}

Part 9 of the Fire Compartment/Fire Cell Walkdown Checklist identifies the various types of fire detection systems available to detect and warn of a fire in a compartment/cell.

4.9.9.1 Using the information gathered in Section 4.8.9, verify the entries previously made in Part 9 of the Checklist. In addition, verify the locations of detectors on the drawings or sketches gathered or prepared in Section 4.8.8.

4.9.9.2 Assess the physical condition of each detector and device, using the legend on the Checklist.

Guidance: The physical condition of the fire detection systems may be evaluated using the following descriptions. The detectors and devices may have to be tested, in accordance with the manufacturer's instructions or the plant's approved methods, to adequately assess condition.

- A - Acceptable 


\section{U.S. DEPARTMENT OF ENERGY'S REACTOR CORE \\ PROTECTION EVALUATION METHODOLOGY FOR FIRES AT \\ SOVIET-DESIGNED RBMK AND VVER NUCLEAR POWER PLANTS}

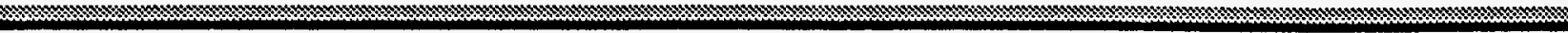

Detectors and devices are securely mounted. Detectors and devices are not obstructed. Locations and detector types appear appropriate for the usage. Detectors and devices are not painted. Wiring is tightly connected. Power indicator light, if so equipped, is illuminated. Testing provides assurance that systems can be expected to operate on demand when required.

- $\quad$ - Marginal

Detectors and devices are securely mounted. Detectors and devices are partly obstructed. Detectors and devices are not painted. Wiring is tightly connected. Power indicator light, if so equipped, is illuminated. Testing is inconclusive. Operation of system is in doubt. (Note reasons in the Comments section.)

- U - Unacceptable

Detectors and devices are not securely mounted. Detectors and devices are obstructed. Locations and detector types do not appear appropriate for the usage. Detectors and devices are painted. Wiring is not tightly connected. Power indicator light, if so equipped, is not illuminated. Testing reveals that systems cannot be expected to operate on demand as required.

\subsubsection{FIRE HOSE STATIONS AND WATER CANNON}

Part 10 of the Fire Compartment/Fire Cell Walkdown Checklist identifies the quantities and locations of fire hose stations and water cannons that are available for use to extinguish a fire in a compartment/cell.

4.9.10.1 Using the information and drawings gathered in Section 4.8.10, verify the entries previously made in Part 10 of the Checklist.

4.9.10.2 Indicate whether each hose station is easily accessible.

Guidance: Hose stations should not be blocked by equipment or debris.

4.9.10.3 Indicate whether each hose station has a functioning shutoff valve.

Guidance: Valve should be installed and operable.

4.9.10.4 Assess the condition of each station's hose, using the legend on the Checklist.

Guidance: Hoses should be installed, pliable, and without cracks or tears.

4.9.10.5 Assess the condition of each station's nozzle, using the legend on the Checklist. 
Guidance: Nozzles should be installed and operable.

4.9.10.6 Indicate whether each water cannon is easily accessible.

Guidance: Water cannons should not be blocked by equipment or debris.

4.9.10.7 Access the condition of the water cannon, using the legend on the Checklist.

Guidance: Water cannons should rotate and pivot freely. Valves should be installed and operable. Nozzles should be installed and adjustable. There should be no leakage. Nozzles should not be blocked or have foreign materials.

4.9.10.8 If apparent, note the purpose of each water cannon inside and adjacent to the fire compartment/fire cell. This can be done in the Comments section of Part 10B of the Checklist.

Guidance: Water cannons can be installed to cool structural components only, while others are dedicated to fighting fires. Note this purpose on the Checklist.

\subsubsection{FIRE EXTINGUISHERS}

Part 11 of the Fire Compartment/Fire Cell Walkdown Checklist identifies the quantity and locations of portable fire extinguishers available for use to extinguish a fire in a compartment/cell.

4.9.11.1 Using the information and drawings gathered in Section 4.8.11, verify the entries previously made in Part 11 of the Checklist.

4.9.11.2 Indicate whether each fire extinguisher is easily accessible.

Guidance: Fire extinguishers should not be blocked by equipment or debris.

4.9.11.3 Assess the condition of each fire extinguisher, using the legend in Part 11 of the Checklist.

Guidance: The extinguisher gauge (if provided) should read "full" at all times. The tank itself should not have peeling paint or rust. Hoses should be flexible and without cracks.

4.9.11.4 Based on the types of combustibles contained in the compartment/cell, determine if the type of fire extinguisher is appropriate. 


\section{DRAINAGE}

Part 12 of the Fire Compartment/Fire Cell Walkdown Checklist identifies drainage system features available to remove fire water used to fight a fire in the compartment/cell.

4.9.12.1 Indicate on the Checklist whether the fire compartment/cell has floor drains.

4.9.12.2 Indicate if the floor drains appear functional (not blocked, sealed, or otherwise obstructed).

4.9.12.3 Indicate if the compartment/cell has drain pits or sumps.

4.9.12.4 Indicate if there is a drain located in the drain pits or sumps.

4.9.12.5 Indicate if equipment located in the compartment/cell has concrete curbs or pedestals and enter the curb or pedestal height, if applicable.

4.9.12.6 Indicate if combustible liquid storage tanks located in the compartment/cell have dikes capable of containing liquid spills.

\section{VENTLATION}

Part 13 of the Fire Compartment/Fire Cell Walkdown Checklist identifies the various types of ventilation provided for the fire compartment/fire cell and how the systems operate and provides information that will be used to determine the effect of a fire on the ventilation systems.

4.9.13.1 Using the information gathered in Section 4.8.13, verify the entries previously made in Part 13 of the Checklist.

\subsubsection{EMERGENCY LIGHTING}

Part 14 of the Fire Compartment/Fire Cell Walkdown Checklist identifies the quantity and locations of emergency lighting that would be available for use in fighting a fire or performing manual actions in the compartment/cell. The suitability of the emergency lighting is determined in Sections 4.12 and 4.13.

4.9.14.1 Indicate on the Checklist whether the compartment/cell and its access/egress routes are provided with emergency lighting.

4.9.14.2 Enter the total number of each battery powered, hard wired, and other fixture types in the compartment/cell and in the access/egress routes. Specifically identify "other" fixture types. 
4.9.14.3 Test each fixture in accordance with manufacturer's instructions or approved plant methods and indicate operability on the Checklist.

4.9.14.4 Note the apparent purpose of the area fixtures on the Checklist.

Guidance: To aid in the suitability determination of emergency lighting in Sections 4.12 and 4.13 , initial qualitative statements about brightness, directional aim, lack of fixtures, etc., should be recorded here.

\subsubsection{EMERGENCY COMMUNICATIONS}

Part 15 of the Fire Compartment/Fire Cell Walkdown Checklist identifies the types of emergency communications available for use in fighting a fire in a compartment/cell.

4.9.15.1 Indicate whether the compartment/cell and its access or egress routes have telephones. Also indicate if they are operational.

4.9.15.2 Indicate whether the compartment/cell and its access or egress routes are provided with a portable radio system. Indicate if it is operational.

Guidance: A communication system is considered operational if speech can be transmitted clearly and continuously without interference from other radio-emitting or electromagnetic devices in the plant.

4.9.15.3 If applicable, indicate if communication is possible from the compartment/cell to the control room and to the fire command center.

4.9.16.1 Review all Fire Compartment/Fire Cell Walkdown Checklists for completeness. Assure that all fire compartments/fire cells identified in Section 4.7 have a Checklist and have been walked down.

4.9.16.2 Obtain the Buildings and Outdoor Structures form prepared in Section 4.7.1. Verify that the safe shutdown equipment location (fire compartment/fire cell) given in Part 3A of each Fire Compartment/Fire Cell Walkdown Checklist corresponds with the Buildings and Outdoor Structures form. If a building was assumed to contain shutdown equipment on the Buildings and Outdoor Structures form but the walkdown revealed otherwise, a fire hazard evaluation is not required for that building. The Buildings and Outdoor Structures form should then be corrected Verify that all shutdown equipment has been located. 
4.9.16.3 Revise all drawings found to be incorrect as a result of the walkdowns. 

INSTRUMENTATION CABLES

\section{GENERAL}

Once a safe shutdown electrical component is selected, a list of cables required for successful operation of that component is identified (see Section 4.4). The list of control, instrument, and power cables is generally obtained from a study of the elementary (schematic) diagrams. Other electrical drawings such as one-line diagrams, wiring diagrams, and cable block diagrams are also used, depending on the conventions used for that plant's electrical drawings. Other documents, such as a circuit and cable tray or conduit program output report, can be used to facilitate this process of cable identification.

Once the electrical cables are identified, it is then necessary to find where the cables are located in the plant. The process of identifying cables to be located depends highly on analysis completed in Section 4.4 , as well as on the selection of the solutions to identified fire vulnerabilities, and may, therefore, have to be repeated several times, depending on the equipment selection process. Cables in U.S.-designed power plants are usually (although not always) routed in conduits, cable trays, gutters, wireways, and duct banks. In these cases, it is necessary to find where the conduits or cable trays are located. Many U.S. plants use automated circuit and routing programs that can easily be sorted to obtain which tray or conduit has which cable or which cable uses which conduit or tray.

The meaning of "location of cables and cable trays or conduit" requires a discussion. If separation of redundant trains of safe shutdown equipment is credited in the safe shutdown analysis because the cables and trays or conduits are located in different fire compartments/cells, precise spatial details are not required. In this case, only approximate diagrammatic locations are required. In some cases, precise dimensions may be required if detailed fire analysis (considering such things as fire loading, fire spread time, fire protection, and fire detection equipment) has to be done.

After the cables and trays or conduits are located, they are identified or drawn on the fire compartment/cell or similar plant drawings. As noted above, the precision necessary depends on the nature of the separation taken credit for. In some cases diagrammatic representations will be adequate. In other cases, precisely dimensioned drawings are necessary.

Cables, and/or cable trays or conduits need to be located during a comprehensive plant walkdown if: 
1. The cables and trays or conduits are not shown on any detailed as-built plant drawings.

2. They are only shown diagramatically without sufficient detail to support the analysis.

3. There is a general concern about the as-built validity of the physical location drawing or the cable and circuit schedule.

Specific procedures should be developed for a variety of different needs to ensure that appropriate data is collected. Following are procedural guidelines for various situations that may be encountered, depending on the plant and cables being analyzed.

If the cable routing of safe shutdown system or associated circuit cable(s) can notbe adequately determined, it should be conservatively assumed that the cable(s) in question will experience damage as the result of a fire in any compartment/cell and appropriate resolutions developed. In many instances, the assumed cable damage may either be: (a) eliminated from further consideration through the performance of detailed circuit analysis which consider cable functions and the consequences of credible cable failure modes (hot-short, open circuit, or short to ground) on safe shutdown system operability, or (b) mitigated through the adoption of post-fire manual operator actions to restore operability and/or align system components to their desired configuration. In the event such options are not viable, or for cases where routing of a large number of safe shutdown and associated circuit cables is indeterminate, the installation of a "dedicated Shutdown System," as described in Appendix A to this document should be considered.

\subsubsection{PROCEDURAL GUDELINES}

\subsubsection{Procedural Guideline 1}

For this guideline assume that the shutdown component's cables are routed throughout the plant in conduit or cable tray. The objective for this safe shutdown component is to determine which fire compartments/cells contain the subject cables. In this case, it has been determined that the plant drawings such as elementaries, cable block diagrams, physical cable tray drawings, and circuit and cable tray schedule are adequately verified.

In this case, the fire compartments/cells are simply identified and listed from the appropriate plant drawings. This information can than be used in the overall analysis. For example, it can be determined that this component is lost if a fire is postulated in any of the fire compartments/cells containing the cables. Redundant 
equipment needs to be found whose cables are not located in the same fire compartments/cells.

It is important to note that this case could be the most dominant because precise physical dimensions are not critical. Plant drawings (even diagrammatical) are often accurate enough to determine which general areas of the plant contain which equipment, and this is all the information that is required for the fire hazards analysis if redundant cables can be found in different fire compartments/cells.

\subsubsection{Procedural Guideline 2}

The case is the same as guideline 1 , except that either it has been determined that plant drawings related to cables and their locations are not sufficiently verified to credit their use without independent verification, or drawings locating cables and trays or conduits do not exist.

The first step is to determine the cable number(s), and the "from" and "to" location of the cables. Next, the tray or conduit numbers and the tray or conduit locations are determined.

Following this, a walkdown team is sent into the plant to verify the information. The first thing to verify is the cables attached to each end of the equipment. The walkdown team should record the cable number (or lack thereof) on the cable attached to the equipment. Continuity test equipment can be used to verify that the subject cable is in fact the same cable at each end.

Once the cable is verified, the entire route is visually traced from beginning to end. In some cases visual tracing may be difficult, particularly if the routing is a cable tray or other type of routing where many cables could be present. In this case, signal tracing equipment is used. Such equipment is very common in the U.S., is easy to use, and is very reliable in locating cables.

In this case, once again, precise physical measurements are not necessary because the analysis to be done will only use the specific fire compartments/cells in which the cable is located.

\subsubsection{Procedural Guideline 3}

This case is similar to guideline 2 except that a precise location of the cable or tray or conduit is required. This precision is required because the analysis being done will try to show that the subject cable/tray or conduit is a specific distance from a redundant component's cable and tray or conduit. Precision may also be required to determine the spatial relationship between the subject cable or tray or conduit and area fire detection and fire protection equipment. Additionally, if the desired 
separation is not found, specific fire analysis can be done taking into consideration fire load, fire protection, and fire detection equipment, but precise location is usually required.

In this case cable and/or tray or conduit measurements are made along the whole path using as reference points walls and other fixed references.

Another issue to consider relates to the number of dimensions required. Generally, if precise dimensions are required, three dimensions are preferred, although two dimensions may be adequate. This depends on the nature of the specific fire hazard analysis intended for the subject safe shutdown component. 


\subsection{DETERMINE EFFECT OF FIRE ON ABILITY TO ACHIEVE SAFE} SHUTDOWN ON A FIRE COMPARTMENT/CELL BASIS

This section provides guidance to determine the effect of a fire on the plant's ability to achieve and maintain safe shutdown by performing detailed evaluations of fire compartments/fire cells. This process is done in four basic steps:

1. Initial screening of fire compartment to determine the extent of evaluations required.

2. Evaluation of fire compartment for its ability to contain a fire within the compartment.

3. Assessment of fire compartment for the potential effects of an explosion.

4. Evaluation of fire compartment for plant capability to achieve/maintain safe shutdown during and after a fire in the compartment.

The data collected and walkdown information obtained in the previous sections will be the basis for these evaluations. In some cases, it may be necessary to obtain additional, more detailed information than was obtained on the walkdown checklist in order to complete the evaluation for a compartment/cell. This information should be obtained by additional walkdowns as required.

The evaluation process initially addresses and evaluates fire compartments on the basis that the fire-rated barriers provide adequate fire separation between the compartment and adjacent compartments. (The procedure checks to make sure that the level of fire separation required is actually installed.) If an entire fire compartment can successfully pass the evaluation process, then each fire cell within the compartment will also successfully pass the evaluation process. Therefore, there is no need to initially review the plant on a fire cell basis. However, as the evaluation process continues and if an entire fire compartment cannot successfully pass the evaluation process, then each cell in the fire compartment must be evaluated individually. In such cases, the fire cells are reviewed and evaluated on their capability to perform as fire compartments by preventing fire from crossing the cell's boundaries. 


\subsection{1}

4.11.1.2

\section{INITIAL SCREENING OF FIRE COMPARTMENTS}

This initial screening will determine if a fire containment evaluation, a safeshutdown evaluation, or an explosion potential assessment is required for each fire compartment.

4.11.1.1 Using the Fire Compartment and Fire Cell Drawings, list each fire compartment on the Initial Screening of Fire Compartments form (Exhibit 4.11-1).

For each fire compartment, determine if a fire containment evaluation is required. A fire containment evaluation is required for a compartment if any of the following conditions exist:

1. The fire compartment contains safe shutdown equipment/cables.

2. Any safe shutdown path requires access to or through the compartment to perform a safe shutdown manual action.

3. The fire compartment is adjacent to a fire compartment with safe shutdown equipment/cables or is adjacent to a fire compartment for which access to or through is required in order to perform a safe shutdown manual action.

4. The fire compartment contains a significant fire hazard (the fire loading in the compartment is significantly higher than the fire loading in adjacent compartments).

Note: In the above cases, adjacent fire compartments are those that share any portion of a common fire barrier such as a wall, floor, or ceiling.

Place a check in the appropriate column on Exhibit 4.11-1 to indicate if a fire containment evaluation is required.

4.11.1.3 For each fire compartment listed, determine if the potential for an explosion exists and place a check in the appropriate Assessment of Explosion Potential Required column of Exhibit 4.11-1. If no explosion hazard exists, check "no."

Guidance: An explosion hazard exists if a fire compartment contains flammable/combustible liquids (gasoline, kerosene), combustible gases (hydrogen), or combustible dusts and powders (phenolic resin). These substances have the potential to mix with air or other oxidants in the proper proportions and produce an explosion, which may or may not initiate a fire. Data on combustibles in each compartment can be obtained from Part 7 of the Fire Compartment/ Fire Cell Walkdown Checklists. The type of equipment contained in the fire 
compartment can also be helpful and indicative of the possibility of explosion potential. For example, a hydrogen recombiner handles hydrogen, which could explode under certain circumstances.

4.11.1.4 For each fire compartment listed on Exhibit 4.11-1, determine if access to the fire compartment is required during or after the fire and place a check in the appropriate column. This access could be to perform a manual safe shutdown action, such as operating a valve, or to traverse the fire compartment to get to another fire compartment/fire cell. Access to the cell for direct fire fighting purposes should not be considered here.

NOTE: The need for access to or through additional fire compartment/cells may - occur as the result of the safe shutdown analysis. This may require additional fire confinement evaluations.

4.11.1.5 For each fire compartment listed on the evaluation form, determine if it contains shutdown equipment or cables. If it does, check "yes" in the Safe Shutdown Evaluation Required column of the form. Also check "yes" if access is required to the fire compartment during or after the fire specifically to support safe shutdown. This evaluation takes place in Section 4.11.4. If not, check "no".

4.11.1.6 The completed Exhibit 4.11-1 defines the extent of evaluation required for each fire compartment.

\section{FIRE CONTAINMENT EVALUATION}

This subsection provides guidance to evaluate a fire compartment's ability to contain a fire within its barriers. The process is shown on Figure 4.11-1.

A separate Fire Containment Evaluation form (Exhibit 4.11-2) should be completed for each fire compartment evaluated.

The determination that fire compartment/cell boundaries are capable of limiting the spread of fir shall be based on the use of comprehensive and conservative fire hazards analysis techniques. Guidance on such techniques should be in accordance with internationally accepted practices as adopted by the authority having jurisdiction. 


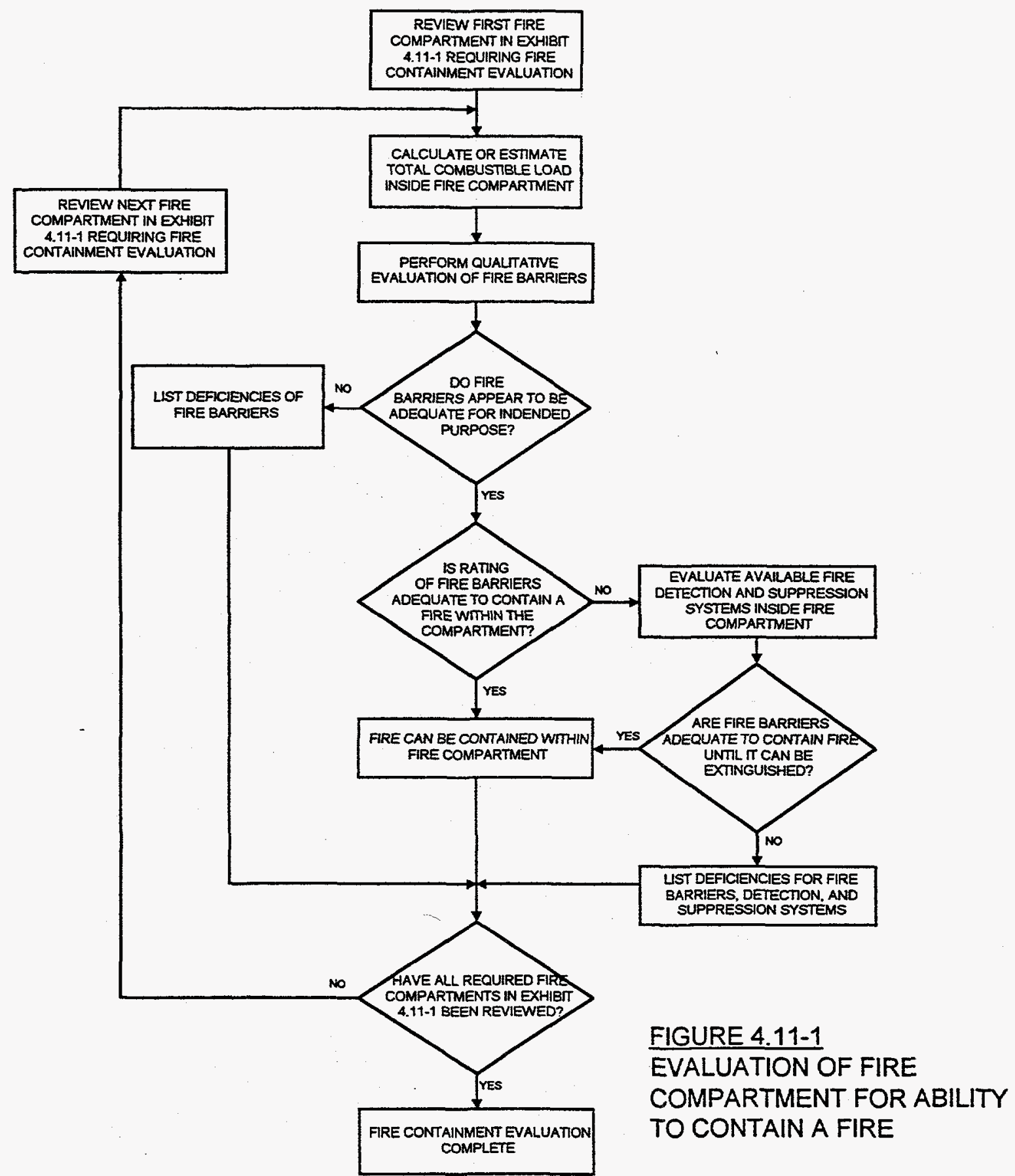


4.11.2.1 For each fire compartment requiring a fire containment evaluation as listed on the initial screening form (Exhibit 4.11-1), calculate or estimate its total combustible fire load in Joules per square meter. Obtain the total amount of combustibles in the fire compartment from Part 7 of the appropriate Fire Compartment/Fire Cell Walkdown Checklists.

Guidance: Combustible fire load may be calculated as follows:

$$
\sum\left(\mathrm{W}_{\mathrm{i}} \mathrm{HV}_{\mathrm{i}}\right) / \mathrm{CA}
$$

where:

$$
\begin{aligned}
& \mathrm{i}=\quad \begin{array}{l}
\text { each combustible, taken one at a time, from Part } 7 \text { of the checklist } \\
\text { (cable, oil, gas, wood, plastic, paper, and other combustibles) }
\end{array} \\
& \mathrm{W}=\quad \begin{array}{l}
\text { the total weight in kilograms }(\mathrm{kg}) \text { or volume in liters (1) of each } \\
\text { combustible }
\end{array} \\
& \mathrm{HV}=\quad \begin{array}{l}
\text { the net heat of combustion value of a particular combustible in Joules } \\
(\mathrm{J}) \text { per unit weight or volume (Ordinary combustibles like paper and } \\
\text { wood have a heat of combustion value of about } 18 \mathrm{MJ} / \mathrm{kg}[8,400
\end{array} \\
& \text { Btu/lb]) } \\
& \mathrm{CA}=\text { the area of the fire compartment in square meters }\left(\mathrm{m}^{2}\right)
\end{aligned}
$$

Typical heat of combustion values are provided in Table 4.11-1. The values for some items, such as cable insulation and transformer oil, are based on typical materials used in U.S. nuclear power plants. All values given in this table should be evaluated to determine their applicability and correctness for use for the materials utilized in the plant being evaluated.

Example: A fire compartment $3 \mathrm{~m}$ by $5 \mathrm{~m}$ contains $90 \mathrm{~kg}$ of cable insulation, 2 liters of lubricating oil, and $5 \mathrm{~kg}$ of paper. Calculate the combustible fire load. 
Table 4.11-1

\section{TYPICAL NET HEAT OF COMBUSTION VALUES \\ Taken from $18^{\text {th }}$ Edition of the US SFPE Handbook \\ (Except where noted by footnote)}

\begin{tabular}{|c|c|c|c|c|c|}
\hline \multirow[t]{2}{*}{ Fuel } & \multicolumn{2}{|c|}{ Heat Of Combustion (MJ/kg) } & \multirow{2}{*}{$\begin{array}{l}\text { Density }^{4} \\
(\mathrm{~kg} / \mathrm{l})\end{array}$} & \multirow{2}{*}{$\begin{array}{l}\text { Net Heat of } \\
\text { Combustion } \\
(\mathrm{MJ} / \mathrm{I})\end{array}$} & \multirow{2}{*}{$\begin{array}{l}\text { Net Heat of } \\
\text { Combustion in } \\
\text { English Units }\end{array}$} \\
\hline & $\begin{array}{l}\text { Gross }^{5} \\
(\mathrm{MJ} / \mathrm{kg})\end{array}$ & $\begin{array}{l}\mathrm{Net}^{5} \\
(\mathrm{MJ} / \mathrm{kg})\end{array}$ & & & \\
\hline Acetone & 30.83 & 28.56 & .7899 & 22.6 & $81,100 \mathrm{Btu} / \mathrm{gal}$ \\
\hline Benzene & 41.83 & 40.14 & .8765 & 35.1 & $125,900 \mathrm{Btu} / \mathrm{gal}$ \\
\hline Fuel Oil, Heavy ${ }^{3}$ & & & & 38.5 & 144,000 Btu/gal \\
\hline Gasoline $^{3}$ & & & & 32.3 & $128,000 \mathrm{Btu} / \mathrm{gal}$ \\
\hline Heptane & 48.07 & 44.56 & .6837 & 30.1 & $108,000 \mathrm{Btw} / \mathrm{gal}$ \\
\hline Ethanol (Ethylene Alcohol) & 29.67 & 26.81 & .7893 & 21.3 & $84,100 \mathrm{Btu} / \mathrm{gal}$ \\
\hline Methanol (Methyl Alcohol) & 22.68 & 19.94 & .7914 & 15.9 & $64,800 \mathrm{Btu} / \mathrm{gal}$ \\
\hline Kerosene $^{1}$ & 46.4 & 43.3 & .8176 & 35.4 & $136,000 \mathrm{Btu} / \mathrm{gal}$ \\
\hline Oil, Transformer ${ }^{3}$ & & & & 35.3 & $126,000 \mathrm{Btu} / \mathrm{gal}$ \\
\hline Oil, Lubricating ${ }^{3}$ & & & & 42.1 & $151,000 \mathrm{Btu} / \mathrm{gal}$ \\
\hline Acetylene & 49.91 & 48.22 & & & $21,500 \mathrm{Btu} / \mathrm{bb}$ \\
\hline Cable Insulation ${ }^{23}$ & & & & $23.7 \mathrm{MJ} / \mathrm{kg}$ & $10,200 \mathrm{Btu} / \mathrm{b}$ \\
\hline Charcoal & $33.7-34.7$ & $33.2-34.2$ & & & $14,600 \mathrm{Btu} / \mathrm{hb}$ \\
\hline Cloth, Cotton & $16.5-20.4$ & & & & $8,700 \mathrm{Btu} / \mathrm{lb}$ \\
\hline Hydrogen & 141.79 & 130.8 & & & $61,000 \mathrm{Btu} / \mathrm{b}$ \\
\hline Methane & 55.5 & 50.03 & & & $23,900 \mathrm{Btu} / \mathrm{b}$ \\
\hline Paper & 17.9 & & & & 7,700 Btu/lb \\
\hline Propane & 50.35 & 46.36 & & & $21,700 \mathrm{Btu} / \mathrm{b}$ \\
\hline Rubber $^{3}$ & 28.4 & & & & $12,200 \mathrm{Btu} / \mathrm{lb}$ \\
\hline Trash $^{3}$ & 17.9 & & & & $7,700 \mathrm{Bta} / \mathrm{lb}$ \\
\hline Cardboard Boxes $^{3}$ & 18.0 & & & & $8,400 \mathrm{Btu} / \mathrm{lb}$ \\
\hline Polyethylene (PE) & $46.2-46.5$ & $43.1-43.4$ & & & $18,700 \mathrm{Btu} / \mathrm{b}$ \\
\hline Polypropylene (PP) & 46.37 & 43.23 & & & $18,600 \mathrm{Btu} / \mathrm{fb}$ \\
\hline Polyurethane (PU) & $26.1-31.6$ & $23.0-28.0$ & & & 10,000 - 12,000 Btu/lt \\
\hline Polyvinyl Chloride (PVC) & 17.95 & 16.9 & & & $7,100 \mathrm{Btu} / \mathrm{lb}$ \\
\hline Wood ${ }^{3}$ & 18.0 & & & & $8,400 \mathrm{Btw} / \mathrm{b}$ \\
\hline
\end{tabular}

1. Value also typical for other volatiles such as toluene.

2. Value is for IEEE-383 qualified cables. Heat of combustion values for other cable types should be estimated or obtained directly from test results. For plastic material of unknown composition, use the heat of combustion value for polyethylene.

3. NFPA Handbook, Appendix A.

4. Values for densities taken from the $64^{\text {th }}$ Edition of the CRC Handbook of Chemistry and Physics, 1984

5. The following excerpt from the SFPE Handbook explains the difference between the gross and net heats of combustion. When available, the net heat of combustion is used in the calculations in this methodology. However, it is felt that generally, either value could be used without significantly affecting the outcome of the calculations.

"The heat of combustion is, by definition, the enthalpy of reaction when fuel and oxidant at standard conditions (1 atm pressure and 298K) are reacted and form products at standard conditions. In many cases the products are not cooled down to $298 \mathrm{~K}$. Thus, it often becomes convenient to define a lower, or net, heat of combustion where the products are as before except that $\mathrm{H}_{2} \mathrm{O}$ stays in gaseous form (and sulfur, if any, goes into gaseous $\mathrm{SO}_{2}$ )." 
For each combustible, obtain the heat of combustion value from Table 4.11-3 or other source and multiply it by the amount of combustible located in the compartment:

$(90 \mathrm{~kg}$ cable insulation $)(23.7 \mathrm{MJ} / \mathrm{kg})=$

$(5 \mathrm{~kg}$ paper $)(17.9 \mathrm{MJ} / \mathrm{kg})$

The compartment area is $(3 \mathrm{~m})(5 \mathrm{~m})=15 \mathrm{~m}^{2}$. This yields a combustible fire load of $(2306.7 \mathrm{MJ}) /\left(15 \mathrm{~m}^{2}\right)=153.7 \mathrm{MJ} / \mathrm{m}^{2}$.

The evaluator must review the distribution of the combustibles located throughout the fire compartment. If the fire compartment is generally open, with no cells or no walls or barriers between cells, and the combustibles are evenly distributed throughout the entire fire compartment, the fire load can reasonably be calculated on a fire compartment/floor area basis. This fire load could then be used as the fire load anywhere in the compartment. If the fire compartment is divided into cells separated by walls or has concentrations of combustibles in specific parts of the compartment, the evaluator should consider determining local fire loadings for the fire compartment. These local fire loadings would be used to evaluate the fire compartment's fire barriers and to perform qualitative evaluations.

4.11.2.1.1 When a fire compartment is physically divided into multiple cells by walls and/or barriers, the evaluator must determine if the fire load for each cell would be similar. If cell sizes are relatively uniform and the combustibles within the cells are evenly distributed, then the evaluator may decide that the overall fire compartment fire load would be applicable for each cell. If, by inspection, it is determined that cell sizes vary widely and the distribution of combustible material varies significantly from cell to cell, then the fire load should be determined for each cell. Where the evaluator cannot determine by inspection whether the compartment fire load is representative for each fire cell, then the fire load for each cell should be determined.

4.11.2.1.2 When a fire compartment or fire cell is relatively large (has a large floor area) and has combustible materials concentrated at specific locations in the compartment/cell, the evaluator should determine the local fire load at each concentration of combustible material. The local fire load would be calculated based on the floor area that the concentrated material actually occupies.

Example: A fire compartment $10 \mathrm{~m}$ by $20 \mathrm{~m}$ contains $100 \mathrm{~kg}$ of cable insulation, 4 liters of lubricating oil, and $10 \mathrm{~kg}$ of paper. The 
uniform, with most of the combustible material contained in a $3 \mathrm{~m}$ by $5 \mathrm{~m}$ corner of the compartment. The combustible material in the $3 \mathrm{~m}$ by $5 \mathrm{~m}$ corner area consists of $90 \mathrm{~kg}$ of cable insulation, 2 liters of lubricating oil, and $5 \mathrm{~kg}$ of paper. Calculate the overall and local fire loading.

The fire loading for the overall compartment would be calculated as follows:

$\begin{array}{llr}(100 \mathrm{~kg} \text { cable insulation)(23.7 MJ/kg) } & = & 2370 \mathrm{MJ} \\ (4 \text { liters lubricating oil)(42.1 M/liter) } & = & 168.4 \mathrm{MJ} \\ (10 \mathrm{~kg} \text { paper })(17.9 \mathrm{MJ} / \mathrm{kg}) & = & \frac{179.0 \mathrm{MJ}}{2717.4 \mathrm{MJ}}\end{array}$

The overall fire loading is therefore $(2717.4 \mathrm{MJ}) /(10 \mathrm{~m} \times 20 \mathrm{~m})=$ $13.6 \mathrm{MJ} / \mathrm{m}^{2}$.

The local fire loading at the concentrated combustibles would be calculated similarly using the $3 \mathrm{~m}$ by $5 \mathrm{~m}$ floor area. This local fire load would be $154 \mathrm{MJ} / \mathrm{m}^{2}$. This local load would be used to evaluate fire barriers in the vicinity of the concentrated combustibles and for other qualitative evaluations at or near the combustibles.

4.11.2.2 Perform a qualitative evaluation of each compartment's fire barriers. Use the data obtained on the Checklists concerning the presence and physical condition of walls (including ceiling and floor, from Part 2), fire doors (from Part 4), penetration seals (from Parts 5A, 5B, and 5C), and structural beams/columns (from Part 6). The evaluations of existing fire protection features performed in Section 4.6 should also be considered.

Guidance: The qualitative evaluation should consider both the design of the features and their as-found physical condition. For example, fire doors may have been purchased for the plant with testing performed showing that the doors have a 90 -minute fire barrier rating. However, if the doors were found blocked open during the walkdown, the doors would not be able to perform their intended function of preventing the spread of fire. Fire doors and penetration seals that are considered in marginal condition (as indicated on the Checklist) should be reevaluated. Justify why their present condition can be considered acceptable or revise their condition to unacceptable. 
The presence of a fireproof coating on structural beams and columns within a compartment must be considered from the perspective that a fire of great-enough intensity could cause buckling of uncoated structural members. This could lead to serious plant damage and poses a grave threat to the fire brigade.

If necessary, perform additional walkdowns to gather information. List all fire barrier deficiencies and recommended improvements as part of the evaluation.

4.11.2.3 Using the total combustible fire load and local fire loads calculated in Section 4.11.2.1, determine if the ratings of the compartment's fire barriers are adequate to contain a fire. This can be done by comparing the fire barrier rating with the required containment time of a fire as shown in Table 4.11-2. This table was adapted from Table 7-9B of Reference 5.10. It should be noted that the values in Table 4.11-2 were established for office and light industrial spaces. However, the values are considered in the US to be conservative for use in NPPs because they do not consider the fire resistive nature of typical NPP construction such as significant amounts of concrete. They have been used in many US analyses.

Table 4.11-2

ESTIMATED FIRE BARRIER CONTAINMENT TIMES

\begin{tabular}{|c|c|}
\hline Fire Load, $\mathbf{M J} / \mathbf{m}^{2}\left(\mathrm{Btu} / \mathrm{ft}^{2}\right)$ & $\begin{array}{c}\text { Required Containment } \\
\text { Time }\end{array}$ \\
\hline$\leq 456(40,000)$ & $1 / 2$ hour \\
\hline$\leq 912(80,000)$ & 1 hour \\
\hline$\leq 1368(120,000)$ & $1 \frac{1 / 2 \text { hours }}{}$ \\
\hline$\leq 1824(160,000)$ & 2 hours \\
\hline$\leq 2736(240,000)$ & 3 hours \\
\hline$\leq 3648(320,000)$ & $4 \frac{1}{2}$ hours \\
\hline
\end{tabular}

4.11.2.4 If the fire barrier rating is adequate, a fire can be considered to be contained within the compartment. If not, perform a qualitative evaluation of the compartment's fire detection, suppression, and support (lighting, communication, drainage, etc.) systems. Use the data obtained on the Checklists concerning these systems (Parts through 15). The evaluation of existing fire protection features performed in Section 4.6 should also be considered. 
Guidance: The qualitative evaluation should consider both the design of the fire detection/suppression/support feature and its as-found condition. For example, hose stations for fighting a fire in the fire compartment being evaluated should not be relied upon if they are normally isolated by a locked closed valve, unless opening that valve is a part of the normal fire response procedure. Other examples of Checklist data considerations are given in the following paragraphs.

Drainage must be considered from the perspective that a buildup of fire protection water in a compartment/cell could affect the operation of shutdown equipment. In addition, water draining or leaking from one compartment to another (via penetrations) could also affect shutdown equipment. Also, combustible liquids draining or leaking from a storage tank without a dike can spread fire.

Not only should the presence of portable fire extinguishers be considered, but their suitability for an expected fire as well. For example, an extinguisher best suited for electrical fires should not be placed in a compartment/cell that contains a large amount of wood and paper and no electrical equipment.

The loss of ventilation to a compartment could result in higherthan-design room temperatures that could affect the operation of shutdown equipment. The loss of ventilation could also increase the time necessary for the fire brigade to respond to and extinguish a fire. However, a smoke removal system connected to a compartment/cell would aid the fire brigade in extinguishing a fire.

The presence of normal and emergency lighting and communications must be also considered when evaluating response time to contain and extinguish a fire.

The qualitative evaluation should be documented and attached to the evaluation form, indicating how each of the above factors was considered and factored into the conclusion.

As required, perform additional walkdowns to gather information.

4.11.2.5 Based on the above evaluation, determine if the fire barriers are adequate to contain a fire until it can be detected, controlled by an automatic fire system, and extinguished by available manual systems. For manual suppression systems, the 
time necessary to detect the fire and mobilize the fire brigade to begin manual suppression must be factored into the evaluation.

4.11.2.6 If the fire barriers, in conjunction with the available detection, suppression, and support systems, are adequate, a fire can be considered to be contained within the compartment. If not, list all fire barrier, detection system, suppression system, support system, and procedural deficiencies as part of the evaluation.

Guidance: Examples of procedural deficiencies are:

1. Fire brigade response procedure to a building does not contain a requirement for the brigade to bring hoses and nozzles for standpipes without that equipment.

2. Fire doors are blocked open for ventilation/cooling purposes.

3. Valves are found locked closed; however, fire response procedures do not address this and treat the valves as normally open.

\subsubsection{ASSESSMENT OF EXPLOSION POTENTIAL}

This subsection provides guidance on assessing the potential for explosions to occur in each compartment/cell. The broader aspects of the effects or containment of explosions are not part of this methodology, but should be considered in a separate analysis.

An Assessment of Explosion Potential form (Exhibit 4.11-3) should be completed for each fire compartment requiring evaluation as shown on Exhibit 4.11-1.

4.11.3.1 Identify the specific potential explosion hazard contained in the fire compartment on Exhibit 4.11-3.

A separate analysis, outside the scope of this Methodology, should be performed foe each compartment/cell identified on Exhibit 4.11-3. This separate evaluation may utilize any explosion analysis normally used by the NPP or recognized by the Authority Having Jurisdiction. The results of these analyses should be reviewed, separately from this Methodology, for any effects on achieving shutdown.

\subsubsection{SAFE SHUTDOWN EVALUATION}

This subsection provides guidance to perform a safe shutdown evaluation of fire compartments that were identified to contain equipment, instrumentation, or cables required to achieve and maintain safe shutdown. The initial assumption is that all 


\section{U.S. DEPARTMENT OF ENERGY'S REACTOR CORE

equipment and cables located in the compartment under review are lost due to a fire. If safe shutdown can be achieved using either the primary shutdown path (Path A) or the secondary shutdown path (Path B) using this initial assumption, then no further evaluation of the fire compartment is required. In the event that neither the primary nor secondary shutdown paths are available due to a fire in the compartment, then an additional, or tertiary, means to achieve and maintain shutdown must be investigated (tertiary shutdown paths such as Path $\mathrm{C}$ are discussed in Section 4.4).

The initial screening process for each fire compartment identified in Exhibit 4.11-1 as requiring a safe shutdown evaluation is shown in Figure 4.11-2. When a successful shutdown path cannot be identified for a fire compartment, the individual fire cells of the fire compartment should be evaluated. This process is shown in Figure 4.11-3.

The safe shutdown evaluation for each fire compartment/fire cell will yield one of the following results:

1. At least one successful shutdown path will be identified for a fire in the compartment/cell

or

2. Specific safe-shutdown-related fire vulnerabilities will be identified for the compartment/cell. These fire vulnerabilities may be compartment/cell specific, such as open fire barrier penetrations, or shutdown system related, such as loss of reactor core cooling water flow due to loss of a power cable.

The fire vulnerabilities identified in this section of the Methodology are summarized in Section 4.12. Section 4.13 addresses the development of solutions to the fire vulnerabilities so that a successful safe shutdown path can be identified for each fire compartment/fire cell.

\subsubsection{List each fire compartment and each fire cell on Exhibit 4.11-4.}

4.11.4.2 If Exhibit 4.11-1 does not indicate that a safe shutdown evaluation is required for a fire compartment, then the normal shutdown path (Path A) can be utilized for the fire compartment and all fire cells in the compartment. Indicate Path A as the successful safe shutdown path for all fire compartments/fire cells on Exhibit 4.11-4 that do not require a safe shutdown evaluation, as indicated on Exhibit 4.11-1. 
FIGURE 4.11-2

INITIAL EVALUATION OF FIRE COMPARTMENTS FOR SHUTDOWN

CAPABILITY DURINGIAFTER FIRE

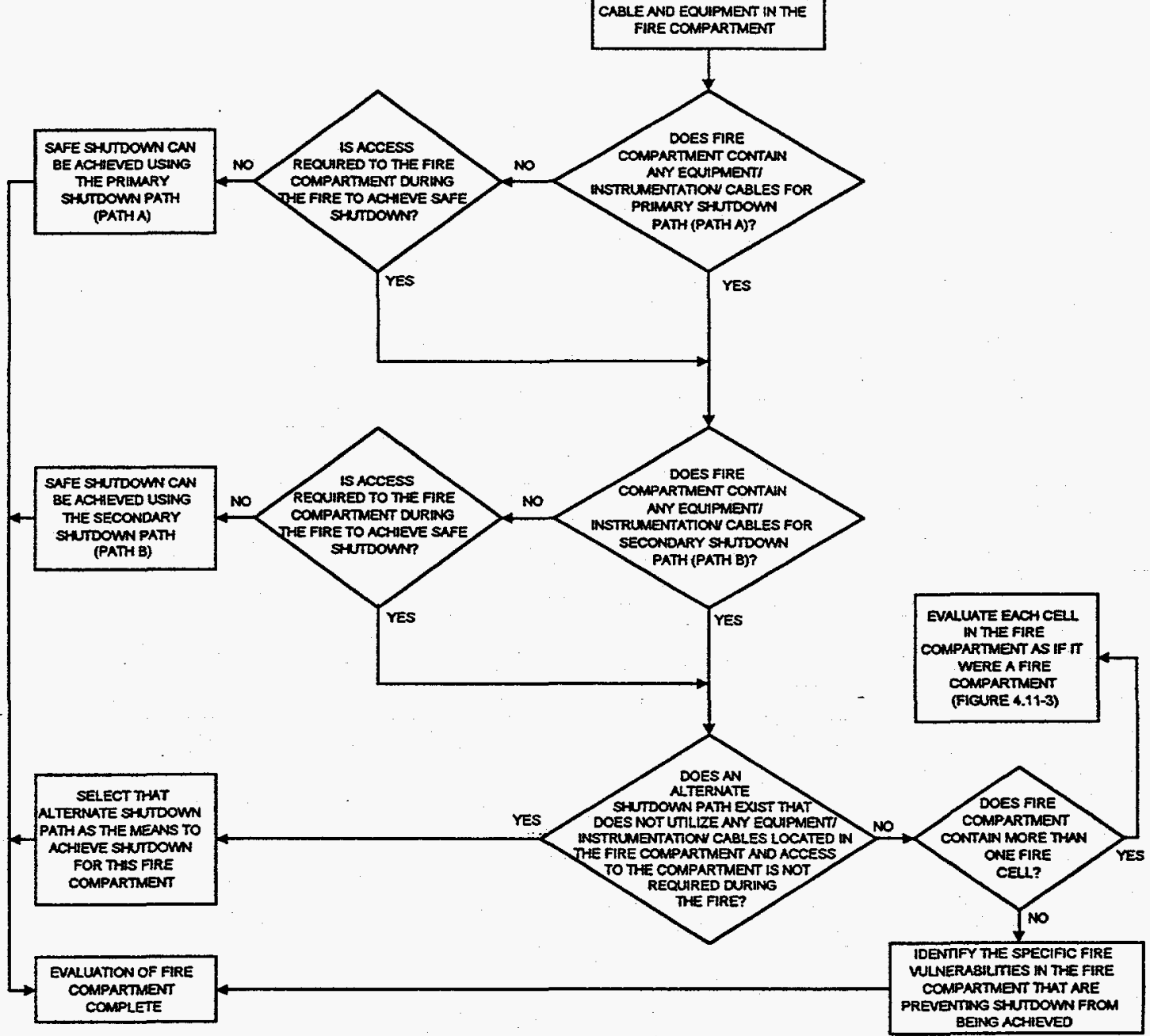




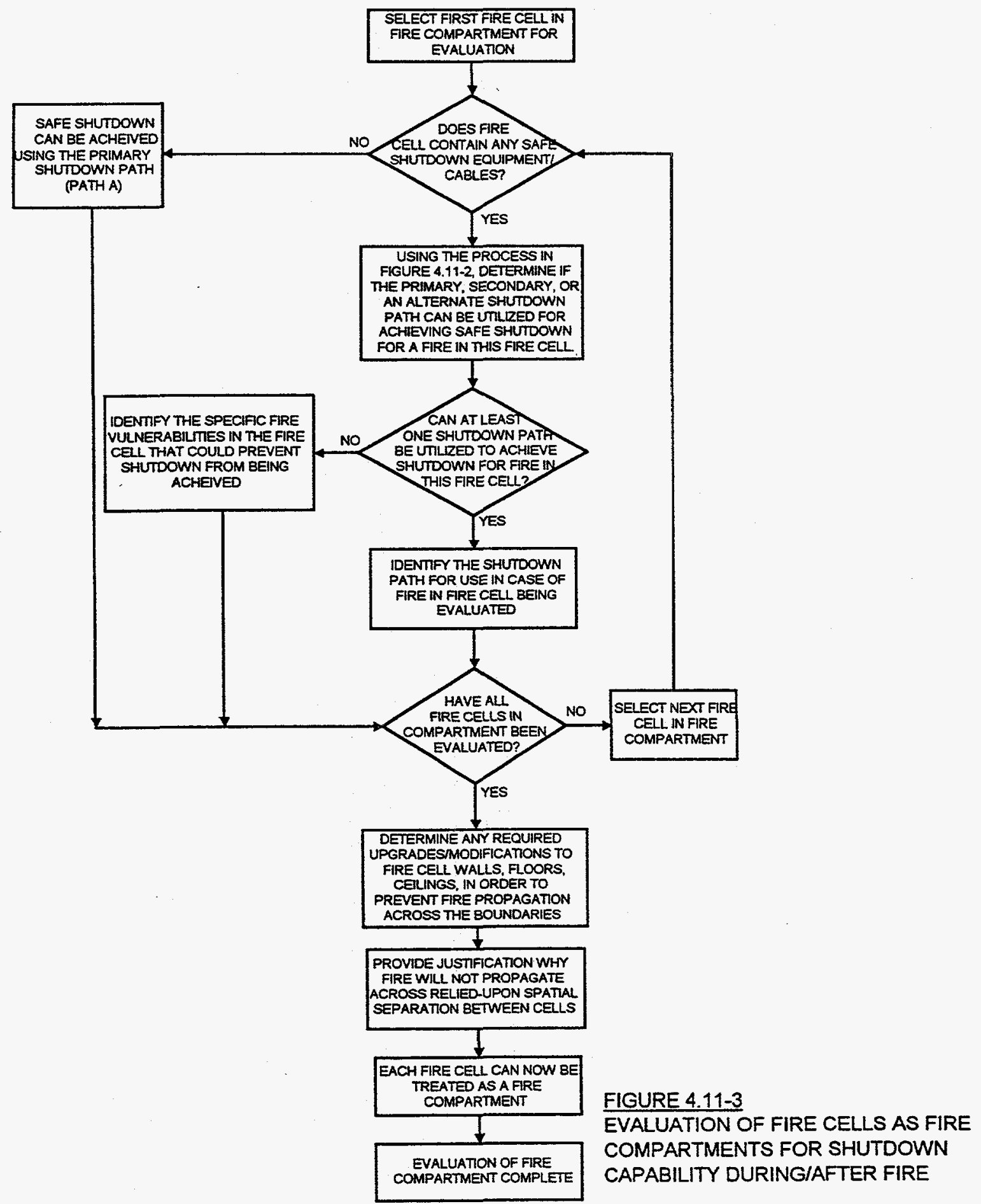


All fire compartments requiring a safe shutdown evaluation must be evaluated as indicated in Sections 4.11.4.3 through 4.11.4.11.

4.11.4.3 Select from Exhibit 4.11-4 the first fire compartment to be evaluated for safe shutdown during and after a fire.

4.11.4.4 Assume that a fire occurs in the selected fire compartment that results in the total loss of all equipment, instrumentation, and cables contained in that fire compartment.

4.11.4.5 Evaluate the plant's ability to achieve and maintain safe shutdown using the primary shutdown path (Path A). The equipment, instrumentation, and cables required for Shutdown Path A are identified in Section 4.4.

The identification of shutdown paths in Section 4.4 considers the shutdown related equipment, instrumentation, and cables required for shutdown and any required manual actions and associated circuit concerns. The fire compartment with the fire should not be entered for any shutdown function (manual action, passage to other compartments, etc.) until it can be shown that the fire can be reasonably extinguished and personnel access would not be restricted due to fire effects such as heat, smoke, extinguishing agents, etc. If access to or through the fire compartment being evaluated is required by the shutdown path during the fire in order to perform a manual action, then that shutdown path cannot be utilized for the fire compartment.

Check that the fire compartment does not contain any of the equipment, instrumentation, and cables associated with Path $\mathrm{A}$.

Check that access to the compartment is not required during the fire. If the fire compartment does not contain any equipment, instrumentation, or cables associated with Path $\mathrm{A}$, then the fire did not damage Path A equipment.

If no Path A equipment, instrumentation, or cables have been damaged and access is not required to the fire compartment to achieve shutdown, then shutdown can be achieved and maintained utilizing Shutdown Path A. Shutdown Path A is therefore identified on Exhibit 4.11-4 as the successful shutdown path for the fire compartment.

Note: 1. The fire barriers for each fire compartment that either contained shutdown equipment/cables or was adjacent to those compartments are reviewed and evaluated in Section 4.11.2. Any fire barrier deficiencies are assumed to be corrected. 
Therefore, the fire will not spread to compartments with shutdown equipment.

2. The shutdown paths identified in Section 4.4 account for any possible effects and required manual actions resulting from associated circuit concerns in compartments that do not contain shutdown equipment/cable.

If Path A is a successful shutdown path for the fire compartment being evaluated, the evaluation for the fire compartment is complete. Indicate on Exhibit 4.11-4 that Path $\mathrm{A}$ is the successful shutdown path for the fire compartment and for each fire cell in the compartment.

Note: Fire compartments are evaluated first to avoid the unnecessary review of each fire cell. If a successful shutdown path can be identified for a fire compartment, then each fire cell in that compartment can utilize that same successful shutdown path.

Select the next fire compartment from Exhibit 4.11-1 and repeat the evaluation, starting with Section 4.11.4.4.

If the fire compartment contains any equipment, instrumentation, or cables for Shutdown Path A, or access to the fire compartment is required during the fire for any reason, then Shutdown Path A cannot be used for the fire compartment. Continue the evaluation with Section 4.11.4.6.

4.11.4.6 Evaluate the plant's ability to achieve and maintain safe shutdown using the secondary shutdown path (Path B). This evaluation should be performed similarly to that described for Path A in Sections 4.11.4.4 and 4.11.4.5.

If shutdown Path B cannot be used for the fire compartment, continue the evaluation with Section 4.11.4.7.

4.11.4.7 Evaluate the plant's ability to achieve and maintain safe shutdown using a tertiary shutdown path. One such shutdown path is identified in Section 4.4 as Path C. Additional shutdown paths may be identified as described in Section 4.4.

Evaluate the plant's ability to achieve and maintain safe shutdown using tertiary Shutdown Path $\mathrm{C}$. This evaluation should be performed similarly to that described for Path A in Sections 4.11.4.4 and 4.11.4.5.

If Shutdown Path $\mathrm{C}$ cannot be used for the fire compartment, additional shutdown paths (beyond Path $C$ ) should be identified and safe shutdown evaluations performed as described above. 
If a successful shutdown path cannot be found for the fire compartment after reviewing several other shutdown paths, then the fire compartment should be evaluated on a fire cell basis. Continue the evaluation with Section 4.11.4.8.

Guidance: After investigating two or three other shutdown paths, the evaluator should be able to determine if it appears likely that a successful shutdown path can be found for the fire compartment. Rather than continuing to look for other shutdown paths for the entire fire compartment, it may be more practical to continue the evaluation on a fire cell basis for the fire compartment. Depending on the results of the fire cell evaluation, the evaluator could choose to again investigate additional shutdown paths for either the entire compartment or specific fire cells of the compartment.

4.11.4.8 If the fire compartment is not already divided into fire cells from Section 4.7, the evaluator may choose to reevaluate it at this time. Using the guidance of Section 4.7, determine if the fire compartment can be subdivided into fire cells.

Guidance: At this point the evaluator may decide to take credit for potential or proposed plant modifications in order to divide the fire compartment into fire cells. For example, the evaluator may decide that a large room could be divided into two fire cells by either adding additional fire detection and suppression or removing combustibles, or both. (See Examples 4.11-1 and 4.11-2.) All fire cells created must be evaluated to confirm that fire will not spread across the fire cell boundaries if the barriers are relied upon to maintain shutdown capability.

If the evaluator chooses to add additional fire suppression to a compartment to form new cells, a separate evaluation must be done to ensure that the actuation of the new fire suppression system will not affect the operation of shutdown equipment in the cell or in adjacent cells. Such an evaluation may determine that protective measures, such as the addition of protective spray shields on certain electrical safe shutdown components, are warranted. 


\section{Example 4.11-1}

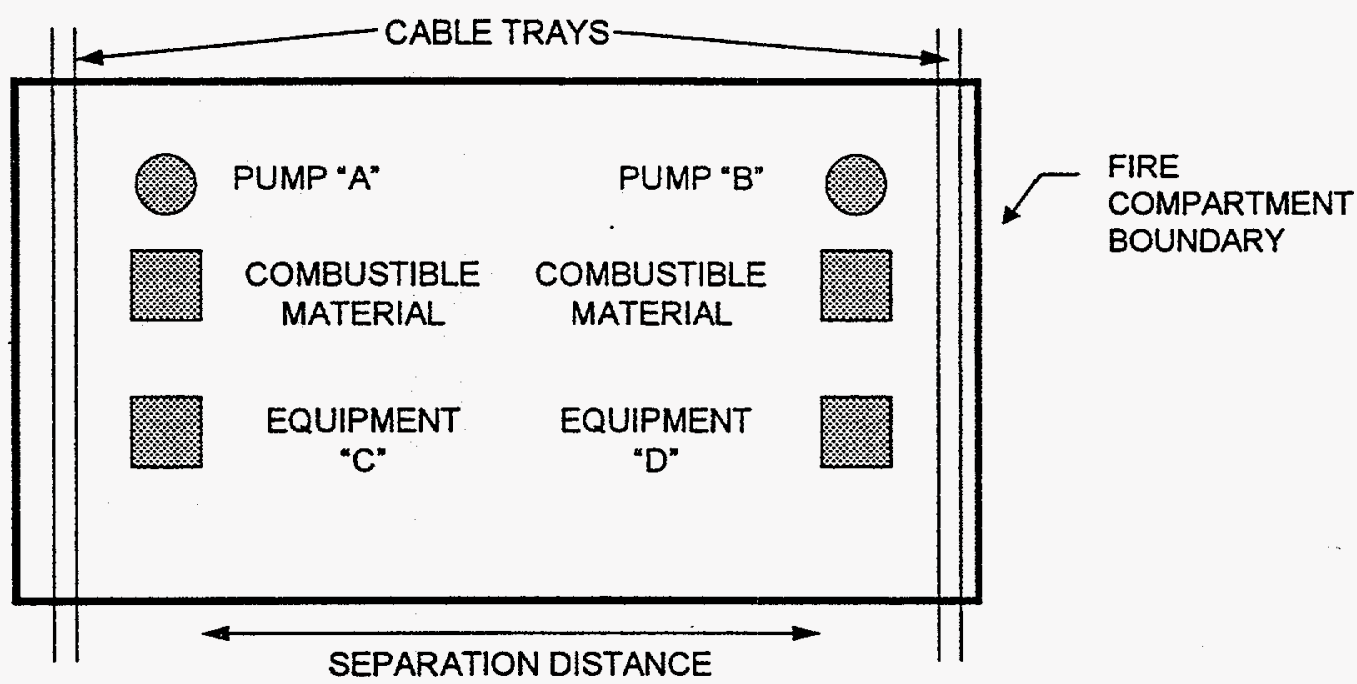

Example: When the above fire compartment was initially evaluated, as required in Section 4.7, it was determined that sufficient spatial separation (distance) did not exist between the equipment on the right and left sides of the room to divide the room into two fire cells. The room does not contain either fire detection or automatic fire suppression.

At this point, the evaluator determines that separating the room into two fire cells will provide a safe shutdown enhancement by separating pumps " $A$ " and " $B$ ". The evaluator determines that if fire detection and automatic fire suppression are added to the fire compartment, the combination of existing spatial separation and the proposed fire detection/suppression will prevent the spread of fire between the right side of the room and the left side. The evaluator therefore divides the fire compartment into two fire cells as shown below, on the basis that both fire detection and automatic fire suppression will be added to the fire compartment .

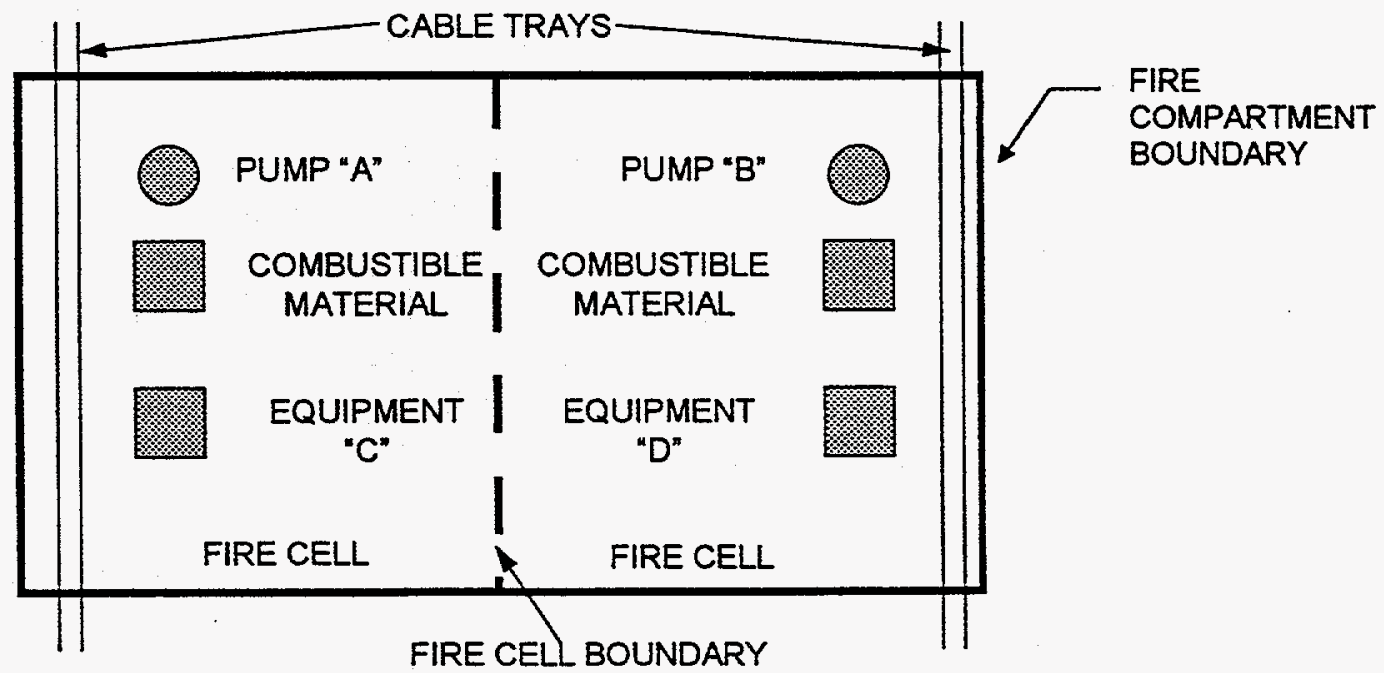


Example 4.11-2

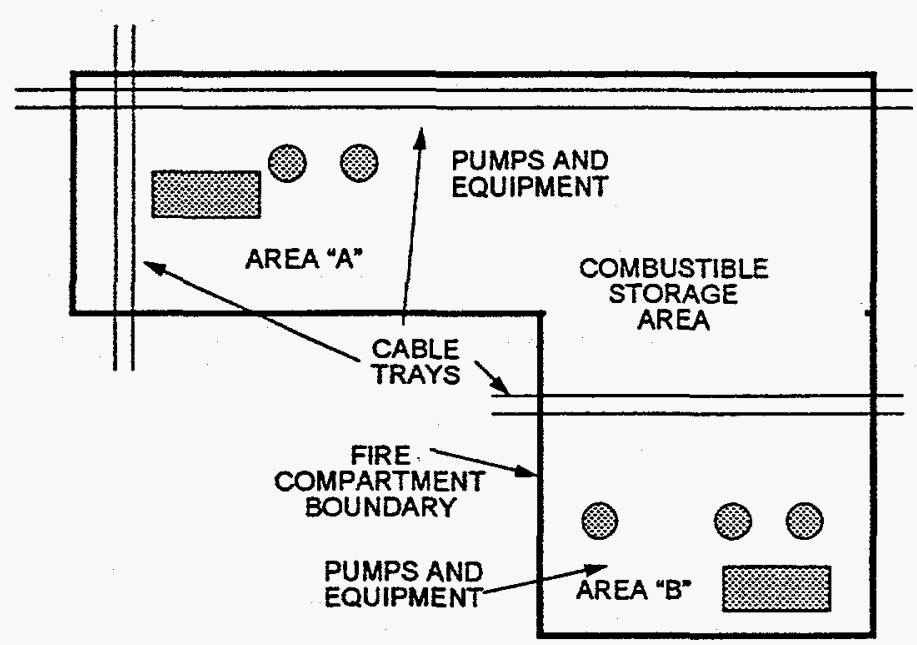

Example: When the above fire compartment was initially evaluated, as required in Section 4.7, it was determined that the pumps and equipment located in the upper and lower portions of the room were not separated sufficiently to create two fire cells due to the combustible storage area between them. Although the room contains fire detection and automatic suppression, sufficient spatial separation does not exist between equipment to prevent fire spread between them, due to the intervening combustibles. A fire in one part of the room would likely spread across the combustible storage area to the other part of the room.

At this point, the evaluator determines that separating equipment in areas " $A$ " and " $B$ " will provide a safe shutdown enhancement. If the combustible storage area was removed, there would be no intervening combustibles to allow fire propagation between areas " $A$ " and " $B$ ", considering the existing fire detection and automatic fire suppression. The evaluator therefore divides the fire compartment into two fire cells as shown below, on the basis that the combustible storage area and all combustible materials will be removed from the compartment, and the area maintained in this manner by administrative procedures.

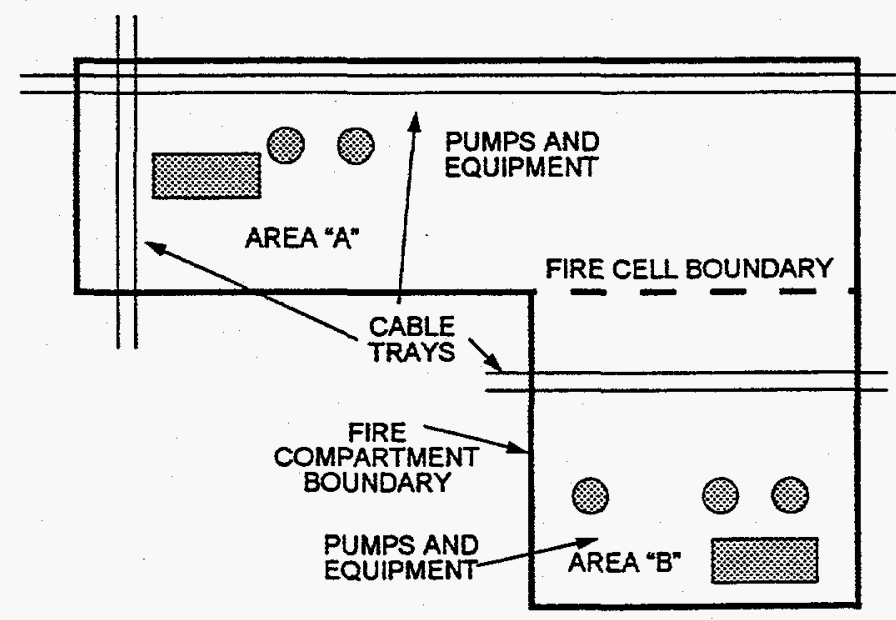


The evaluation may also reveal that the addition of a sprinkler system, for example, may pose a greater threat to safe shutdown equipment due to water spray than the fire itself (such as the addition of sprinklers in a central Control Room).

If the fire compartment still contains only one fire cell, then continue the evaluation with Section 4.11.4.11. If the fire compartment now contains two or more fire cells, continue with Section 4.11.4.9.

4.11.4.9 Each fire cell of the fire compartment must be evaluated for safe shutdown capability during and after a fire. The fire cells will be evaluated as if they were fire compartments, that is, as if fire and its harmful effects could not cross the fire cell boundaries. Each cell boundary that is relied upon to prevent fire spread must be evaluated to keep fires from propagating across the boundary. This evaluation should include any potential or proposed plant modifications that involve the fire separation capabilities of the fire cell boundaries.

Select the first fire cell of the fire compartment. Perform the evaluation method provided in Sections 4.11.4.4 and 4.11.4.5 to this fire cell, treating the cell as if it were a fire compartment. Continue with Sections 4.11.4.6 and 4.11.4.7 as required.

If a successful safe shutdown path can be identified for the fire cell being evaluated, then identify on Exhibit 4.11-4 the successful shutdown path for the fire cell.

If a successful safe shutdown path cannot be found for the fire cell being evaluated, indicate "yes" in the Fire Vulnerabilities Identified for Fire Compartment/Cell column on Exhibit 4.11-4.

Repeat this process for each fire cell in the fire compartment. Continue the evaluation with Section 4.11.4.10.

4.11.4.10 If, on Exhibit 4.11-4, all fire cells in the fire compartment either have an identified successful safe shutdown path on Exhibit 4.11-4 or have fire vulnerabilities identified, then the evaluation for that fire compartment is complete. It is not necessary that the shutdown paths for the cells be identical. Each fire cell could use a different shutdown path. Evaluate the next fire compartment, starting with Section 4.11.4.4, until all fire compartments have been evaluated and then continue with the next section.

4.11.4.11 If a fire compartment has been evaluated and does not have an identified shutdown path on Exhibit 4.11-4, then fire vulnerabilities exist for the compartment that 
prevent shutdown. Indicate "yes" for that fire compartment in the Fire Vulnerabilities Identified for Fire Compartment/Cell column.

Continue the evaluation starting at Section 4.11.4.4 with the next fire compartment from Exhibit 4.11-1 until all fire compartments have been evaluated.

4.11.4.12 At this point of the evaluation, all fire compartments have been evaluated based on the assumption that all equipment and cables in the fire compartment/fire cell are destroyed by the fire. This is a conservative assumption that results in a high confidence level that safe shutdown can be successfully achieved and maintained.

Complete and total loss of all equipment and cables in a fire compartment/fire cell due to a fire may not actually occur based on the actual plant condition. The actual physical arrangement of equipment and cables, the amount of installed and transient combustibles, the physical layout and dimensions of the fire compartment/cell, and installed automatic fire suppression could significantly limit the amount of damage from fire and its effects.

A detailed qualitative evaluation may be considered as an option for those fire compartments/fire cells that cannot be assigned successful shutdown paths based on the "total loss" assumption. These evaluations address the specific fire vulnerabilities found by the "total loss" fire compartment/fire cell evaluation and determine if those fire vulnerabilities would exist for the actual conditions found in the compartment/cell.

A qualitative evaluation would take into account the physical features of the fire compartment/fire cell, such as:

- Compartment/cell layout and dimensions

- Special and specific physical features of the compartment/cell such as partial height walls, partitions, radiation shielding walls, etc.

- Locations of major equipment and cable trays

- Locations of all combustible material, including transient combustibles

- Locations of required safe shutdown equipment and cables in the compartment/cell and their relative locations to combustibles

- Design of automatic fire detection and suppression systems, including actuating method and coverage (Note: When evaluating coverage, it should be noted that too great a coverage, or excess water spray, can have adverse effects, as well as too little coverage. Actuation of fire suppression 
equipment, or a fire brigade's use of water, in one fire cell must not affect the operation of shutdown equipment in another, adjacent fire cell.)

- Passive fire protection features such as cable tray fire stops

The qualitative evaluation would also consider the following fire aspects for the fire compartment/fire cell:

- Total combustible loading

- Distribution of the combustibles within the compartment/cell and the locations of concentrated combustible loads relative to shutdown equipment/cables

- Type of fire expected based on the combustibles present (such as slow spreading, smoldering fire or fast burning fire)

- Ignition sources

The fire compartment/fire cell should be evaluated for the fire effects on safe shutdown utilizing the physical factors and fire factors described above and other factors as determined to be appropriate for the specific case being evaluated.

Guidance: The results of qualitative analyses can be used as justification for demonstrating an adequate level of fire protection to achieve safe shutdown.

The results of any qualitative evaluations performed should be incorporated into Exhibit $4.11-4$ by entering any successful shutdown paths identified by the analysis.

4.11.4.13 Check Exhibit 4.11-4 to determine that each fire compartment and fire cell either has an identified successful shutdown path or has fire vulnerabilities that were identified.

Evaluate any fire compartments or fire cells that do not have results (either a successful shutdown path or vulnerabilities provided on Exhibit 4.11-4.

4.11.4.14 The specific fire vulnerabilities for each fire compartment and fire cell should be listed and attached to Exhibit 4.11-4. This list should include any required changes identified to allow fire cell boundaries to function as fire separation barriers. 
U.S. DEPARTMENT OF ENERGY'S REACTOR CORE

PROTECTION EVALUATION METHODOLOGY FOR FIRES AT

SOVIET-DESIGNED RBMK AND VVER NUCLEAR POWER PLANTS

Exhibit 4.11-1

INITIAL SCREENING OF FIRE COMPARTMENT

\begin{tabular}{|c|c|c|c|c|}
\hline $\begin{array}{c}\text { Fire } \\
\text { Compartment } \\
\text { Number }\end{array}$ & $\begin{array}{c}\text { Fire } \\
\text { Containment } \\
\text { Evaluation } \\
\text { Required? } \\
\text { Yes / No } \\
\end{array}$ & $\begin{array}{c}\text { Assessment of } \\
\text { Explosion } \\
\text { Potential } \\
\text { Required? } \\
\text { Yes / No } \\
\end{array}$ & $\begin{array}{c}\text { Access } \\
\text { Required } \\
\text { During/After } \\
\text { Fire? } \\
\text { Yes / No } \\
\end{array}$ & $\begin{array}{c}\text { Safe } \\
\text { Shutdown } \\
\text { Evaluation } \\
\text { Required? } \\
\text { Yes / No } \\
\end{array}$ \\
\hline & 1 & 1 & I & 1 \\
\hline & 1 & 1 & 1 & 1 \\
\hline & 1 & I & 1 & 1 \\
\hline & 1 & 1 & 1 & 1 \\
\hline & 1 & 1 & 1 & 1 \\
\hline & 1 & 1 & 1 & 1 \\
\hline & 1 & 1 & 1 & I \\
\hline & 1 & 1 & 1 & 1 \\
\hline & 1 & 1 & 1 & 1 \\
\hline & 1 & 1 & 1 & 1 \\
\hline & 1 & 1 & 1 & 1 \\
\hline & 1 & 1 & 1 & 1 \\
\hline & 1 & 1 & 1 & 1 \\
\hline & 1 & 1 & 1 & 1 \\
\hline & 1 & 1 & 1 & 1 \\
\hline & 1 & 1 & 1 & 1 \\
\hline & 1 & 1 & 1 & 1 \\
\hline & 1 & 1 & 1 & 1 \\
\hline & 1 & 1 & 1 & 1 \\
\hline & 1 & 1 & 1 & 1 \\
\hline
\end{tabular}


Exhibit 4.11-2

\section{FIRE CONTANMENT EVALUATION}

Fire Compartment Number:

Fire Cell Number (if applicable):

1. Combustible Load in Fire Compartment/Cell:

(Note: attach calculations as required)

2. Qualitative evaluation of fire barriers (based on walkdown checklist information)

Barriers are acceptable: Yes / No

If no, list specific deficiencies and recommended improvements below.

3. Fire Barrier Ratings (Hours): Ceiling

\section{Floor}

Walls

4. Fire Barrier Evaluation:

a) Fire Barriers are adequate to contain fire based on fire barrier ratings being greater than maximum expected fire in compartment: Yes / No

b) Fire Barriers are adequate to contain fire until fire can be extinguished by manual or automatic suppression: Yes / No

c) If no, describe deficiencies below.

5. Deficiencies: 
Exhibit 4.11-3

\section{ASSESSMENT OF EXPLOSION POTENTIAL}

Fire Compartment Number:

Fire Cell Number (if applicable):

1. Describe specific source of potential explosion hazard contained in the fire compartment/fire cell: 
Exhibit 4.11-4

RESULTS OF SAFE SHUTDOWN EVALUATION

\begin{tabular}{|c|c|c|c|}
\hline $\begin{array}{c}\text { Fire } \\
\text { Compartment } \\
\text { Number }\end{array}$ & $\begin{array}{c}\text { Fire } \\
\text { Cell } \\
\text { Number }\end{array}$ & $\begin{array}{l}\text { Successful Safe Shutdown } \\
\text { Path Identified for Fire } \\
\text { Compartment/Cell }\end{array}$ & $\begin{array}{c}\text { Fire Vulnerabilities } \\
\text { Identified for Fire } \\
\text { Compartment/Cell } \\
\text { Yes / No }\end{array}$ \\
\hline & & & 1 \\
\hline & & & 1 \\
\hline & & & 1 \\
\hline & & & 1 \\
\hline & & & 1 \\
\hline & & & 1 \\
\hline & & & 1 \\
\hline & & & 1 \\
\hline & & & 1 \\
\hline & & & .1 \\
\hline & & & 1 \\
\hline & & & 1 \\
\hline & & & 1 \\
\hline & & & 1 \\
\hline & & & 1 \\
\hline & & & 1 \\
\hline & & & 1 \\
\hline & & & 1 \\
\hline
\end{tabular}


LIST ALL FIRE VULNERABILITIES BY FIRE COMPARTMENT/CELL. SYSTEM, AND SUBJECT

This section of the Methodology provides guidance for grouping all plant fire vulnerabilities that have been identified during the Fire Hazard Evaluation by fire compartment/fire cell, by system, and by subject.

\subsubsection{IDENTIFICATION BY FIRE COMPARTMENT/FIRE CELL}

This subsection provides guidance for listing all plant vulnerabilities that have been identified during the evaluation process. All lists will be on a building or outdoor structure basis and further identified on a fire compartment and fire cell basis.

4.12.1.1 For each building and outdoor structure, list all the fire compartments by both title and number and all fire cells within fire compartments by both title and number. If there are no fire cells within a fire compartment, indicate this condition.

4.12.1.2 For each fire compartment/fire cell, provide a unique number and a detailed description of each vulnerability that has been identified for that cell. The vulnerabilities should include all items that were identified during any of the evaluation steps and should include both physical and procedural fire vulnerabilities. The detailed description should be such that the potential problem is clearly identified and fully described and defined.

4.12.1.3 The unique numbering scheme may be a continuation of the fire compartment/fire cell numbering scheme developed in Section 4.7. One example would be:

XXX-YYY-ZZZ.01

Where $X X X, Y Y Y$, and $Z Z Z$ are as developed from Section 4.7 and .01 is assigned to the first vulnerability in the cell, .02 is assigned to the second vulnerability in the cell, etc.

Note: A numbering scheme such as this is recommended so that the list may be easily entered into a computer database for sorting and tracking.

4.12.1.4 The listing should be continued for each building and outdoor structure.

\subsubsection{IENTIFICATION BY SYSTEM}

This subsection provides guidance to use the lists generated above and re-group them on a system-by-system basis to identify any common system vulnerabilities.

4.12.2.1 Identify and list the various systems within the plant. 


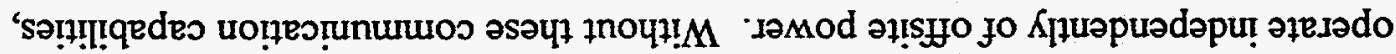

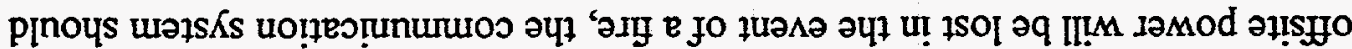

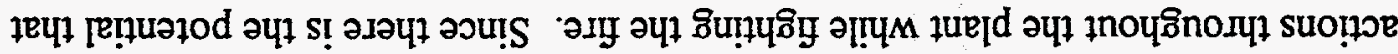

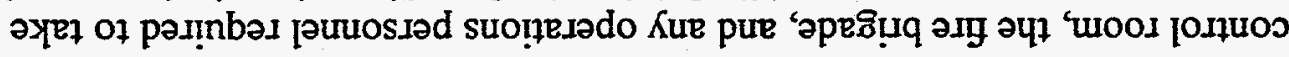

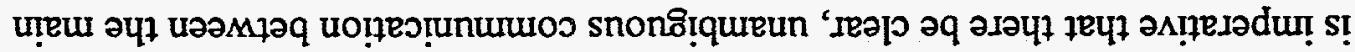
I! 'วIy e 8uunp suo!̣

Z゙とIڤ

-spurej

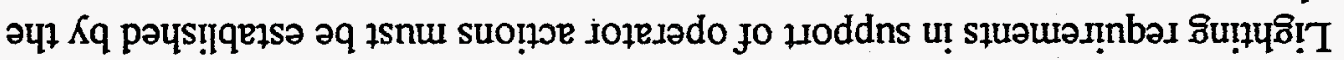

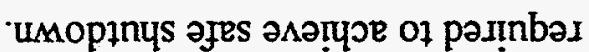

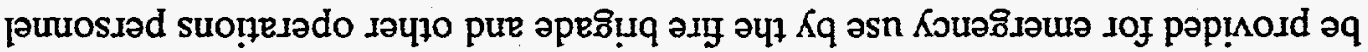

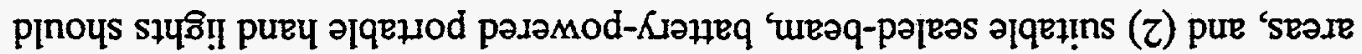

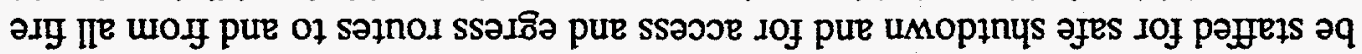

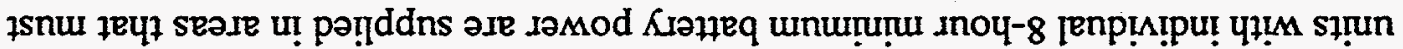

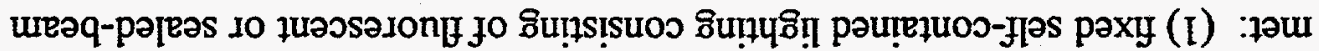

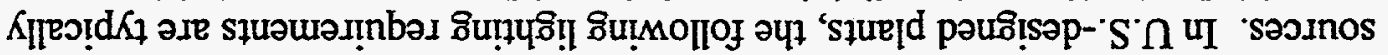

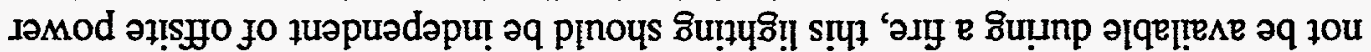

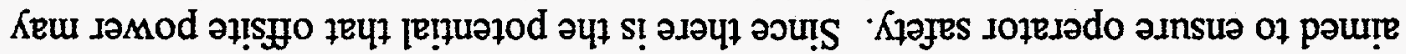

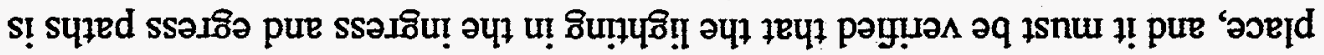

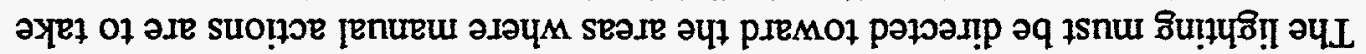

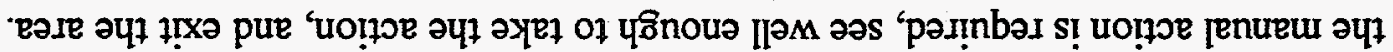

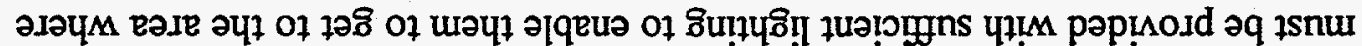

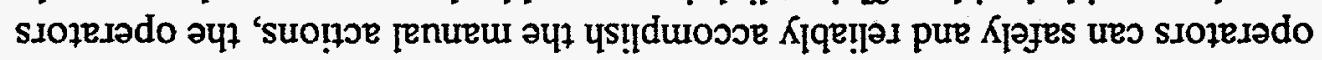

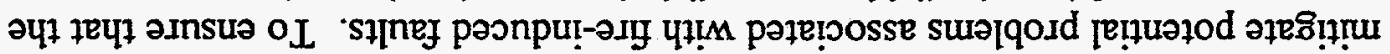

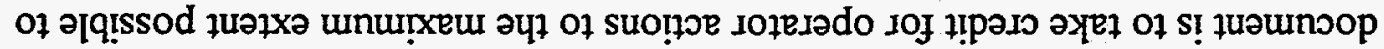

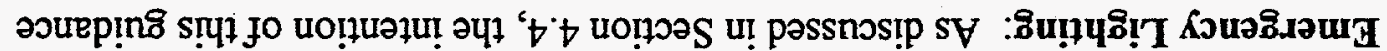

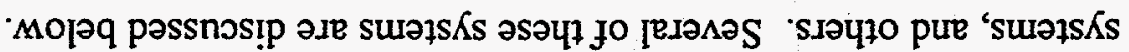

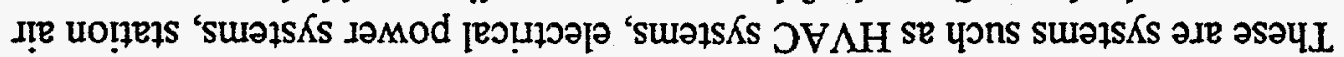

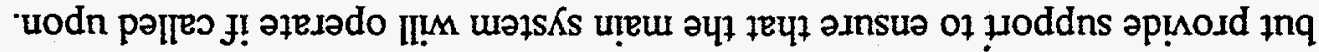

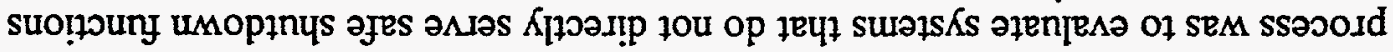

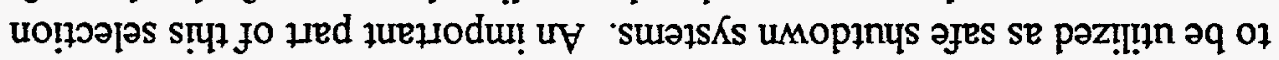

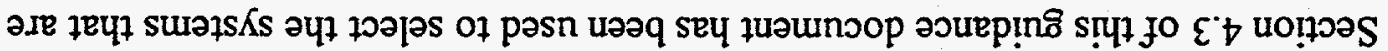

SWHISXSGAS IXOddAS LNVTd Xg NOLIVDIHILAG

E*ZI*

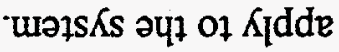

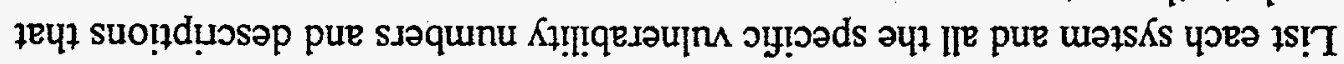

$\varepsilon \cdot{ }^{*}$ ZI๋

'uә7s

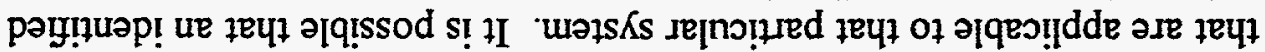

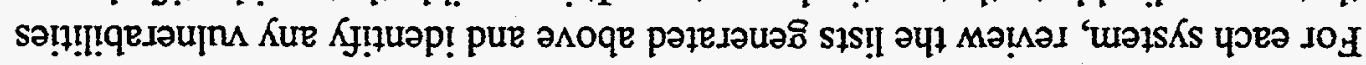




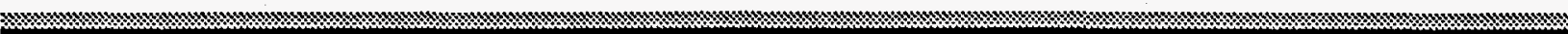

effective fire mitigation operations would be very difficult or impossible. The existing communications capabilities at the plant should be evaluated to ensure that they will support the required needs of any fire cell countermeasures that are developed from this guidance.

4.12.3.3 Plant Drainage: Fire fighting activities will likely require the use of large volumes of water. The water would come from hose stream operations and/or the operation of the suppression systems that would be manually or automatically actuated. These large volumes of water must be drained from the plant areas to ensure that area flooding does not cause required systems to become inoperable. Care must be taken to review not only the area where the water is being introduced but also the areas that are drained to. The plant should ensure that drainage is considered as part of any fire cell counter measures.

4.12.3.4 HVAC: Safe shutdown equipment requires a proper environment to function; therefore, HVAC availability must be evaluated as part of the safe shutdown process. Different types of equipment have different thermal ruggedness, which should be considered when determining if HVAC is required. When determining the need for HVAC, options like opening doors or utilizing temporary ventilation fans should be considered to limit the need for adding HVAC to the safe shutdown equipment list. 

4.13 ANALYZE POSSIBLE SOLUTIONS TO POST-FIRE SAFE SHUTDOWN VULNERABILTIES AND IDENTIFY ANY COMMONALITIES

With the completion of Sections 4.11 and 4.12, all of the fire vulnerabilities have been identified and categorized. Often there are many ways to resolve these vulnerabilities. This section outlines the method for developing workable and costeffective solutions. Appendix A illustrates some of these typical solutions.

This section is based on the assumption that any plant vulnerability that could be resolved by the use of alternate equipment or procedural changes has been so resolved. The section focuses on plant modifications to resolve vulnerabilities. All of the potential vulnerability resolutions need to be identified by system and by cell prior to deciding on a resolution technique. An integrated approach to resolving the various problems can then be ensured. Care must be taken to ensure that additional vulnerabilities are not created with the resolution of an identified vulnerability. For instance, if a new suppression system is to be added to a fire compartment/cell, the design must ensure that the operation of the suppression system will not affect the operation of required safe shutdown systems.

Additionally, one design change skillfully conceived and installed may be able to resolve vulnerabilities in several fire cells. Figure 4.13-1 is provided to assist in accomplishing this process.

Design controls must be put in place to make sure that future changes to the plant do not invalidate the results of this evaluation by creating unanalyzed fire vulnerabilities.

\subsubsection{SYSTEM EVALUTION}

4.13.1.1 From the list of plant vulnerabilities by system developed in Section 4.12.2, select the system that has the largest number of vulnerabilities. Review the types of vulnerabilities and the commonalities of the vulnerabilities between cells.

4.13.1.2 Develop proposed conceptual designs intended to resolve the vulnerabilities identified. The conceptual designs need not be limited to one per vulnerability; each potential design change is evaluated and prioritized in Section 4.14. Some of the conceptual designs may include the need to evaluate the combustible loading in a compartment or cell if the evaluation was not completed in Section 4.11. After close review of the vulnerabilities and the cells, the conceptual designs should be developed in a manner that resolves as many possible vulnerabilities as possible with a given design change. 


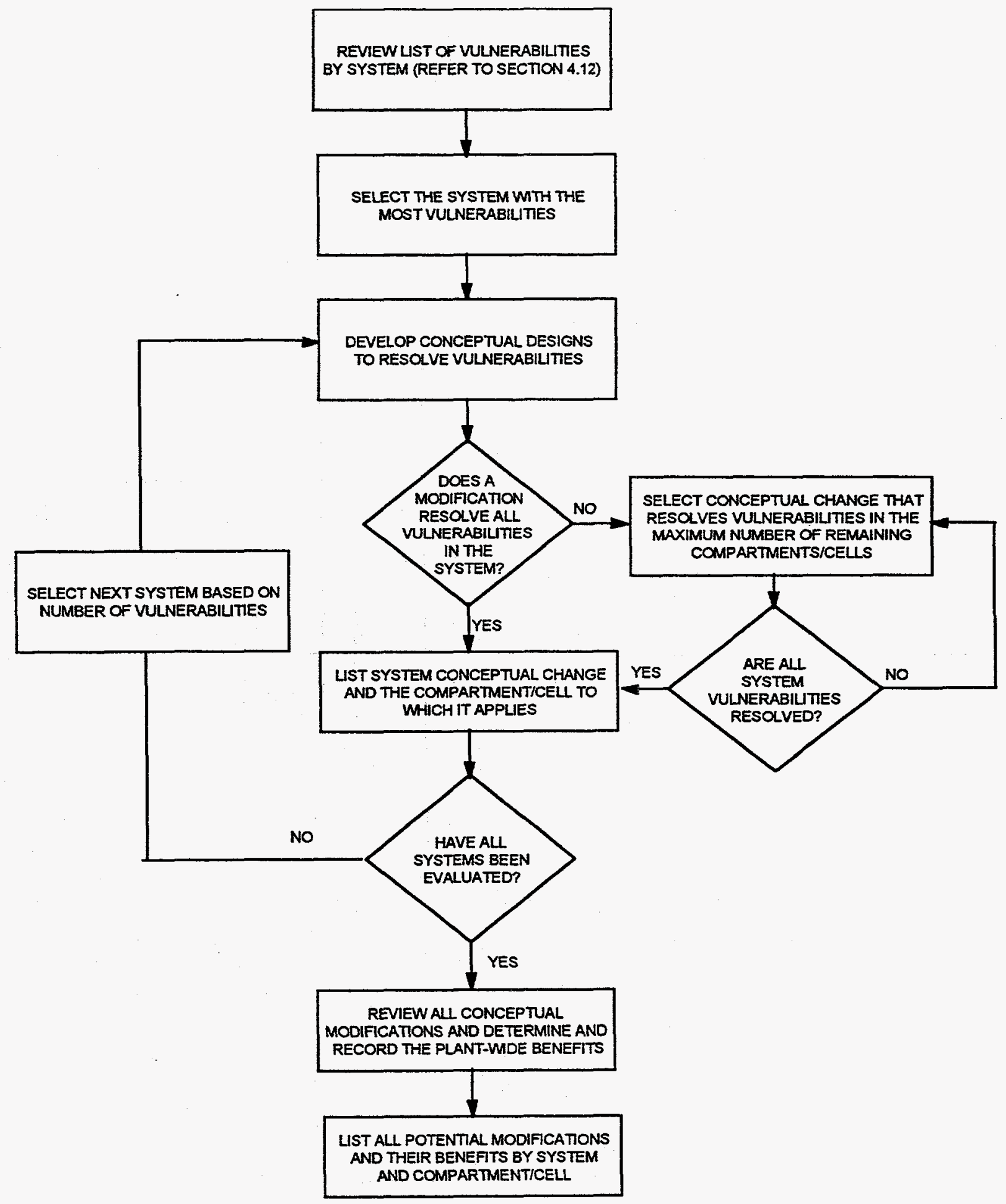

FIGURE 4.13-1

VULNERABILITY ANALYSIS 
For instance, if a power cable for a motor-operated valve is noted as a vulnerability in four cells, rerouting that one cable would resolve vulnerabilities in four areas, as opposed to doing four designs, one for each cell.

4.13.1.3 List the proposed conceptual design(s) developed that would resolve each vulnerability for each cell on Exhibit 4.13-1. Note that there may be several options that could be implemented to resolve a given vulnerability. If this is the case, they should all be listed.

4.13.1.4 Select the system that has the next largest number of vulnerabilities and repeat Sections 4.13.1.2 and 4.13.1.3. This process should be continued until all system vulnerabilities have been reviewed and one or more conceptual designs developed for each vulnerability.

4.13.2

\section{PLANT EVALUATION}

Review the list of conceptual modifications to identify those changes that, if accomplished, will provide the plant with additional, non-fire-related, benefits. These benefits can be related to changes that would result in better plant availability, better efficiency, less maintenance, or other improvements. These benefits should be detailed in the NOTES column of Exhibit 4.13-1.

\subsubsection{DEVELOPMENT OF RECOMMENDATIONS}

Using the data developed in Sections 4.13.1 and 4.13.2, a list of the best solution for each compartment/cell should be developed. Exhibit 4.13-1 lists system changes that could resolve plant vulnerabilities to postulated fires. The objective of the safe shutdown analysis is to identify a set of changes that would assure a pathway to safe shutdown for a fire at any location in the plant. The purpose of this section of the analysis is to pick the best set of safety improvements that provide this assurance. From the system conceptual designs identified in Exhibit 4.13-1, sets of improvements should be developed that provide safe shutdown assurance for all.fire locations. These sets of safety improvements represent the alternatives from which the best is to be selected. Typically, a selection of the best alternative would rely on cost-benefit analysis, where the benefit is the reduction in risk associated with the changes and the cost is the cost of the changes. In this case, however, each of the alternative sets provides protection against all of the identified vulnerabilities. Thus, for the purpose of this evaluation, it can be assumed that the risk reduction value of each alternative is the same, and cost becomes the principal evaluation criterion.

Other factors can also be used to select the best alternative. Timing and ease of installation may be important considerations. For each of the alternative sets of 
safety improvements, Exhibit 4.13-2 lists the system improvements that constitute each set and shows the results of the evaluation of costs. The last column in the exhibit is used to provide comments on other factors that could influence the selection.

4.13.3.1 Develop sets (at least two) of possible system improvements from Exhibit 4.13-1 that provide pathways to safe shutdown for all identified vulnerabilities. The alternative sets should be developed in such a manner that the system improvements complement each other to provide broad coverage of system vulnerabilities. Enter the lists of systems for each alternative set in Exhibit 4.13-2.

4.13.3.2 Estimate the cost of each improvement. If an improvement involves a continuing cost, this cost should be represented by an equivalent single expenditure. This can be obtained by discounting future expenditures back to the date of the assessment. The current interest rate for EBRD loans can be used for the discount rate. Include all potential cost contributions, including the value of lost power generation if the implementation of the change would extend a power outage. Enter in Exhibit 4.13-2 and sum for each alternative set.

4.13.3.3 In the last column, comments should be provided on other factors that could influence the selection. As appropriate, indicate if changes must be made during a plant outage, if delay could be expected in the delivery of equipment, if changes are required in the control room, if spare parts are readily available, if the change will enhance plant reliability, if the change will make the plant easier to operate, or if any other aspect of installation could affect the decision. The implementation schedule should be a consideration. If a delay of many years could be associated with implementation of an improvement, its value would be decreased.

4.13.3.4 Based on total cost and other factors, select the preferred approach (set of safety improvements) for obtaining assured safe shutdown. Document the rationale for the decision on Exhibit 4.13-3. 
Exhibit 4.13-1

POTENTIAL DESIGN CHANGES WORKSHEET

\begin{tabular}{|c|c|c|c|c|}
\hline SYSTEM & VULNERABILITY & $\begin{array}{l}\text { COMP./CELLS } \\
\text { AFFECTED }\end{array}$ & CONCEPTUAL DESIGN & NOTES \\
\hline & & & & \\
\hline & & & & \\
\hline & & & & \\
\hline & & & & \\
\hline & & & & \\
\hline & & & & \\
\hline & & & & \\
\hline & & & & \\
\hline & & & & \\
\hline & & & & \\
\hline & & & & \\
\hline & & & & \\
\hline & & & & \\
\hline & & & & \\
\hline
\end{tabular}


U.S. DEPARTMENT OF ENERGY'S REACTOR CORE

PROTECTION EVALUATION METHODOLOGY FOR FIRES AT

SOVIET-DESIGNED NUCLEAR POWER PLANTS

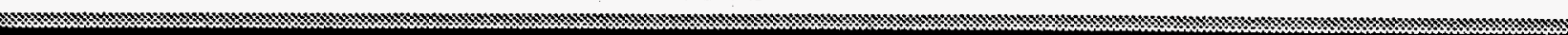

Exhibit 4.13-2

SELECTION OF PREFERRED SAFE SHUTDOWN OPTION

\begin{tabular}{|c|c|c|c|c|c|}
\hline $\begin{array}{l}\text { Set } \\
\text { ID }\end{array}$ & $\begin{array}{c}\text { Upgrade } \\
\text { ID }\end{array}$ & Conceptual Design & $\begin{array}{c}\text { Upgrade } \\
\text { Cost }\end{array}$ & $\begin{array}{c}\text { Total } \\
\text { Set } \\
\text { Cost }\end{array}$ & Other Considerations \\
\hline & & & & & \\
\hline & & & & & \\
\hline & & & & & \\
\hline & & & & & \\
\hline & & & & & \\
\hline & & & & & \\
\hline & & & & & \\
\hline & & & & & \\
\hline & & & & & \\
\hline & & & & & \\
\hline & & & & & \\
\hline & & & & & \\
\hline & & & & & \\
\hline & & & & & \\
\hline & & & & & \\
\hline & & & & & \\
\hline & & & & & \\
\hline & & & & & \\
\hline & & & & & \\
\hline & & & & & \\
\hline & & & & & \\
\hline & & & & & \\
\hline & & & & & \\
\hline & & & & & \\
\hline
\end{tabular}


U.S. DEPARTMENT OF ENERGY'S REACTOR CORE

PROTECTION EVALUATION METHODOLOGY FOR FIRES AT

SOVIET-DESIGNED NUCLEAR POWER PLANTS

Exhibit 4.13-3

\section{SAFE SHUTDOWN SOLUTION SET}

Indicate the safe shutdown solution set selected and provide a detailed discussion of the bases for that solution and the additional benefits the solution set provides the plant. 



\subsubsection{GENERAL}

In Section 4.14, a preferred approach to assuring safe shutdown during and after a fire is developed. Because the cost of immediately addressing all safe shutdown vulnerabilities may be impractical for some Soviet-designed nuclear power plants, it may be necessary to prioritize the safety improvements that constitute a complete safe shutdown solution. That is the purpose of this section of the Methodology.

In Section 4.14, the risk-reduction benefit of system improvements is not an important consideration in the selection process because each of the alternative sets of improvements addresses all of the safe shutdown vulnerabilities. Thus, implementation of any of the alternative sets could be expected to result in approximately the same degree of reduction in risk from the postulated fires. However, in determining the priorities of safety improvements from within a set, the risk significance of each safety improvement becomes a very important consideration.

In the following discussion, an approach is described for prioritizing system improvements according to the ratio of benefit to cost, where the benefit is the assessed extent of risk reduction associated with the improvement. This approach provides the greatest risk reduction from postulated fires for the invested money.

If a risk analysis has been performed for the specific plant being analyzed or for one of similar design, quantitative information can be used to assess the benefit in risk reduction associated with a safety improvement. If a risk analysis has not been performed previously, it will be necessary to perform a rudimentary risk analysis or to rely on qualitative indicators of risk significance. Two approaches to assessing the value in risk reduction of a safety improvement are provided as examples. In each case, the measure of risk considered is the frequency of core damage. The first approach involves a rudimentary risk analysis. The second approach is more qualitative.

\subsubsection{Example Approach 1. Cell-by-Cell Analysis}

In this approach, the incremental change in risk associated with a safety improvement is assessed for each cell/compartment in the plant. A measure of the total change in risk is then obtained as the summation of the contributions from each of the cells. 
The safety significance of each cell is first determined without taking credit for any safety improvements. For each cell, the frequency of fires is estimated based on the history of fires in the plant and the cell inventory of combustible materials. The probability that safe shutdown equipment will survive the fire is then assessed approximately (such as $0.5,0.1,0.01,0.001, \ldots$ ) by considering the locations of combustible materials, the locations of safe shutdown equipment, and protective features within the cell, such as separation, sprinklers, and barriers. Given that an item of safe shutdown equipment is damaged within a cell, the probability is assessed that the safety function will be lost. The probability of loss of safety function depends on the redundancy of equipment capable of providing that safety function. For the cell being analyzed, the safety significance of the cell is defined as:

$$
S_{j}=f_{j} \sum_{k=i}^{K} P_{D}^{j k} P_{S F}^{j k}
$$

where:

$$
\begin{aligned}
& S_{j} \equiv \text { safety significance of cell } j \\
& f_{j}=\text { frequency of fires in cell } j \\
& P_{D}{ }^{j k}=\text { probability of damage to safe shutdown equipment in cell } j \\
& \text { for safety function } k \\
& P_{S F}{ }^{j k}=\begin{array}{l}
\text { probability of loss of safety function } k \text { given damage to safe } \\
\text { shutdown equipment in cell } j
\end{array} \\
& k=\text { number of safety functions }
\end{aligned}
$$

To evaluate the risk significance of a safety improvement, the safety significance is reanalyzed taking credit for the changes in fire frequency, probability of damage to safe shutdown equipment, and probability of loss of safe shutdown function associated with the safety significance calculated with and without the safety improvement, $\delta \mathrm{S}_{\mathrm{j}}$. The overall measure of risk reduction is then the summation over all cells:

$$
\delta \mathrm{R}_{\mathrm{i}}=\sum_{j=1}^{J} \delta \mathrm{S}_{\mathrm{j}}
$$

where:

$$
\delta \mathrm{R}_{\mathrm{i}} \equiv \text { measure of risk reduction for improvement } \mathrm{i}
$$




$$
\begin{aligned}
& \mathrm{J}=\text { number of cells } \\
& \delta \mathrm{S}_{\mathrm{j}}=\text { change in safety importance for cell } \mathrm{j} \text { with safety } \\
& \text { improvement } \mathrm{i}
\end{aligned}
$$

\subsubsection{Example Approach 2. Risk Reduction Proportional to Number of Cells Affected}

This approach is more qualitative than the first example. As a first order approximation, it can be assumed that the more cells for which a safety improvement removes a safe shutdown vulnerability, the greater the reduction in risk. This is the rationale behind Equation 4.14.3:

$$
\delta R_{i \mathrm{i}}=F \times D_{1} \times D_{2}
$$

where:

$$
\begin{aligned}
& \delta \mathrm{R}_{\mathrm{i}}=\text { measure of risk reduction for improvement " } \mathrm{i} " \\
& \mathrm{~F}=\text { fraction of cells affected by the safety improvement } \\
& \mathrm{D}_{1}=\text { importance of safety equipment affected } \\
& \quad(\text { low }=0.5 ; \text { medium }=1 ; \text { high }=2) \\
& \mathrm{D}_{2}=\text { significance of fire threat in cells affected by improvement } \\
& \quad(\text { low }=0.5 ; \text { medium }=1 ; \text { high }=2)
\end{aligned}
$$

Equation 4.14 .3 is not a rigorous estimate of the risk reduction associated with the "i" safety improvement. If it is assumed that fires occur randomly in the cells within the plant, $F$ represents the fraction of postulated fires that are affected by the safety improvement. $\mathrm{F}$ is therefore proportional to the frequency of fires that are mitigated by the safety improvement. $D_{1}$ and $D_{2}$ are additional factors that can be used by the analyst to recognize positive or negative aspects of the risk significance of a safety improvement. These factors help to discriminate between the priorities of the safety improvements. If the analyst assigns no special significance to the factor, he assesses the impact as medium, which multiplies the risk measure by unity (no effect). If the analyst feels that the factor should reduce the risk measure for safety improvement " $i$ ", he makes the assessment of low, which applies a weighing factor of 0.5 . Conversely, if the analyst feels that the factor should increase the risk measure for safety improvement " $\mathrm{i}$ ", he makes the assessment of high, which applies a weighing factor of 2 . This is not intended to represent a quantitative assessment of the true reduction in risk, but to allow the 
analyst to use his judgment to differentiate between the risk significance of improvements.

\subsubsection{Ratio of Benefit to Cost}

The ratio of benefit to cost is obtained by dividing $\delta \mathrm{R}_{\mathrm{i}}$ by the cost for that safety improvement, as determined in Section 4.13. Because the measure of benefit has not been quantified in monetary terms, it is not possible to use a ratio of benefit to cost of unity to determine which backfits to the plant are warranted, as is typically done in cost-benefit analysis. However, this benefit-to-cost ratio can be used to prioritize the different safety improvement options.

\subsubsection{PRIORITIZATION OF IMPROVEMENTS}

4.14.2.1 List all of the safety improvements for the preferred approach to safe shutdown in Exhibit 4.14-1 (these are listed in Exhibit 4.14-2).

4.14.2.2 Estimate the risk reduction associated with incorporating each safety improvement. This estimate can be based on the results of a risk analysis, on the approach described in Section 4.14.1.1, on the approach described in Section 4.14.1.2, or on the subjective judgment of safety analysts, depending on the types of information available to the analyst. However, the analyst must be consistent in using the same approach for each safety improvement. Enter the estimated change in risk in Exhibit 4-15.1.

4.14.2.3 Enter the cost for each safety improvement (calculated in Section 4.13) in Exhibit 4.14-1. Calculate the ratio of $\delta \mathrm{R}_{\mathrm{i}}$ to cost and enter in Exhibit 4.14-1.

4.14.2.4 Order the safety improvements from highest to lowest benefit-to-cost ratio and enter in Exhibit 4.14-2.

Note: $\quad$ The factors utilized in Equation 4.1 are qualitative and arbitrary and are intended to provide a non-rigorous and approximate ranking method. The analyst should utilize his overall plant knowledge and experience to adjust the prioritized list to correct any aberrations that might occur.

4.14.2.5 Enter the cost for each safety improvement in Exhibit 4.14-2 and total with each additional safety improvement.

4.14.2.6 In the final column provide important comments from Exhibits 4.14-1 and 4.14-2 that could influence funding decisions. 
4.14.2.7 Develop funding recommendations as a function of availability of funds. The priorities based on the ratio of benefit to cost are an aid to making these decisions but should not be the only consideration. The analyst should also recognize the high degree of subjectivity in assessing the risk significance of safety improvements. Do not overemphasize the significance of small differences in benefit-to-cost ratio. As a rule, differences less than a factor of 2 should be considered insignificant. After making a preliminary selection of safety improvements at each level of available funding, evaluate the effect of the set of selected improvements on the resolution of vulnerabilities for each cell. It is important to maximize the number of cells for which vulnerabilities are completely resolved. Document the rationale for funding recommendations. 
U.S. DEPARTMENT OF ENERGY'S REACTOR CORE

PROTECTION EVALUATION METHODOLOGY FOR FIRES AT

SOVIET-DESIGNED RBMK AND VVER NUCLEAR POWER PLANTS

Exhibit 4.14-1

CALCULATION OF BENEFIT-TO-COST RATIO

\begin{tabular}{|c|c|c|c|c|}
\hline ID & Description & $\delta \mathrm{R}_{\mathbf{i}}$ & Cost & $\delta \mathrm{R}_{\mathrm{i}} /$ Cost \\
\hline & & & & \\
\hline & & & & \\
\hline & & & & \\
\hline & & & & \\
\hline & & & & \\
\hline & & & & \\
\hline & & & & \\
\hline & & & & \\
\hline & & & & \\
\hline & & & & \\
\hline & & & & \\
\hline & & & & \\
\hline & & & & \\
\hline & & & & \\
\hline & & & & \\
\hline & & & & \\
\hline & & & & \\
\hline & & & & \\
\hline & & & & \\
\hline & & & & \\
\hline . & & & & \\
\hline
\end{tabular}


U.S. DEPARTMENT OF ENERGY'S REACTOR CORE

PROTECTION EVALUATION METHODOLOGY FOR FIRES AT

SOVIET-DESIGNED RBMK AND VVER NUCLEAR POWER PLANTS

Exhibit 4.14-2

PRIORITIZATION OF IMPROVEMENTS

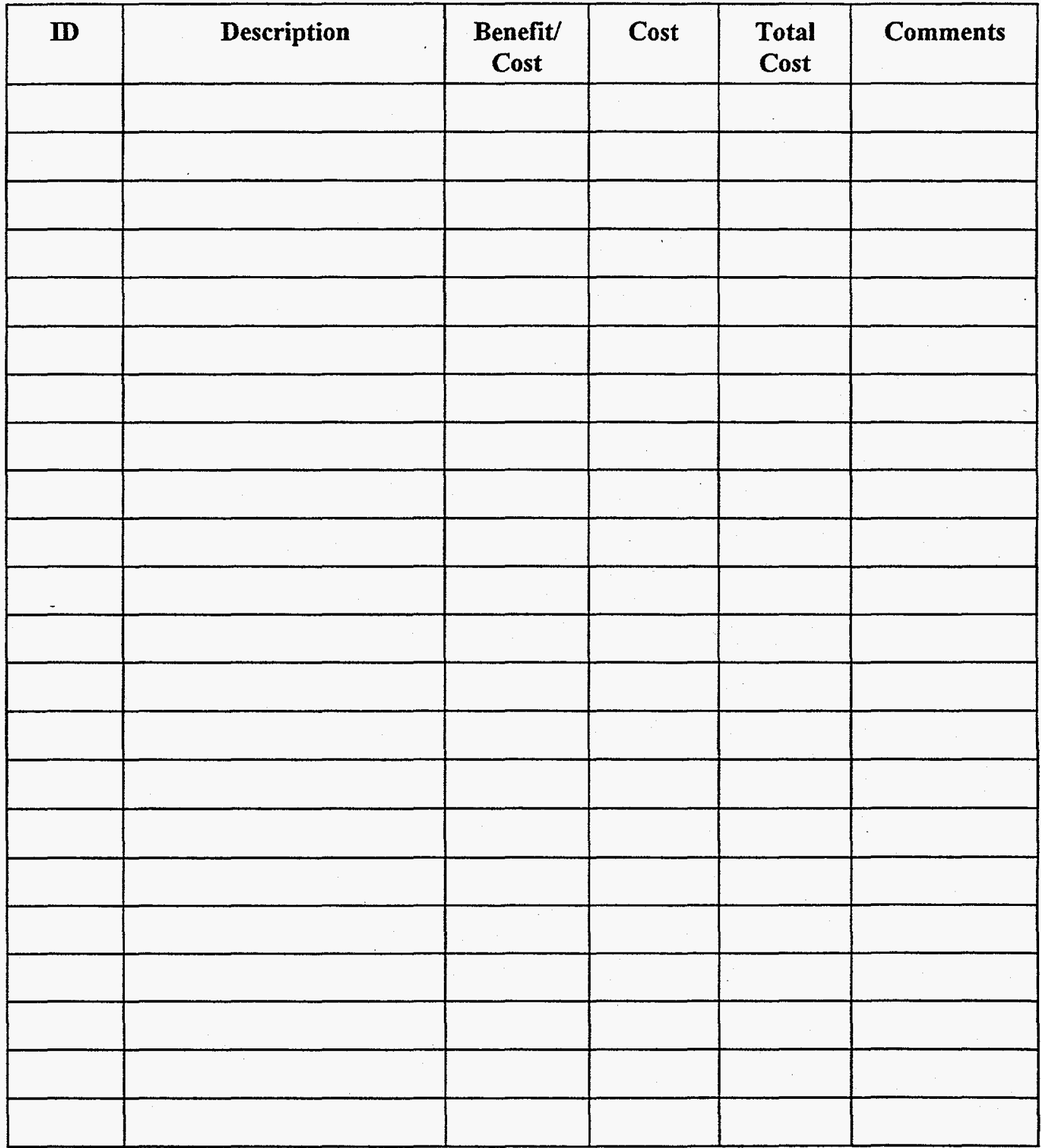





\subsection{BIBLIOGRAPHY}

The documents included in this section were utilized for guidance in preparing this Methodology, and may or may not be specifically referenced within the body of the document.

5.1 IAEA - TECDOC-778, "Fire Hazard Analysis for WWER Nuclear Power Plants, Report of the IAEA Extrabudgetary Programme on the Safety of WWER Nuclear Power Plants," December 1994.

5.2 Code of Federal Regulations, Title 10 Part 50, Appendix R, "Fire Protection Program for Nuclear Power Facilities Operating Prior to January 1, 1979."

5.3 USNRC Standard Review Plan 9.5.1, "Fire Protection Program," Rev. 3, July 1981.

5.4 Branch Technical Position CMEB 9.5-1, "Guidelines for Fire Protection for Nuclear Power Plants," Rev. 2, July 1981.

Appendix A to Branch Technical Position APCSB 9.5-1, "Guidelines for Fire Protection for Nuclear Power Plants Docketed Prior to July 1, 1976," August 23, 1976.

5.6 USNRC Generic Letter 86-10, "Implementation of Fire Protection Requirements," April 24, 1986.

5.7 USNRC Generic Letter 83-33, "NRC Positions on Certain Requirements of Appendix R to 10 CFR 50," October 19, 1983.

5.8 USNRC IE Information Notice No. 84-09: "Lessons Learned from NRC Inspections of Fire Protection Safe Shutdown Systems (10 CFR 50, Appendix R)," February 13, 1984.

5.9 IEEE Standard 384-1992, "Standard Criteria for Independence of Class 1 E Equipment and Circuits."

5.10 Fire Protection Handbook, Seventeenth Edition, National Fire Protection Association, 1991.

5.11 The SFPE Handbook of Fire Protection Engineering, First Edition, 1988, and Second Edition, 1995, Society of Fire Protection Engineers/National Fire Protection Association, 1995. 
ANS 58.14, "Safety and Pressure Integrity Classifications Criteria for Light Water Reactors," 1994. Document Describing Requirements for Commercial Nuclear Power Plants Operating in the United States," March 1995, USNRC., K. Sullivan, Brookhaven National Lab, K. Parkinson, Sonalysts, Inc., T. Storey, Science Applications International Corp, and R. Porterfield, Consulting Engineer. $\mathrm{Ph} . \mathrm{D}$, Fire Protection Engineering, University of Maryland at College Park, May 1996.

IAEA Safety Series No. 50-P-6, "Inspection of Fire Protection Measures and Fire Fighting Capability at Nuclear Power Plants," October 1994.

IAEA Safety Series No. 50-P-9, "Evaluation of Fire Hazard Analyses for Nuclear Power Plants," July 1995.

IAEA Draft 4, "Treatment of Internal Fires in Probabalistic Safety Assessments for Nuclear Power Plants", April, 1997.

5.19 Handbook of Chemistry and Physics, $64^{\text {th }}$ Edition, The Chemical Rubber Publishing Company, Cleveland, Ohio, 1984. 


\section{APPENDIX A}

POSSIBLE APPROACHES FOR RESOLVING IDENTIFIED FIRE VULNERABILITIES

AND

GUIDANCE FOR EVALUATING THE EQUIVALENCY OF EXCEPTIONS TO ESTABLISHED CRITERIA

\section{A.1 INTRODUCTION}

To achieve the high degree of fire safety required for nuclear power plants, protection should be directed at establishing multiple levels of safety features. This "defense-in-depth" approach is focused on achieving an adequate balance in: (1) preventing fires from starting; (2) detecting quickly, controlling, and extinguishing promptly those fires that occur; and (3) protecting structures, systems, and components so that a fire that is not promptly extinguished will not prevent the safe shutdown of the plant.

The fundamental objective of the guidance contained in the Reactor Core Protection Evaluation Methodology (RCPEM) is to provide a systematic method of identifying fire vulnerabilities that could jeopardize protection of the reactor core. Once identified, various possible protection options may be considered and evaluated for their ability to provide a balanced approach toward fire protection, in accordance with the defense-in-depth concept. In all cases, the protection approach selected should provide reasonable assurance that at least one means of achieving and maintaining safe shutdown conditions will remain available during and after a postulated fire.

Section A.2 presents examples of possible solution options for resolving some common plant design and configuration problems (fire vulnerabilities). The challenge to the fire safety analyst and plant operating organization is to determine the best solution possible based on its ability to provide costeffective protection against the threat of fire that is in accord with the defensein-depth philosophy, regulatory criteria, and plant-specific design and operating practices. However, it must be emphasized that the best solution for reducing the risk from fire is to prevent them from occurring. Great safety benefits can often be achieved in this area at very modest costs. Eliminating or controlling potential sources of fire ignition (smoking, open flames, hot surfaces, metal cutting/welding, sparks, and certain chemical reactions) and combustible materials in areas of the plant containing safety-critical systems and equipment 
is an important first step toward establishing defense-in-depth protection from fire.

\section{ADMINISTRATIVE CONTROLS}

Administrative controls are a part of any comprehensive fire protection program. They are an effective means to govern plant work activities to ensure that good plant housekeeping practices are adhered too and that controls are placed on the storage and use of combustible materials, including fire retardant treated materials, flammable and combustible liquids, and compressed gasses. Administrative controls should also be utilize to ensure that Hot work permits are utilized during all maintenance and operating activities that have the potential for being fire initiators. They should also be used to control the disabling of fire detection and fire suppression systems as well as systems necessary to ensure safe shutdown of the plant after a fire

\section{ENGINEERING EVALUATIONS}

When a fire vulnerability is identified, it is desirable to develop technically sound resolutions that have a minimum impact on the physical configuration and operating procedures of the plant. In many cases, potential vulnerabilities identified during the initial application of the RCPEM may be satisfactorily resolved through more detailed engineering evaluations directed at obtaining additional insight into the specific concerns. For example, the analysis process may reveal that a fire in one fire compartment could threaten the operating integrity of redundant instruments required to accomplish safe shutdown conditions in the reactor. A plant modification to relocate one train of the required instruments would resolve this problem, but at considerable expense. The performance of additional engineering evaluations may, however, reveal that the existing plant-specific design features, including the large size of the compartment, separation distance between instruments, operating temperature limits of the affected instruments, limited amount of combustible material, and presence of automatic detection and suppression systems, provide reasonable assurance that a postulated fire will be rapidly detected and quickly extinguished before both trains of equipment are affected.

\section{USE OF ALTERNATE EQUIPMENT}

Nuclear power plants typically contain a diversity of systems that may be configured to perform required safety functions. Consequently, the simplest and most viable option for resolving fire vulnerabilities in a given fire compartment or cell is to use other systems or equipment capable of performing the desired shutdown function but located outside the area of 
concern. This approach may be very broad, involving a complete revision of the method and systems selected to accomplish safe shutdown, or limited to verifying the availability a single piece of equipment. Since this approach can be readily accommodated by procedural changes and operator training, its implementation is highly cost effective.

\section{USE OF OPERATOR ACTIONS}

The use of manual operator actions to mitigate the possible effects of fire damage provides a cost-effective approach to resolving identified vulnerabilities. However, the use of this approach requires careful consideration of several important technical and operational concerns, including:

- Time: There must be sufficient time for manual safe shutdown equipment manipulations to take place before the safe shutdown capability is jeopardized. The time available to perform manual realignment of equipment will vary significantly according to the specific system or component affected, and the location complexity of the manual alignments to be performed. For example, the time available to close a manual valve to mitigate flow diversion from a required system flow path depends largely on the size of the flow diversion path, the time for operators to reach the valve location, and the time to manually close the valve. The evaluation should conservatively assume the failure to take place at the onset of fire unless it can be shown that adequate means (e.g., instrumentation, procedures, and training) are available for operators to "detect and defeat" the fire-induced failure before it causes the plant to enter a transient condition.

- Environment: The ability of operators to access the compartment where the manual action is performed must be demonstrated. This evaluation should examine the environmental conditions in the compartment, as well as the routes to be traveled by the operator before and after the action is performed. Typical factors to consider include radiation exposure rates, temperature, smoke and/or hot gases, manual and automatic fire suppression activities, and flooding.

Typically, operator actions inside a fire-affected compartment or cell should not be credited unless it can be demonstrated that the action will not be required before the fire is fully extinguished and suitable environmental conditions are restored. 
- Lighting: The availability and adequacy of plant lighting necessary to accomplish all required shutdown tasks should be demonstrated. This evaluation should examine plant lighting illumination requirements in the compartment where manual operations are performed, as well as in any access and egress routes traveled by the operator. Factors to consider during this evaluation include environmental conditions expected during a fire, the potential effect of fire on the operability of the plant normal and emergency lighting sources (note: this evaluation is not necessary if it is assumed that these sources will be affected by fire and adequate back-up lighting is provided), physical location and complexity of the operator actions to be performed, and the availability and adequacy of hand-held portable lighting units.

- Communications: A reliable communication system is necessary to coordinate reactor shutdown activities between operators located in remote locations of the plant and operators stationed in the control room or remote shutdown panels. There are several types of "normal" plant communications systems (telephones, sound-powered phones, paging systems, and portable radios) already installed that may be used where possible. However, due to the location of equipment or connected cabling, these systems may be lost or unreliable during certain fire events. In such cases, or, where the performance (operation and effectiveness) of existing communication systems during fire has not been evaluated, a new, independent, communication system may be necessary. The specific type of communication system selected should consider the effects of fire on its operation and its availability, reliability, and adequacy of operation in all areas of the plant where manual safe shutdown actions are performed.

- Equipment: Manual safe shutdown actions should be reviewed to determine the need for supplemental repair equipment and tools. If required, these items should be readily available to the operator at all times, preferably stored at the location of the manual action and dedicated for use during post-fire shutdown procedures. For example, if the operator action involves the removal of fuses, a fuse puller should either be stored at the fuse panel or made available to the operators prior to performing the activity. Additionally, administrative procedures should be in effect to provide periodic verification of the availability and condition of any required tools and equipment.

- Manpower: It should be demonstrated that a sufficient number of operating personnel are on each shift and available to support all manual 
reactor safe shutdown actions in conjunction with all other activities necessary to mitigate the fire.

- Training: All operator activities should be governed by, and performed in accordance with, established plant abnormal operating procedures, and operators should be trained in their implementation. The training program should include drills (practice sessions) demonstrating the feasibility of performing the required reactor safe shutdown actions.

\section{EXCEPTIONS TO ESTABLISHED CRITERIA}

As indicated in the examples provided in Section A.2, fire protection criteria typically delineate certain specific design features, such as separation distance, fire barrier ratings, and fire detection or suppression systems, as a means of protecting required equipment from the effects of fire. However, in certain cases, plant-specific conditions may preclude compliance with one or more of the provisions specified in the established criteria. For example, the criteria may specify fire barriers to have a minimum fire resistive rating of 2 hours while the "as built" rating of a particular fire cell wall may be somewhat less (1 $1 \frac{1}{2}$ hours). In such a case, the operating organization should demonstrate, by means of a detailed fire hazards analysis, that the existing protection, or the existing protection in conjunction with proposed modifications, will provide a level of safety equivalent to compliance with the specific technical requirements of the criteria. An approach that does not satisfy the specific technical requirements of the established criteria is called an "exception." Guidance for determining the equivalency of "exceptions" to established criteria is provided in Section A.3, "Guidance for Evaluating Equivalency of Exceptions to Established Criteria."

Section A.4, "Alternative Approaches to Completing the Methodology Steps When Plant Data is Not Available" is provided to augment the steps in the Methodology where it may not be possible to find or develop plant data.

\section{ILLUSTRATIVE EXAMPLES OF POSSIBLE SOLUTIONS TO IDENTIFIED PROBLEMS (FIRE VULNERABILITIES)}

The following "case studies" serve as examples of problems encountered by U.S. plants during their implementation of similar analyses. The examples are directed at providing the analyst with additional insight into the many conceivable methods of resolving fire protection concerns in a manner satisfying the established criteria. For each "case study" an example problem is stated and a number of "possible solution options" are then presented to demonstrate the variety of possible resolutions. Since it is not possible to 
address every potential plant-specific equipment configuration and fire vulnerability that may be encountered, the analyst is cautioned that the "possible solution options" described in this section of the report are provided for informational purposes only and may not be directly applicable to specific problems encountered. Should problems similar to those described in this section be identified during the analysis, the analyst must evaluate the merits of the suggested solutions on a case-by-case basis. This evaluation should consider such factors as the plant-specific design, equipment configurations, existing fire safety features, and operating practices. 


\section{CASE 1-LARGE PENETRATION IN FIRE CELL BARRIER}

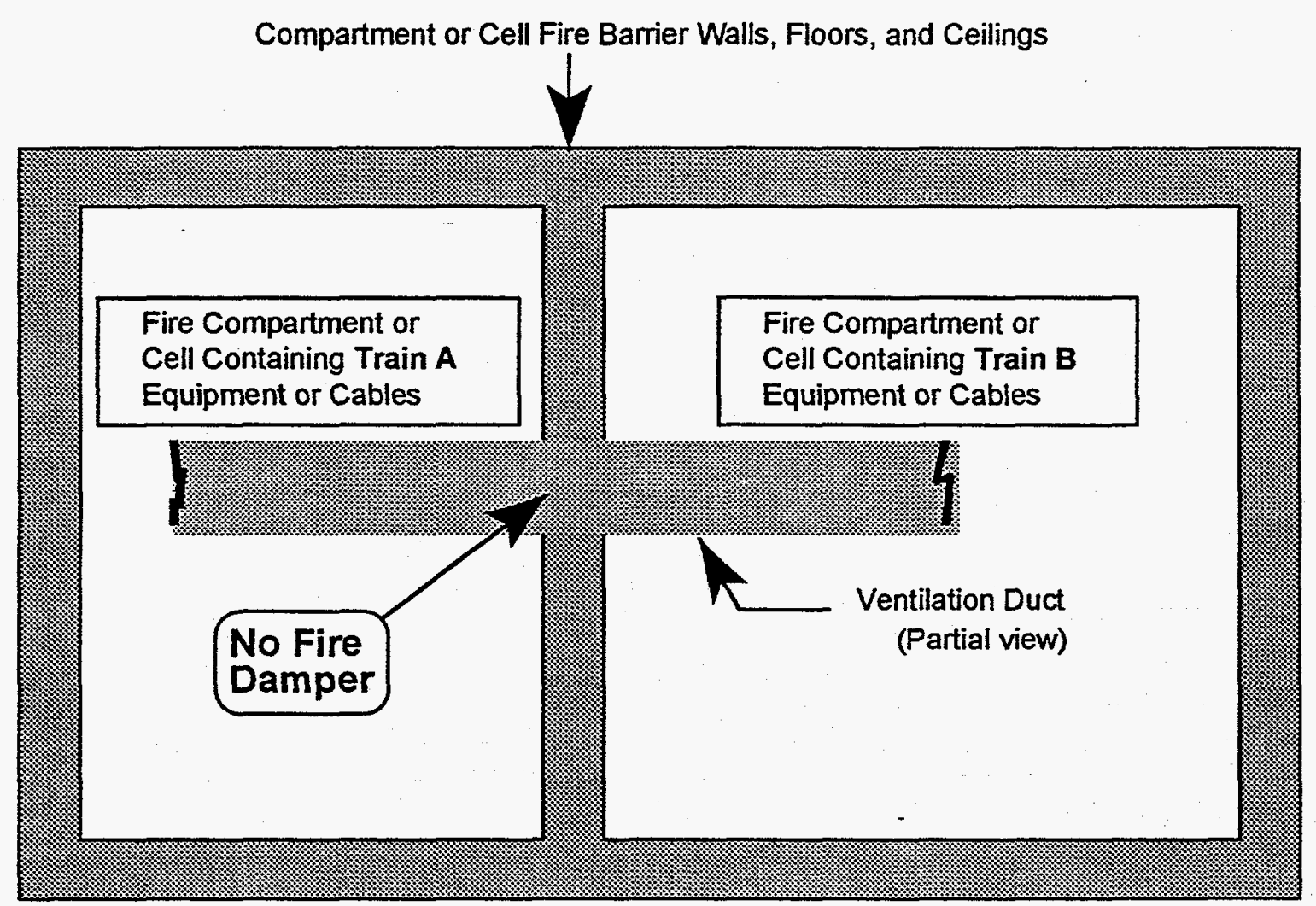

Problem: A ventilation duct traverses a fire compartment or cell barrier wall that separates redundant trains of shutdown equipment. Since the effects of fire had not been considered in the as-installed design of the ventilation duct, there is a potential for fire, and/or the products of combustion, to propagate to the adjacent fire compartment or cell, thereby jeopardizing the operability of the redundant equipment.

\section{Possible Solution Options:}

1.

Demonstrate that other equipment, located outside the fire affected compartments or cells, will be readily available and capable of accomplishing the necessary shutdown function(s).

2. Demonstrate that other equipment, located outside the fire affected compartments or cells, can be configured to perform the required shutdown function in a timely manner through manual operator actions and develop post- 
fire abnormal operating procedures to govern the implementation of this capability.

3. Consider the acceptability of installing fire detection in each fire compartment or cell and an automatic suppression system (sprinklers) capable of mitigating fire damage to the ventilation duct and controlling the spread of fire between the adjacent fire cells. To minimize the likelihood of fire involving transient combustibles, designate the area under the ventilation duct a "combustible free zone" and develop administrative controls to maintain this feature.

4. Evaluate the effectiveness of installing an automatic fire-rated damper in the ventilation duct (at the penetration) and providing automatic shut-down of the ventilation supply fan. To ensure rapid detection and response to fire, this option should also consider the adequacy of fire detection in each fire compartment or cell. Additionally, based on the quantity of combustible material (fixed and transient) in the area, the installation of automatic fire suppression systems should also be considered.

5. Install fire detection in each fire compartment or cell and provide fire-retardant wrap and/or coatings on the ventilation duct. Based on the quantity of combustible material (fixed and transient) in the area, the need for automatic fire suppression should also be considered. It is important to note that the installation of fire-retardant wrap and/or coatings requires careful consideration of their potentially adverse effect on plant operations. Factors to be considered include the ability of encapsulated items (especially cables) to withstand additional thermal stress, mechanical/seismic loading, possible impediments to future maintenance and modifications, and need for surveillance requirements to ensure long-term effectiveness of the barrier.

6. Reroute the ventilation duct and seal the penetration. 


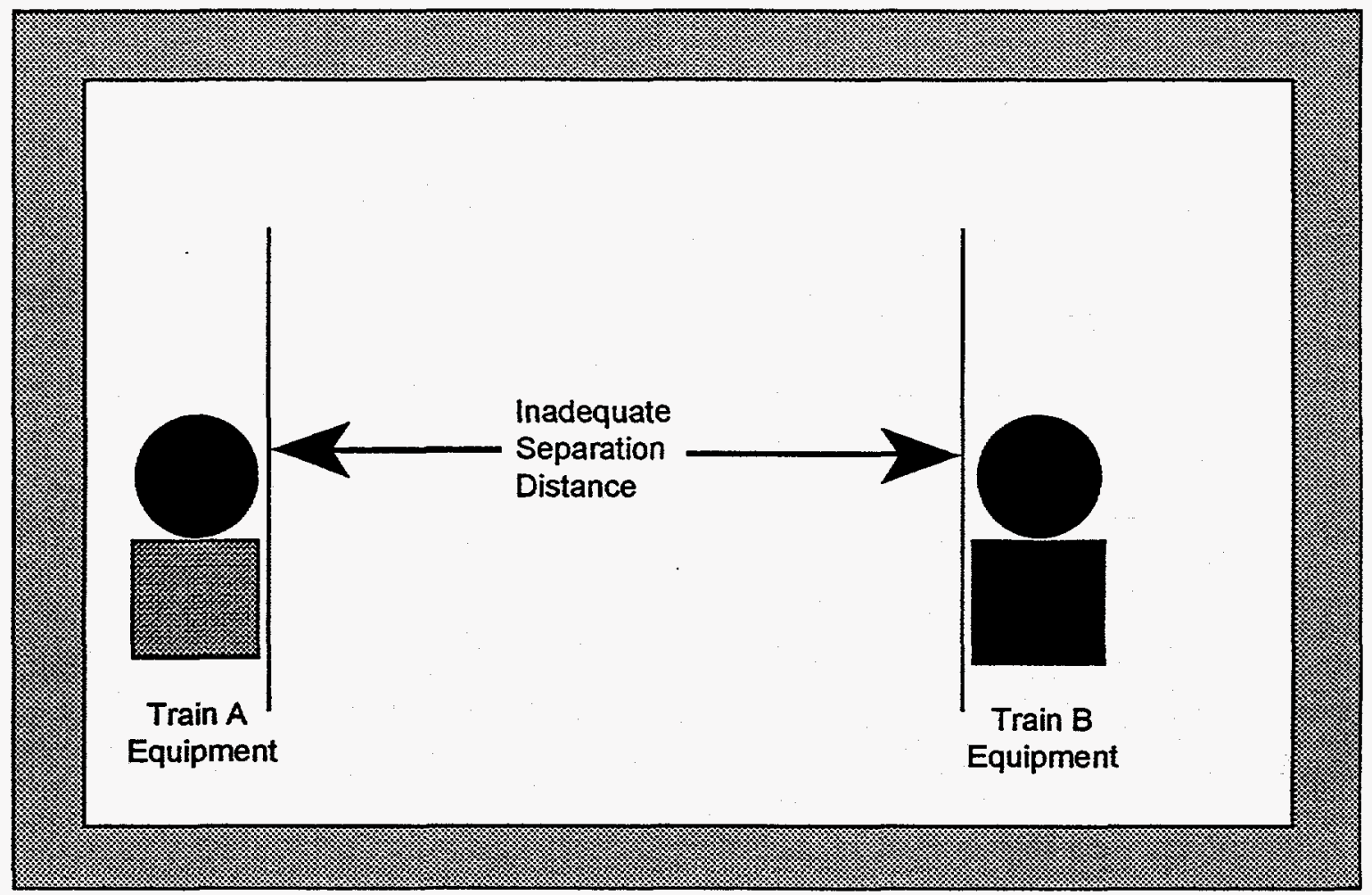

Problem: Due to their close physical proximity, redundant feedwater pumps are susceptible to common-cause fire damage.

\section{Possible Solution Options:}

1. Demonstrate that other equipment, located outside the fire affected compartments or cells, will be readily available and capable of accomplishing the required shutdown function(s).

2.

Demonstrate that other equipment, located outside the fire affected cells, can be configured to perform the required shutdown function in a timely manner through manual operator actions and develop post-fire abnormal operating procedures to govern the implementation of this capability.

3.

Evaluate the effectiveness of establishing a "combustible free zone" between pumps (i.e., no intervening combustibles), installing fire detection and an automatic suppression system (sprinklers) suitable for hazards in area, and 


\section{U.S. DEPARTMENT OF ENERGY'S REACTOR CORE}

providing a partial-height fire barrier wall between redundant pumps as shown below:

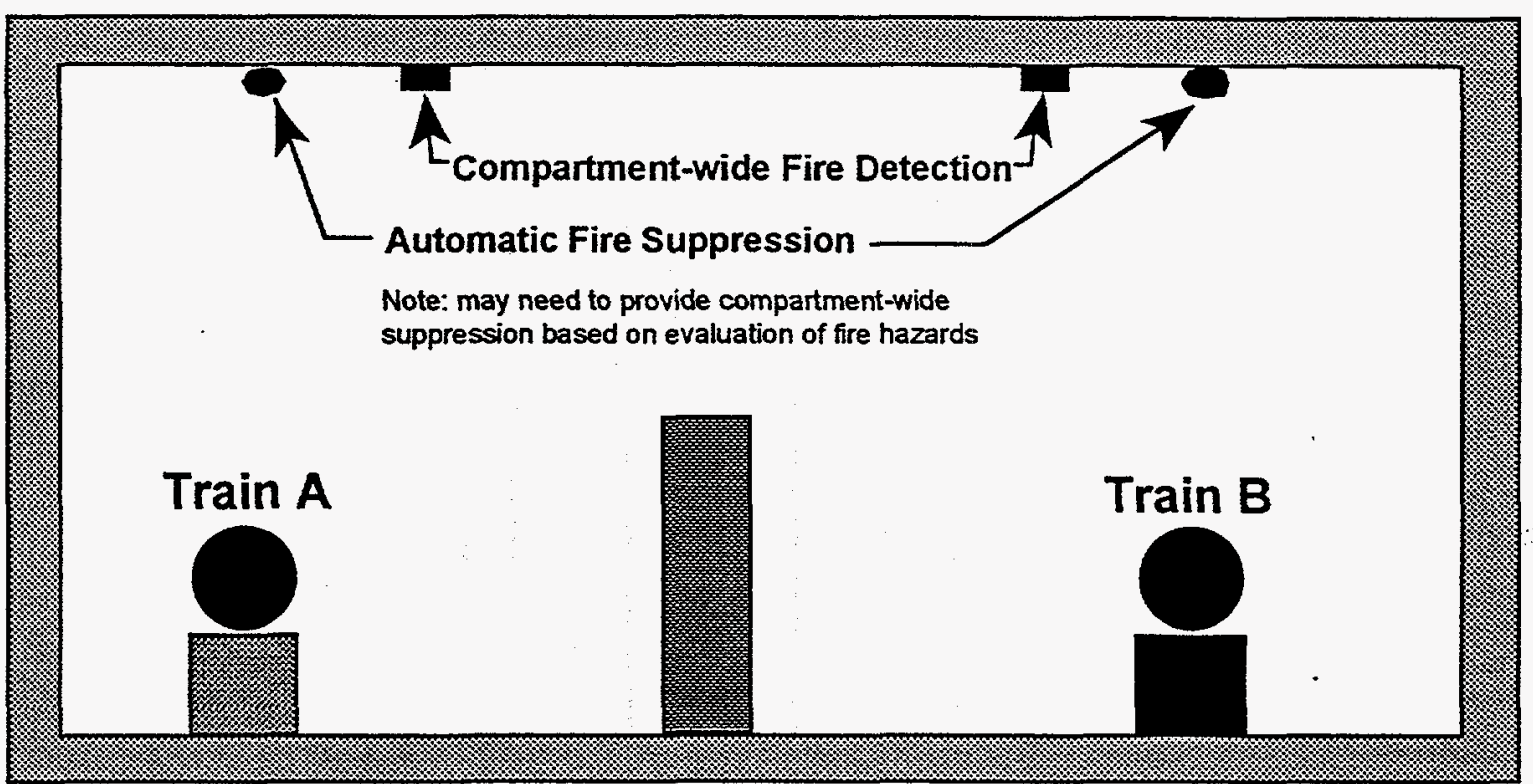

4.

Consider the acceptability of establishing a "combustible free zone" between pumps (i.e., no intervening combustibles), providing fire detection and automatic suppression systems suitable for the fire hazards, and installing a fire-detector-activated water curtain as depicted below. Note that the need to contain and remove the large quantity water released by the water curtain should be considered when this option is used.

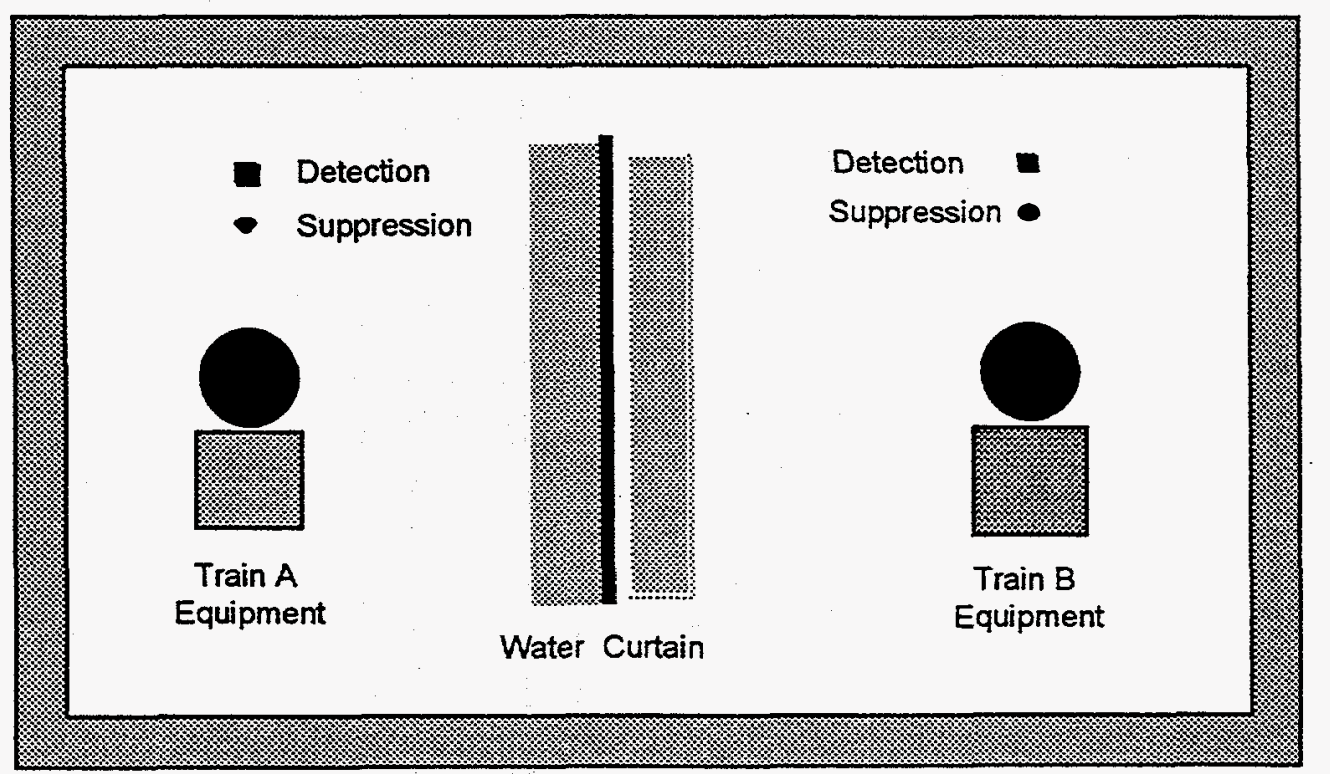


5. Provide area wide fire detection and automatic suppression capability, and install a "dedicated" feedwater pump that is physically and electrically independent of the fire compartment or cell under consideration.

6. Construct fire barriers to divide fire compartment or cell into two (or more) smaller cells.

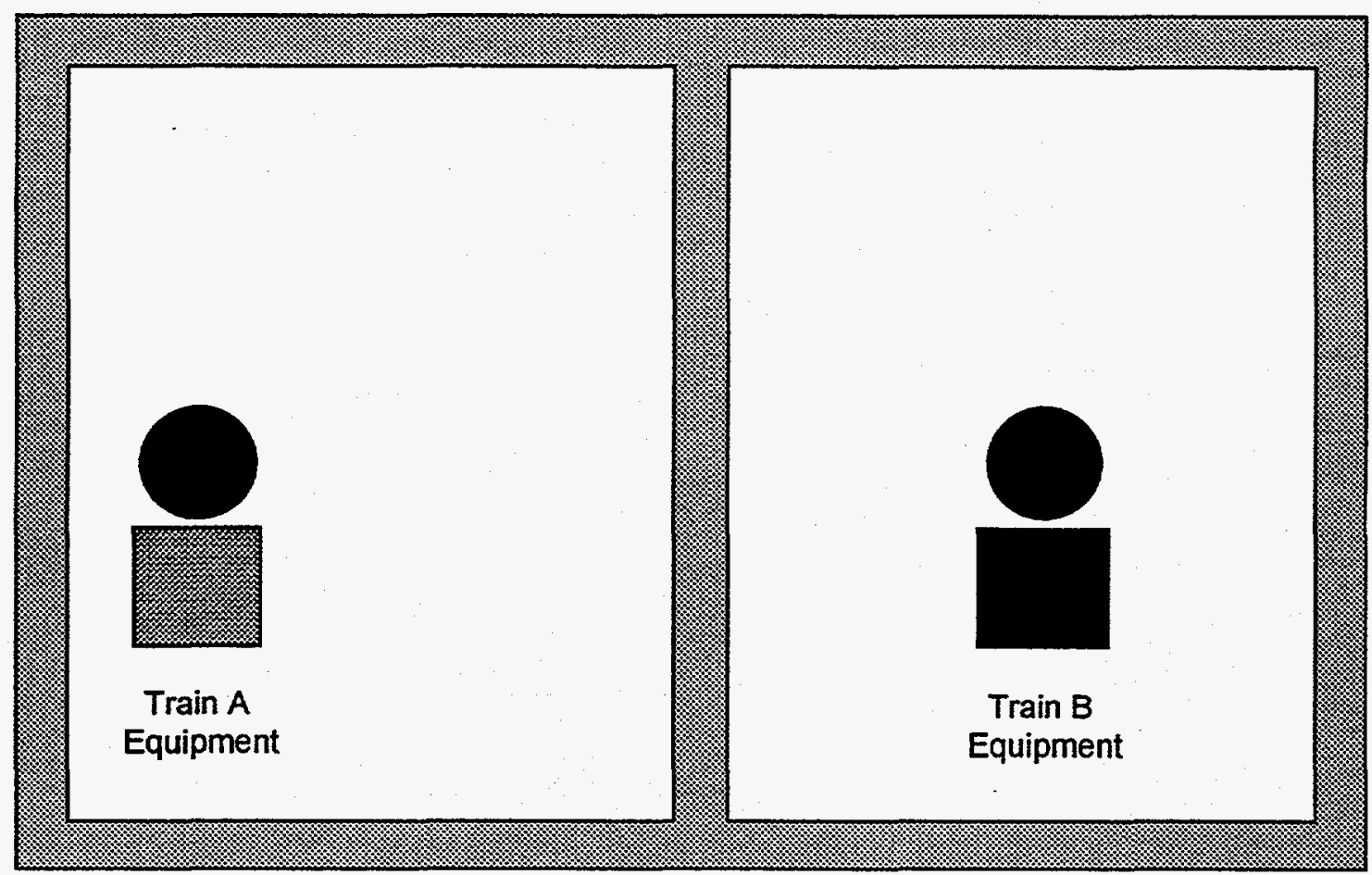

Caution comment: The need for additional design enhancements, such as ventilation, lighting, and operator access should be considered when this option (installing a floor-to-ceiling fire-barrier wall) is selected. Additionally, since the cables of both pieces of redundant equipment may cross the newly installed wall, the adequacy of separation this design change will provide for any electrical cables associated with the redundant equipment must also be considered.

7.

For cases where: (a) a large quantity of redundant components may be exposed to damage as a result of fire in a single fire compartment; or (b) the adequacy of fire protection features provided for redundant components is uncertain in a number of compartments; or (c) it is not feasible or cost-effective to provide fire protection features necessary to establish reasonable assurance that one train of systems required for plant shutdown will remain free of fire damage, an Alternative or Dedicated Shutdown Capability should be provided. An Alternative Shutdown System is one that relies on the use of existing plant 
systems that have been modified to provide the requisite level of independence from the fire affected area(s). A Dedicated Shutdown System consists of a minimum set of new equipment having the explicit purpose of accomplishing and maintaining safe shutdown functions (e.g., reactor coolant makeup, pressure control, and decay heat removal). A Dedicated Shutdown System should be independent (physically and electrically) of the fire areas under consideration, capable of being powered from its own source of electrical power, and typically located in a separate structure, outside the power block.

DUE TO CAPITAL EQUTPMENT AND CONSTRUCTION COSTS, THE INITIAL EXPENSE OF A DEDICATED SHUTDOWN SYSTEM IS TYPICALLY HIGHER THAN AN ALTERNATIVE SHUTDOWN CAPABILITY OR PLANT MODIFICATIONS NECESSARY TO IMPROVE THE LEVEL OF FIRE PROTECTION FOR EXISTING PLANT SYSTEMS. THIS “UP-FRONT" EXPENSE, HOWEVER, COULD BE APPRECIABLY OFFSET BY A NUMBER OF MITIGATING FACTORS, INCLUDING: (A) THE NUMBER OF PLANT MODIFICATIONS NECESSARY TO PROVIDE REASONABLE ASSURANCE THAT EXISTING PLANT SYSTEMS WILL REMAIN AVAILABLE TO PERFORM ESSENTIAL SHUTDOWN FUNCTIONS IN THE EVENT OF FIRE, (B) LONGTERM OPERATING AND MAINTENANCE COSTS OF REQUIRED PLANT MODIFICATIONS, SUCH AS COSTS ASSOCIATED WITH VERIFYING AND MAINTAINING THE DESIGN INTEGRITY OF FIRE-PROTECTIVE FEATURES, (C) THE COST OF PERFORMING ENGINEERING ANALYSES NECESSARY TO EVALUATE THE POTENTIAL EFFECT OF COMMON-CAUSE FIRE DAMAGE AND DEVELOP APPROPRIATE REMEDIES, (D) THE IMPACT OF REQUIRED MODIFICATIONS ON PLANT OPERATIONS AND MAINTENANCE ACTIVTTTES, (E) COSTS ASSOCIATED WITH MAINTAINING LONG-TERM CONTROL OF THE ALTERNATIVE SHUTDOWN CONFIGURATION (I.E., EVALUATIONS OF PLANT MODIFICATIONS FOR THEIR POTENTIAL IMPACT ON THE ALTERNATIVE SHUTDOWN CAPABILITY) AND (E) THE POTENTIAL FOR THE DEDICATED SHUTDOWN SYSTEM TO RESOLVE OTHER ABNORMAL EVENTS NOT RELATED TO FIRE, SUCH AS EARTHQUAKE, FLOODING, AND STATION BLACKOUT (LOSS OF ALL NORMAL SOURCES OF ELECTRICAL POWER). 


\section{CASE 3-INADEQUATE SEPARATION BETWEEN REDUNDANT CABLES}

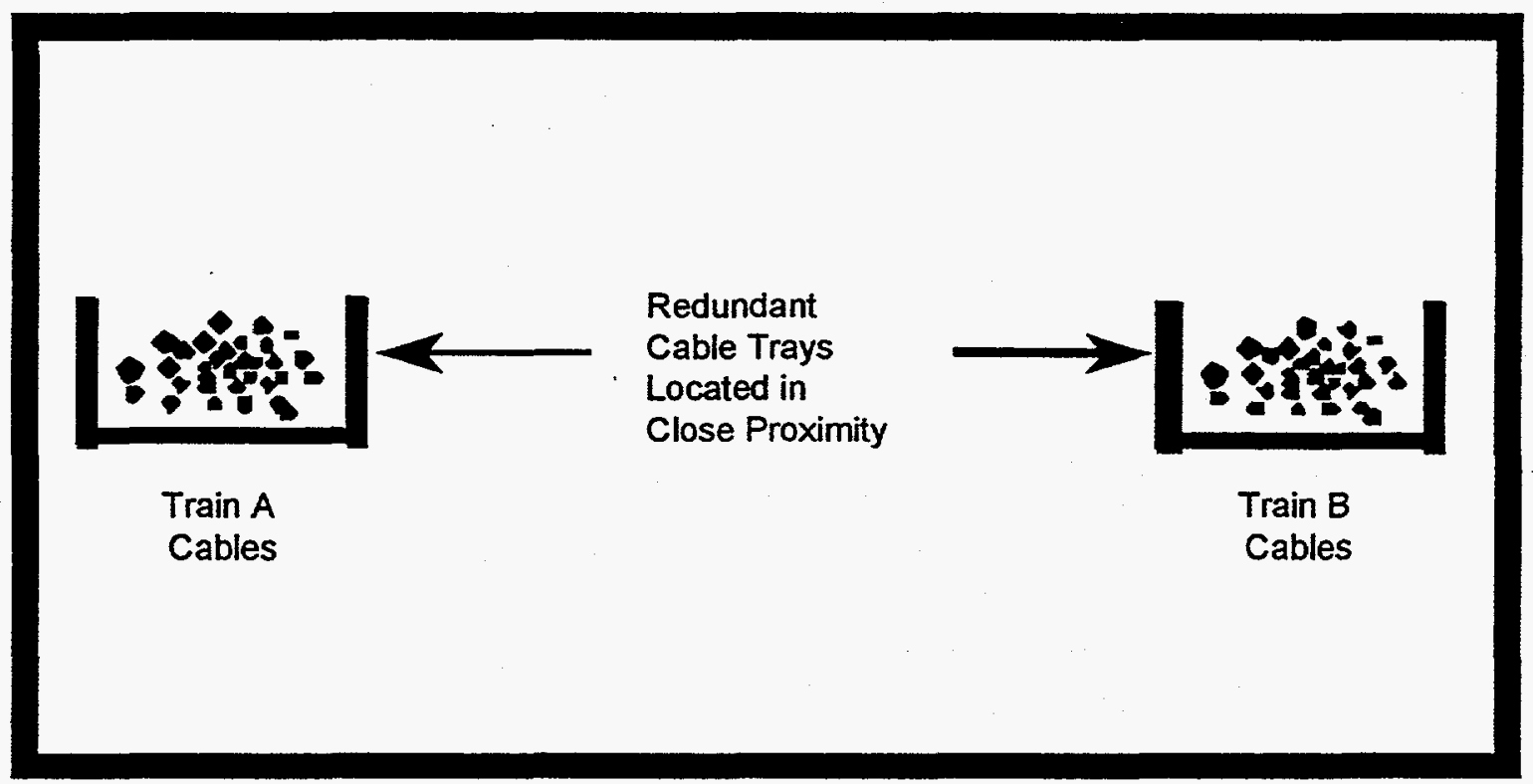

Problem: The horizontal distance between enclosures containing cables associated with redundant trains of shutdown systems does not satisfy established separation criteria.

\section{Possible Solution Options}

1. Demonstrate that other equipment capable of accomplishing the necessary shutdown function(s) is independent of the fire affected compartment or cell and will be readily available when needed.

2.

Demonstrate that other equipment, located outside the fire affected cells, can be configured to perform the required shutdown function(s) in a timely manner through the implementation of manual operator actions. Develop post-fire abnormal operating procedures to govern operator implementation of this capability.

3. Identify the specific fire consequences of concern by performing a detailed circuit evaluation of the potential effects of fire-induced circuit faults (hot shorts, open circuits, and shorts to ground) on cables associated with one division of shutdown systems. This may be accomplished by first identifying the specific cables of interest, and then evaluating, on a cable by cable basis, 
the potential consequences of fire damage to these cables on safe shutdown capability. This approach, while engineering labor intensive, frequently serves to reduce the quantity of cables requiring protection or separation and helps define cost-effective protection alternatives. For example, rather than assume the fire would result in "worst-case" damage to all of the exposed cables, this evaluation may determine that safe shutdown can be assured if only certain cables are prevented from becoming inadvertently energized (hot-short condition) as a result of fire damage. With this detailed level of knowledge, cost-effective protection measures can then be considered. Such measures could include rerouting only the identified cables outside of the fire affected compartment or cell or enclosing the cables in a metallic conduit (tube) and, if necessary, enhancing the available fire mitigation features.

It should be noted that while metallic tubing may provide some limited degree of protection from fire, it is not typically credited for use as a fire barrier. In the specific example cited above, removing the identified cables from the cable tray and routing them within metallic tubing serves to reduce the likelihood of the undesired "hot-short" failure mode (i.e., cables shorting to other energized cables), thereby mitigating the consequences of fire. Depending on the physical configuration and specific fire hazards of the fire compartment or cell being evaluated, enhancing the available fire mitigation features (detection and manual or automatic suppression systems) may also be necessary to provide defense-in-depth protection.

4.

Depending on the existing separation between the redundant-division cable trays, the establishment of a "combustible free zone" between the redundant cable trays (i.e., no intervening combustibles) and installation of area-wide fire detection automatic suppression systems may provide a suitable level of protection. In cases of high cable concentrations or other fire hazards, an enhanced suppression capability, which provides additional protection for the immediate area of the cable trays of concern, should also be considered.

5.

Consider the acceptability of constructing additional fire barrier walls to divide the fire compartment or cell into two (or more) smaller cells. (See caution comment in Case 2, Solution 6.)

6.

Evaluate the effectiveness of providing fire-retardant wrap and/or coatings on cable trays (or other enclosures) containing cables requiring protection (i.e., cables necessary to accomplish the required shutdown function[s]) and installing fire detection and automatic suppression. Depending on the specific design features of the fire compartment or cell and the quantity of combustible material (fixed and transient) present, a partial area automatic fire suppression system, which provides protection for a relatively small area (typically the 


\section{U.S. DEPARTMENT OF ENERGY'S REACTOR CORE \\ PROTECTION EVALUATION METHODOLOGY FOR FIRES AT \\ SOVIET-DESIGNED RBMK AND VVER NUCLEAR POWER PLANTS}

specific cable trays and combustibles of concern), may provide sufficient protection. Also, for fire cells containing low quantities of combustibles or other hazards, enhanced manual fire fighting features may provide adequate protection in lieu of automatic suppression systems.

As indicated in the figure below, in certain cases involving large fire compartments, adequate protection may also be achieved by encapsulating one of the redundant trays of cable with fire-retardant wrap until an acceptable separation distance is achieved. When this option is selected, however, a more robust wrap material should be used. The fire resistance rating of the fireretardant wrap should be equivalent to that of the fire compartment/cell barrier walls, and it must be ensured that the outside surface of the wrap material will not support the spread of flame when exposed to fire (i.e., non-combustible). Additionally, area-wide detection should be provided and, as a minimum, automatic suppression should be installed throughout the area of concern.

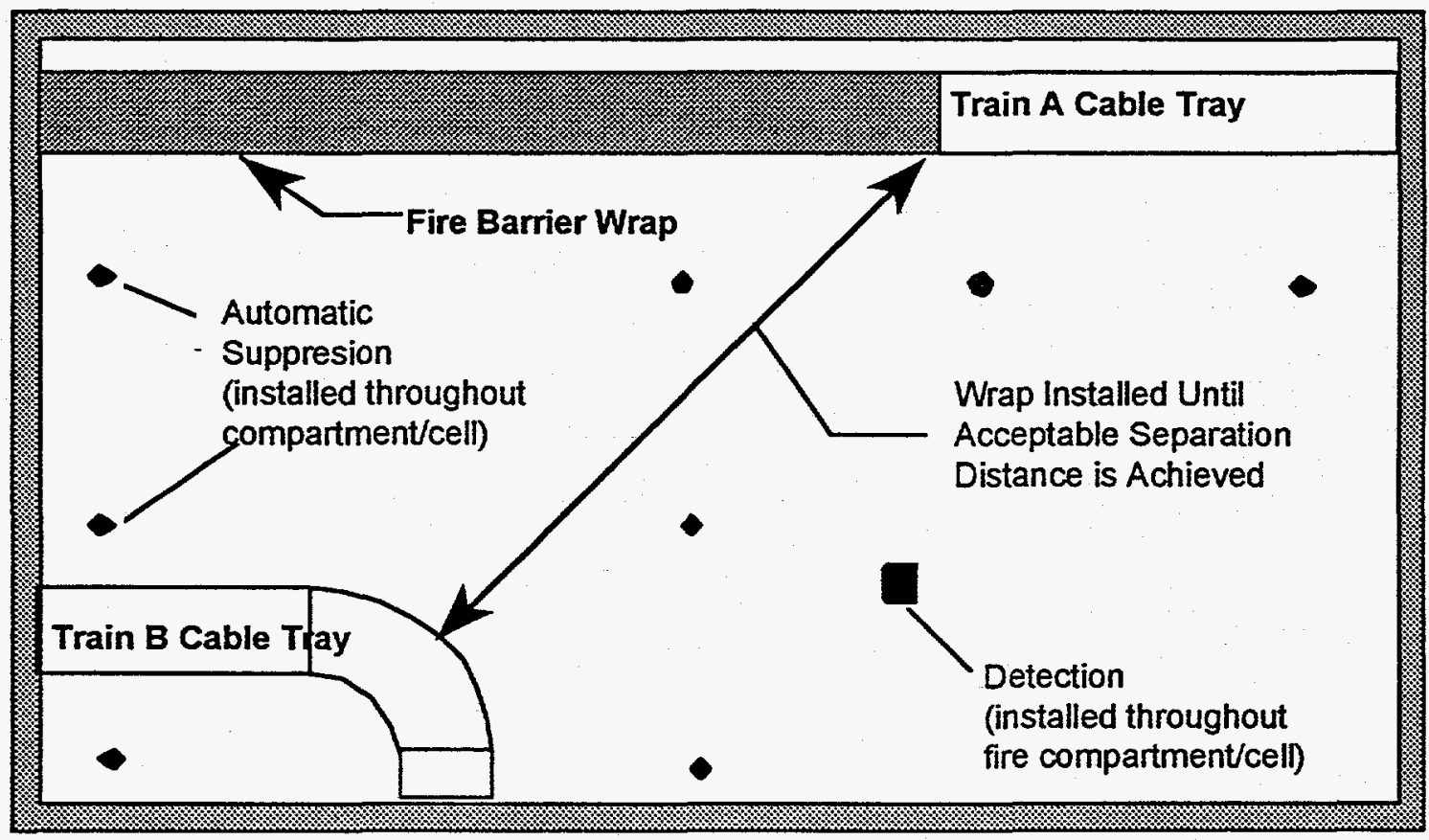

It is important to note that the installation of fire-retardant wrap and/or coatings requires careful consideration of their potentially adverse effect on the equipment being protected and plant operations. Factors to be considered include the ability of encapsulated items (especially cables) to withstand additional thermal stress, mechanical/seismic loading, possible impediments to future maintenance activities and plant modifications, and the need for additional surveillance requirements to ensure long-term effectiveness of the 
barrier. For example, due to the additional thermal stress imposed, it may be unsuitable to wrap certain types of cables, such as those constructed of polyvinyl chloride (PVC) insulation.

7.

For cases where redundant cables of systems required to achieve and maintain stable shutdown conditions are located in proximity to each other and it is not feasible or cost-effective provide fire protection features necessary to establish reasonable assurance that one train of systems required for plant shutdown will remain free of fire damage, an Alternative or Dedicated Shutdown Capability should be considered (see Case 2, Solution 7). 


\section{CASE 4-INADEQUATE ELECTRICAL INDEPENDENCE/ISOLATION}

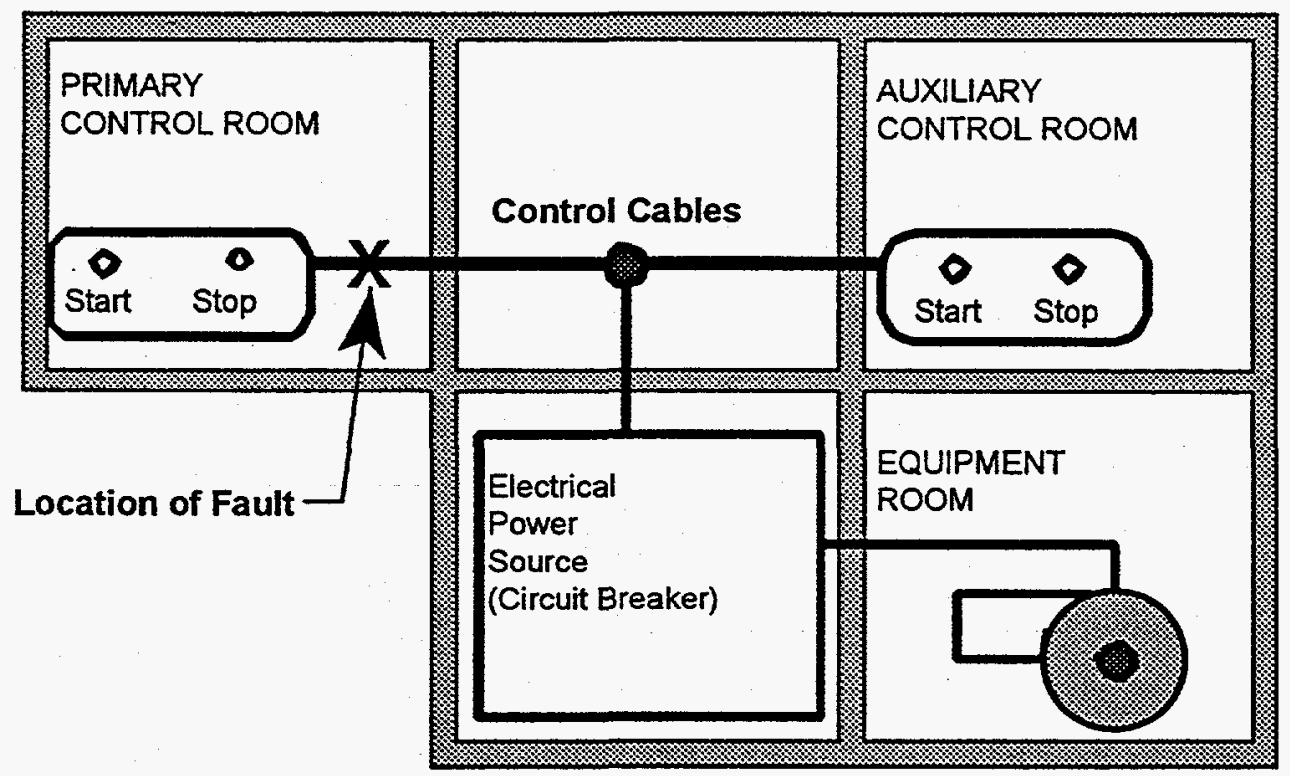

Problem: In the event that a fire in the Primary Control Room requires control room abandonment, the design of the alternative shutdown system credits operator control of required shutdown equipment from the Auxiliary Control Room, which is physically independent of the Primary Control Room. However, since the design of this capability did not fully consider electrical isolation, control of required equipment may be susceptible to common cause failure due to fire damage (i.e., fire-induced hot shorts, open circuits, or shorts to ground) in the Primary Control Room.

\section{Possible Solution Options:}

1. Consider the effectiveness of developing emergency operating procedures that direct manual operator actions to disconnect remote control capability (e.g., removal of control power fuses) from the fire affected area (control room) and establish local control of equipment. See note on operator actions following Solution 3.

2.

Evaluate the effectiveness of installing isolation/transfer schemes (switches or relays) to provide electrical isolation of fire affected circuits. Once actuated following control room abandonment, these electromechanical devices serve to isolate the fire affected portion of the circuit and transfer control to the 
Auxiliary Control Room. A simplified diagram depicting one method of providing this capability is shown below:

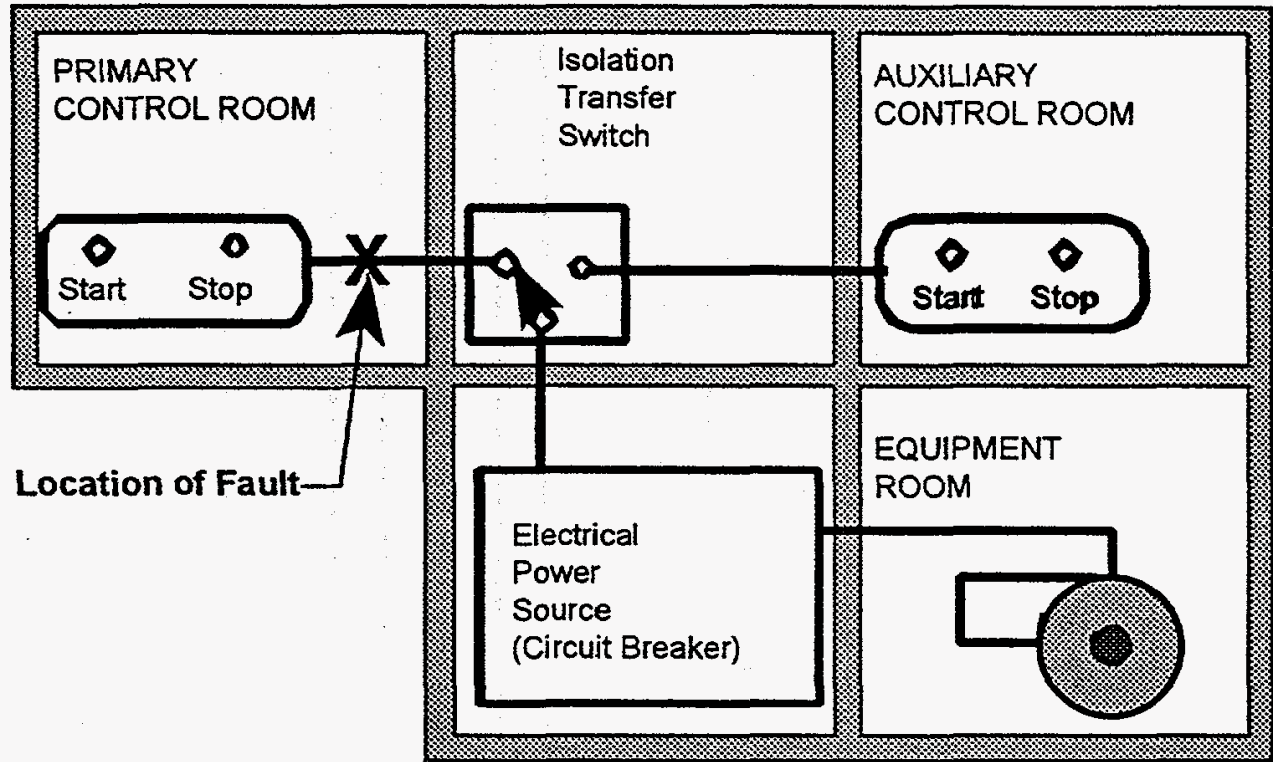

3. Consider the effectiveness of providing a combination of equipment and procedural enhancements such as the installation of an isolation switch (for isolation) and manual operator action to control equipment locally.

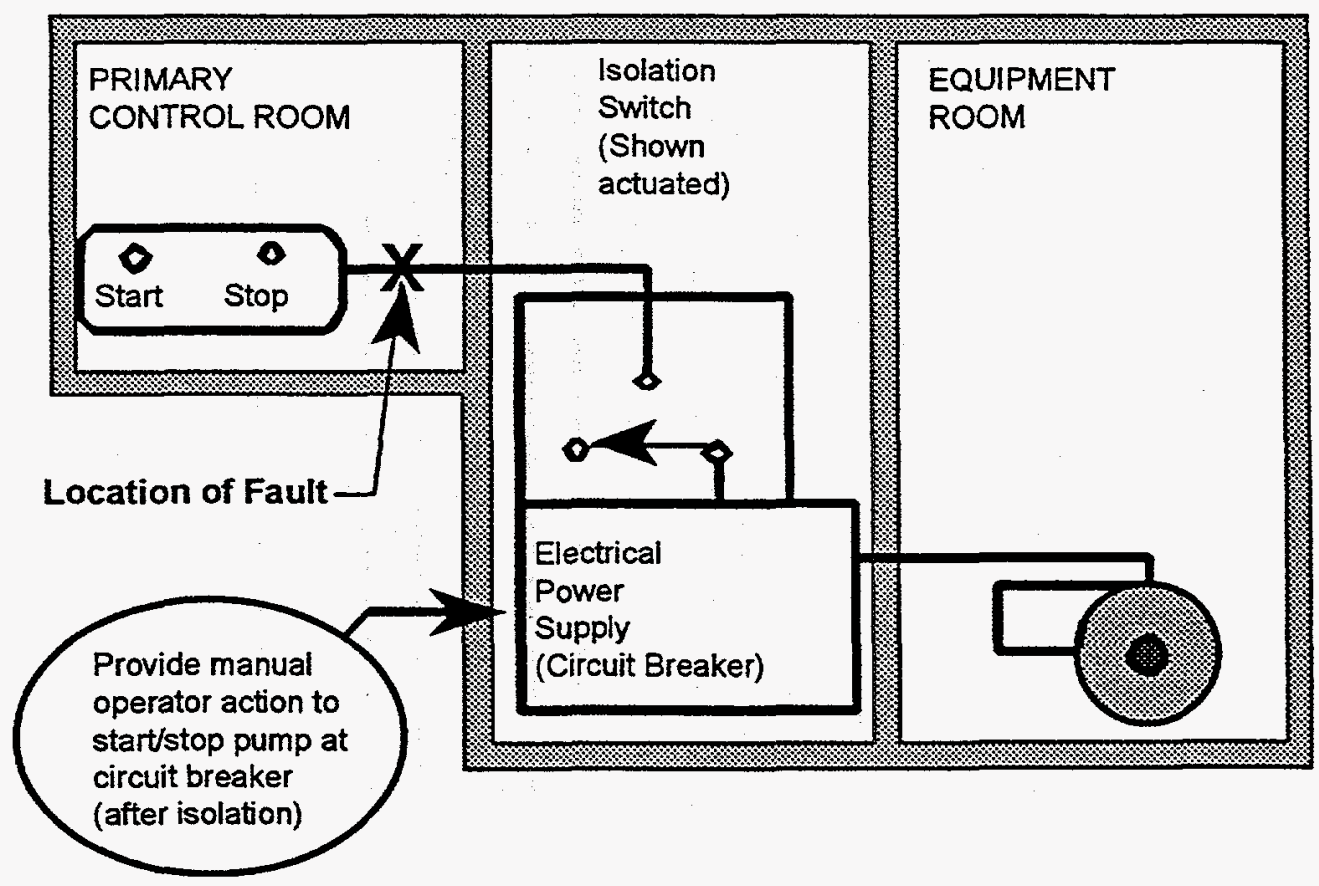


Note: Simplified drawings are for illustration purposes only. In certain cases the isolation switch may be physically located at the Electrical Power Supply or Auxiliary Control Room. However, consideration must also be given to a fire in these areas affecting operability from the control room. In cases where all redundant safety systems are capable of being controlled from the Auxiliary Control Room, it may be necessary to locate isolation switches as shown, in an area physically independent of both the Primary and Auxiliary Control Rooms. It should also be noted that all operator actions should be directed by written emergency operating procedures and require careful consideration by both the regulatory and operating organizations for feasibility, adequacy of communications, operator training, and operator/plant safety. 


\section{CASE 5-POTENTIAL FOR INADVERTENT SPURIOUS VALVE OPERATIONS}

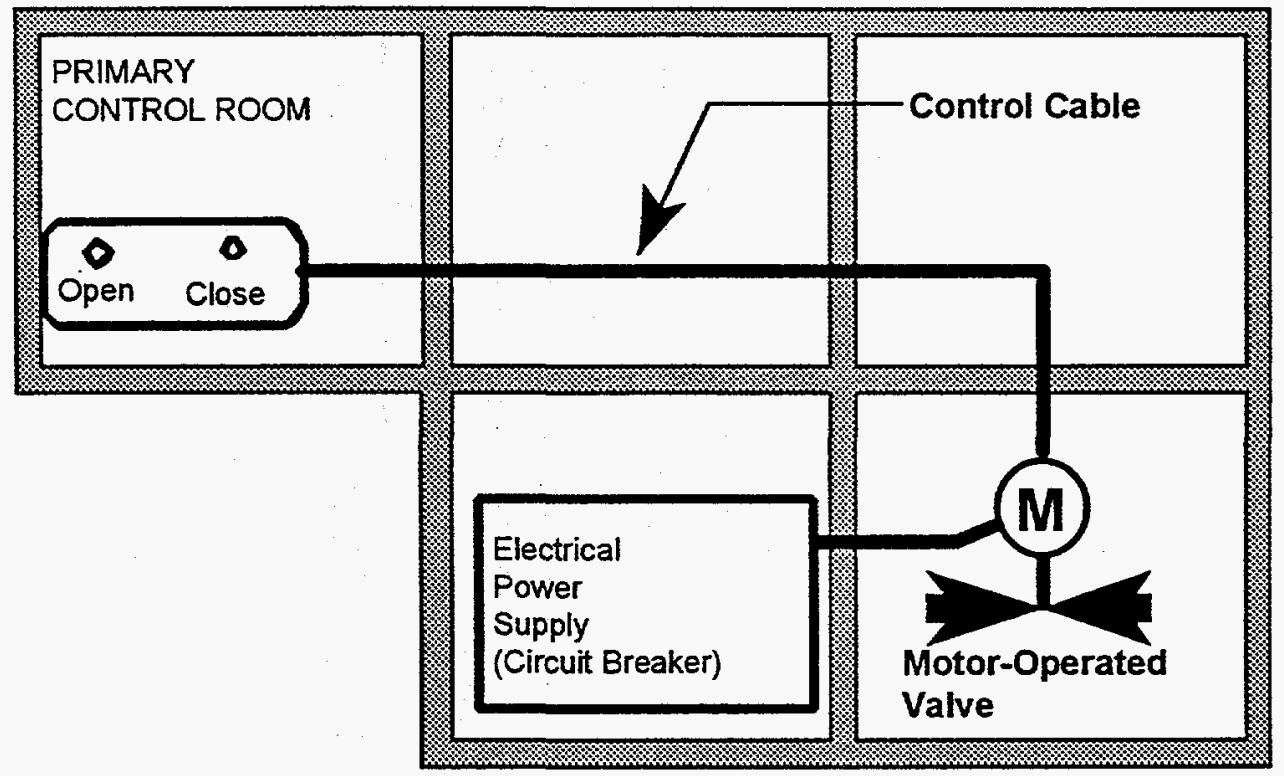

Problem: A review of the plant piping and flow diagrams has identified a normally closed motor-operated valve (MOV) that is required to remain closed to preclude diversion from a required system flow path. However, a fire-induced electrical fault (hot short, open circuit, or short to ground) at the control switches or anywhere along the path of the connected control cables may cause the valve to inadvertently change position to the undesired open condition.

\section{Possible Solution Options:}

1. Determine availability and capability of any redundant flow-path valve(s) that may be connected in series with the fire affected MOV. Assure that operability of the redundant valve will not be affected by the same fire event.

2. Identify the availability, accessibility, and capability of any manually operated valves connected in series with the fire affected MOV. If necessary, develop post-fire strategies ensuring that the valve will be manually realigned to the desired position for shutdown.

3. Identify the availability and capability of any check-valves connected in series with the fire affected MOV. 

faults required to cause the valve to change position. Protection may then be provided commensurate with the probability of occurrence (number and type of circuit faults required to cause spurious actuation) and the consequences of the event. For example, the results of this analysis may demonstrate: (a) the probability of spurious valve action is highly unlikely due to the number and type of circuit faults required and (b) the spurious opening of the valve (should it occur anyway) would not cause the plant to enter a significant plant transient (i.e., unisolable LOCA) or result in a large release of radioactivity to the environment. In this case, no further fire protection enhancements may be necessary. However, if the analysis were to show that spurious valve actuation were more probable (such as a single fire-induced short circuit at the control switches), fire-induced spurious valve actuation should be assumed to occur, and appropriate preventive or mitigative features provided. Examples of possible solutions for this case are described below.

5.

Evaluate the effectiveness of manual operator actions necessary to mitigate spurious operation: (a) perform an evaluation demonstrating that sufficient procedures, instrumentation, and time are available for operators to "detect and defeat" the spurious valve actuation before the spurious actuation adversely affects the accomplishment of safe shutdown conditions, (b) assure that all required operator actions are feasible and that adequate manpower, tools, communications, and lighting are available, (c) develop abnormal operating procedures to provide necessary operator guidance, and (d) provide operator training/familiarization in the new procedure. For MOVs, manual operator actions typically consist of: (a) removing motive power (tripping circuit breaker/removing fuse), (b) verifying valve position, and (c) manually repositioning the valve as necessary. Where sufficient time and manpower are available, this approach can be used to resolve many cases involving inadvertent spurious operation of MOVs in a specified fire area. Once all valves of concern are identified, a procedure can then be developed.

Evaluate the feasibility of establishing operational administrative controls to maintain the affected valve in the desired "pre-fire" position during plant operation. Examples of this approach include: (a) establishing operating procedures requiring the removal of motive power and installation of physical lock-out restraints during power operations and (b) precluding spurious actuations that may occur as a result of fire in specified areas (e.g., the control room), by disconnecting circuits associated with the remote control capability. 
include: (a) providing fire-retardant wrap and/or coatings on affected cables and augmenting the available fire detection and suppression capability (see Case 3, Solution 6 for important cautions regarding use of fire-retardant wrap and/or coatings); (b) enclosing cable in metallic conduit (tubing) to prevent energized cables from contacting (shorting to) cable of concern (see Case 3, Solution 3), (c) reducing the likelihood of fire initiation and propagation by reducing and administratively controlling combustible material and ignition sources (e.g., welding and cutting operations, smoking, direct heat and flame, hot surfaces, sparks) to the greatest extent possible and augmenting the available fire detection and suppression capability, and (d) implementing a combination of these options.

8. Evaluate the effectiveness of identifying and rerouting cable(s) of concern outside the fire compartment/cell.

9. For cases such as the Primary Control Room, where redundant equipment and/or cables of systems required to achieve and maintain stable shutdown conditions may be located in proximity to each other and it is not feasible or cost-effective provide fire protection features necessary to establish reasonable assurance that one train of systems required for plant shutdown will remain free of fire damage, an Alternative or Dedicated Shutdown Capability should be considered (see Case 2, Item 7). 


\section{U.S. DEPARTMENT OF ENERGY'S REACTOR CORE \\ PROTECTION EVALUATION METHODOLOGY FOR FIRES AT \\ SOVIET-DESIGNED RBMK AND VVER NUCLEAR POWER PLANTS

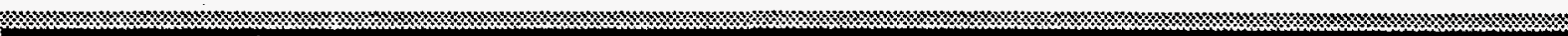 \\ CASE 6-POTENTIAL FOR LOSS OF HEATING, VENTILATION, AND AIR CONDITIONING}

\section{Compartment A}

Contains temperature sensitive equipment

required for shutdown in the event of fire in Compartment $B$

\section{Compartment B}

Contains ventilation controls or equipment required to maiintain an acceptable operating environment in Compartment $A$

Problem: Compartment A contains temperature-sensitive equipment and instruments relied on to accomplish safe shutdown functions in the event of fire in Compartment B. However, Compartment $B$ contains ventilation controls and equipment necessary to maintain an acceptable operating environment for equipment and/or personnel in Compartment $\mathrm{A}$.

\section{Possible Solution Options:}

1.

Determine the availability of alternate or redundant equipment that is capable of performing required shutdown functions and will remain unaffected by fire in Compartment $\mathrm{B}$.

2.

Perform an analysis demonstrating that a loss of ventilation will not cause the maximum operating temperature of equipment located in Compartment $A$ to be exceeded for a sufficient length of time to cause damage (i.e., demonstrate by analysis that safe shutdown functions will be accomplished before temperature limits are exceeded). For the example illustrated, this evaluation would also 
need to consider the expected rise in temperature resulting from fire in the adjacent compartment.

3. Evaluate the effectiveness of providing post-fire operator actions to mitigate the effects of fire in Compartment B. Such actions may include opening doors and installing portable ventilation fans in Compartment $\mathrm{A}$. When this option is selected, an evaluation should be performed to demonstrate that the operator actions are feasible and that the actions will be effective in controlling the operating environment in Compartment $\mathrm{A}$ to within acceptable limits.

Additionally, since the fire may also affect the availability of electrical power, the ability to power portable fans should be verified.

4. Evaluate the effectiveness of enhancing the fire protection features provided for Compartment B. Possible solution options include: (a) providing fireretardant wrap, barriers, and/or coatings for affected cables/equipment and augmenting the available fire detection and suppression capability (see Case 3 , Solution 6 for important cautions regarding use of fire-retardant wrap and/or coatings); (b) decreasing the likelihood of fire initiation and propagation by reducing, and administratively controlling combustible material and ignition sources (e.g., welding and cutting operations, smoking, direct heat and flame, hot surfaces, sparks) to the greatest extent possible, and (c) implementing a combination of these options. 


\section{A.3 GUIDANCE FOR EVALUATING EOUIVALENCY OF EXCEPTIONS TO ESTABLISHED CRITERIA}

\section{DEMONSTRATION OF EQUTVALENCY}

Fire protection criteria frequently delineate specific plant design basis safety features, such as separation distance, fire barrier ratings, and fire detection or suppression systems. In certain cases, plant-specific design conditions and/or operating requirements may preclude compliance with one or more of the provisions specified in the established criteria. In such a case, the operating organization must demonstrate, by means of a detailed fire hazards analysis, that the existing protection, or the existing protection in conjunction with proposed modifications, will provide a level of safety that is equivalent to compliance with the specific technical requirements of the criteria. Generally, such an "exception" to established criteria (i.e., substitute fire protection configuration) is deemed to be equivalent if the results of a detailed fire hazards analysis demonstrate:

(1) the alternative ensures that one train of equipment necessary to achieve hot shutdown from either the control room or emergency control stations is free of fire damage;

(2) the alternative ensures that fire damage to equipment necessary to achieve cold shutdown is limited so that it can be repaired within a reasonable time (minor repair using components stored on the site);

(3) fire-retardant coatings are not used as fire barriers; and

(4) modifications required to meet the established criteria would not enhance fire protection safety levels above that provided by either existing or proposed alternatives.

A substitute fire protection configuration (exception) may also be acceptable if, on the basis of a detailed fire hazards analysis, the plant operating organization can demonstrate that modifications required to meet the established criteria would be detrimental to overall facility safety, and the alternative configuration provides an adequate level of fire safety.

Exceptions provide reasonable assurance that an adequate level of protection exists to assure that fire will not hinder the capability to shut down the reactor in a manner precluding core damage and large releases of radioactivity to the environment. If the established criteria for fire protection of redundant trains of safe shutdown equipment cannot be met and an acceptable exception 
(substitute approach) cannot be demonstrated, an alternative or dedicated shutdown capability, independent of the fire area of concern, should be provided. Additionally, fire detectors and a fixed fire suppression system should be installed in the area of concern.

\section{EXCEPTION DEVELOPMENT PROCESS}

Using the guidance contained in the RCPEM and other sources, and applying the defense-in-depth concept, the operating organization should determine the fire protection features provided for plant safety systems and fire compartments by analyzing the effects of the postulated fire relative to maintaining the ability to safely shut down the plant. The analysis must demonstrate that the plant will maintain the ability to perform safe shutdown functions in the event of a fire.

When the fire hazards analysis shows that adequate fire safety can be provided by an alternative or substitute approach (i.e., an approach different from the specified requirement), operating organizations should document this conclusion and, if necessary, request approval from the appropriate regulatory authority for an exception from the technical requirements of the established criteria. Such requests for exception should include a sound technical basis that clearly demonstrates that the defense-in-depth concept is appropriately maintained and that the exception is technically justified. As part of its evaluation, the plant operating organization should provide sound technical justification if it does not propose to install or improve the automatic suppression and/or detection capabilities in the compartment of concern (i.e., compartment or cell for which the exception is requested) or to implement other more restrictive fire prevention, detection, or suppression measures.

A.4 ALTERNATIVE APPROACHES TO COMPLETING THE METHODOLOGY STEPS WHEN PLANT DATA IS NOT AVAILABLE

The Methodology provides various alternatives as to how the various steps can be completed. In some cases however, the alternative approaches given in the methodology steps may not be accomplishable due to the lack of plant data. For those cases, additional alternative approaches may be required in order to complete the methodology.

\section{MISSING OR INADEQUATE INFORMATION}


The lack of equipment and material information (drawings, specifications, descriptions, etc.) may be resolved by means of collecting the required information/data from plant walkdowns. The walkdowns, however, may not provide sufficient overall information to evaluate the equipment or material in the context of the fire hazards evaluation. Using the documentation collected and the walkdown information gathered, the evaluator must establish three major characteristics of the equipment or material, physical appearance, appropriate usage, and qualification.

The physical appearance may tell the analyst if the equipment or material is of sufficient capacity or is in good enough condition to perform its intended function. For example, the nameplate on a pump may provide the pump's rated flow rate and design pressure which was not available in documents. As an additional example, a penetration seal may have a smooth, uniform surface and its depth could be measured, providing assurance that the minimum seal depth is installed and the seal is not damaged.

The analyst must also determine that the equipment or material is appropriate for its intended function. For example, a penetration seal may appear to be in good physical condition, however the material may not be the type used in fire rated seals (wrong type of material). The material could actually be used in other fire protection related uses, such as a fire retarding coating, but would be inappropriately used as a seal.

Finally, the analyst must determine that the equipment or material is qualified for its usage. For example, a fire door design would typically be tested by a testing laboratory to determine its fire rating in hours. This test would qualify the door for use as a fire door and provide assurance that the door would provide a fire barrier for the tested time period. If documentation could not be found in the data collection to show that the fire door was qualified by test, the analyst must determine the qualification by other means. In some cases the door may have a "label" or nameplate showing its qualification. Another means would be to examine the door during the walkdown and compare the door design and materials to a known qualified door. An additional means would be to have a representative door sent out for testing and therefore qualify the actual installed doors. If documentation and data cannot be found for equipment or materials and the walkdowns cannot provide sufficient information to show equipment/material qualification, then testing may be required. Another solution would be to replace the material or equipment, however, this is not normally economical.

Cable routing and insulation property data can be particularly difficult to determine. If cable locations can not be determined by walkdowns, there are 
methods within the industry that facilitate the locations of cables by applying an electronic pulse to a given cable and tracing the cable through the cable trays and raceways by detecting the pulse with an electronic sensor. If the properties of the cable insulation can not be verified by reviewing the vendor information or if there is a question of the validity of the vendor information, the common practice is to test a sample of identical cable and apply the results to the cable installed in the plant.

\section{POTENTIAL ALTERNATE SOLUTIONS}

The approaches presented below are options that may be considered to assist in the resolution of fire vulnerabilities identified during the implementation of the analysis conducted following this Methodology. $m$ Many id these approaches have been alluded to throughout the Methodology and particularly in Section A. 2 of this Appendices.

\section{DESIGN AND INSTALL PROTECTIVE ENCLOSURES:}

This option requires that a plant modification be designed and installed. If the methods discussed in Al cannot be technically justified or the regulatory authorities will not accept any of the previous options, then a fire-rated enclosure can be placed around the affected circuit or equipment. This protection can be provided by installing walls constructed of fire-rated materials or by using a fire-rated wrap material. This, in effect will create a unique compartment for the equipment. Once protected, the equipment need not be considered to fail.

\section{AUGMENT THE FIRE DETECTION AND SUPPRESSION SYSTEMS:}

This option also requires that the plant be modified. It may be possible to make minor modifications to the fire suppression and/or detection systems to provide enough additional technical support to meet the fire protection regulation. This approach may be less expensive than rerouting cables or installing new equipment.

\section{INSTALL DISCONNECT SWITCHES:}

This option requires that the plant be modified. The design change effectively installs a switch in the component circuit to disconnect cables that have been analyzed to induce fire-related faults. This solution can only be used after it 
has been determined that time is available to actuate the switch before the fireinduced fault causes an unacceptable result.

\section{INSTALL JUMPERS:}

This option is typically used in conjunction with manual actions. It involves making plant modifications to provide a place within the component circuitry to install a jumper that bypasses a fire-induced fault. Alternatively, a location may be identified that does not require any modification within the existing circuitry. This method can be used to repower a component in the event of a fire or to provide an alternate control method. Typically, when this approach is used, the cables and connection hardware are predesigned, fabricated, and stored in a location convenient to the installation point.

\section{REROUTE CABLES:}

This option is often used to ensure that fire damage will not prevent the plant from reaching and maintaining a safe shutdown condition. If a cable to a piece of safe shutdown equipment runs through a fire cell, it can be rerouted out of the affected cell, thus ensuring that there will not be fire damage that can render the equipment inoperable. Additionally, it may be determined during the analysis that there are certain pieces of equipment whose operation is required so early in a fire event that the cables must be protected. It may be more economical to reroute the cables than to trace them throughout the plant. This decision would be based on a cost-benefit analysis.

\section{POST FIRE REPAIRS:-}

In certain limited instances it may be acceptable to make post fire repairs. In these cases the equipment must be staged in an acceptable location and detailed procedures written covering the repair. The operators must be fully trained in the implementation of the repairs, and typically a walk through of the procedure is accomplished to demonstrate that the repairs can be accomplished with the available staff and within an acceptable time frame. The same limitations on operator actions that are discussed in Section A. 1 are applicable here. If equipment is dedicated to be used for repairs, administrative procedures should be in place to ensure that the necessary equipment is maintained available for this purpose.

INSTALL A DEDICATED SHUTDOWN SYSTEM: 
Typically, the installation of a dedicated system is very costly; however, when the costs of all potential modifications required to increase the safe shutdown capability after fire events to the desired level are totaled, a dedicated shutdown system may be a viable option. 


\section{APPENDIX B}

\section{COMPUTER FIRE MODELS}

During the initial screening of fire compartments and cells for the Safe Shutdown Evaluation process, it is assumed that if a fire occurs in a given compartment/cell, all components in that compartment/cell are destroyed. This is a typical assumption that yields conservative results. However, there is actually a time delay before a component can no longer perform its function due to fire, depending on where it is located in the compartment/cell, the size of the fire, and the component's distance from the fire. In some cases, the actual fire may not result in any significant damage to the shutdown equipment. Computer fire models have been developed to help predict the propagation of fire in a compartment/cell when that level of detail and analysis appears to be warranted.

Computer fire models are programs used to evaluate the effects of fire within an area. These computer models can be used to study the propagation and effects of fire inside a compartment/cell, allow different geometries to be modeled, and give time-dependent results. Computer fire models are sometimes used as an aid to the analyst for compartments/cells that have not been screened out during the initial evaluation.

Major advances have been made in developing computational models structured to predict the interaction of multiple fire processes involving heat transfer, fluid mechanics, and combustion chemistry occurring simultaneously in an enclosure. These models provide estimates of particular elements of hazard development such as fire growth, temperature rise, and smoke generation and transport. The models represent the processes encountered in a compartment fire by interrelated mathematical expressions based on physics and chemistry.

To date, about 62 fire models are available internationally. These models, which range from simple closed-form data correlations to more detailed controlled volume or zone models, treat different aspects of compartment/cell fires with varying degrees of sophistication.

The most common type of fire model is the "zone" model, which solves the energy conservation equations for distinct regions. The dominant characteristic of this type of model is that it divides the compartment into an upper hot gas layer and a lower cooler layer. Figure B-1 illustrates this concept. 


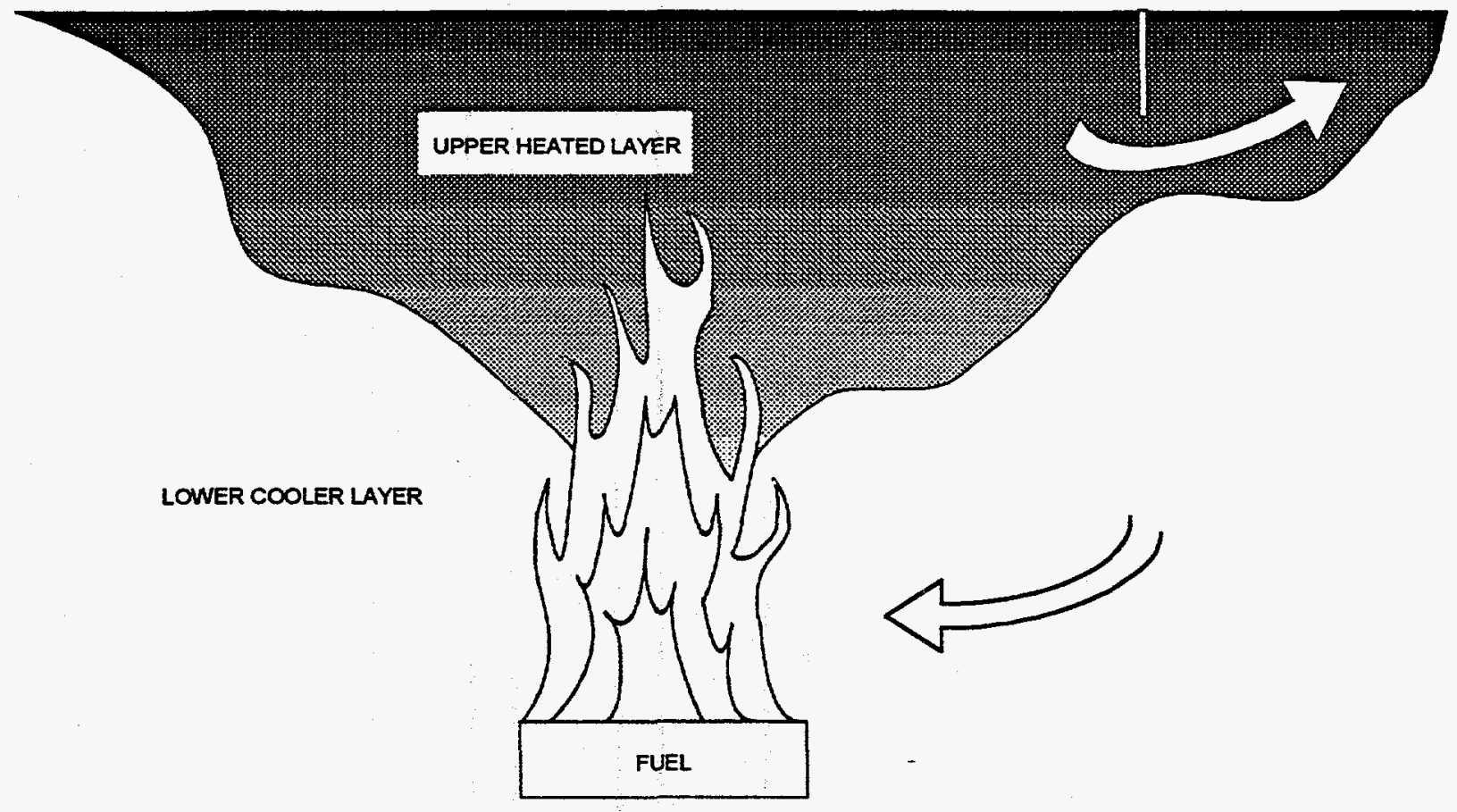

FIGURE B-1

TWO-LAYER ZONE MODEL 
Buoyant gases generated by a fire rise, along with entrained air, in a turbulent plume to the ceiling and spread beneath the ceiling in a relatively thin ceiling jet to the vertical boundaries of the compartment/cell, then bank down to form a hot gas layer. The hot gas layer continues to descend within the compartment/cell until there is equilibrium between the mass flow rates into and out of the layer. This equilibrium depends on the size and location of ventilation openings between the compartment/cell and adjacent spaces and on the mechanical ventilation of the areas.

In many enclosure fires, the turbulent mixing induced by the plume as it rises through the hot gas layer produces fairly uniform temperature, smoke, and gas concentrations in the layer. Under such circumstances, variations of conditions within the hot gas layer are small relative to the average conditions that exist. Consequently, conditions within the layer are characterized in terms of average, presumably uniform conditions with little loss of accuracy or validity.

The use of computer fire models can be useful in analyzing the effects of fire on components in a compartment. Each component within a compartment is viewed as a separate "target." The models calculate the fire-induced exposure conditions at those targets. From this, the response of a target (theability of the components to remain functional during the fire) can be predicted.

The effects of fire on a target are related to the location of the target relative to the fire source. Targets are generally located in one of three locations:

- Directly above a fire source, in the fire plume

- In the hot gas layer, but outside the plume

- Laterally from the fire source

Figures B-2A, B-2B, and B-2C, respectively, illustrate these concepts.

Other necessary parameters include the exposure fire peak intensity and total energy content, the fire compartment volume, ventilation, and thermal response characteristics.

Using the above parameters, computer fire models can predict the estimated time required to damage a target within the fire compartment, based on a target's upper operating design temperature (that is, a temperature value above which the component cannot reasonably be expected to remain functional). 


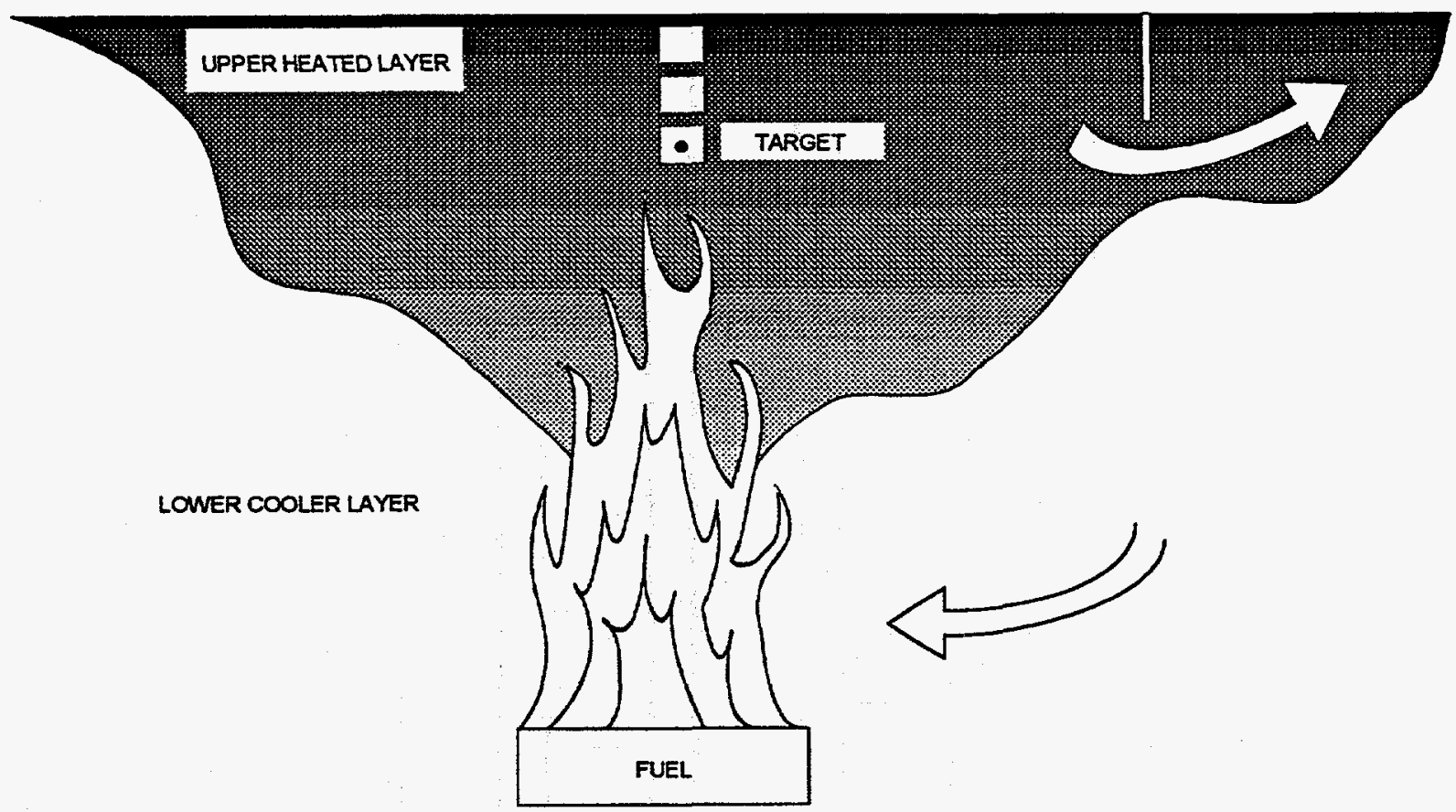

FIGURE B-2A

TARGET IN FIRE PLUME 


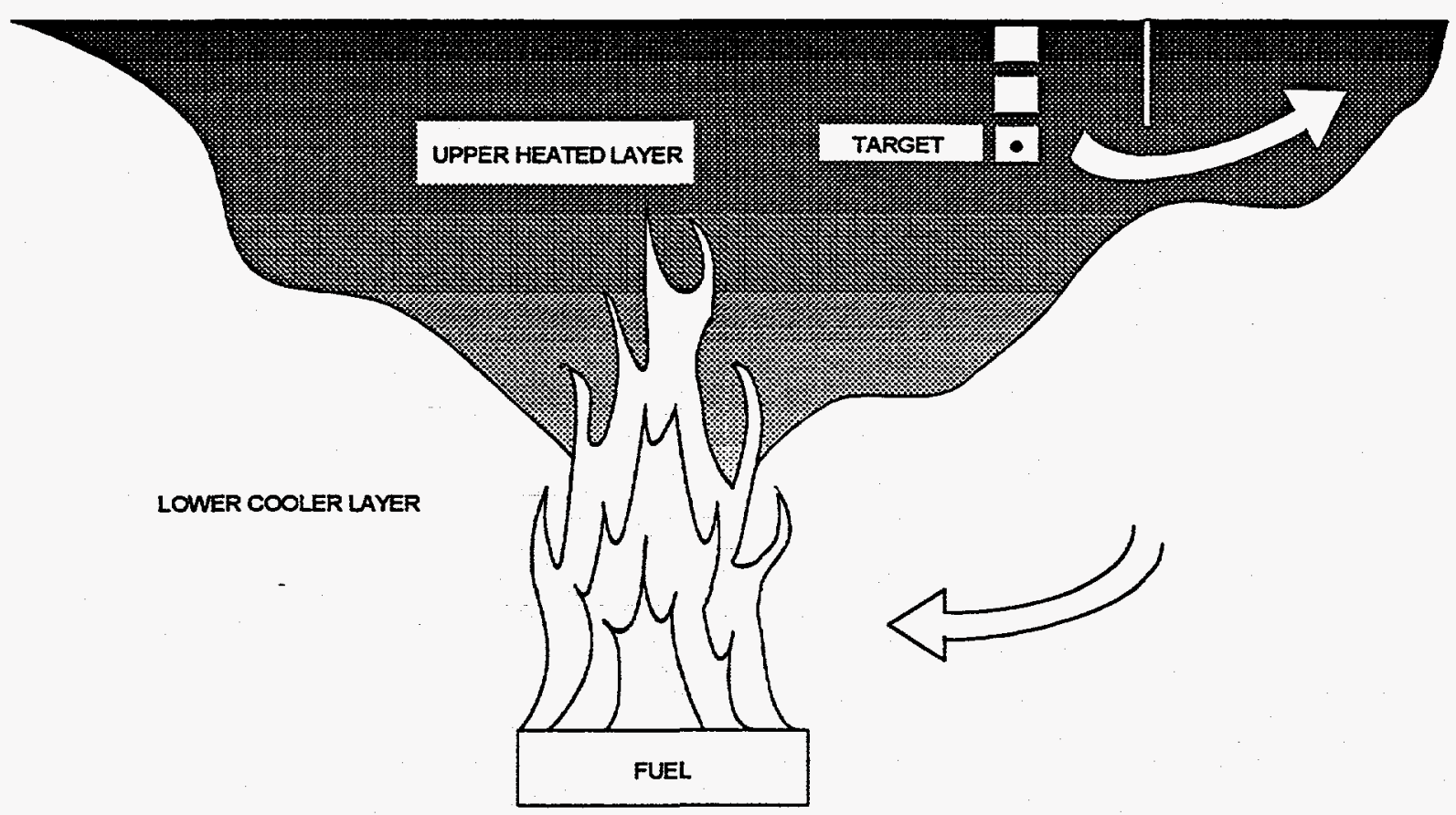

FIGURE B-2B

TARGET IN HOT GAS LAYER, OUT OF PLUME 


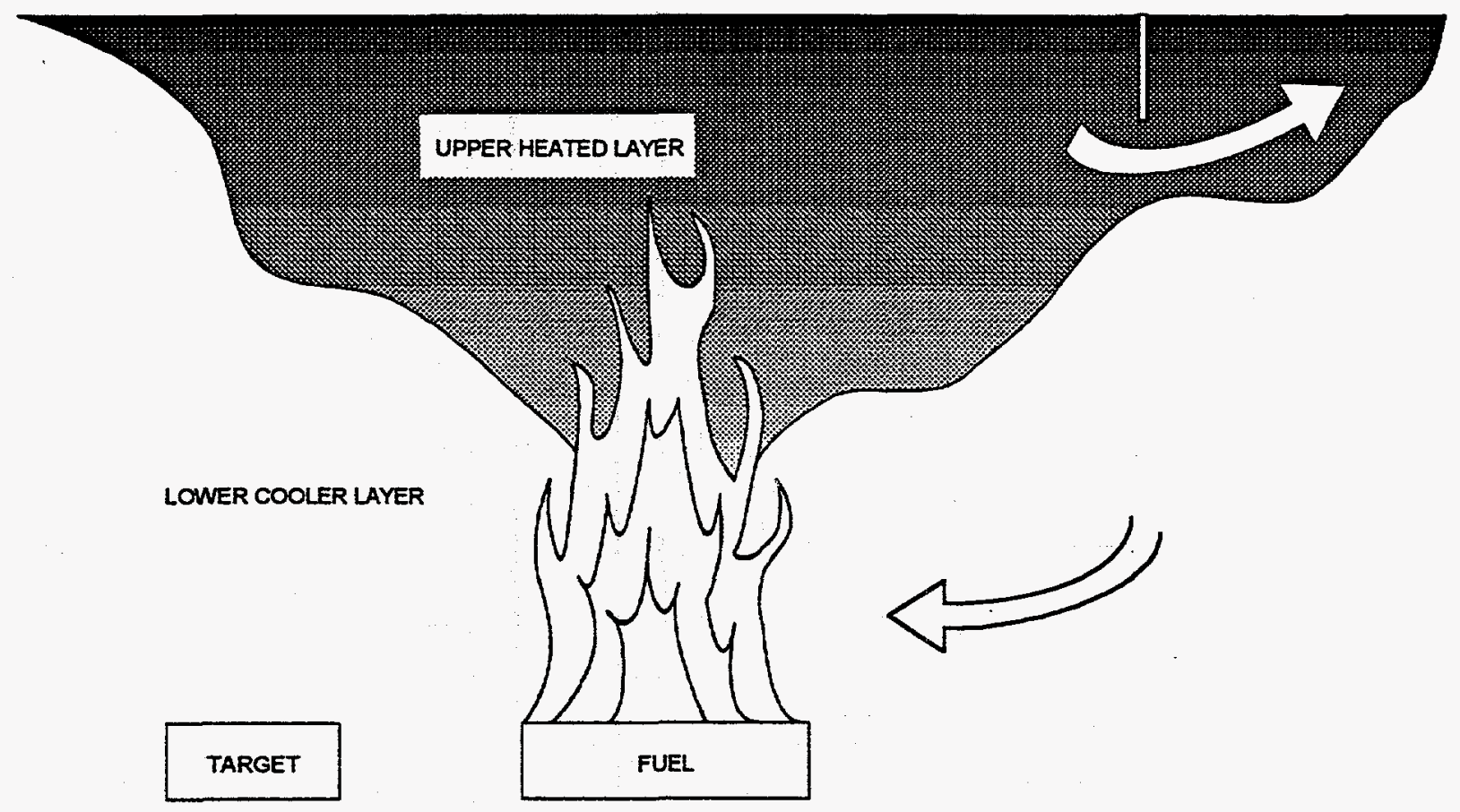

FIGURE B-2C

TARGET LATERAL FROM FIRE 
As stated before, different fire models treat the various aspects of compartment/cell fires in different ways and with varying degrees of sophistication. To a large extent, fire models are distinguished by the ways they treat the various fire elements. The following briefly summarizes four fire models; CFAST, COMPBRN IIIe, FIVE, and MAGIC:

- CFAST is a zone model developed by the Building and Fire Research Laboratory of the National Institute of Standards and Technology. This model predicts the conditions of a multiple-compartment fire. It was developed to address the need to understand and accurately estimate the environmental conditions that occur during such a fire. The model attempts to predict the fire growth, spread, and smoke transport conditions for a given set of conditions in a multiple-compartment scenario.

- COMPBRN IIIe is a single-compartment zone model, developed at the University of California at Los Angeles (UCLA), for probabilistic risk analysis of fire growth in nuclear power plant scenarios. The code includes a determination of time intervals between fire initiation and damage to critical components. This is done by deterministically characterizing the environment surrounding selected combustibles, such as electric cables, and calculating their thermal response to the environment. Thus, the time to damage of various safety-related components may be determined. This assessment would only be required in a few specified critical locations, but requires an extensive effort in scenario modeling, database development, and computation of thermal and mass transport phenomena. This model is not currently being actively developed or formally supported in the U.S.

- The FIVE methodology is a semi-quantitative method of fire risk and hazard analysis intended for screening purposes. This methodology has been used to perform risk-based fire induced vulnerability evaluations for nuclear power plants. The methodology uses relatively simple quantitative fire hazard analysis techniques and algorithms reported in U.S. fire safety literature to evaluate the potential for credible fire sources to cause critical damage to safe shutdown equipment. The critical damage potential is evaluated to consider direct exposure or exposure by ignition of intermediate combustibles within a compartment. The general scenarios depicted in Figures B-2A, B-2B, and B-2C are addressed in the code.

- MAGIC is a multi-compartment model where each compartment is divided into two homogeneous control volumes; the smoke and the fresher air below it. Fire is modeled by using a mass and energy balance between the control volumes, together with a heat diffusion equation for the walls, corrected for individual wall thickness. Specific sub-models, based on experimental data, 


\section{U.S. DEPARTMENT OF ENERGY'S REACTOR CORE \\ PROTECTION EVALUATION METHODOLOGY FOR FIRES AT \\ SOVIET-DESIGNED RBMK AND VVER NUCLEAR POWER PLANTS}

are used to characterize various phenomena. These phenomena are pyrolysis of the fuel(s) on the fire; combustion of the pyrolysis gases and smoke production; simulation of an individual thermal plume over each fire source; heat exchanges between the flame, gases, smoke, and boundaries of the compartments; forced and natural ventilation; circulation of air and smoke between compartments; and thermal behavior of devices to deduce their malfunction or ignition. The code also computes the concentration of oxygen and unburned gases to anticipate a secondary ignition induced by a sudden entry of fresh air.

In the hands of experienced users, computer fire models can aid in the analysis of fire-induced conditions in a compartment/cell; however, they cannot be used to discriminate many realistic scenarios. Fire models can be of use in identifying areas where significant fire hazards do and do not exist. There exists a broad range of realistic scenarios between these two extremes where, for a number of reasons, fire models are of a more limited use. Perhaps the most significant limitation of all fire models in current use is the need for the user to specify the fire history. Inaccuracies in this specification have a direct and significant impact on the results. In addition, limitations in the computational algorithms used in the models, especially those related to plume entrainment and heat transfer, can lead to inaccurate results. Finally, current computer fire models can address only simple compartment geometries and cannot consider the complexity of equipment, piping, and cable trays that typically fill power plant rooms.

The limitations of current computer fire models are such that it would be difficult to determine the conditions under which they might be used for quantitative purposes. Nonetheless, these models are useful tools that can help well-trained and capable analysts assess a range of fire hazards in plant compartments/cells. While they cannot generally stand alone as the only tool, they do provide insight into the parameters that affect the growth and spread of a fire. 


\section{APPENDIX C \\ REACTOR CORE PROTECTION EVALUATION REPORT GUIDANCE}

This section provides guidance on preparing a formal Fire Hazards Analysis report based on the information obtained from performing the activities outlined in the Methodology. The following sample outline shows the topics that should be addressed, at a minimum. The order of the topics may, however, change.

\section{Sample Outline}

I. INTRODUCTION
A. Background
B. Purpose

The report introduction should include background information on the Soviet-designed nuclear power plant being evaluated. The purpose and scope of the report should also be clearly stated, including what will be accomplished and how it will be accomplished.

\section{TERMINOLOGY}

This section should clearly define key words and phrases used in the report. The definitions used in the Methodology may be adopted to the extent that they are applicable.

\section{ASSUMPTIONS AND LMMTING CONDITIONS}

This section should list any assumptions and limiting conditions utilized to perform the evaluations. These assumptions and limiting conditions may include some or all of those provided in the Methodology and may include additional items. 
IV. SAFE SHUTDOWN DEFINITION

This section should provide the definition of safe shutdown as established in Section 4.2 of the Methodology. It should also include a discussion of the basis of that definition and those functions that must be accomplished to achieve and maintain safe shutdown. Exhibit 4.2-1 and Exhibit 4.2-2 from Section 4.2 can be included here or as an appendix to the report.

V. SAFE SHUTDOWN SYSTEMS

This section should discuss all systems capable of providing or supporting safe shutdown functions. The completed safe shutdown Safety Functions forms (Exhibit 4.3-1) from Section 4.3 of the Methodology con be included here or as an appendix to the report.

VI. SAFE SHUTDOWN EQUIPMENT/COMPONENTS/CABLES

A. Component/Support Component Analysis

B. Cable/Circuit Analysis

C. Associated Circuit Analysis

D. Conclusion

This section should discuss all required components and their associated cables/circuits necessary to ensure that the safe shutdown systems will fulfill their intended functions. The results of the associated circuit analysis should be discussed. It should also discuss which safe shutdown path the components are associated with and the results of the cable failure analysis performed for each component (short circuit, etc.) in Section 4.4 of the Methodology. A brief summation of the findings of the analyses should also be included. Completed Exhibits 4.4-1, 4.4-2, 4.4-3, 4.4-4, 4.4-5, and 4.4-6 can be included here or as an appendix. 


\section{CODED DRAWINGS AND LOGIC DIAGRAMS}

This section should describe the coded drawings and safety sequence logic diagrams prepared in Section 4.5 of the Methodology. Reduced copies of safe shutdown piping diagrams, P\&IDs, and safety sequence logic diagrams, or simply a list of them, can be included here or as an appendix.

VIII. EXISTING FIRE PROTECTION FEATURES EVALUATION
A. Fire Water Supply Systems
B. Fire Suppression Systems
C. Fire Detection Systems
D. Fire Separation
E. Fire Brigade
F. Conclusion

This section should present $a$ description and evaluation of each existing fire protection feature listed above and reviewed and evaluated in Section 4.6 of the Methodology. A conclusion should also be included summarizing the evaluations and identifying potential areas of weakness. The completed Fire Protection System Evaluation (Exhibit 4.6-I) from Section 4.6 can, be included here or as an appendix. All data and information collected and utilized in the evaluations should be either referenced or attached as an appendix.

\section{FIRE COMPARTMENTS AND FIRE CELLS}

This section should include a list and description of each fire compartment and fire cell assigned in Section 4.7. The description may include data from the Fire Compartment/Fire Cell Walkdown Checklists (Exhibit 4.8-1) obtained in Sections 4.8 and 4.9. Exhibit 4.7-1 and reduced copies of the final fire compartment and fire cell drowings can be included here or as an appendix. 


\section{CABLE ROUTING VERIFICATION}
A. Cable Routing Verification
B. Conclusion

This section should discuss the results of the cable routing verification performed in 4.10. Test results, computations, etc., can be presented here. $A$ brief conclusion should also be provided.

\section{RESULTS OF VERIFICATION WALKDOWNS}

A summary description should be provided of how the walkdowns were conducted and their results. The completed Fire Compartment/Fire Cell Walkdown Checklists (Exhibit 4.8-1) completed as part of Sections 4.8 and 4.9 of the Methodology should be referenced here and included as an appendix.

XII. EFFECTS OF FIRE ANALYSES
A. Fire Containment Evaluation
B. Assessment of Explosion Potential
C. Safe Shutdown Evaluation
D. Conclusion

This section should discuss the above evaluations, performed in Section 4.11, for each fire compartment and fire cell. The discussions should include why and how each evaluation was performed Qualitative analyses performed as part of the safe shutdown evaluation shall be described and discussed. Exhibits 4.11-1, 4.11-2, 4.11-3, and 4.11-4, along with any applicable computations, can be included here or as an appendix. A brief conclusion should summarize the evaluations and their findings. 
XIII. FIRE VULNERABILITIES

This section should describe the fire vulnerabilities identified in Section 4.12 of the Methodology. All lists generated in this section should be included here.

\section{FIRE VULNERABILITY RESOLUTIONS}

This section should discuss the resolutions to the fire vulnerabilities identified in Section 4.12. The discussion should include such items as evaluation of current plant procedures, development of fire countermeasures, and any design controls required to preclude the creation of fire vulnerabilities.

In addition, this section should describe the evaluation and factors utilized to determine the final set of solutions recommended to address all fire vulnerabilities determined. $A$ description and basis for all economic evaluations should also be provided.

All exhibits completed as part of Section 4.13 of the Methodology should be included here.

\section{PRIORITIZATION OF FIRE SAFETY IMPROVEMENTS}

This section should discuss the prioritization process utilized for the proposed fire safety improvements identified in Section 4.13 of the Methodology. The discussion should include ranking criteria, ranking method, funding concerns, scheduling concerns, and other evaluation factors utilized in the prioritization process. Exhibits 4.141 and 4.14-2 from Section 4.14 should be included here. 
XVI. ADDITIONAL TOPICS

This section should discuss topics related to maintaining the evaluation once it is performed. Such topics should include administrative controls, control of modifications, control of out-of-service equipment (time limits, limiting conditions of operation, etc.), and drills and training. It may also discuss plant conditions that are not formally addressed by the fire hazards analysis. Any analysis determined to be required to support or augment this Methodology should be described and discussed.

XVII. OVERALL CONCLUSIONS

This section should summarize, based on the body of the report, how and why the plant has the capability to mitigate the consequences of a fire and to achieve and maintain safe shutdown. It should also discuss short- and long-term fire safety improvements and goals, including a proposed schedule.

\section{REFERENCES}

This section should cite all drawings and documents collected in Section 4.1 of the Methodology and used to create the report. Any additional drawings and documents utilized should also be referenced. All references should note specific revision numbers, dates, or editions.

\section{APPENDICES}

As mentioned earlier, completed exhibits from the Methodology can be included here. Any additional or background information relevant to the report should also be included. 


\section{APPENDIX D}

\section{BLANK FORMS}

This appendix contains the following blank forms:

Same as Exhibit

Safe Shutdown Definition

Safe Shutdown Function Definition

Safe Shutdown/Support System Safety Functions Worksheet

Safe Shutdown Equipment Worksheet

Safe Shutdown Component Worksheet

Safe Shutdown Cable Worksheet

Input Data for Selective Coordination Study

Coordination Study Summary

Safe Shutdown Path Identification Worksheet

Fire Protection System Evaluation Checklist

Site Buildings and Outdoor Structures

Fire Compartment/Fire Cell Walkdown Checklist

Initial Screening of Fire Compartment

Fire Containment Evaluation

Assesment of Explosion Potential

Results of Safe Shutdown Evaluation

Potential Design Changes Worksheet

Selection of Preferred Safe Shutdown Option

Safe Shutdown Solution Set

Calculation of Benefit-to-Cost Ratio

4.14-1

Prioritization of Improvements

$4.14-2$ 

DEFINITION OF SAFE SHUTDOWN:

\section{DISCUSSION:}

IS THERE A TIME LIMTT ASSOCIATED WITH ESTABLISHING SAFE SHUTDOWN? YES NO

DISCUSSION: 


\section{SAFE SHUTDOWN FUNCTION DEFINITION}

SAFE SHUTDOWN FUNCTION:

DISCUSSION: 


\section{SAFE SHUTDOWN/SUPPORT SYSTEM SAFETY FUNCTIONS WORKSHEET}

\begin{tabular}{|c|c|c|c|c|c|c|c|c|c|c|c|c|}
\hline \multirow[b]{2}{*}{$\begin{array}{l}\text { System } \\
\text { Designator }\end{array}$} & \multirow[b]{2}{*}{ System Name } & \multirow[b]{2}{*}{\begin{tabular}{|c|} 
SSD/ \\
Support \\
Yes/No
\end{tabular}} & \multicolumn{9}{|c|}{ Safe Shutdown Function Provided } & \multirow[b]{2}{*}{$\begin{array}{l}\text { Supporting } \\
\text { Function }\end{array}$} \\
\hline & & & $\begin{array}{l}\text { Reactivity } \\
\text { Control }\end{array}$ & $\begin{array}{c}\text { Reactor } \\
\text { Coolant } \\
\text { Inventory } \\
\text { Control }\end{array}$ & \begin{tabular}{|} 
Secondary \\
Pressure \\
Control
\end{tabular} & \begin{tabular}{|c|} 
Reactor \\
Heat- \\
Removal
\end{tabular} & $\begin{array}{l}\text { Secondary } \\
\text { Heat } \\
\text { Removal }\end{array}$ & $\begin{array}{l}\text { Secondary } \\
\text { System } \\
\text { Isolation } \\
\text { (Integrity } \\
\text { Control) }\end{array}$ & $\begin{array}{l}\text { Pressurizer } \\
\text { Cooldown }\end{array}$ & \begin{tabular}{|} 
Primary \\
Pressure \\
Control
\end{tabular} & $\begin{array}{l}\text { Primary } \\
\text { Isolation }\end{array}$ & \\
\hline & & & & & & & & & & & & \\
\hline & & & & & & & & & & & & \\
\hline & & & & & & & & & & & & \\
\hline & & & & & & & & & & & & \\
\hline & & & & & & & & & & & & \\
\hline & & & & & & & & & & & & \\
\hline & & & & & & & & & & & & \\
\hline & & & & & & & & & & & & \\
\hline & & & & & & & & & & & & \\
\hline & & & & & & & & & & & & \\
\hline & & & & & & & & & & & & \\
\hline & & & & & & & & & & & & \\
\hline & & & & & & & & & & & & \\
\hline & & & & & & & & & & & & \\
\hline & & & & & & & & & & & & \\
\hline & & & & & & & & & & & & \\
\hline & & & & & & & & & & & & \\
\hline
\end{tabular}


SYSTEM:

SAFE SHUTDOWN EQUIPMENT WORKSHEET

SYSTEM DESIGNATOR:

IS THIS SYSTEM A SUPPORT SYSTEM? YES __ NO __ IF YES, WHICH SYSTEM(S) DOES IT SUPPORT?

MODE OF OPERATION: 1

2.

3.

4.

\begin{tabular}{|c|c|c|c|c|c|c|c|c|c|c|c|c|}
\hline $\begin{array}{c}\text { PATH } \\
\text { NO. }\end{array}$ & \begin{tabular}{|l|} 
SYS. \\
MODE \\
\end{tabular} & \begin{tabular}{|l|} 
EQUIPMENT \\
MDENTIFIER \\
\end{tabular} & $\begin{array}{l}\text { COMP. } \\
\text { DESC. }\end{array}$ & SSD FUNCTION & \begin{tabular}{|c} 
DWG. \\
REF.
\end{tabular} & \begin{tabular}{|c|} 
NORM. \\
POS. \\
\end{tabular} & \begin{tabular}{|l} 
SSD \\
POS.
\end{tabular} & \begin{tabular}{|l} 
PLANT \\
LOCAT.
\end{tabular} & $\begin{array}{c}\text { FIRE } \\
\text { COMPT. }\end{array}$ & \begin{tabular}{|c|} 
PWR \\
SUPPLY \\
\end{tabular} & $\begin{array}{l}\text { FIRE } \\
\text { CELL }\end{array}$ & NOTES \\
\hline & & & & & & & & & & & & \\
\hline & & & & & & & & & & & & \\
\hline & & & & & & & & & & & & \\
\hline & & & & & & & & & & & & \\
\hline & & & & & & & & & . & & & \\
\hline & & & & & & & & & & & & \\
\hline & & & & & & & & & & & & \\
\hline & & & & & & & & & & & & \\
\hline & & & & & & & & & & & & \\
\hline & & & & & & & & & & & & \\
\hline
\end{tabular}




\section{SAFE SHUTDOWN COMPONENT WORKSHEET}

\section{COMPONENT:}

NORMAL POSITION:

REQUIRED POSITION FOR A FIRE:

INCLUDED ON SAFE SHUTDOWN EQUIPMENT LIST YES NO

BASIS FOR ABOVE: 


\section{SAFE SHUTDOWN CABLE WORKSHEET}

COMPONENT:

SSD POSITION:

CABLE NO:

POWER SUPPLY:

SCHEME NUMBER:

REF. DWG.

CABLE FUNCTION:

ISOLATION DEVICE:

CABLE LOCATION KNOWN: YES

NO

$\overline{\mathrm{NO}} \_$(If NO, Refer to Section 4.8)

TYPE OF POTENTIAL FAILURE:

SHORT CIRCUTT

OPEN CIRCUIT

SHORT TO GROUND

HOT SHORT
YES

YES

YES

YES

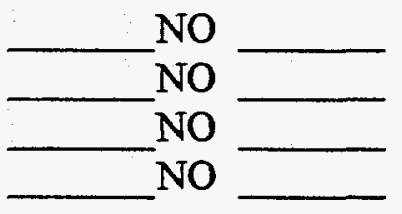

ANALYSIS:

EFFECT OF FAIIURE(S):

PROTECTION REQUIRED:

YES

NO

COMPENSATORY ACTION POSSIBLE: YES

NO

SUGGESTED RESOLUTION: 


\section{INPUT DATA FOR SELECTIVE COORDINATION STUDY}

SAFE SHUTDOWN POWER SUPPLY DESIGNATION:

AVAILABLE SHORT-CIRCUIT CURRENT:

\begin{tabular}{|c|c|c|c|}
\hline $\begin{array}{c}\text { Associated } \\
\text { Circuit } \\
\text { Number } \\
\end{array}$ & $\begin{array}{c}\text { Protective Device } \\
\text { Manufacturer/Model } \\
\text { Number }\end{array}$ & Rating/Setting & Remarks \\
\hline & & & \\
\hline & & & \\
\hline & & & \\
\hline & & & \\
\hline & & & \\
\hline & & & \\
\hline & & & \\
\hline & & & \\
\hline & & & \\
\hline & & & \\
\hline & & & \\
\hline & & & \\
\hline & & & \\
\hline & & & \\
\hline & & & \\
\hline & & & \\
\hline & & & \\
\hline & & & \\
\hline & & & \\
\hline & & & \\
\hline
\end{tabular}


COORDINATION STUDY SUMMARY

\begin{tabular}{|c|c|c|c|c|}
\hline $\begin{array}{c}\text { Associated Circuit } \\
\text { Number }\end{array}$ & $\begin{array}{c}\text { Applicable } \\
\text { Figure Number }\end{array}$ & $\begin{array}{l}\text { Coordinate } \\
\text { Yes/No }\end{array}$ & $\begin{array}{l}\text { Recommended } \\
\text { Action }\end{array}$ & Final Action \\
\hline & & & & \\
\hline & & & & \\
\hline & & & & \\
\hline & & & & \\
\hline & & & & \\
\hline & & & & \\
\hline & & & & \\
\hline & & & & \\
\hline & & & & \\
\hline & & & & \\
\hline & & & & \\
\hline & & & & \\
\hline & & & & \\
\hline & & & & \\
\hline & & & & \\
\hline & & & & \\
\hline & & & & \\
\hline & & & & \\
\hline & & & & \\
\hline & & & & \\
\hline & & & & \\
\hline & & & & \\
\hline
\end{tabular}




\section{SAFE SHUTDOWN PATH IDENTIFICATION WORKSHEET}

SHUTDOWN PATH:

\begin{tabular}{|c|c|}
\hline SAFE SHUTDOWN SYSTEM & SAFE SHUTDOWN FUNCTION \\
\hline & \\
\hline & \\
\hline & \\
\hline & \\
\hline
\end{tabular}

DISCUSSION:

\begin{tabular}{|l|l|}
\hline SUPPORT SYSTEMS & FUNCTION \\
\hline & \\
\hline & \\
\hline & \\
\hline & \\
\hline & \\
\hline
\end{tabular}

DISCUSSION: 
FIRE PROTECTION SYSTEM EVALUATION CHECKLIST

\begin{tabular}{|c|c|c|c|c|c|}
\hline \multirow[t]{2}{*}{ No. } & \multirow[t]{2}{*}{ Item } & \multicolumn{3}{|c|}{ Adequacy } & \multirow{2}{*}{$\begin{array}{c}\text { Comments \& Objective } \\
\text { Evidence Reviewed }\end{array}$} \\
\hline & & $\mathbf{S}$ & $\mathbf{N}$ & $\mathbf{U}$ & \\
\hline \multicolumn{6}{|c|}{ Fire Water Supply System } \\
\hline 1. & $\begin{array}{l}\text { The capacity of the fire water source is } \\
\text { adequate to meet the design water flow } \\
\text { requirements as described in Section 4.6.1.1. }\end{array}$ & & & & \\
\hline 2. & $\begin{array}{l}\text { Redundant components are available in the fire } \\
\text { water path so that a failure of one component } \\
\text { will not prevent fire water from being } \\
\text { delivered to each building or outdoor structure. }\end{array}$ & & & & \\
\hline 3. & $\begin{array}{l}\text { A testing and inspection program indicates } \\
\text { that the fire water supply system is reliable and } \\
\text { can be expected to operate when called on. }\end{array}$ & & & & \\
\hline 4. & $\begin{array}{l}\text { There is more than one supply pipe from the } \\
\text { water source to the fire pumps. }\end{array}$ & & & & \\
\hline 5. & $\begin{array}{l}\text { There is more than one fire pump for each fire } \\
\text { pump function (pressure maintenance, full } \\
\text { flow, etc.). }\end{array}$ & & & & \\
\hline 6. & There is more than one set of fire pumps. & & & & \\
\hline 7. & $\begin{array}{l}\text { Each fire pump or set of fire pumps is located } \\
\text { in a separate fire compartment. }\end{array}$ & & & & \\
\hline 8. & $\begin{array}{l}\text { The capacity of each set of fire pumps is } \\
\text { adequate to supply the minimum amount of } \\
\text { fire water required. }\end{array}$ & & & & \\
\hline 9. & $\begin{array}{l}\text { The fire pumps are connected to different } \\
\text { power sources so that upon loss of one power } \\
\text { source, the fire pumps can continue to perform } \\
\text { their intended function. }\end{array}$ & & & & \\
\hline 10. & $\begin{array}{l}\text { Fire pumps are tested periodically to determine } \\
\text { their continued ability to provide the required } \\
\text { design water flow and pressure. }\end{array}$ & & & & \\
\hline
\end{tabular}


FIRE PROTECTION SYSTEM EVALUATION CHECKLIST (Continued)

\begin{tabular}{|c|c|c|c|c|c|}
\hline \multirow[t]{2}{*}{ No. } & \multirow[t]{2}{*}{ Item } & \multicolumn{3}{|c|}{ Adequacy } & \multirow{2}{*}{$\begin{array}{c}\text { Comments \& Objective } \\
\text { Evidence Reviewed }\end{array}$} \\
\hline & & $\mathbf{S}$ & $\mathbf{N}$ & $\mathbf{U}$ & \\
\hline 11. & $\begin{array}{l}\text { Fire pump test results are recorded and } \\
\text { compared to previous tests in order to } \\
\text { determine any problems and/or unacceptable } \\
\text { trends. }\end{array}$ & & & & \\
\hline 12. & $\begin{array}{l}\text { Each set of fire pumps has a separate discharge } \\
\text { pipe and connection to the plant fire loop. }\end{array}$ & & & & \\
\hline 13. & $\begin{array}{l}\text { There is more than one connection from the } \\
\text { fire loop to each building. }\end{array}$ & & & & \\
\hline 14. & $\begin{array}{l}\text { Isolation valves are located in the fire loop so } \\
\text { that sections of the fire loop may be isolated for } \\
\text { maintenance and repair without preventing the } \\
\text { flow of fire water to any required building or } \\
\text { outdoor structure. }\end{array}$ & & & & \\
\hline 15. & $\begin{array}{l}\text { Isolation valves are properly located in the fire } \\
\text { loop so that closing one isolation valve will not } \\
\text { prevent fire water from being delivered to any } \\
\text { required building or outdoor structure. }\end{array}$ & & & & \\
\hline 16. & $\begin{array}{l}\text { Locations of yard hydrants allow for adequate } \\
\text { coverage of all buildings and outdoor } \\
\text { structures. }\end{array}$ & & & & \\
\hline 17. & $\begin{array}{l}\text { Yard main piping and hydrants are routinely } \\
\text { flushed out to remove sediment and debris. }\end{array}$ & & & & \\
\hline 18. & $\begin{array}{l}\text { Fire water piping is protected from damage by } \\
\text { such adverse effects as freezing, mechanical } \\
\text { damage, ground movement, etc. }\end{array}$ & & & & \\
\hline
\end{tabular}


FIRE PROTECTION SYSTEM EVALUATION CHECKLIST (Continued)

\begin{tabular}{|c|c|c|c|c|c|}
\hline \multirow[t]{2}{*}{ No. } & \multirow[t]{2}{*}{ Item } & \multicolumn{3}{|c|}{ Adequacy } & \multirow{2}{*}{$\begin{array}{c}\text { Comments \& Objective } \\
\text { Evidence Reviewed }\end{array}$} \\
\hline & & $\mathbf{S}$ & $\mathbf{N}$ & $\mathbf{U}$ & \\
\hline \multicolumn{6}{|c|}{ Fire Detection Systems } \\
\hline 19. & $\begin{array}{l}\text { Plant operators receive indication, either in the } \\
\text { control room or at a central staffed location, } \\
\text { that a fire detection system (as listed in Section } \\
4.6 .3 .1 \text { ) has been activated. }\end{array}$ & & & & \\
\hline 20. & $\begin{array}{l}\text { Plant operators receive indication of where the } \\
\text { activated fire detection system is located. }\end{array}$ & & & & \\
\hline 21. & $\begin{array}{l}\text { Each fire detection panel receives power from } \\
\text { two different sources. }\end{array}$ & & & & \\
\hline 22. & $\begin{array}{l}\text { All fire detection circuits are electronically } \\
\text { supervised to identify any faulted conditions. }\end{array}$ & & & & \\
\hline \multicolumn{6}{|c|}{ Fire Suppression Systems } \\
\hline 23. & $\begin{array}{l}\text { Plant operators receive indication, either in the } \\
\text { control room or at a central staffed location, } \\
\text { that a fire suppression system (as listed in } \\
\text { Section } 4.6 .2 .1 \text { ) has been activated. }\end{array}$ & & & & \\
\hline 24. & $\begin{array}{l}\text { Plant operators receive indication of where the } \\
\text { activated fire suppression system is located. }\end{array}$ & & & & \\
\hline 25. & $\begin{array}{l}\text { Plant operators have written procedures } \\
\text { available to indicate what manual actions are } \\
\text { required to place manual fire suppression } \\
\text { systems into operation. }\end{array}$ & & & & \\
\hline
\end{tabular}


FIRE PROTECTION SYSTEM EVALUATION CHECKLIST (Continued)

\begin{tabular}{|c|c|c|c|c|c|}
\hline \multirow{2}{*}{ No. } & \multirow{2}{*}{ Item } & \multicolumn{3}{|c|}{ Adequacy } & \multirow{2}{*}{$\begin{array}{c}\text { Comments \& Objective } \\
\text { Evidence Reviewed }\end{array}$} \\
\hline & & $\mathbf{S}$ & $\mathbf{N}$ & $\mathbf{U}$ & \\
\hline \multicolumn{6}{|c|}{ Fire Separation and Fireproofing } \\
\hline 26. & $\begin{array}{l}\text { Evaluations and/or fire tests were performed to } \\
\text { verify that each type of fire barrier will } \\
\text { maintain its integrity for the time frame } \\
\text { specified. }\end{array}$ & & & & \\
\hline 27. & $\begin{array}{l}\text { Evaluations and/or fire tests were performed to } \\
\text { verify that each type of penetration seal will } \\
\text { maintain its integrity for the time frame } \\
\text { specified. }\end{array}$ & & & & \\
\hline 28. & $\begin{array}{l}\text { The fire ratings of penetration seal systems are } \\
\text { compatible with the fire ratings of their } \\
\text { associated fire barriers. }\end{array}$ & & & & \\
\hline 29. & $\begin{array}{l}\text { Evaluations and/or fire tests were performed to } \\
\text { verify that each type of fire door will maintain } \\
\text { its integrity for the time specified. }\end{array}$ & & & & \\
\hline 30. & $\begin{array}{l}\text { The fire ratings of fire doors are compatible } \\
\text { with the fire ratings of their associated fire } \\
\text { barriers. }\end{array}$ & & & & \\
\hline 31. & $\begin{array}{l}\text { Evaluations and/or fire tests were performed to } \\
\text { verify that each type of fire damper will } \\
\text { maintain its integrity for the time specified. }\end{array}$ & & & & \\
\hline 32. & $\begin{array}{l}\text { The fire ratings of fire dampers are compatible } \\
\text { with the fire ratings of their associated fire } \\
\text { barriers. }\end{array}$ & & & & \\
\hline 33. & $\begin{array}{l}\text { Evaluations and/or fire tests were performed to } \\
\text { verify that other types of closures will maintain } \\
\text { their integrity for the time specified. }\end{array}$ & & & & \\
\hline 34. & $\begin{array}{l}\text { The fire ratings of other types of closures are } \\
\text { compatible with the fire ratings of their } \\
\text { associated fire barriers. }\end{array}$ & & & & \\
\hline
\end{tabular}


FIRE PROTECTION SYSTEM EVALUATION CHECKLIST (Continued)

\begin{tabular}{|c|c|c|c|c|c|}
\hline \multirow[t]{2}{*}{ No. } & \multirow[t]{2}{*}{ Item } & \multicolumn{3}{|c|}{ Adequacy } & \multirow{2}{*}{$\begin{array}{c}\text { Comments \& Objective } \\
\text { Evidence Reviewed }\end{array}$} \\
\hline & & $\mathbf{S}$ & $\mathbf{N}$ & $\mathbf{U}$ & \\
\hline 35. & $\begin{array}{l}\text { Evaluations and/or fire tests were performed to } \\
\text { verify that each type of fireproofing will } \\
\text { maintain the structural integrity of structural } \\
\text { members for the time frame specified. }\end{array}$ & & & & \\
\hline 36. & $\begin{array}{l}\text { The fire ratings of fireproofing systems are } \\
\text { compatible with the anticipated duration and } \\
\text { intensity of fires. }\end{array}$ & & & & \\
\hline \multicolumn{6}{|c|}{ Fire Brigade } \\
\hline 37. & $\begin{array}{l}\text { Adequate fire fighting equipment is available } \\
\text { for use in fighting a fire. }\end{array}$ & & & & \\
\hline 38. & $\begin{array}{l}\text { Records are available to indicate that the fire } \\
\text { fighting equipment has been inspected and is } \\
\text { in proper operating condition for use in } \\
\text { fighting a fire. }\end{array}$ & & & & \\
\hline 39. & $\begin{array}{l}\text { Adequate personal protective equipment is } \\
\text { available for use in fighting a fire. }\end{array}$ & & & & \\
\hline 40. & $\begin{array}{l}\text { Records are available to indicate that the } \\
\text { personal protective equipment has been } \\
\text { inspected and is in proper condition for use in } \\
\text { fighting a fire. }\end{array}$ & & & & \\
\hline 41. & $\begin{array}{l}\text { A particular supervisor of the fire brigade is } \\
\text { identified for each shift }\end{array}$ & & & & \\
\hline 42. & $\begin{array}{l}\text { Specific members of the fire brigade are } \\
\text { identified for each shift. }\end{array}$ & & & & \\
\hline 43. & $\begin{array}{l}\text { Records are available that show that each } \\
\text { member of the fire brigade is properly trained } \\
\text { to fight NPP fires. }\end{array}$ & & & & \\
\hline 44. & $\begin{array}{l}\text { Records are available that indicate what the } \\
\text { fire brigade response times are to various areas } \\
\text { of the plant. }\end{array}$ & & & & \\
\hline
\end{tabular}


FIRE PROTECTION SYSTEM EVALUATION CHECKLIST (Continued)

\begin{tabular}{|c|c|c|c|c|c|}
\hline \multirow[t]{2}{*}{ No. } & \multirow[t]{2}{*}{ Item } & \multicolumn{3}{|c|}{ Adequacy } & \multirow{2}{*}{$\begin{array}{c}\text { Comments \& Objective } \\
\text { Evidence Reviewed }\end{array}$} \\
\hline & & $\mathbf{S}$ & $\mathbf{N}$ & $\mathbf{U}$ & \\
\hline 45. & $\begin{array}{l}\text { The fire brigade is provided with a means to } \\
\text { communicate with the control room to } \\
\text { coordinate fire fighting activities with plant } \\
\text { operators. }\end{array}$ & & & & \\
\hline 46. & $\begin{array}{l}\text { The communication system is available and } \\
\text { operable in all portions of the plant. }\end{array}$ & & & & \\
\hline 47. & $\begin{array}{l}\text { All communication devices are regularly tested } \\
\text { and maintained, and spare devices and spare } \\
\text { parts are available. }\end{array}$ & & & & \\
\hline 48. & $\begin{array}{l}\text { The authorities and responsibilities of all } \\
\text { groups of personnel (control room operators, } \\
\text { fire brigade, plant workers, etc.) are clearly } \\
\text { defined before and during a fire. }\end{array}$ & & & & \\
\hline 49. & $\begin{array}{l}\text { Training sessions are implemented to practice } \\
\text { plant and fire brigade response and } \\
\text { coordination. }\end{array}$ & & & & \\
\hline 50. & $\begin{array}{l}\text { Written fire brigade procedures are available } \\
\text { for fighting fires in specific areas of the plant. }\end{array}$ & & & & . \\
\hline
\end{tabular}




\section{SITE BUILDINGS AND OUTDOOR STRUCTURES}

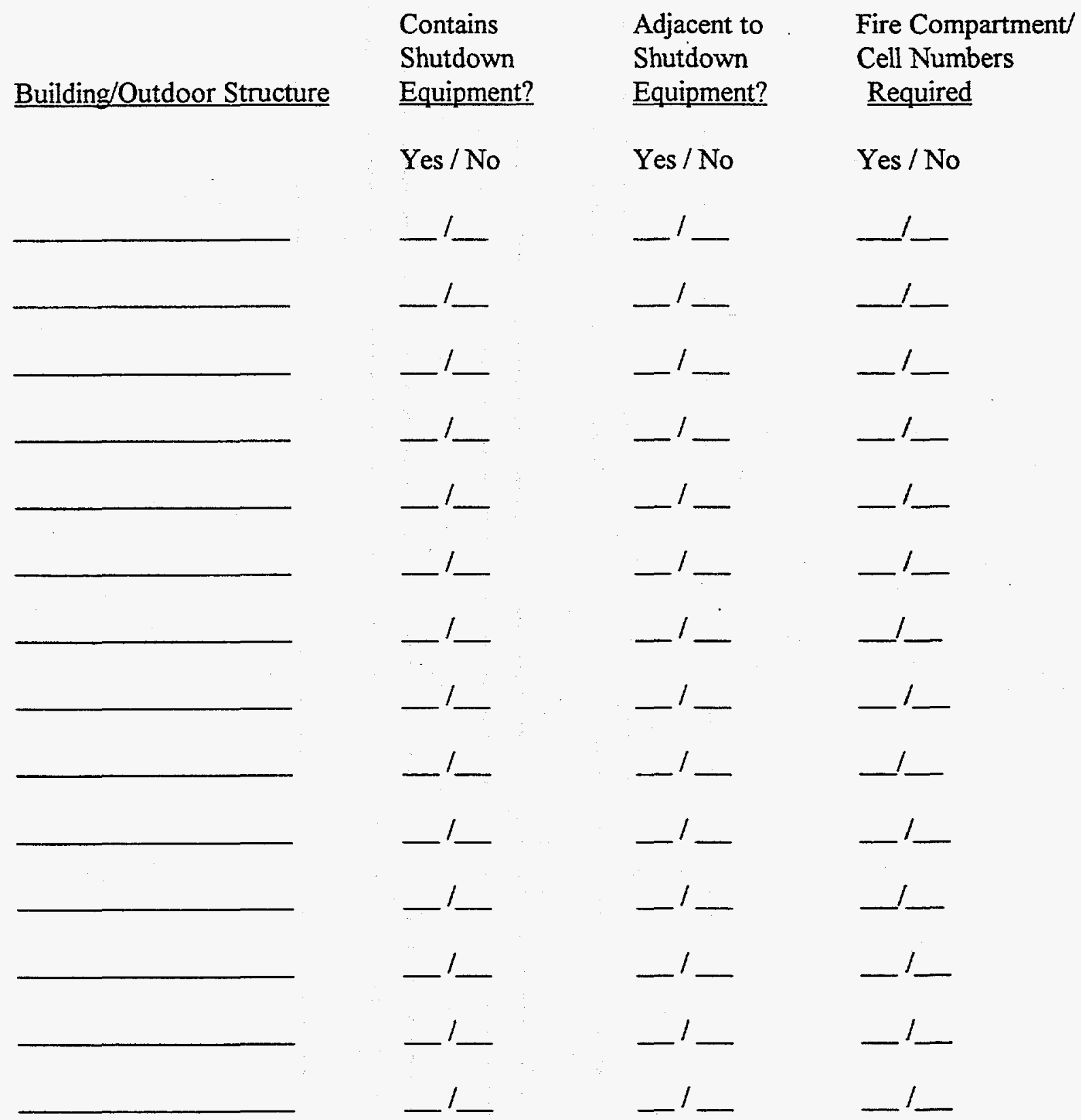

A "yes" response in either of the first two columns identifies the building/outdoor structure as requiring further evaluation. A "no" response in both columns eliminates the structure from further evaluation. 
1. FIRE COMPARTMENT AND FIRE CELL DATA

Fire Compartment:

Fire Cell:

Reference Drawing:

Building:

Elevation:

2. CONSTRUCTION BOUNDARIES

\begin{tabular}{|c|c|c|c|c|c|c|c|}
\hline \multirow[t]{2}{*}{ Boundary } & \multicolumn{2}{|c|}{$\begin{array}{c}\text { Fire } \\
\text { Barrier }\end{array}$} & \multirow[t]{2}{*}{$\begin{array}{c}\text { Fire } \\
\text { Barrier } \\
\text { Rating } \\
\text { (Minutes) }\end{array}$} & \multirow[t]{2}{*}{$\begin{array}{l}\text { Material of } \\
\text { Construction }\end{array}$} & \multirow[t]{2}{*}{$\begin{array}{l}\text { Thickness } \\
\text { (cm approx.) }\end{array}$} & \multirow[t]{2}{*}{ Covering } & \multirow[t]{2}{*}{$\begin{array}{l}\text { Verified } \\
\text { (as built) }\end{array}$} \\
\hline & Yes & No & & & & & \\
\hline \multicolumn{8}{|l|}{ Wall 1} \\
\hline \multicolumn{8}{|l|}{ Wall 2} \\
\hline \multicolumn{8}{|l|}{ Wall 3} \\
\hline \multicolumn{8}{|l|}{ Wall 4} \\
\hline \multicolumn{8}{|l|}{ Wall 5} \\
\hline \multicolumn{8}{|l|}{ Wall 6} \\
\hline \multicolumn{8}{|l|}{ Wall 7} \\
\hline \multicolumn{8}{|l|}{ Wall 8} \\
\hline \multicolumn{8}{|l|}{ Ceiling } \\
\hline Floor & & & & & & & \\
\hline
\end{tabular}

COMMENTS: 
FIRE COMPARTMENT/FIRE CELL WALKDOWN CHECKLIST (Continued) 3. MAJOR EQUIPMENT AND COMPONENTS Compartment No.

Cell No.

\section{A. Safe Shutdown Related}

\begin{tabular}{|l|l|l|l|}
\hline Item & Equipment Number & Equipment Title & Equipment Type \\
\hline 1. & & & \\
\hline 2. & & & \\
\hline 3. & & & \\
\hline 4. & & & \\
\hline 5. & & & \\
\hline 6. & & & \\
\hline 7. & & & \\
\hline 8. & & & \\
\hline 9. & & & \\
\hline 10. & & & \\
\hline 11. & & & \\
\hline 12. & & & \\
\hline 13. & & & \\
\hline 14. & & & \\
\hline 15. & & & \\
\hline 16. & & & \\
\hline 17. & & & \\
\hline 18. & & & \\
\hline 19. & & & \\
\hline 20. & & & \\
\hline
\end{tabular}

COMMENTS: 
FIRE COMPARTMENT/FIRE CELL WALKDOWN CHECKLIST (Continued)

3. MAJOR EQUIPMENT AND COMPONENTS

Compartment No.

Cell No.

3B. Non-Shutdown Related (large or significant equipment and components)

\begin{tabular}{|l|l|l|l|}
\hline Item & Equipment Number & Equipment Title & Equipment Type \\
\hline 1. & & & \\
\hline 2. & & & \\
\hline 3. & & & \\
\hline 4. & & & \\
\hline 5. & & & \\
\hline 6. & & & \\
\hline 7. & & & \\
\hline 8. & & & \\
\hline 9. & & & \\
\hline 10. & & & \\
\hline 11. & & & \\
\hline 12. & & & \\
\hline 13. & & & \\
\hline 14. & & & \\
\hline 15. & & & \\
\hline 16. & & & \\
\hline 17. & & & \\
\hline 18. & & & \\
\hline 19. & & & \\
\hline 20. & & & \\
\hline
\end{tabular}

COMMENTS: 
FIRE COMPARTMENT/FIRE CELL WALKDOWN CHECKLIST (Continued)

4. DOORS

Compartment No.

Cell No.

\begin{tabular}{|c|c|c|c|c|c|c|c|c|c|c|c|}
\hline \multirow[t]{2}{*}{$\begin{array}{c}\text { Door } \\
\text { Number }\end{array}$} & \multirow[t]{2}{*}{$\begin{array}{c}\text { Reference } \\
\text { Drawing }\end{array}$} & \multicolumn{2}{|c|}{ Fire Door } & \multirow[t]{2}{*}{$\begin{array}{c}\text { Rating } \\
\text { (Minutes) }\end{array}$} & \multirow[t]{2}{*}{$\begin{array}{c}\text { Material/ } \\
\text { Type }\end{array}$} & \multicolumn{2}{|c|}{ Door Closer } & \multirow[t]{2}{*}{$\begin{array}{l}\text { Condition } \\
\text { (A/M/U) }\end{array}$} & \multirow[t]{2}{*}{$\begin{array}{c}\text { Fit } \\
(A / M / U)\end{array}$} & \multirow[t]{2}{*}{$\begin{array}{c}\text { Position } \\
(\mathrm{O} / \mathrm{BO} / \mathrm{C} / \mathrm{LC})\end{array}$} & \multirow[t]{2}{*}{$\begin{array}{c}\text { Operation } \\
\text { (A/M/U) }\end{array}$} \\
\hline & & Yes & No & & & Yes & No & & & & \\
\hline \multicolumn{12}{|l|}{1.} \\
\hline \multicolumn{12}{|l|}{2.} \\
\hline \multicolumn{12}{|l|}{3.} \\
\hline \multicolumn{12}{|l|}{4.} \\
\hline \multicolumn{12}{|l|}{5.} \\
\hline \multicolumn{12}{|l|}{6.} \\
\hline \multicolumn{12}{|l|}{7.} \\
\hline \multicolumn{12}{|l|}{8.} \\
\hline \multicolumn{12}{|l|}{9.} \\
\hline 10. & & & & & & & & & & & \\
\hline
\end{tabular}

COMMENTS:

LEGEND:

A - Acceptable

M - Marginal

U - Unacceptable
O - Open

BO - Blocked Open

C - Closed
LC - Locked Closed 


\section{FIRE COMPARTMENT/FIRE CELL WALKDOWN CHECKLIST (Continued)}

\section{PENETRATIONS}

Compartment No.

Cell No.

5A. Wall Penetrations

\begin{tabular}{|c|c|c|c|c|c|c|c|c|c|}
\hline \multirow[t]{2}{*}{$\begin{array}{l}\text { Location (wall } \\
\text { number) }\end{array}$} & \multicolumn{2}{|c|}{$\begin{array}{c}\text { Fire } \\
\text { Barrier }\end{array}$} & \multirow[t]{2}{*}{$\begin{array}{l}\text { Rating } \\
\text { (Minutes) }\end{array}$} & \multirow[t]{2}{*}{$\begin{array}{c}\text { Penetration } \\
\text { Number }\end{array}$} & \multirow[t]{2}{*}{$\begin{array}{c}\text { Penetration } \\
\text { Type } \\
\text { (See Note 1) }\end{array}$} & \multirow[t]{2}{*}{$\begin{array}{c}\text { Penetration Size } \\
\text { (cm x cm, approx.) }\end{array}$} & \multirow[t]{2}{*}{$\begin{array}{c}\text { Seal } \\
\text { Material }\end{array}$} & \multirow[t]{2}{*}{$\begin{array}{l}\text { Condition } \\
(\mathbf{A} / \mathbf{M} / \mathbf{U})\end{array}$} & \multirow[t]{2}{*}{ Comments } \\
\hline & Yes & No & & & & & & & \\
\hline & & & & & & & & & \\
\hline & & & & & & & & & \\
\hline & & & & & & & & & \\
\hline & & & & & & & & & \\
\hline & & & & & & & & & \\
\hline & & & & & & & & & \\
\hline & & & & & & & & & \\
\hline & & & & & & & & & \\
\hline
\end{tabular}

Note 1: Enter type, such as: Cable, Cable Tray, Conduit, Pipe, Duct, etc.

LEGEND:

A - Acceptable

M - Marginal

U - Unacceptable 
FIRE COMPARTMENT/FIRE CELL WALKDOWN CHECKLIST (Continued)

\section{PENETRATIONS (continued)}

5B. Ceiling Penetrations

\begin{tabular}{|c|c|c|c|c|c|c|c|c|c|}
\hline \multirow[t]{2}{*}{ Location } & \multicolumn{2}{|c|}{$\begin{array}{c}\text { Fire } \\
\text { Barrier }\end{array}$} & \multirow[t]{2}{*}{$\begin{array}{c}\text { Rating } \\
\text { (Minutes) }\end{array}$} & \multirow[t]{2}{*}{$\begin{array}{c}\text { Penetration } \\
\text { Number }\end{array}$} & \multirow[t]{2}{*}{$\begin{array}{c}\text { Penetration } \\
\text { Type } \\
\text { (See Note 1) }\end{array}$} & \multirow[t]{2}{*}{$\begin{array}{l}\text { Penetration } \\
\text { Size }(\mathrm{cm} \times \mathrm{cm} \text {, } \\
\text { approx.) }\end{array}$} & \multirow[t]{2}{*}{$\begin{array}{c}\text { Seal } \\
\text { Material }\end{array}$} & \multirow[t]{2}{*}{$\begin{array}{c}\text { Condition } \\
\text { (A/M/U) }\end{array}$} & \multirow[t]{2}{*}{ Comments } \\
\hline & Yes & No & & & & & & & \\
\hline \multicolumn{10}{|l|}{ Ceiling } \\
\hline & & & & & & & & & \\
\hline & & & & & & & & & \\
\hline & & & & & & & & & \\
\hline & & & & & & & & & \\
\hline & & & & & & & & & \\
\hline & & & & & & & & & \\
\hline & & & & & & & & & \\
\hline & & & & & & & & & \\
\hline
\end{tabular}

Note 1: Enter type, such as: Cable, Cable Tray, Conduit, Pipe, Duct, etc.
A - Acceptable

M - Marginal

U - Unacceptable
Compartment No.

Cell No. 
FIRE COMPARTMENT/FIRE CELL WALKDOWN CHECKLIST (Continued)

5. PENETRATIONS (continued)

5C. Floor Penetrations

\begin{tabular}{|c|c|c|c|c|c|c|c|c|c|c|c|}
\hline \multirow[t]{2}{*}{ Location } & \multicolumn{2}{|c|}{$\begin{array}{c}\text { Fire } \\
\text { Barrier }\end{array}$} & \multirow[t]{2}{*}{$\begin{array}{c}\text { Rating } \\
\text { (Minutes) }\end{array}$} & \multirow[t]{2}{*}{$\begin{array}{c}\text { Penetration } \\
\text { Number }\end{array}$} & \multirow[t]{2}{*}{$\begin{array}{c}\text { Penetration } \\
\text { Type } \\
\text { (See Note 1) }\end{array}$} & \multirow[t]{2}{*}{$\begin{array}{c}\text { Penetration } \\
\text { Size } \\
\text { (cm } \times \text { cm, } \\
\text { approx.) }\end{array}$} & \multirow[t]{2}{*}{$\begin{array}{c}\text { Seal } \\
\text { Material }\end{array}$} & \multirow[t]{2}{*}{$\begin{array}{l}\text { Condition } \\
(\mathrm{A} / \mathrm{M} / \mathrm{U})\end{array}$} & \multicolumn{3}{|c|}{ Floor Curbs } \\
\hline & Yes & No & & & & & & & Yes & No & $\begin{array}{l}\text { Height } \\
\text { (cm) }\end{array}$ \\
\hline \multicolumn{12}{|l|}{ Floor } \\
\hline & & & & & & & & & & & \\
\hline & & & & & & & & & & & \\
\hline & & & & & & & & & & & \\
\hline & & & & & & & & & & & \\
\hline
\end{tabular}

Note 1: Enter type, such as: Cable, Cable Tray, Conduit, Pipe, Duct, etc. COMMENTS:
Compartment No.

Cell No.
LEGEND:

A - Acceptable

M - Marginal

U - Unacceptable 
FIRE COMPARTMENT/FIRE CELL WALKDOWN CHECKLIST (Continued)

6. STRUCTURAL

Compartment No.

Cell No.

\begin{tabular}{|l|l|l|l|l|l|l|}
\hline \multicolumn{1}{|c|}{ Item } & \multirow{2}{*}{ Type } & \multicolumn{2}{c|}{ Exposed } & \multicolumn{2}{|l|}{ Fireproofing } & \multirow{2}{*}{ Comments } \\
\cline { 3 - 6 } & & Yes & No & Yes & No & \\
\hline Beams & Steel & & & & & \\
\hline & Other & & & & & \\
\hline Columns & Steel & & & & & \\
\hline & Other & & & & & \\
\hline
\end{tabular}

COMMENTS:

7. COMBUSTIBLE MATERIAL

\begin{tabular}{|l|l|l|}
\hline \multicolumn{1}{|c|}{ Type } & Fixed Quantity & Transient Quantity \\
\hline $\begin{array}{l}\text { Cable } \\
\text { insulation }\end{array}$ & & \\
\hline Lube Oil & & \\
\hline Wood & & \\
\hline Plastic & & \\
\hline $\begin{array}{l}\text { Plastic } \\
\text { Floor } \\
\text { Covering }\end{array}$ & & \\
\hline Paper & & \\
\hline Grease & & \\
\hline Gases (list) & & \\
\hline
\end{tabular}

COMMENTS: 
FIRE COMPARTMENT/FIRE CELL WALKDOWN CHECKLIST (Continued)

8. FIRE SUPPRESSION SYSTEMS

Compartment No.

Cell No.

\begin{tabular}{|l|c|c|c|c|c|c|}
\hline \multicolumn{2}{|c|}{ Fire Suppression } & \multicolumn{1}{c|}{$\begin{array}{c}\text { Type of } \\
\text { Fixtures } \\
\text { (See Note 1) }\end{array}$} & $\begin{array}{c}\text { Number } \\
\text { of } \\
\text { Fixtures }\end{array}$ & $\begin{array}{c}\text { Location } \\
\text { (Reference Drawing } \\
\text { Number) }\end{array}$ & $\begin{array}{c}\text { Condition } \\
\text { (A/M/U) }\end{array}$ \\
\hline Type & Yes & No & & & & \\
\hline Deluge & & & & & & \\
\hline Halon & & & & & & \\
\hline $\mathrm{CO}_{2}$ & & & & & & \\
\hline & & & & & & \\
\hline
\end{tabular}

Note 1: Enter type, such as closed head (fusible link) sprinkler, open head sprinkler, nozzle, etc.

COMMENTS:

LEGEND: A - Acceptable

M - Marginal

U - Unacceptable

9. FIRE DETECTION SYSTEMS

\begin{tabular}{|c|c|c|c|c|c|c|c|}
\hline \multicolumn{3}{|c|}{ Fire Detection } & \multirow[t]{2}{*}{$\begin{array}{c}\text { Number } \\
\text { of } \\
\text { Detectors }\end{array}$} & \multirow[t]{2}{*}{$\begin{array}{c}\text { Location } \\
\text { (Reference } \\
\text { Drawing Number) }\end{array}$} & \multirow[t]{2}{*}{$\begin{array}{l}\text { Condition } \\
(\mathrm{A} / \mathrm{M} / \mathrm{U})\end{array}$} & \multicolumn{2}{|c|}{ Alarm } \\
\hline Type & Yes & No & & & & Local & $\begin{array}{c}\text { Control } \\
\text { Room }\end{array}$ \\
\hline Smoke & & & & & & & \\
\hline Heat & & & & & & & \\
\hline Linear Therma & & & & & & & \\
\hline Pneumatic & & & & & & & \\
\hline & & & & & & & \\
\hline
\end{tabular}

COMMENTS:

LEGEND:

A - Acceptable

M - Marginal

U - Unacceptable 
FIRE COMPARTMENT/FIRE CELL WALKDOWN CHECKLIST (Continued)

10. FIRE HOSE STATIONS AND WATER CANNONS

Compartment No.

Cell No.

10A. Fire Hose Stations

\begin{tabular}{|c|c|c|c|c|c|c|c|c|c|c|}
\hline \multirow[t]{2}{*}{ Area } & \multicolumn{2}{|c|}{ Hose Station } & \multirow[t]{2}{*}{$\begin{array}{l}\text { Number } \\
\text { of } \\
\text { Stations }\end{array}$} & \multirow[t]{2}{*}{$\begin{array}{c}\text { Location } \\
\text { (Reference } \\
\text { Drawing } \\
\text { Number) }\end{array}$} & \multicolumn{2}{|c|}{ Accessible } & \multicolumn{2}{|c|}{ Operable } & \multirow[t]{2}{*}{$\begin{array}{c}\text { Hose } \\
\text { Condition } \\
\text { (A/U) }\end{array}$} & \multirow[t]{2}{*}{$\begin{array}{c}\text { Nozzle } \\
\text { Condition } \\
\text { (A/U) }\end{array}$} \\
\hline & Yes & No & & & Yes & No & Yes & No & & \\
\hline \multicolumn{11}{|l|}{ Inside } \\
\hline Adjacent & & & & & & & & & & \\
\hline
\end{tabular}

COMMENTS:

LEGEND: A - Acceptable

$\mathrm{U}$ - Unacceptable

10B. Water Cannons

\begin{tabular}{|c|c|c|c|c|c|c|c|}
\hline \multirow[t]{2}{*}{ Area } & \multicolumn{2}{|c|}{ Water Cannon } & \multirow[t]{2}{*}{ Number } & \multirow[t]{2}{*}{$\begin{array}{l}\text { Location (Reference } \\
\text { Drawing Number) }\end{array}$} & \multicolumn{2}{|c|}{ Accessible } & \multirow[t]{2}{*}{$\begin{array}{l}\text { Condition } \\
(\mathrm{A} / \mathrm{U})\end{array}$} \\
\hline & Yes & No & & & Yes & No & \\
\hline Inside & & & & & & & \\
\hline Adjacent & & & & & & & \\
\hline
\end{tabular}

COMMENTS:

LEGEND: A - Acceptable

U - Unacceptable

11. PORTABLE FIRE EXTINGUISHERS

\begin{tabular}{|c|c|c|c|c|c|c|c|c|c|c|}
\hline \multirow[t]{2}{*}{ Area } & \multicolumn{2}{|c|}{$\begin{array}{l}\text { Portable Fire } \\
\text { Extinguishers }\end{array}$} & \multirow[t]{2}{*}{ Number } & \multirow[t]{2}{*}{ Type } & \multirow[t]{2}{*}{$\begin{array}{l}\text { Location } \\
\text { (Reference } \\
\text { Drawing } \\
\text { Number) }\end{array}$} & \multicolumn{2}{|c|}{ Accessible } & \multirow[t]{2}{*}{$\begin{array}{c}\text { Condition } \\
\text { (A/U) }\end{array}$} & \multicolumn{2}{|c|}{$\begin{array}{c}\text { Detector } \\
\text { Type Correct } \\
\text { for } \\
\text { Application? }\end{array}$} \\
\hline & Yes & No & & & & Yes & No & & Yes & No \\
\hline \multicolumn{11}{|l|}{ Inside } \\
\hline Adjacent & & & & & & & & & & \\
\hline
\end{tabular}

COMMENTS:

LEGEND:

A - Acceptable

U - Unacceptable 
FIRE COMPARTMENT/FIRE CELL WALKDOWN CHECKLIST (Continued)

12. DRAINAGE

Compartment No.

Cell No.

\begin{tabular}{|c|c|c|c|c|c|c|c|c|c|c|c|c|}
\hline & \multicolumn{2}{|c|}{$\begin{array}{c}\text { Do Floor Drains Appear } \\
\text { To Be in Working } \\
\text { Floor Drains }\end{array}$} & \multicolumn{2}{|c|}{ Condition } & Drain Pits & $\begin{array}{c}\text { Drain Located } \\
\text { in Pit }\end{array}$ & \multicolumn{2}{|c|}{$\begin{array}{c}\text { Equipment } \\
\text { Curbs }\end{array}$} & $\begin{array}{c}\text { Curb } \\
\text { Height } \\
\text { (cm) }\end{array}$ & $\begin{array}{c}\text { Dikes Around } \\
\text { Tanks }\end{array}$ \\
\hline Yes & No & Yes & No & Yes & No & Yes & No & Yes & No & & Yes & No \\
\hline & & & & & & & & & & & & \\
\hline
\end{tabular}

COMMENTS:

13. VENTILATION

Ventilation System(s) serving Compartment/Cell:

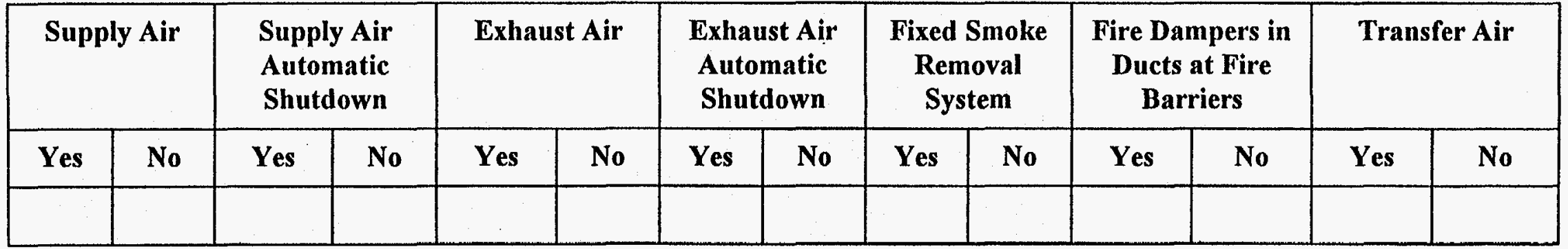

COMMENTS: 
FIRE COMPARTMENT/FIRE CELL WALKDOWN CHECKLIST (Continued)

14. EMERGENCY LIGHTING

Compartment No.

Cell No.

\begin{tabular}{|c|c|c|c|c|c|c|c|c|c|c|}
\hline \multirow[t]{2}{*}{ Area } & \multicolumn{2}{|c|}{$\begin{array}{c}\text { Emergency } \\
\text { Lighting }\end{array}$} & \multirow[t]{2}{*}{$\begin{array}{c}\text { Number } \\
\text { of } \\
\text { Fixtures }\end{array}$} & \multicolumn{3}{|c|}{ Type of Fixtures } & \multicolumn{2}{|c|}{$\begin{array}{c}\text { Do } \\
\text { Lights } \\
\text { Work? } \\
\end{array}$} & \multicolumn{2}{|c|}{$\begin{array}{c}\text { Are Lights } \\
\text { Suitable for } \\
\text { the } \\
\text { Environment? }\end{array}$} \\
\hline & Yes & No & & $\begin{array}{l}\text { Battery } \\
\text { Pack }\end{array}$ & $\begin{array}{l}\text { Hard } \\
\text { Wired }\end{array}$ & $\begin{array}{c}\text { Other } \\
\text { (Identify } \\
\text { Type) }\end{array}$ & Yes & No & Yes & No \\
\hline Cell & & & & & & & & & & \\
\hline $\begin{array}{l}\text { Access } \\
\text { Route }\end{array}$ & & & & & & & & & & \\
\hline & & & & & & & & & & \\
\hline
\end{tabular}

COMMENTS:

\section{EMERGENCY COMMUNICATIONS}

\begin{tabular}{|c|c|c|c|c|c|c|c|c|c|c|}
\hline \multirow[t]{2}{*}{ Area } & \multicolumn{2}{|c|}{$\begin{array}{c}\text { Telephones/ } \\
\text { Two-way PA } \\
\text { System }\end{array}$} & \multicolumn{2}{|c|}{ Operational } & \multicolumn{2}{|c|}{$\begin{array}{c}\text { Portable } \\
\text { Radio }\end{array}$} & \multicolumn{2}{|c|}{ Operational } & \multicolumn{2}{|c|}{$\begin{array}{l}\text { Communication } \\
\text { Available with } \\
\text { Control Room } \\
\text { and Fire } \\
\text { Command } \\
\text { Center? }\end{array}$} \\
\hline & Yes & No & Yes & No & Yes & No & Yes & No & Yes & No \\
\hline \multicolumn{11}{|l|}{ Cell } \\
\hline Adjacent Cell & & & & & & & & & & \\
\hline & & & & & & & & & & \\
\hline
\end{tabular}

COMMENTS: 
INITLAL SCREENING OF FIRE COMPARTMENT

\begin{tabular}{|c|c|c|c|c|}
\hline $\begin{array}{c}\text { Fire } \\
\text { Compartment } \\
\text { Number }\end{array}$ & $\begin{array}{c}\text { Fire } \\
\text { Containment } \\
\text { Evaluation } \\
\text { Required? } \\
\text { Yes / No }\end{array}$ & $\begin{array}{c}\text { Assessment of } \\
\text { Explosion } \\
\text { Potential } \\
\text { Required? } \\
\text { Yes / No }\end{array}$ & $\begin{array}{c}\text { Access } \\
\text { Required } \\
\text { During/After } \\
\text { Fire? } \\
\text { Yes / No }\end{array}$ & $\begin{array}{c}\text { Safe } \\
\text { Shutdown } \\
\text { Evaluation } \\
\text { Required? } \\
\text { Yes / No }\end{array}$ \\
\hline & 1 & 1 & 1 & 1 \\
\hline & 1 & $I$ & 1 & 1 \\
\hline & 1 & 1 & 1 & 1 \\
\hline & 1 & 1 & 1 & 1 \\
\hline & I & 1 & 1 & 1 \\
\hline & 1 & 1 & 1 & 1 \\
\hline & 1 & 1 & 1 & 1 \\
\hline & 1 & 1 & 1 & 1 \\
\hline & 1 & 1 & 1 & 1 \\
\hline & 1 & 1 & 1 & 1 \\
\hline & 1 & 1 & 1 & 1 \\
\hline & 1 & 1 & 1 & 1 \\
\hline & 1 & 1 & 1 & 1 \\
\hline & I & 1 & 1 & 1 \\
\hline & 1 & 1 & 1 & 1 \\
\hline & 1 & 1 & 1 & 1 \\
\hline & 1 & 1 & 1 & 1 \\
\hline & 1 & 1 & 1 & 1 \\
\hline & 1 & 1 & 1 & 1 \\
\hline & 1 & 1 & 1 & 1 \\
\hline
\end{tabular}




\section{FIRE CONTAINMENT EVALUATION}

Fire Compartment Number:

Fire Cell Number (if applicable):

1. Combustible Load in Fire Compartment/Cell:

(Note: attach calculations as required)

2. Qualitative evaluation of fire barriers (based on walkdown checklist information)

Barriers are acceptable: Yes / No

If no, list specific deficiencies and recommended improvements below.

3. Fire Barrier Ratings (Hours): Ceiling

\section{Floor}

Walls

4. Fire Barrier Evaluation:

a) Fire Barriers are adequate to contain fire based on fire barrier ratings being greater than maximum expected fire in compartment: Yes / No

b) Fire Barriers are adequate to contain fire until fire can be extinguished by manual or automatic suppression: Yes / No

c) If no, describe deficiencies below.

5. Deficiencies: 


\section{ASSESSMENT OF EXPLOSION POTENTIAL}

Fire Compartment Number:

Fire Cell Number (if applicable):

1. Describe specific source of potential explosion hazard contained in the fire compartment/fire cell: 


\section{RESULTS OF SAFE SHUTDOWN EVALUATION}

\begin{tabular}{|c|c|c|c|}
\hline $\begin{array}{c}\text { Fire } \\
\text { Compartment } \\
\text { Number }\end{array}$ & $\begin{array}{l}\text { Fire } \\
\text { Cell } \\
\text { Number }\end{array}$ & $\begin{array}{l}\text { Successful Safe Shutdown } \\
\text { Path Identified for Fire } \\
\text { Compartment/Cell }\end{array}$ & $\begin{array}{c}\text { Fire Vulnerabilities } \\
\text { Identified for Fire } \\
\text { Compartment/Cell } \\
\text { Yes / No }\end{array}$ \\
\hline & & & 1 \\
\hline & & & 1 \\
\hline & & & 1 \\
\hline & & & I \\
\hline & & & 1 \\
\hline & & & 1 \\
\hline & & & 1 \\
\hline & & & 1 \\
\hline & & & 1 \\
\hline & & & 1 \\
\hline & & & 1 \\
\hline & & & I \\
\hline & & & 1 \\
\hline & & & 1 \\
\hline & & & 1 \\
\hline & & & 1 \\
\hline & & & 1 \\
\hline & & & 1 \\
\hline
\end{tabular}




\section{POTENTIAL DESIGN CHANGES WORKSHEET}

\begin{tabular}{|l|l|l|l|l|}
\hline SYSTEM & VULNERABILTTY & $\begin{array}{c}\text { COMP./CELLS } \\
\text { AFFECTED }\end{array}$ & CONCEPTUAL DESIGN & NOTES \\
\hline & & & & \\
\hline & & & & \\
\hline & & & & \\
\hline & & & & \\
\hline & & & & \\
\hline & & & & \\
\hline & & & & \\
\hline & & & & \\
\hline & & & & \\
\hline & & & & \\
\hline & & & & \\
\hline & & & & \\
\hline & & & & \\
\hline
\end{tabular}


SELECTION OF PREFERRED SAFE SHUTDOWN OPTION

\begin{tabular}{|c|c|c|c|c|c|}
\hline $\begin{array}{l}\text { Set } \\
\text { D }\end{array}$ & $\underset{\text { UD }}{\text { Uprade }}$ & Conceptual Design & $\begin{array}{c}\text { Upgrade } \\
\text { Cost }\end{array}$ & $\begin{array}{c}\text { Total } \\
\text { Set } \\
\text { Cost }\end{array}$ & Other Considerations \\
\hline & & & & & \\
\hline & . & & & & \\
\hline & & & & & \\
\hline & & & & & \\
\hline & & & & & \\
\hline & & & & & \\
\hline & & & & & \\
\hline & & & & & \\
\hline & & & & & \\
\hline & & & & & \\
\hline & & & & & \\
\hline & & & & & \\
\hline & & & & & \\
\hline & & & & & \\
\hline & & & & & \\
\hline & & & & & \\
\hline & & & & & \\
\hline & & & & & \\
\hline & & & & & \\
\hline & & & & & \\
\hline & & & & & \\
\hline & & & & & \\
\hline & & & & & \\
\hline & & & & & \\
\hline
\end{tabular}




\section{SAFE SHUTDOWN SOLUTION SET}

Indicate the safe shutdown solution set selected and provide a detailed discussion of the bases for that solution and the additional benefits the solution set provides the plant. 
CALCULATION OF BENEFIT-TO-COST RATIO

\begin{tabular}{|c|c|c|c|c|}
\hline $\mathbf{m}$ & Description & $\delta \mathrm{R}_{\mathrm{i}}$ & Cost & $\delta \mathrm{R}_{\mathrm{i}} /$ Cost \\
\hline & & & & \\
\hline & & & & \\
\hline & & & & \\
\hline & & & & \\
\hline & & & & \\
\hline & & & & \\
\hline & & & & \\
\hline & & & & \\
\hline & & & & \\
\hline & & & & \\
\hline & & & & \\
\hline & & & & \\
\hline & & & & \\
\hline & & & & \\
\hline & & & & \\
\hline & & & & \\
\hline & & & & \\
\hline & & & & \\
\hline & & & & \\
\hline & & & & \\
\hline & & & & \\
\hline
\end{tabular}


PRIORITIZATION OF IMPROVEMENTS

\begin{tabular}{|c|c|c|c|c|c|}
\hline ID & Description & $\begin{array}{c}\text { Benefit/ } \\
\text { Cost } \\
\end{array}$ & Cost & $\begin{array}{l}\text { Total } \\
\text { Cost }\end{array}$ & Comments \\
\hline & & & & & \\
\hline & & & & & \\
\hline & & & & & \\
\hline & & & & & \\
\hline & & & & & \\
\hline & & & & & \\
\hline & & & & & \\
\hline & & & & & \\
\hline & & & & & \\
\hline & & & & & \\
\hline & & & & & \\
\hline & & & & & \\
\hline & & & & & \\
\hline & & & & & \\
\hline & & & & & \\
\hline & & & & & \\
\hline & & & & & \\
\hline & & & & & \\
\hline & & & & & \\
\hline & & & 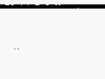 & & \\
\hline & & & & & \\
\hline & & & & & \\
\hline
\end{tabular}


